\title{
CLARIFICATION OF RECREATIONAL POOL WATER USING BIOLOGICAL ADDITIVES PRODUCED BY BIOWISH ${ }^{\mathrm{TM}}$
}

\author{
A Thesis \\ presented to \\ the Faculty of California Polytechnic State University, \\ San Luis Obispo
}

\author{
In Partial Fulfillment \\ of the Requirements for the Degree \\ Master of Science in Civil and Environmental Engineering
}

by

Reese Nathaniel Wilson

June 2015 
(C) 2015

Reese Nathaniel Wilson

ALL RIGHTS RESERVED

ii 
TITLE:

AUTHOR:

DATE SUBMITTED:

COMMITTEE CHAIR:

COMMITTEE MEMBER:

COMMITTEE MEMBER:
Clarification of Recreational Pool Water using Biological Additives Produced by $\mathrm{BiOWiSH}^{\mathrm{TM}}$

Reese Nathaniel Wilson

June 2015

Nirupam Pal, Ph.D.

Professor of Civil and Environmental Engineering

Yarrow Nelson, Ph.D.

Professor of Civil and Environmental Engineering

Rebekah Oulton, Ph.D.

Assistant Professor of Civil and Environmental Engineering 


\begin{abstract}
Clarification of Recreational Pool Water using Biological Additives Produced by $\mathrm{BiOWiSH}^{\mathrm{TM}}$

Reese Nathaniel Wilson
\end{abstract}

Effects of commercially available bacterial products were investigated on two common recreational pool contaminants: sunscreen and cyanuric acid (CYA). Microbial products developed by BiOWiSH Technologies, Inc. were tested for enhancing mechanical filtration and water clarification in bench-scale bioreactors, with conditions mimicking those of recreational pool water. Bacterial consortia included proprietary mixes of Bacillus, Lactobacillus and Pseudomonas, and other genera of bacteria. BiOWiSH products are either fermented on a solid substrate consisting of rice bran and soy meal, or they are mixed with a soluble diluent. Twenty-nine BiOWiSH products were tested throughout forty experiments.

Experiments were carried out to determine both the efficacy of BiOWiSH products for turbidity reduction and the mechanism by which BiOWiSH removes sunscreen from solution. In trials without mechanical filtration, the only product which showed a reduction in turbidity relative to the control, albeit inconsistently, was the solid substrate version of BiOWiSH Aqua FOG ${ }^{\mathrm{TM}}$ (Thai FOG). Experiments on BiOWiSH coupled with mechanical filtration showed a $79 \%$ average reduction of turbidity in the first 24 hrs. BiOWiSH products containing solid substrate, both active and abiotic, showed an average turbidity reduction of $90 \%$ in the first 24 hrs. In the same timeframe, soluble BiOWiSH products 
showed a $79 \%$ average reduction in turbidity. Thus, the solid substrate provided an additional $11 \%$ reduction in turbidity over soluble products and un-amended mechanical filtration. Through experimentation and scanning electron microscopy, it was concluded that the primary mechanism of clarification by the solid substrate is adsorption of sunscreen to the substrate surface.

Further experiments were performed in anaerobic and aerobic environments to determine whether BiOWiSH products can remove cyanuric acid from solution through adsorption or biodegradation. Two measurement methods, turbidimetric and HPLC (high performance liquid chromatography) were used to independently quantify CYA. A reverse-phase HPLC method was developed which utilizes a phosphate buffer and methanol for the separation of cyanuric acid from nitrate and other chemical species. The solid BiOWiSH Aqua FOG product (prod. in Thailand) interfered with the turbidimetric analysis, showing false decreases in CYA. Using HPLC, there was no measureable biodegradation or adsorption of CYA by BiOWiSH products in these bench-scale tests. Significant systematic error in the HPLC analysis prevented conclusive findings; therefore, the ability of BiOWiSH products to reduce CYA from solution remains inconclusive.

Keywords: Bioremediation, BiOWiSH Technologies Inc., Recreational Pool, Swimming Pool, Chlorine, Sunscreen, Turbidity, Cyanuric Acid, HPLC 


\section{ACKNOWLEDGMENTS}

I would like to thank my advisor and thesis Committee Chair, Dr. Pal, for taking me on as a graduate student, guiding me through the entire process, and providing invaluable experience and insight into bacteriological research.

Many thanks to my thesis committee members Dr. Nelson, and Dr. Oulton, for providing insight on experimental setup and HPLC operation as well as reviewing my thesis drafts.

I would like to thank BiOWiSH Technologies, Inc., for fully funding this research project. Without the assistance of Richard Carpenter, Michael Showell, JoElla Barnes, and John Gorsuch, I would not have been able to perform such a thorough and well-thought-out study.

I want to thank Dr. Trevor Harding for taking time from his busy schedule to meet with me and to operate the scanning electron microscope.

I would like to thank Dr. Kitts, and Alice Hamrick for facilitating my use of lab space in the Center for Applications in Biotechnology. Additionally, I extend my thanks to Dr. Jimenez and Dr. VanderKelen for their oversight and assistance in the CAB Lab.

To my fellow researchers, Ada, Diego, Paul, Kyle, Nick, Andy, Melissa, and Joelle, thanks for supporting me and for lending your helping hands. This research would have taken much longer without all of your help!

Finally, I want to extend my deepest thanks to my parents, Timothy and Deanne, and to my brother, Andrew, for always encouraging and supporting me through the ups and downs of my life decisions. The three of you mean the world to me. 


\section{TABLE OF CONTENTS}

Page

LIST OF TABLES ...................................................................................... xiii

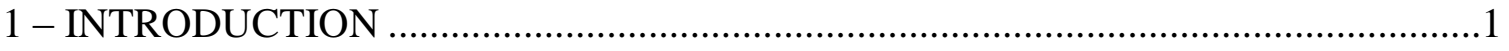



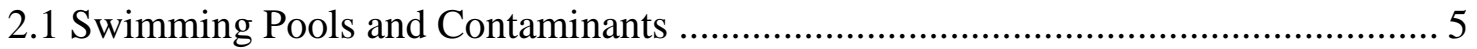

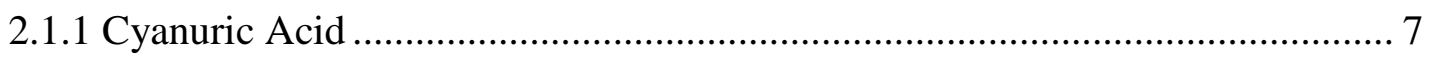

2.1.2 Clarification Mechanisms ........................................................................... 9

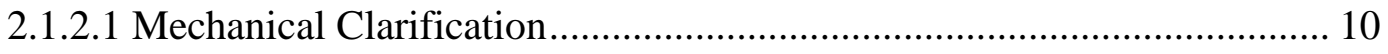





2.2 Parameters Tested and Quantification Methods............................................. 15

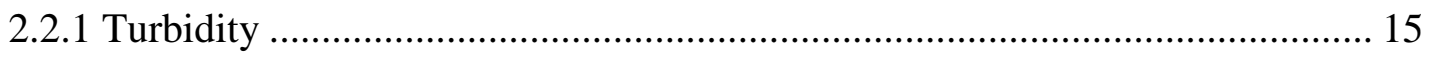

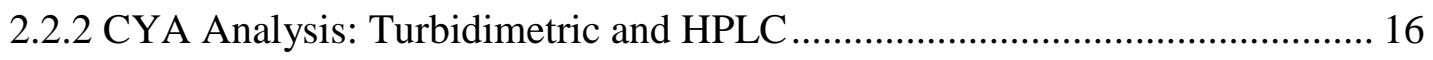

2.2.3 Chlorine: Free vs Total Cl Colorimetric .................................................... 17

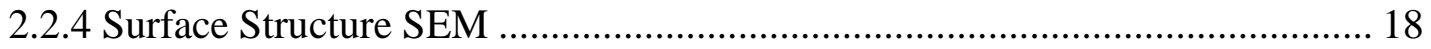

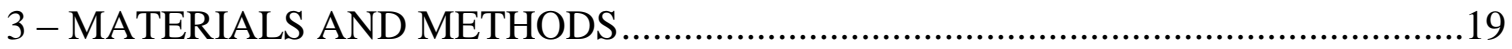

3.1 Generalized Tests and Experimental Setup.................................................... 19



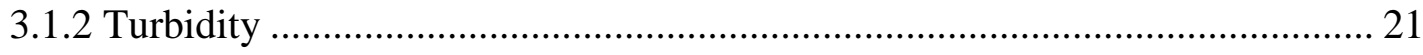

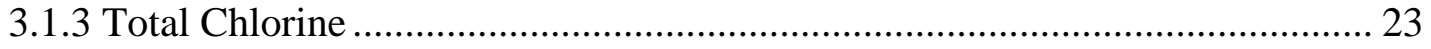

3.1.4 Cyanuric Acid Turbidimetric Measurement ............................................... 25



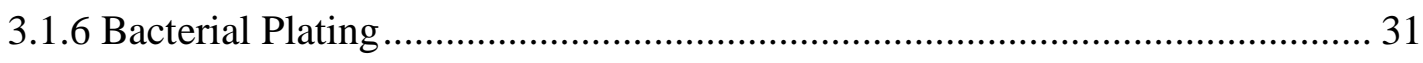

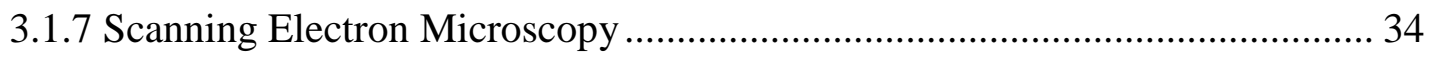

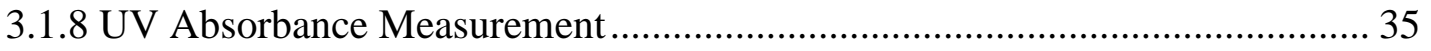

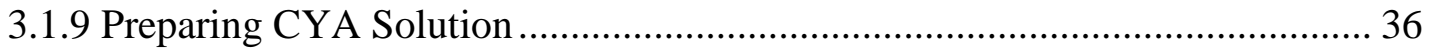



3.1.11 Preparing HPLC Mobile Phase .............................................................. 37

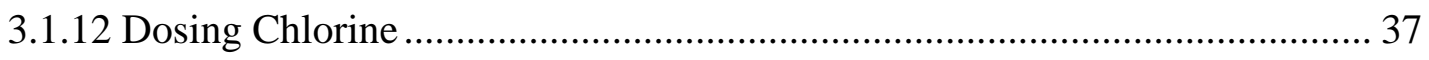

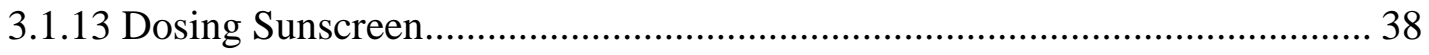


3.1.14 Inoculating Shaker Flasks ..................................................................... 38

3.1.15 Inoculating Aquaria ……………………………..................................... 39

3.2 Task I - Determination of Clarification Mechanism ............................................... 40

3.2.1 Experiment I-1 Effect of Thai FOG on Turbidity, with Mechanical

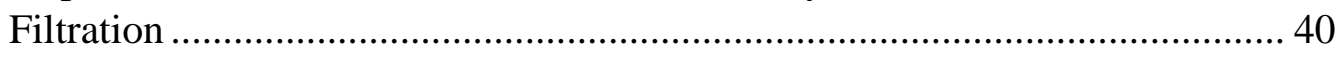

3.2.2 Experiment I-2 Effects of BiOWiSH on Turbidity with Sodium Azide Control

3.2.3 Experiment I-3 Effects of BiOWiSH on Turbidity with Re-Dosed Sunscreen 42

3.2.4 Experiment I-4 Comparison of Re-Dosed US FOG to Single Dosed Products 43

3.2.5 Experiment I-5 Effects of BiOWiSH Products on Re-Dosed Sunscreen ........ 44

3.2.6 Experiment I-6 Investigation of Solid Substrate Products' Effects on Turbidity 44

3.2.7 Experiment I-7 Effects of BiOWiSH Products on Re-Dosed Turbidity 45

3.2.8 Experiment I-8 Effects of Thai BiOWiSH Products on Re-Dosed Turbidity 46

3.2.9 Experiment I-9 Experiment I-9 Effects of Vegetative Bacterial Cultures on Turbidity 47

3.3 Task II - Efficacy of BiOWiSH Clarifying Oils from Swimming Pools 49

3.3.1 Experiment II-1 Water Clarification by Thai FOG........................................... 49

3.3.2 Experiment II-1.1 Absorbance Calibration Curve for Sunscreen ..................... 50

3.3.3 Experiment II-1.2 Investigation of Growth Media Compatibility with



3.3.4 Experiment II-2 Chlorine Decay with BiOWiSH Products ............................... 51

3.3.5 Experiment II-3 Turbidity Reduction by BiOWiSH Products.......................... 53

3.3.6 Experiment II-4 Agitated vs. Un-Agitated Turbidity Reduction by



3.3.7 Experiment II-5 Turbidity Reduction by BiOWiSH Products.......................... 54

3.3.8 Experiment II-6 Effect of BiOWiSH Products on Turbidity with Dextrose ... 55

3.3.9 Experiment II-7 Effect of BiOWiSH Products on Turbidity with

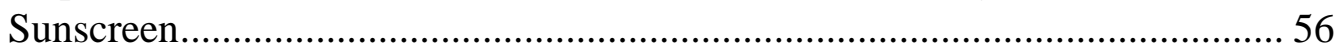

3.4 Task III - Isolation and Identification of Bacteria.................................................. 57

3.4.1 Experiment III-1 Bacterial Plating of Experiment II-6.................................... 57 
3.4.2 Experiment III-2 Bacterial Plating of Experiment I-8 .............................. 57

3.5 Task IV - Biodegradation of Cyanuric Acid .................................................. 58

3.5.1 Experiment IV-1 CYA Biodegradation in a Respirometer............................ 58

3.5.2 Experiment IV-2 CYA Adsorption to Irradiated Thai FOG .......................... 58

3.5.3 Experiment IV-3 Anaerobic Degradation of CYA in DI Water ...................... 59

3.5.4 Experiment IV-4 Anaerobic Degradation of CYA in Minimal Media ............ 60

3.5.5 Experiment IV-5 Effect of Activated Thai FOG Supernatant on CYA........... 62

3.5.6 Experiment IV-6 Effects of US FOG and Activated Thai FOG on CYA ....... 62

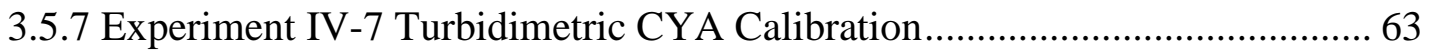



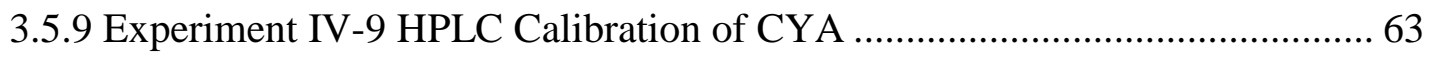

3.5.10 Experiment IV-10 HPLC Calibration using Thai FOG ............................... 64

3.5.11 Experiment IV-11 Method Development of HPLC using Thai FOG and



3.5.12 Experiment IV-12 Investigation of Products' Effects on CYA ..................... 65

3.5.13 Experiment IV-13 HPLC Method Development - Inconclusive Mobile

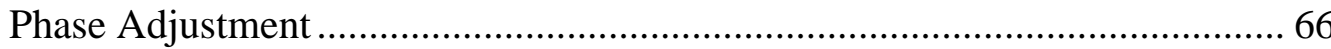

3.5.14 Experiment IV-14 HPLC Method Development - High Injection

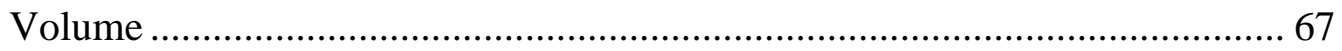

3.5.15 Experiment IV-15 Investigation of C:N:P Ratios on CYA Degradation....... 67

3.5.16 Experiment IV-16 Hour-by-Hour Time-Point CYA Degradation.................. 68

3.5.17 Experiment IV-17 Effect of CAR on CYA Concentration.......................... 69

3.5.18 Experiment IV-18 Effect of CAR on CYA with $\mathrm{K}_{2} \mathrm{HPO}_{4}$, Varied

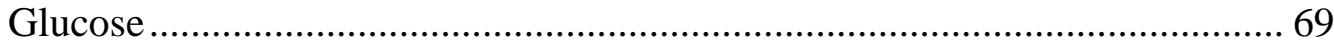

3.5.19 Experiment IV-19 Effect of Activated CAR on CYA, Varying Dextrose .... 71

3.5.20 Experiment IV-20 Effect of Activated CAR and Filter Media on CYA ....... 72



4.1 Task I - Determination of Clarification Mechanism ........................................ 74

4.1.1 Experiment I-1 Efficacy of Thai FOG Removing Turbidity, with

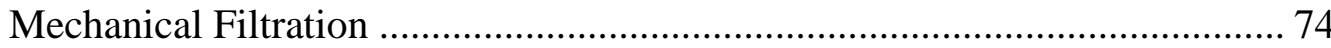

4.1.2 Experiment I-2 Effects of BiOWiSH on Turbidity with Sodium Azide

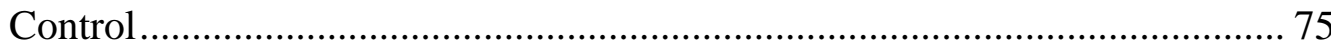

4.1.3 Experiment I-3 Effects of BiOWiSH on Turbidity with Re-Dosed Sunscreen. 76 
4.1.4 Experiment I-5 Effects of BiOWiSH Products on Re-Dosed Sunscreen ........ 78

4.1.5 Experiment I-4 Comparison of Re-Dosed US FOG to Single Dosed

Products 80

4.1.6 Experiment I-6 Effects of Additional Solid Substrate Products on Turbidity..... 82

4.1.7 Experiment I-7 Effects of BiOWiSH Products on Re-Dosed Turbidity 83

4.1.8 Experiment I-8 Effects of Thai BiOWiSH Products on Re-Dosed

Turbidity 85

4.1.9 Experiment I-9 Effects of Vegetative Bacterial Cultures on Turbidity ........... 89

4.1.10 Turbidity Reduction for All Experiments at $\mathrm{T}=1$ and $\mathrm{T}=3$ Days ................. 93

4.2 Task II - Efficacy of BiOWiSH for Clarifying Oils from Swimming Pools........... 96

4.2.1 Experiment II-1 Water Clarification by Thai FOG, No Mechanical Filtration 96

4.2.2 Experiment II-1.1 Absorbance Calibration Curve for Sunscreen ..... 98

4.2.3 Experiment II-1.2 Investigation of Growth Media Compatibility with Chlorine 99

4.2.4 Experiment II-2 Chlorine Decay with BiOWiSH Products 100

4.2.5 Experiment II-3 Turbidity Reduction by Various BiOWiSH Products without Mechanical Filtration 102

4.2.6 Experiment II-4 Agitated vs. Un-Agitated Turbidity Reduction by BiOWiSH Products 104

4.2.7 Experiment II-5 Turbidity Reduction by BiOWiSH Products 108

4.2.8 Experiment II-6 Effect of BiOWiSH Products on Turbidity with Dextrose . 109

4.2.9 Experiment II-7 Effect of BiOWiSH Products on Turbidity with Sunscreen 112

4.3 Task III - Isolation and Identification of Bacteria. 114

4.3.1 Experiment III-1 Bacterial Plating of Experiment II-6 114

4.3.2 Experiment III-2 Bacterial Plating of Experiment I-8 . 120

4.4 Task IV - Biodegradation of Cyanuric Acid 122

4.4.1 Experiment IV-1 CYA Biodegradation in a Respirometer 122

4.4.2 Experiment IV-2 CYA Adsorption to Irradiated Thai FOG 122

4.4.3 Experiment IV-3 Anaerobic Degradation of CYA in DI Water.... 124

4.4.4 Experiment IV-4 Anaerobic Degradation of CYA in Minimal Media 125

4.4.5 Experiment IV-5 Effect of Activated Thai FOG Supernatant on CYA 127 
4.4.6 Experiment IV-6 Effects of US FOG and Activated Thai FOG on CYA .... 128

4.4.7 Experiment IV-7 Turbidimetric CYA Calibration....................................... 130

4.4.8 Experiment IV-8 Standard Preparation for HPLC .................................... 131

4.4.9 Experiment IV-9 HPLC Calibration of CYA ......................................... 131

4.4.10 Experiment IV-10 HPLC Calibration using Thai FOG .............................. 133

4.4.11 Experiment IV-11 Method Development of HPLC using Thai FOG and

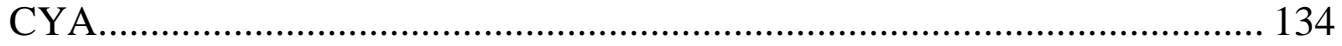

4.4.12 Experiment IV-12 Investigation of Products' Effects on CYA ................... 135

4.4.13 Experiment IV-13 HPLC Method Development - Inconclusive Mobile Phase Adjustment .......................................................................... 138

4.4.14 Experiment IV-14 HPLC Method Development - High Injection

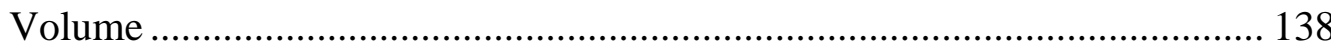

4.4.15 Experiment IV-15 Investigation of C:N:P Ratios Effects on CYA

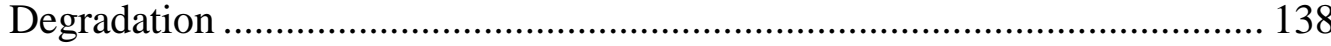

4.4.16 Experiment IV-16 Hour-by-Hour Time-Point CYA Degradation ............... 140

4.4.17 Experiment IV-17 Effect of Cyanuric Acid Reducer on CYA Concentration 140

4.4.18 Experiment IV-18 Effect of CAR on CYA with $\mathrm{K}_{2} \mathrm{HPO}_{4}$, Varied Glucose 142

4.4.19 Experiment IV-19 Effect of Activated CAR on CYA, Varying Dextrose .. 144 4.4.20 Experiment IV-20 Effect of Activated CAR and Filter Media on CYA ..... 146 5 - CONCLUSIONS.

5.1 Results of the Determination of Clarification Mechanism 149

5.2 Results Regarding the Efficacy of BiOWiSH Clarifying Oils from Swimming Pools. 149

5.3 Results Regarding the Isolation and Identification of Bacteria 150

5.4 Results Regarding the Biodegradation of Cyanuric Acid 150

5.5 Future Research 152 REFERENCES APPENDICES

Appendix A: Data Tables

Appendix B: Example of Normalization Calculation

Appendix C: Example of HPLC Calibration and Conversion of Peak Area to CYA Concentration from Experiment IV-20. 173 
Appendix D: SEM Images from Experiment I-8 .............................................. 179

Appendix E: Example HPLC Chromatograms from Experiment IV-20 .................. 185 


\section{LIST OF TABLES}

Table

Table 2-1: List of Products Tested ......................................................................... 12

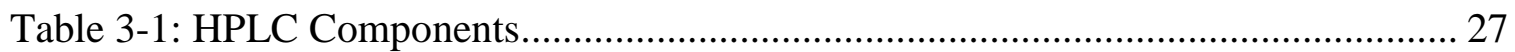

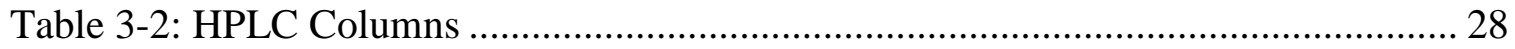

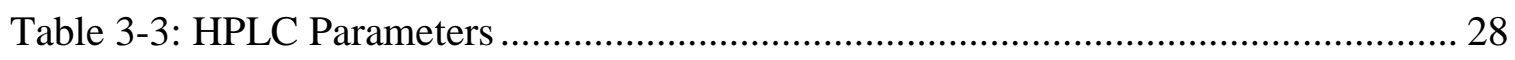

Table 3-4: Scanning Electronic Microscope Operating Parameters ............................... 34

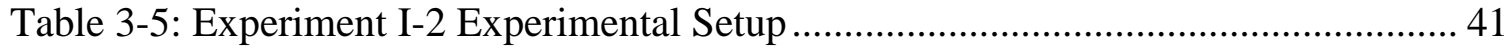

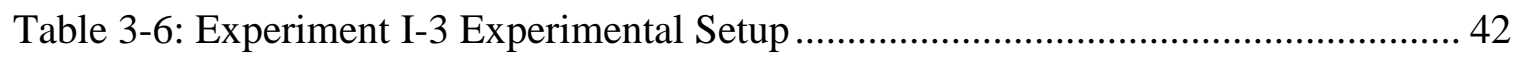

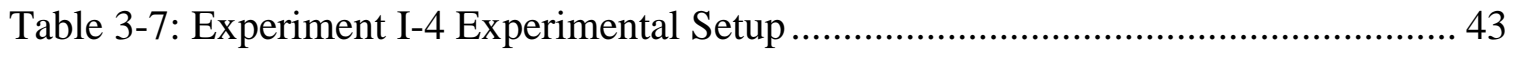

Table 3-8: Experiment I-5 Experimental Setup ........................................................ 44

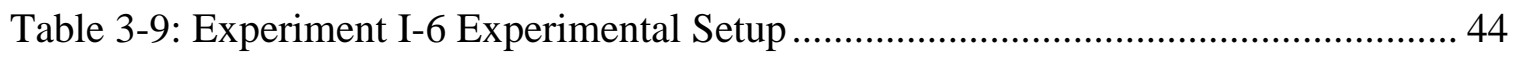

Table 3-10: Experiment I-7 Experimental Setup ...................................................... 45

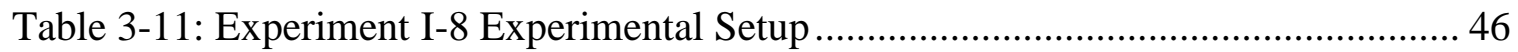

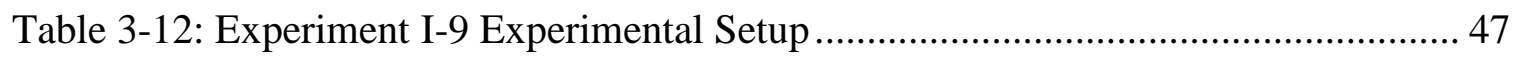

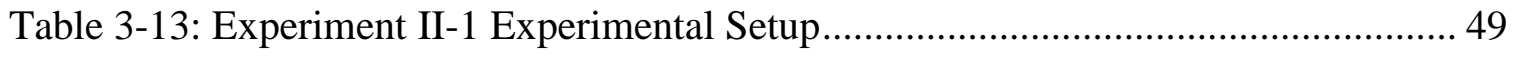

Table 3-14: Experiment II-1.2 Experimental Setup................................................. 51

Table 3-15: Experiment II-2 Minimal Media Composition......................................... 52



Table 3-17: Experiment II-3 Aquarium Contents ..................................................... 53

Table 3-18: Experiment II-4 Experimental Setup................................................... 54

Table 3-19: Experiment II-5 Experimental Setup....................................................... 55

Table 3-20: Experiment II-6 Experimental Setup..................................................... 55

Table 3-21: Experiment IV-2 Irradiated Thai FOG Concentrations.............................. 58

Table 3-22: Experiment IV-3 Flask Labels and Contents .......................................... 59

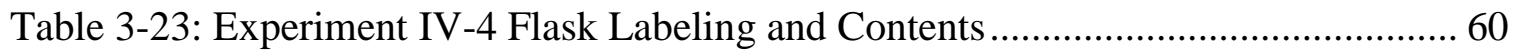

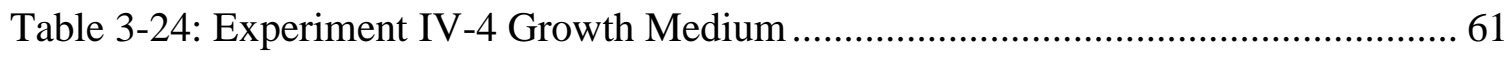




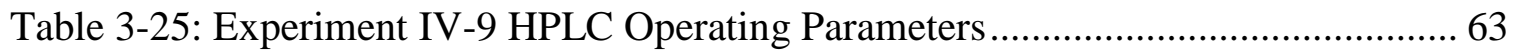

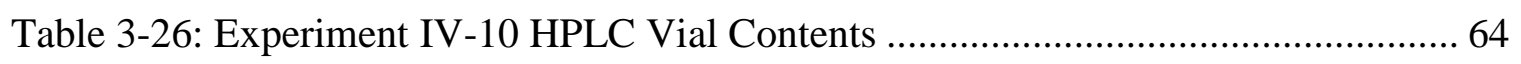

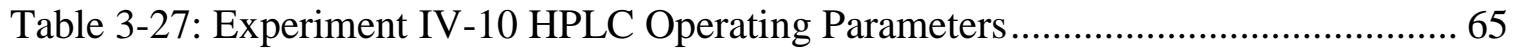

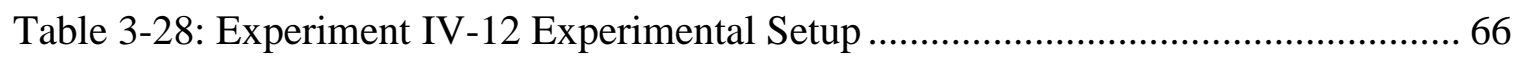

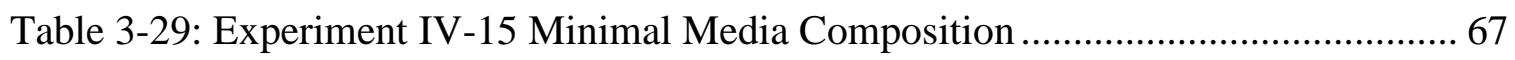

Table 3-30: Experiment IV-15 Carbon, Nitrogen, and Phosphorus Concentrations ........ 67

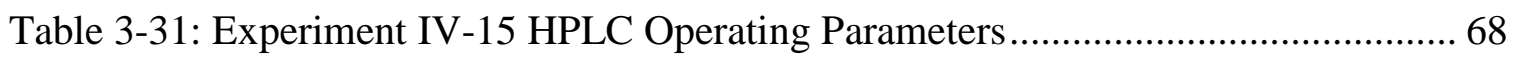

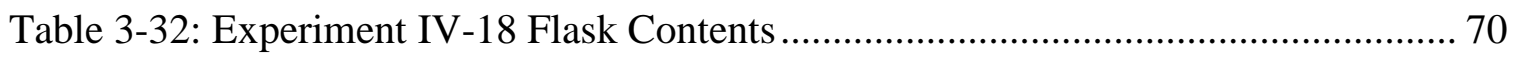

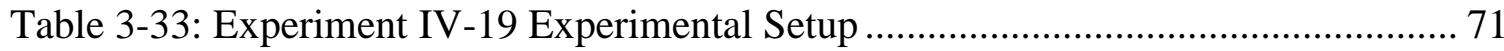

Table 3-34: Experiment IV-20 Minimal Media Composition ....................................... 72



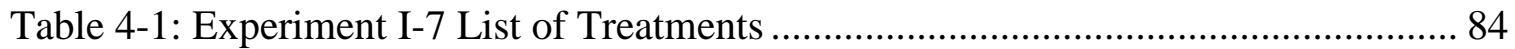

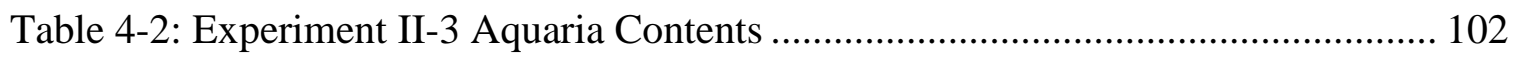

Table 4-3: Experiment II-4 Treatments, Duplicated ................................................. 105

Table 4-4: Experiment II-4 Turbidity Change by Agitation ....................................... 107

Table 4-5: Experiment II-7 List of Treatments ........................................................ 112

Table 4-6: Experiment III-1 Plate Count CFU per 100 mL after 48 hours, PCA.......... 114

Table 4-7: Experiment III-2 Plate Count Results ................................................... 120

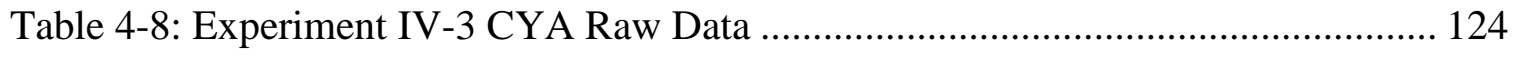

Table 4-9: Experiment IV-10 CYA and Thai FOG Peak Areas .................................. 133

Table 4-10: Experiment IV-12 Experimental Setup ............................................... 136

Table 4-11: Experiment IV-15 Carbon:Nitrogen:Phosphorus Ratios........................... 139

Table 5-1: Final HPLC Method for separation of Nitrate/Nitrite from CYA................ 151



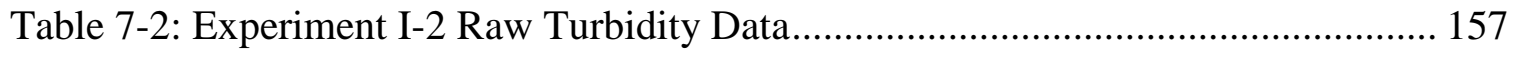



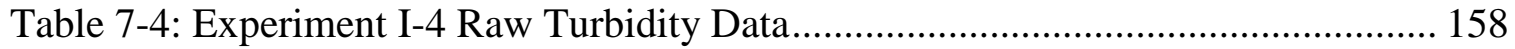

Table 7-5: Experiment I-5 Raw Turbidity Data.................................................... 158 


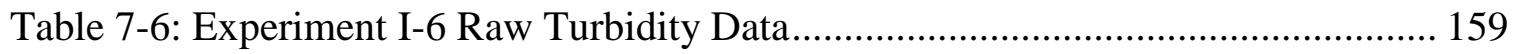

Table 7-7: Experiment I-7 Raw Data Turbidity.......................................................... 160

Table 7-8: Experiment I-8 Raw Turbidity Data............................................................ 160



Table 7-10: Experiment I-9 CYA Concentration vs. Time.............................................. 161

Table 7-11: Compiled Percent Reduction after 1 Day, for Each Experiment ................ 162

Table 7-12: Experiment II-1 Raw Absorbance Data at $470 \mathrm{~nm}$.................................... 163

Table 7-13: Experiment II-1.2 Chlorine Compatibility Raw Data ................................. 163

Table 7-14: Experiment II-2 Raw Total Chlorine Data .................................................. 164

Table 7-15: Experiment II-4 Raw Turbidity Data, Un-Agitated ...................................... 164

Table 7-16: Experiment II-5 Turbidity Raw Data …………………………………..... 165

Table 7-17: Experiment II-6 Raw Turbidity Data …………………………………..... 165

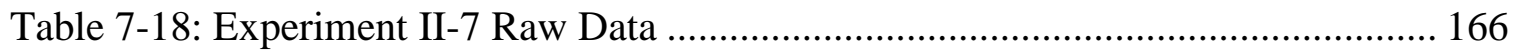

Table 7-19: Experiment IV-2 CYA Concentration vs. Time Raw Data........................... 166

Table 7-20: Experiment IV-4 Raw CYA vs. Time Data ............................................... 167

Table 7-21: Experiment IV-5 Raw CYA vs. Time Data ............................................... 167

Table 7-22: Experiment IV-6 Raw CYA vs. Time Data ................................................ 168

Table 7-23: Experiment IV-11 CYA Peak Area Raw Data.............................................. 168

Table 7-24: Experiment IV-12 CYA Peak Area Raw Data............................................ 168

Table 7-25: Experiment IV-15 CYA Peak Area Raw Data............................................. 169

Table 7-26: Experiment IV-17 CYA Peak Area Raw Data........................................... 169

Table 7-27: Experiment IV-18 CYA Peak Area Raw Data............................................ 169

Table 7-28: Experiment IV-19 CYA Concentration Raw Data....................................... 170

Table 7-29: Experiment IV-20 Raw CYA Data ……………................................... 170

Table 7-30: Experiment I-3 Raw and Normalized Turbidity Data …………………..... 171

Table 7-31: Experiment IV-20, Day 13, CYA Standard Curve Peak Areas................... 177

Table 7-32: Experiment IV-20, Day 13, Peak Area and CYA Concentration................ 178 


\section{LIST OF FIGURES}

Figure

Page

Figure 2-1: Cyanuric Acid Degradation Mechanism (Kotharu 2014) ............................ 11

Figure 4-1: Experiment I-1 Turbidity vs. Time, BiOWiSH Thai FOG, Tap Water at $30^{\circ} \mathrm{C}$, Mechanical Filtration

Figure 4-2: Experiment I-2 Turbidity vs. Time, US FOG and Thai FOG, Tap Water at $30^{\circ} \mathrm{C}$, Mechanical Filtration.

Figure 4-3: Experiment I-3 Turbidity vs. Time, Tap Water at $30^{\circ} \mathrm{C}$, Re-dosed Sunscreen, Mechanical Filtration 77

Figure 4-4: Experiment I-5 Turbidity vs. Time, Tap Water at $30^{\circ} \mathrm{C}$, Re-dosed Sunscreen, Mechanical Filtration 79

Figure 4-5: Experiment I-4 Turbidity vs. Time, Tap Water at $30^{\circ} \mathrm{C}$, Re-dosed Sunscreen Between 24 and 31 Days, Mechanical Filtration 81

Figure 4-6: Experiment I-6 Turbidity vs. Time, Tap Water at $30^{\circ} \mathrm{C}$, Re-dosed Sunscreen, Mechanical Filtration 83

Figure 4-7: Experiment I-7 Turbidity vs. Time, Tap Water at $30^{\circ} \mathrm{C}$, Re-dosed Sunscreen, Mechanical Filtration 84

Figure 4-8: Experiment I-8 Averaged Turbidity vs. Time, Thai Products in Duplicate, Tap Water at $30^{\circ} \mathrm{C}$, Re-dosed Sunscreen, Mechanical Filtration .....

Figure 4-9: Thai FOG New (Left) and Used (Right) 3000x Magnification 88

Figure 4-10: Premix New (Left) and Used (Right) 3000x Magnification .. 89

Figure 4-11: Experiment I-9 Turbidity vs. Time, Tap Water at $30^{\circ} \mathrm{C}$, Re-dosed

Sunscreen, Mechanical Filtration, with and without CYA 90

Figure 4-12: Experiment I-9 CYA Concentration vs. Time, Tap Water at $30^{\circ} \mathrm{C}$, No CYA in Tank 2, Mechanical Filtration. 92

Figure 4-13: Compiled Percent Reduction in Turbidity Across Experiments, One Day after $1^{\text {st }}$ Sunscreen Dose, Mechanical Filtration 93

Figure 4-14: Compiled Percent Reduction of Turbidity, One Day after $2^{\text {nd }}$ Sunscreen

Dose, Tap Water at $30^{\circ} \mathrm{C}$, Mechanical Filtration .95

Figure 4-15: Experiment II-1 Absorbance vs. Time at $470 \mathrm{~nm}$, Tap Water at $30^{\circ} \mathrm{C}$, Single Dose of Sunscreen, No Mechanical Filtration 96 
Figure 4-16: Experiment II-1 Normalized Absorbance vs. Time at $470 \mathrm{~nm}$, Excluding Thai FOG, Tap Water at $30^{\circ} \mathrm{C}$, Single Dose of Sunscreen, No Mechanical Filtration

Figure 4-17: Experiment II-1.1 Absorbance vs. Concentration of Sunscreen at 520 $\mathrm{nm}$ 98

Figure 4-18: Experiment II-1.2 Chlorine Concentration vs. Time in Varying Growth Media, DI Water at $20^{\circ} \mathrm{C}$

Figure 4-19: Experiment II-2 Chlorine Concentration vs. Time, DI Water at $20^{\circ} \mathrm{C}$, Covered with Gas-Permeable Membrane, Single dose of Chlorine. 101

Figure 4-20: Experiment II-3 Turbidity vs. Time, Tap Water at $30^{\circ} \mathrm{C}$, Single Dose of $250 \mathrm{mg} / \mathrm{L}$ Sunscreen, No Mechanical Filtration 103

Figure 4-21: Experiment II-4 Turbidity vs. Time, Tap Water at $30^{\circ} \mathrm{C}$, Un-Agitated, Single Dose of Sunscreen, No Mechanical Filtration 106

Figure 4-22: Experiment II-4 Turbidity vs. Time, Tap Water at $30^{\circ} \mathrm{C}$, Agitated, Single Dose of Sunscreen, No Mechanical Filtration 106

Figure 4-23: Experiment II-5 Turbidity vs. Time, Tap Water at $30^{\circ} \mathrm{C}$, Single Dose of Chlorine, Combined Products, No Mechanical Filtration 109

Figure 4-24: Experiment II-6 Turbidity vs. Time, DI Water and Dextrose at $20^{\circ} \mathrm{C}$, No Sunscreen, No Agitation. 110

Figure 4-25: Experiment II-6 Turbidity vs. Time Excluding KLB, Osprey BPB-100, and MDG Micro-N, DI Water and Dextrose at $20^{\circ} \mathrm{C}$, No Sunscreen, No Agitation

Figure 4-26: Experiment II-7 Turbidity vs. Time, DI Water at $20^{\circ} \mathrm{C}$, Single Dose of Sunscreen, Aerobic 113

Figure 4-27: Experiment III-1 Osprey MBP-5 Dilutions $10^{-1}$ to $10^{-4}$ (Top Row, Left to Right), $10^{-6}$ to $10^{-12}$ (Bottom Row, Left to Right).....

Figure 4-28: Experiment III-1 KLB Dilutions $10^{-1}$ to $10^{-4}$ (Top Row, Left to Right), $10^{-6}$ to $10^{-12}$ (Bottom Row, Left to Right)

Figure 4-29: Experiment III-1 US FOG Dilutions $10^{-1}$ to $10^{-4}$ (Top Row, Left to Right), $10^{-6}$ to $10^{-12}$ (Bottom Row, Left to Right)

Figure 4-30: Experiment III-1 Thai FOG Dilutions $10^{-1}$ to $10^{-4}$ (Top Row, Left to Right), $10^{-6}$ to $10^{-12}$ (Bottom Row, Left to Right).....

Figure 4-31: Experiment III-1 Comparison of Varied Colony Structure in Thai FOG (Left) and US FOG (Right). 
Figure 4-32: Experiment III-1 Orange Colony within the Osprey Product................... 118

Figure 4-33: Experiment III-3 Several Globular Colonies in Osprey 10-1 Dilution ....... 119

Figure 4-34: Experiment III-1 Black Colonies after 4 Days' Incubation at $35^{\circ} \mathrm{C} \ldots \ldots . . . .119$

Figure 4-35: Experiment III-2 Control Treatment, Plate 10 ${ }^{-28}$ Dilution ........................ 120

Figure 4-36: Experiment III-2 Thai FOG, Plate $10^{-20}$ Dilution Compared to Blank ...... 121

Figure 4-37: Experiment IV-2 CYA Concentration vs. Time, Turbidimetric Measurement, Varied Irradiated Thai FOG Concentrations, DI Water at $18-20^{\circ} \mathrm{C}$, No Agitation, Anaerobic

Figure 4-38: Experiment IV-4 CYA Concentration vs. Time, Turbidimetric

Measurement, Minimal Media at $30^{\circ} \mathrm{C}$ and $75 \mathrm{RPM}$, Anaerobic 126

Figure 4-39: Experiment IV-5 CYA Concentration vs. Time, Turbidimetric

Measurement, Thai FOG Supernatant in $62.5 \mathrm{mg} / \mathrm{L} \mathrm{CYA}$ at $30^{\circ} \mathrm{C}$ and 75

RPM, Anaerobic 128

Figure 4-40: Experiment IV-6 CYA Concentration vs. Time, Turbidimetric

Measurement, Thai FOG and US FOG in Triplicate, DI Water with

Glucose at $30^{\circ} \mathrm{C}$ and $75 \mathrm{RPM}$, Anaerobic

Figure 4-41: Calibration of Turbidimetric Method for CYA Measurement,

Turbidimetric Measurement

Figure 4-42: Experiment IV-9 Peak Area vs. CYA Concentration Calibration, HPLC

Measurement, $\mathrm{P}=350$ bar....

Figure 4-43: Experiment IV-11 CYA Peak Area vs. Time, HPLC Measurement, Thai FOG in $60 \mathrm{mg} / \mathrm{L} \mathrm{CYA}$, DI Water at $30^{\circ} \mathrm{C}$ and $75 \mathrm{RPM}$, Anaerobic 135

Figure 4-44: Experiment IV-12 Peak Area vs. Time, HPLC Measurement, DI Water at $30^{\circ} \mathrm{C}$ and $75 \mathrm{RPM}$, Anaerobic

Figure 4-45: Experiment IV-12 Relative Peak Area vs. Time, Corrected to 60 PPM Standard, HPLC Measurement, DI Water at $30^{\circ} \mathrm{C}$ and 75 RPM, Anaerobic

Figure 4-46: Experiment IV-15 Peak Area vs. Time, HPLC Measurement, Minimal Growth Media at $30^{\circ} \mathrm{C}$ and 75 RPM, Varying C:N:P Ratios, Aerobic and Anaerobic Treatments

Figure 4-47: Experiment Iv-17 Peak Area vs. Time, HPLC Measurement, CAR Product at $5 \mathrm{mg} / \mathrm{L}$ and $50 \mathrm{mg} / \mathrm{L}$, DI Water with Dextrose at $30^{\circ} \mathrm{C}$ and 75 RPM, Anaerobic 
Figure 4-48: Experiment IV-17 Peak Area vs. Time Relative to Averaged Controls, HPLC Measurement, CAR Product at $5 \mathrm{mg} / \mathrm{L}$ and $50 \mathrm{mg} / \mathrm{L}$, DI Water with Dextrose and at $30 \mathrm{oC}$ and 75 RPM, Anaerobic

Figure 4-49: Experiment IV-18 Peak Area vs. Time HPLC Measurement, CAR Product and Varied Glucose, DI Water with $\mathrm{K}_{2} \mathrm{HPO}_{4}$ at $30^{\circ} \mathrm{C}$ and 75 RPM, Anaerobic

Figure 4-50: Experiment IV-19 CYA Concentration vs. Time, HPLC Measurement, Vegetative Bacterial Inoculums, DI Water with Dextrose at $30^{\circ} \mathrm{C}$ and 75 RPM, Anaerobic

Figure 4-51: Experiment IV-19 CYA Concentration vs. Time Corrected to Control 1, HPLC Measurement, Vegetative Bacterial Inoculums, DI Water with Dextrose at $30^{\circ} \mathrm{C}$ and $75 \mathrm{RPM}$, Anaerobic

Figure 4-52: Experiment IV-20 Anaerobic CYA Concentration vs. Time, Excluding $\mathrm{T}=0$, Vegetative Bacteria, Minimal Media at $30^{\circ} \mathrm{C}$ and $75 \mathrm{RPM}$, Anaerobic 147

Figure 4-53: Experiment IV-20 Averaged CYA Concentration vs. Time, Excluding $\mathrm{T}=0$, Excluding Thai FOG 2, Vegetative Bacteria, Minimal Media at $30^{\circ} \mathrm{C}$ and $75 \mathrm{RPM}$, Anaerobic .....

Figure 7-1: Chromatogram for Experiment IV-20, Day 13, 63 mg/L CYA Standard.... 174

Figure 7-2: Chromatogram for Experiment IV-20, Day 13, “Control 1" Treatment...... 175

Figure 7-3: Chromatogram for Experiment IV-20, Day 13, “Thai FOG 1” Treatment.. 176

Figure 7-4: Chromatogram for Experiment IV-20, Day 13, "Filter Media 2"

Treatment. 177

Figure 7-5: Experiment IV-20, Day 13, CYA Calibration Curve.................................. 178

Figure 7-6: Premix New 400x (Left), Premix New 1600x (Right).............................. 179

Figure 7-7: Premix New 3000x (Left), Premix New 12000x (Right)........................... 179

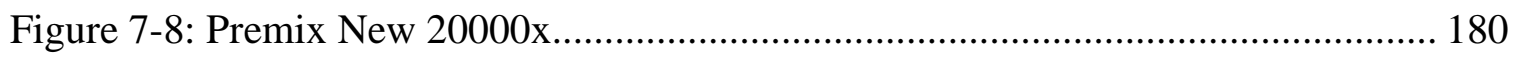

Figure 7-9: Premix Used 400x (Left), Premix Used 1600x (Right) ............................ 180

Figure 7-10: Premix Used 3000x (Left), Premix Used 12000x (Right) ....................... 181

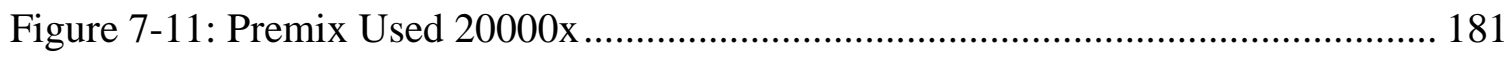

Figure 7-12: Thai FOG New 400x (Left), Thai FOG New 1600x (Right) .................... 182

Figure 7-13: Thai FOG New 3000x (Left), Thai FOG New 12000x (Right) ................ 182 


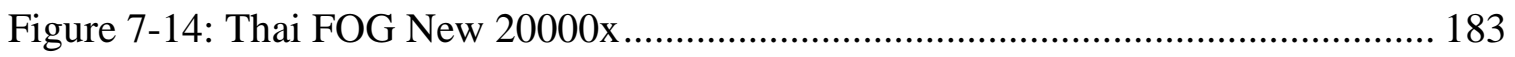

Figure 7-15: Thai FOG Used 400x (Left), Thai FOG Used 1600x (Right).................... 183

Figure 7-16: Thai FOG Used 3000x (Left), Thai FOG Used 12000x (Right)............... 184

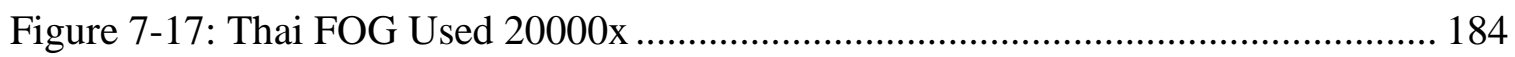

Figure 7-18: Experiment IV-20, 85 mg/L CYA Standard, Day 0 …………………..... 185

Figure 7-19: Experiment IV-20, 85 mg/L CYA Standard, Day 3 ................................. 185

Figure 7-20: Experiment IV-20, 85 mg/L CYA Standard, Day 10 …………………... 186

Figure 7-21: Experiment IV-20, 50 mg/L CYA Control, Day 0 …………………….... 186

Figure 7-22: Experiment IV-20, 50 mg/L CYA Control, Day 3 .................................... 187

Figure 7-23: Experiment IV-20, 50 mg/L CYA Control, Day 10 .................................. 187

Figure 7-24: Experiment IV-20, Growth Media, Thai FOG with CYA, Day 0 ............. 188

Figure 7-25: Experiment IV-20, Growth Media, Thai FOG with CYA, Day 3 ............. 188

Figure 7-26: Experiment IV-20, Growth Media, Thai FOG with CYA, Day 10 ........... 189

Figure 7-27: Experiment IV-20, Growth Media, Filter Media with CYA, Day 0 .......... 189

Figure 7-28: Experiment IV-20, Growth Media, Filter Media with CYA, Day 3 .......... 190

Figure 7-29: Experiment IV-20, Growth Media, Filter Media with CYA, Day 10 ........ 190 


\section{CHAPTER 1 - INTRODUCTION}

The purpose of this research is to investigate the removal of sunscreen and cyanuric acid from swimming pool water by commercially available microbiological products. BiOWiSH Technologies, Inc. provided all bacterial consortia used in these experiments. Based in Cincinnati, Ohio, BiOWiSH is a company dedicated to developing, researching, and manufacturing innovative biological solutions to issues in wastewater, solid waste, agriculture, aquaculture, and recreational pools. Within the recreational pool industry, BiOWiSH products have been used for water clarification and are reported to reduce cyanuric acid levels.

A sufficient chlorine concentration (at least $1-2 \mathrm{mg} / \mathrm{L} \mathrm{Cl}_{2}$ or equivalent) must be maintained in recreational pools to ensure sufficient inhibition of bacteria and protozoa. Hypochlorite $\left(\mathrm{OCl}^{-}\right)$is unstable under UV radiation and must be added in the form of chlorinated isocyanurates. After reacting with oxidizable material, chlorinated isocyanurates release CYA as a stable byproduct. As chlorine is expended and re-dosed, CYA accumulates in swimming pools. While CYA enhances the longevity of residual chlorine, it inhibits the bactericidal effects of chlorine at high concentrations (Shields et al. 2009). Additionally, the only current method for removal of CYA from swimming pools is through draining and dilution with clean water (Pennsylvania Dept. of Public Health 2015). Biodegradation of CYA has been studied extensively, although not in the context of recreational pools. 
Leading up to the onset of this research, a third-party pool operator set up a rudimentary test investigating the clarification of sunscreen by the BiOWiSH Aqua FOG product in an aquarium. An observed drop in turbidity led investigators to begin using the product in routine pool maintenance. This research was started validate BiOWiSH products' abilities to clarify swimming pool water. As preliminary research was carried out, the scope and aims of the project evolved into a robust investigation of water clarification. The scope of work was set out as follows:

\section{$\underline{\text { Specific Tasks }}$}

Task I - Determination of Clarification Mechanism

Task II - Efficacy of BiOWiSH Products Clarifying Swimming Pools

Task III - Isolation and I.D. of Microbes Which Survive in Chlorinated Environments Task IV - Investigation of Biodegradation of Cyanuric Acid

The first task, Task I, sought to determine the mechanism by which BiOWiSH products clarify turbidity from swimming pools. Nine experiments were carried out using heated 10-gallon aquaria filled with chlorinated tap water and fitted with filtration systems to mimic conditions in recreational pools. Sunscreen was used as the sole source of turbidity, as it provided an easily replicable emulsion of oils and carbonaceous material. A wide array of BiOWiSH products were tested in these aquaria against un-amended mechanical filtration. Different combinations of the products' components were tested, including solid substrate products, soluble products, isolated microorganisms, and abiotic solid substrates. 
Task II sought to quantify the abilities of various BiOWiSH products at reducing turbidity from chlorinated and non-chlorinated environments without the assistance of mechanical filtration. Nine experiments were carried out to investigate the effects of $\mathrm{BiOWiSH}$ products on mechanical filtration of turbidity. Experiments included a UV absorbance calibration curve for sunscreen, determining the extent of chlorine scouring caused by various growth media, determining the rates of chlorine scouring by each BiOWiSH product, testing the influence of settling on turbidity reduction, and investigating the effects of BiOWiSH products on turbidity using dextrose versus sunscreen as carbon sources.

Task III investigated the types and quantity of bacteria present in $\mathrm{BiOWiSH}$ products after use in clarification experiments. Samples were plated to investigate the most probable number of Colony Forming Units (CFU), as well as colony morphology, and to isolate individual bacterial species for staining and classification. Due to time constraints, only two experiments were run under this task. One of the experiments became contaminated, leaving just one viable set of data.

Task IV investigated the effects of BiOWiSH products on CYA. This task proved to be the most extensive and challenging, due to highly varied results of CYA measurement from different methods. The first experiment failed due to repeated respirometer malfunctions, and has been omitted. The second through seventh experiments under this task utilized a turbidimetric method of CYA analysis, and a false reduction of CYA was seen due to suspected interference on measurement by solid substrate products. An HPLC method was developed and refined, over seven months, to resolve CYA peaks from those of nitrate and 
other chemicals using a phosphate buffer and methanol. HPLC analysis showed no reduction in CYA by any means, including experiments which had previously shown a reduction in CYA through turbidimetric analysis. 


\section{CHAPTER 2 - BACKGROUND}

\subsection{Swimming Pools and Contaminants}

There are 14.4 million residential swimming pools and hot tubs and 309,000 public recreational pools in the United States, reported by the CDC in 2013 (CDC 2014, P.K. Data, Inc 2013). Additionally, swimming is the fourth most popular recreational sport, with over 300 million visits to swimming venues nationwide in 2009 . There are many health benefits associated with swimming, such as low-impact cardiovascular exercise which is not aggravating to joints, and activity that engages almost every muscle in the body. In order to maintain a healthy environment for swimmers, municipalities have enacted recreational water quality regulations.

Recreational pool water quality is regulated in California by Title 22 Standards (California Code of Regulations 2015). Water clarity is an important indicator of the cleanliness of a recreational pool. Regulated contaminants of swimming pools include dirt, debris, scum, oils, organic and inorganic material (WHO 2006). Almost all recreational pools are fitted with filtration systems which provide predominantly mechanical removal of the abovementioned contaminants (Linhart 2014). Microbial growth in recreational pool water is slowed by chlorination, preventing significant growth. Microorganisms in the pool water are captured in the filtration system and can potentially biodegrade regulated contaminants within the pool.

In addition to mechanical filtration, chemical control of bacterial contaminants is important for maintaining clear pool water and preventing infection in pool-users. The most common 
method of bacterial inhibition in recreational pools is chlorination. Chlorine, when added in the forms of chlorine gas $\left(\mathrm{Cl}_{2}\right)$, hypochlorite $\left(\mathrm{OCl}^{-}\right)$, or chlorine dioxide $\left(\mathrm{ClO}_{2}\right)$, readily oxidizes organic and inorganic contaminants (Cooke 2000).

In California, public swimming pools are governed by Title 22 standards within the California Code of Regulations. Pool operators are required to maintain conditions in which the bottom of the deepest area of the pool can be clearly seen from the pool deck (California Code of Regulations 2015). Public pools must also maintain $\mathrm{pH}$ levels between 7.2 and 7.8. Regulated contaminants of swimming pools include dirt, debris, scum, oils, organic and inorganic material (WHO 2006). Heterotrophic bacterial Standard Plate Count is limited to 200 Colony Forming Units (CFU) per $\mathrm{mL}$, and Total Coliform are limited to 2.2 CFU per $100 \mathrm{~mL}$. Disinfectants and their byproducts are also regulated by Title 22 .

In the 2008 report on swimming pool water quality compiled by the Centers for Disease Control (CDC), violations were categorized as Serious, Water Quality, or Policy and Management. Disinfectant level violations were given their own sub-category under water quality. Cyanurate violations were compiled with algae and bacterial quality among others under "Other Water Chemistry." Of the 121,000 pools sampled for disinfectant levels by the CDC, $10.7 \%$ were in violation. Of the 99,000 pools sampled for Other Water Chemistry issues, $12.5 \%$ were in violation (CDC 2010). Since the Other Water Chemistry issues category only required one of nine criteria to fail, it is impossible to discern the prevalence of cyanurate-related violations. 
One major contaminant in swimming pools is sunscreen, which is commonly used to protect against skin cancer caused by UV radiation during outdoor activity. Sunscreen is ubiquitous in outdoor swimming pools, and contains many oils and UV-blockers which contribute to water turbidity. The inactive ingredients in sunscreens contribute a large amount of oils to recreational pools, in the forms of ethylhexyl palmitate, Bis-Stearyl Ethylenediamine/Neopentyl Glycol/Stearyl Hydrogenated Dimer Dilinoleate Copolymer, retinyl palmitate, and other fatty acids (DailyMed 2012).

\subsubsection{Cyanuric Acid}

Cyanuric Acid (CYA, $\mathrm{C}_{3} \mathrm{H}_{3} \mathrm{O}_{3} \mathrm{~N}_{3}$ ), a common chlorine stabilizer against ultraviolet (UV) degradation, is a byproduct which enters outdoor swimming pools in the form of chlorinated isocyanurates. Stabilized chlorine can be obtained in three forms: monochloroisocyanuric acid (monochloro-s-triazinetrione acid), dichloroisocyanuric acid (dichloro-s-triazinetrione acid), and trichloroisocyanuric acid (trichloro-s-triazinetrione). Chlorinated isocyanurates have a high resistance to UV degradation, because their UV wavelength absorbance maxima are below $220 \mathrm{~nm}$, and any UV radiation below $290 \mathrm{~nm}$ is absorbed by the atmosphere. Hypochlorite has an absorbance maximum of $290 \mathrm{~nm}$ with a spectrum that extends out to around $350 \mathrm{~nm}$. Therefore, hypochlorite is unstable in the presence of UV light, and the introduction of cyanuric acid enhances the longevity of outdoor pools' chlorine residuals.

Although it is an ineffective bactericide, the monochloroisocyanurate ion is beneficial to disinfection. It acts as a reservoir of hypochlorite which can add hypochlorous acid to the 
system on-demand (Wojtowicz 2001). It is generally agreed that $25-30 \mathrm{mg} / \mathrm{L} \mathrm{CYA}$ is required before proper chlorine stabilization is achieved. Alternately, the presence of cyanuric acid has been shown to inhibit the bactericidal effects of. Wojtowicz also noted that there is a strong positive correlation between the concentration ratio of total cyanuric acid to total free available chlorine and the kill time of $99 \%$ of a population of S. faecalis.

$\mathrm{t}_{0.99}\left(\mathrm{pH} 7\right.$ and $\left.20^{\circ} \mathrm{C}\right)=0.119+0.0516 \mathrm{Cy}_{\mathrm{T}} / \mathrm{Cl}_{\mathrm{T}}, \mathrm{r}^{2}=0.98$

At $50 \mathrm{mg} / \mathrm{L}$ CYA, hyperchlorination with $20 \mathrm{mg} / \mathrm{mL}$ free $\mathrm{Cl}$ proved insufficient at obtaining 3-log removal of oocysts in fecal-contaminated swimming pools. After 10 hours of hyperchlorination in the presence of CYA, only $0.7-\log _{10}$ removal of oocysts was achieved, compared to the 3.7- $\log _{10}$ removal without CYA (Shields et al. 2009). From a disinfection standpoint, the need to manage CYA levels in swimming pools is apparent.

As chlorinated isocyanurates react with biological and other pool contaminants, cyanuric acid is left behind as a very stable byproduct. Title 22 standards call for no more than 100 $\mathrm{mg} / \mathrm{L}$ cyanuric acid in pools and that the water appear "clean and clear" (California Code of Regulations 2015), because cyanuric acid contributes adversely to turbidity. Every mole of dichloroisocyanuric acid in a pool liberates one mole of cyanurate ions when the released hypochlorite ions react with contaminants. Assuming a daily dose of $1 \mathrm{mg} / \mathrm{L}$ hypochlorite, in the form of dichloroisocyanuric acid, and assuming no degradation of cyanuric acid, every swimming pool using dichloroisocyanuric acid will be in violation of the standard after 15 weeks of chlorination. The only viable method of reducing cyanuric acid 
concentration is to dump pool water and dilute with clean water (Pennsylvania Dept. of Public Health 2015), which is wasteful and costly to domestic and professional operators.

Cyanuric acid, a white odorless solid, is inactive within the human body passing through the renal system of swimmers without loss of concentration (Zwiener et al. 2007). Concern has arisen regarding the nephrotoxicity (kidney toxicity) of cyanuric acid and melamine (a precursor to cyanuric acid in synthesis) in combination. When ingested together, cyanuric acid and melamine form kidney stones of melamine cyanurate crystals, which can lead to renal failure. In 2007, a crisis emerged in the pet food industry, when a producer added melamine to dog and cat food. Melamine raises the apparent protein content of food samples during analysis, due to its high nitrogen content. Contamination of the melamine with cyanuric acid led to renal failure and the death of up to 36,000 dogs and cats in the United States. The contamination led to the largest FDA recall to date (Rovner 2008).

\subsubsection{Clarification Mechanisms}

The two main possible pathways of swimming pool clarification are mechanical and biological. Mechanical filtration denotes the filtration mechanism of a pool and incorporates physical separation techniques. Biological filtration includes microbial conversion of contaminants to biomass via metabolism and extracellular enzymatic activity. 


\subsubsection{Mechanical Clarification}

There are three main types of pool filters: sand, cartridge, and diatomaceous earth (DE). Sand filters are the cheapest and easiest filters to maintain; however, sand provides the least filtration of water, only removing particles larger than $30 \mu \mathrm{m}$ (Linhart 2014). Cartridge filters provide good water quality, excluding particles as small as $10 \mu \mathrm{m}$ (Linhart 2014). They require minimal maintenance and no backwashing, but filter cartridges must be changed out periodically (on the order of 1-3 years). DE filters, provide the best water quality, removing particles as small as to $3-5 \mu \mathrm{m}$ (Linhart 2014). DE filters require the highest capital investment of the three options, and are the most labor-intensive to maintain.

\subsubsection{Biological Clarification}

Due to the complex composition of commercial sunscreens, there are many possible biodegradation pathways. Inactive ingredients such as sorbitol are readily degraded by many microorganisms (Caspi et al. 2014). The biological degradation of UV blockers in sunscreen is most feasible by fungi such as the white rot fungus Trameces versicolor (Badia-Fabregat et al. 2012).

Many papers studying the biodegradation of the s-triazine ring, and CYA, have been published, due to the prevalence of cyclic s-triazine in pesticides. Cyanuric acid is a key intermediate between cyclic s-triazine pesticides and ammonia. CYA is biodegraded via hydrolysis, ultimately producing $\mathrm{CO}_{2}$ and ammonia. The degradation of CYA produces no

primary BOD; however nitrogenous BOD is added in the form of ammonia. Each mole of 
metabolized CYA liberates 3 moles of ammonia, by the pathway shown in Figure 2-1. It was widely accepted that urea was an intermediate CYA metabolite; however, an extensiveFstudy determined that common analytical methods forced allophanate to decarboxylate into urea which was not present from metabolism (Cheng et al 2005).

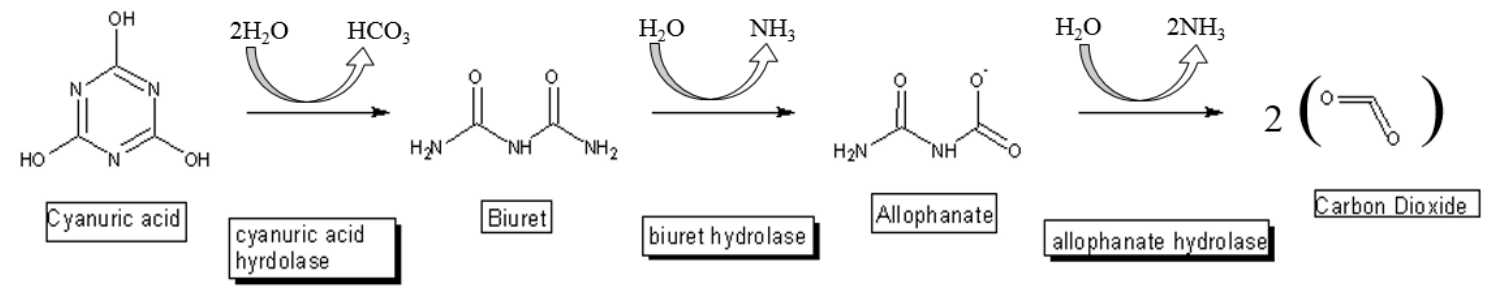

Figure 2-1: Cyanuric Acid Degradation Mechanism (Kotharu 2014)

Biodegradation of cyanuric acid in aqueous systems is possible, especially at low or no dissolved oxygen. While bacteria which degrade CYA proliferate in both aerobic and anaerobic environments, CYA degradation itself only occurs in anaerobic environments (Saldick 1974). Cyanuric acid removal can be obtained at 1-3 mg/L of dissolved oxygen in activated sludge systems with a solids retention time of at least 6 hrs. Systems that have high dissolved oxygen also show CYA reduction, but only in localized anaerobic zones (Saldick 1974). The greatest natural CYA removal occurs in activated sludge systems or mud and muddy creeks. Comparing results from lake water and water containing mud, it is apparent that CYA degradation occurs in the soils and sediment, rather than the water (Saldick 1974). Degradation has also been demonstrated in solutions of 3.5\% NaCl. Saldick noted that the addition of glucose speeds up the degradation process. Saldick also noted a lag time of no more than a few minutes between a system turning anaerobic and the resulting increase in biodegradation of CYA. Doubling the concentration of CYA 
decreased the rate of degradation of tracer CYA, showing degradation as kinetically not first-order.

\subsubsection{Types of Bacteria Used}

BiOWiSH Technologies, Inc. produces bacterial consortia with compositions found in

Table 2-1. Many of the products are proprietary, and only the genera of bacteria are available for publication.

Table 2-1: List of Products Tested

\begin{tabular}{|c|c|c|c|}
\hline Product Name & Abbreviation & Bacterial Species & Composition \\
\hline $\begin{array}{l}\text { BioCure Microbial } \\
\text { Technologies (BMT) } \\
\text { Wastewater }\end{array}$ & $\begin{array}{l}\text { BMT WW } \\
\text { (BMT WW1 and } \\
\text { BMT WW2 are } \\
\text { two different } \\
\text { batches of BMT } \\
\text { WW) }\end{array}$ & Mix of 6-8 Bacillus & $\begin{array}{l}\text { Bacillus spores, } \\
\text { Soluble Diluent }\end{array}$ \\
\hline $\begin{array}{l}\text { BioCure Microbial } \\
\text { Technologies (BMT) } \\
\text { Remediate }\end{array}$ & $\begin{array}{l}\text { BMT Remediate } \\
\text { (BMT SS) }\end{array}$ & $\begin{array}{l}\text { Mix of } \\
\text { Rhodococcus and } \\
\text { Arthobacter }\end{array}$ & Undisclosed \\
\hline $\begin{array}{l}\text { BiOWiSH Fruit and } \\
\text { Vegetable Wash }\end{array}$ & Fruit Wash & $\begin{array}{l}\text { Mix of Bacillus and } \\
\text { Lactobacillus }\end{array}$ & $\begin{array}{l}\text { Bacillus spores, } \\
\text { Lactobacillus, } \\
\text { Soluble Diluent }\end{array}$ \\
\hline $\begin{array}{l}\text { BiOWiSH Lactic } \\
\text { Mix } 1\end{array}$ & LCM & $\begin{array}{l}\text { Mix of } \\
\text { Lactobacillus }\end{array}$ & $\begin{array}{l}\text { Bacteria, Soluble } \\
\text { Diluent }\end{array}$ \\
\hline OBAAG-KLB 30 & KLB & $\begin{array}{l}\text { Single Bacillus } \\
\text { species }\end{array}$ & $\begin{array}{l}\text { Bacillus spores, } \\
\text { Diluent }\end{array}$ \\
\hline $\begin{array}{l}\text { Microbial Discovery } \\
\text { Group (MDG) Waste } \\
\text { Water Treatment }\end{array}$ & MBWWT\#1 & Mix of Bacillus & Salt, Bacillus spores \\
\hline
\end{tabular}




\begin{tabular}{|c|c|c|c|}
\hline Product Name & Abbreviation & Bacterial Species & Composition \\
\hline $\begin{array}{l}\text { Osprey Biotechnics } \\
\text { Waste Water } \\
\text { Treatment }\end{array}$ & $\begin{array}{l}\text { OBWWT\#1 } \\
\text { (Osprey WW) }\end{array}$ & Mix of Bacillus & Undisclosed \\
\hline $\begin{array}{l}\text { BiOWiSH Aqua } \\
\text { (Produced in } \\
\text { Thailand) }\end{array}$ & Thai Aqua & $\begin{array}{l}\text { Mix of Bacillus and } \\
\text { Lactobacillus }\end{array}$ & $\begin{array}{l}\text { Bacillus spores, } \\
\text { vegetative bacteria, } \\
\text { Rice Bran and Soy } \\
\text { meal }\end{array}$ \\
\hline $\begin{array}{l}\text { BiOWiSH Aqua } \\
\text { FOG (Produced in } \\
\text { Thailand) }\end{array}$ & Thai FOG & $\begin{array}{l}\text { Mix of Bacillus and } \\
\text { Lactobacillus }\end{array}$ & $\begin{array}{l}\text { Bacillus spores, } \\
\text { vegetative bacteria, } \\
\text { Rice Bran and Soy } \\
\text { meal }\end{array}$ \\
\hline $\begin{array}{l}\text { BiOWiSH Aqua } \\
\text { FOG (Produced in } \\
\text { Thailand, Irradiated) }\end{array}$ & $\begin{array}{l}\text { Irradiated Thai } \\
\text { FOG, } \\
\text { (Thai Fog I, } \\
\text { IRTF) }\end{array}$ & $\begin{array}{l}\text { Mix of Bacillus and } \\
\text { Lactobacillus, } \\
\text { Inactivated by } \\
\text { Irradiation }\end{array}$ & $\begin{array}{l}\text { Irradiated Bacillus } \\
\text { spores, Irradiated } \\
\text { bacteria, Rice Bran } \\
\text { and Soy meal }\end{array}$ \\
\hline $\begin{array}{l}\text { Microbial Discovery } \\
\text { Group (MDG) } \\
\text { Hydrocarbon } \\
\text { Remediation Product }\end{array}$ & MDG Petro & $\begin{array}{l}\text { Mix of Bacillus and } \\
\text { Pseudomonas }\end{array}$ & $\begin{array}{l}\text { Bacillus spores, } \\
\text { vegetative bacteria, } \\
\text { soluble diluent }\end{array}$ \\
\hline $\begin{array}{l}\text { Osprey Biotechnics } \\
\text { Hydrocarbon } \\
\text { Remediation Product }\end{array}$ & BPB-100 & Pseudomonas & Undisclosed \\
\hline $\begin{array}{l}\text { Osprey Biotechnics } \\
\text { Hydrocarbon } \\
\text { Remediation Product }\end{array}$ & $\begin{array}{l}\text { MPB-5 } \\
\text { (Osprey L, } \\
\text { Osprey Liq) }\end{array}$ & $\begin{array}{l}\text { Mix of Bacillus and } \\
\text { Pseudomonas }\end{array}$ & $\begin{array}{l}\text { Bacillus spores, } \\
\text { vegetative bacteria, } \\
\text { soluble diluent }\end{array}$ \\
\hline $\begin{array}{l}\text { BiOWiSH Manure } \\
\text { and Odor Treatment, } \\
\text { Swine }\end{array}$ & Manure/ Odor & Undisclosed & $1-10 \%$ bacteria \\
\hline $\begin{array}{l}\text { Microbial Discovery } \\
\text { Group Micronutrient } \\
\text { Mix }\end{array}$ & MDG Micro-N & Abiotic & Undisclosed \\
\hline $\begin{array}{l}\text { BiOWiSH Aqua } \\
\text { (Produced in USA) }\end{array}$ & US Aqua & $\begin{array}{l}\text { Mix of Bacillus and } \\
\text { Lactobacillus }\end{array}$ & $\begin{array}{l}\text { Bacillus spores, } \\
\text { vegetative cells, } \\
\text { soluble diluent }\end{array}$ \\
\hline
\end{tabular}




\begin{tabular}{|c|c|c|c|}
\hline Product Name & Abbreviation & Bacterial Species & Composition \\
\hline $\begin{array}{l}\text { BiOWiSH Aqua - } \\
\text { Fats, Oils, and } \\
\text { Grease (Produced in } \\
\text { USA) }\end{array}$ & US FOG & $\begin{array}{l}\text { Mix of Bacillus and } \\
\text { Lactobacillus }\end{array}$ & $\begin{array}{l}\text { Bacillus spores, } \\
\text { vegetative cells, } \\
\text { soluble diluent, } \\
\text { emulsifier }\end{array}$ \\
\hline $\begin{array}{l}\text { BioCure Microbial } \\
\text { Technologies } \\
\text { Prototype Waste } \\
\text { Water Product } 001\end{array}$ & AP001 & Mix of Bacillus & $\begin{array}{l}\text { Bacillus spores, Rice } \\
\text { Bran and Soy Meal }\end{array}$ \\
\hline $\begin{array}{l}\text { BioCure Microbial } \\
\text { Technologies } \\
\text { Prototype Waste } \\
\text { Water Product } 002\end{array}$ & AP002 & Mix of Bacillus & $\begin{array}{l}\text { Bacillus spores, Rice } \\
\text { Bran and Soy Meal }\end{array}$ \\
\hline $\begin{array}{l}\text { BioCure Microbial } \\
\text { Technologies } \\
\text { Prototype Waste } \\
\text { Water Product } 003\end{array}$ & AP003 & Mix of Bacillus & $\begin{array}{l}\text { Bacillus spores, Rice } \\
\text { Bran and Soy Meal }\end{array}$ \\
\hline $\begin{array}{l}\text { BioCure Microbial } \\
\text { Technologies } \\
\text { Prototype Waste } \\
\text { Water Product } 004\end{array}$ & AP004 & Mix of Bacillus & $\begin{array}{l}\text { Bacillus spores, Rice } \\
\text { Bran and Soy Meal }\end{array}$ \\
\hline $\begin{array}{l}\text { Biosource Prototype } \\
\text { Lactic Mix } 001\end{array}$ & BS-AQ-001 & $\begin{array}{l}\text { Mix of } \\
\text { Lactobacillus and } \\
\text { microbial } \\
\text { metabolites }\end{array}$ & $\begin{array}{l}\text { Vegetative cells, } \\
\text { metabolites, Rice } \\
\text { Bran and Soy Meal }\end{array}$ \\
\hline $\begin{array}{l}\text { Biosource Prototype } \\
\text { Lactic Mix } 002\end{array}$ & BS-AQ-002 & $\begin{array}{l}\text { Mix of } \\
\text { Lactobacillus and } \\
\text { microbial } \\
\text { metabolites }\end{array}$ & $\begin{array}{l}\text { Vegetative cells, } \\
\text { metabolites, Rice } \\
\text { Bran and Soy Meal }\end{array}$ \\
\hline $\begin{array}{l}\text { Biosource Prototype } \\
\text { Lactic Mix } 003\end{array}$ & BS-AQ-003 & $\begin{array}{l}\text { Mix of } \\
\text { Lactobacillus and } \\
\text { microbial } \\
\text { metabolites }\end{array}$ & $\begin{array}{l}\text { Vegetative cells, } \\
\text { metabolites, Rice } \\
\text { Bran and Soy Meal }\end{array}$ \\
\hline $\begin{array}{l}\text { BiOWiSH Premix } \\
\text { (Thailand) }\end{array}$ & Premix & $\begin{array}{l}\text { Mix of } \\
\text { Lactobacillus }\end{array}$ & $\begin{array}{l}\text { Vegetative cells, } \\
\text { Rice Bran, Soy Meal }\end{array}$ \\
\hline BiOWiSH Crop & Crop & Undisclosed & Undisclosed \\
\hline
\end{tabular}




\begin{tabular}{llll}
\hline Product Name & Abbreviation & Bacterial Species & Composition \\
\hline $\begin{array}{l}\text { Rice Bran used in } \\
\text { Thai FOG } \\
\begin{array}{l}\text { Production } \\
\text { Riceland Rice Bran }\end{array}\end{array}$ & Thai Rice Bran & Undefined & Rice Bran \\
$\begin{array}{l}\text { BiOWiSH Cyanuric } \\
\text { Acid Reducer }\end{array}$ & CAR & Undefined & Rice Bran \\
& & $\begin{array}{l}\text { Mix of Bacillus and } \\
\text { Lactobacillus }\end{array}$ & $\begin{array}{l}\text { Bacterial spores, } \\
\text { vegetative cells, } \\
\text { soluble diluent }\end{array}$ \\
\hline
\end{tabular}

\subsection{Parameters Tested and Quantification Methods}

Section 2.2 discusses specific parameters used in this study and the theory behind the parameters' quantification.

\subsubsection{Turbidity}

Turbidity is a measure of water clarity which denotes the amount of light occluded from passing through a solution by suspended particulate matter. Turbidity measurement does not necessarily measure the amount of solids in a solution. Particle sizes affecting turbidity range from $0.2 \mu \mathrm{m}$ to $1.0 \mathrm{~mm}$ (EPA 2012). The two most common units of turbidity are Formazin Attenuation Units (FAU) or Nephelometric Turbidity Units (NTU), depending on the angle at which the detector sits and the wavelength of the incident beam. NTU is measured perpendicular to the incident light angle with a white light source, whereas FAU is measured in-line with an infrared light source. When compared to a Formazin standard solution, NTU and FAU units are analogous (HACH 2009). 
Broad-spectrum sunscreens absorb ultraviolet light from 290-400 nm and higher. Sunscreen can be measured turbidimetrically in aqueous samples without additional sample preparation. No literature was found directly correlating sunscreen to turbidity, so a standard curve was developed as a part of this study based on optical density at 520 nm.

\subsubsection{CYA Analysis: Turbidimetric and HPLC}

CYA can be tested through turbidimetric and chromatographic analysis. The most common method for CYA analysis by recreational pool operators is turbidimetric, as kits are portable and cheap. Turbidity is induced in a sample from the addition of melamine and the resulting precipitation of melamine cyanurate (HACH 2009). Although it has an upper test limit of $100 \mathrm{mg} / \mathrm{L}$, this method is inhibited by the solubility of melamine in water of 5-10 mg/L. Since a small amount of melamine will remain in solution rather than bond with CYA, analysis is prevented below $10 \mathrm{mg} / \mathrm{L}$ and accuracy is limited to $+/-10 \mathrm{mg} / \mathrm{L}$. Inexpensive test kits utilize the "disappearing dot" analysis, similar to that of a Secchi disk, where a plunger is lowered into a sample, and the depth at which the plunger cannot be seen corresponds to a concentration. This method is subject to high variability introduced by user discretion.

More sophisticated turbidimetric methods, such as the one developed by HACH Company, utilize IR absorbance for precise measurement of absorbance from CYA precipitation reactions. HACH Method 8139 for CYA utilizes a mixture of monobasic and dibasic 
potassium phosphate, and sodium sulfite to create a white precipitate in the presence of cyanuric acid (HACH 2009). The method has a detection limit of $7.0 \mathrm{mg} / \mathrm{L} \mathrm{CYA}$, and a standard deviation of +/- $1.2 \mathrm{mg} / \mathrm{L}$ was obtained by one HACH operator (HACH 2009).

An even higher level of precision in CYA measurement can be achieved through High Performance Liquid Chromatography (HPLC). HPLC utilizes selective adsorptive chemistry coupled with UV absorbance to separate, identify, and quantify chemical components within a liquid sample. Tran et al. (2010) achieved reversed-phase separation of melamine and cyanuric acid using a Dionex Acclaim Trinity P1 HPLC column using methanol and ammonium acetate buffer as eluents. In method development for this thesis, multiple iterations of ammonium acetate buffers and potassium phosphate buffers with methanol were investigated. A method was adapted from a paper by Cantú et al. (2001) in which a porous graphitic carbon column was used with $50 \mathrm{mM}$ dibasic potassium phosphate and methanol to resolve the CYA peak from that of nitrate.

\subsubsection{Chlorine: Free vs Total Cl Colorimetric}

Chlorine is typically measured in three forms in aqueous systems: free chlorine, combined chlorine, and total chlorine. Free chlorine is a combined concentration of chlorine gas $\left(\mathrm{Cl}_{2}\right)$, hypochlorous acid $(\mathrm{HOCl})$, and the hypochlorite anion $\left(\mathrm{OCl}^{-}\right)$. Combined chlorine is defined as the residual chlorine bound to organic amines and ammonia in the form of chloramines. Combined chlorine is unavailable for disinfection. Total chlorine is the sum of free and combined chlorine (CDC 2009). 
Chlorine was measured using a HACH DR/890 Colorimeter and HACH Method 10070.

"The combined chlorine oxidizes iodide in the reagent to iodine. The iodine reacts with DPD (N,N-diethyl-p-phenylenediamine) along with free chlorine present in the sample to form a pink color which is proportional in intensity to the total chlorine concentration" (HACH 2009).

\subsubsection{Surface Structure SEM}

Scanning electron microscopy (SEM) provides insight into a sample's surface topography by focusing a beam of electrons on the sample in a high vacuum system. SEM imaging can attain resolution on the sub-nanometer scale, between 10x and 500,000x magnification.

Biological samples are prepared via chemical fixation or freeze-drying, to prevent the introduction of unwanted moisture to the SEM system. Non-conductive samples are typically sputter-coated with a conductive material such as gold, gold/palladium alloy, platinum, or others. Coating masks the immediate surface structure of a sample, and is not desirable when investigating delicate organic samples. An SEM can be run at a low vacuum of 6-270 Pa (Ou and Duan 2005). At low vacuum conditions, uncoated insulative materials are able to discharge excess electrons to surrounding gas particles, preventing undesirable surface charging and scorching. 


\section{CHAPTER 3 - MATERIALS AND METHODS}

\subsection{Generalized Tests and Experimental Setup}

Section 3.1 details the materials and methods for tests used across experiments in this study.

\subsubsection{Experimental Setup}

Bioreactor General Materials:

- 10-gallon Aquaria

- Aquarium Filter (Tetra Whisper PF10, activated carbon removed)

- Aquarium Thermometer Strips

- Heating Elements

- 250 mL Screw-Top Shaker Flasks

- 500 mL Screw-Top Shaker Flasks

- Shaker Flask Caps With Removable Septum

- Shaker Flask Caps, Silicone, Breathable

- Tap Water

- DI Water With Squirt Nozzle

- Sunscreen (Coppertone Sport SPF 30)

- Bacterial Consortia

- Glass Funnel

- Magnetic Stir Bar 
- Magnetic Stir Bar Remover

Growth Media Components:

- $\quad$ Miracle Gro ${ }^{\circledR} 20-20-20$ Fertilizer

- $\mathrm{K}_{2} \mathrm{HPO}_{4}$

- $\mathrm{KH}_{2} \mathrm{PO}_{4}$

- Glucose/Dextrose

- $\mathrm{KNO}_{3}$

- $\mathrm{FeSO}_{4}$

- $\mathrm{CaCl}_{2}$

- MRS Broth

- Potato Dextrose Broth (PDB)

Bioreactor Inoculation and Sampling:

- 10-25 mL Serological Pipettes

- Plastic Weigh-Boats

- $200 \mu \mathrm{L}$ Pipette Tips

- $\quad 1000 \mu \mathrm{L}$ Pipette Tips (1 per day of chlorination)

- Clorox Concentrated Bleach

- Electronic Balance

- $100-1000 \mu \mathrm{L}$ Autopipette

- Light-Duty Chemistry Wipes

- 1000 mL Beaker For Liquid Waste 
- $250 \mathrm{~mL}$ Beaker for Solid Waste

- Laboratory Notebook

\subsubsection{Turbidity}

Turbidity levels tested in this study were less than 200 NTU. This was within the acceptable range of 0-1000 NTU for HACH DR/890 Colorimeter using HACH method 8237. No dilution was necessary.

\section{Turbidity Materials:}

- $\mathrm{DR} / 890$ Colorimeter (1)

- $\quad 10-25 \mathrm{~mL}$ cylindrical sample cell with cap (2)

- Serological pipette (1 per sample)

- DI Water

- $70 \%$ Ethanol in DI Water

- Light-Duty chemistry wipes

\section{Turbidity Procedures:}

Before sampling, put on proper Personal Protective Equipment (PPE), including laboratory gloves to prevent smudging of the sample cell. 


\section{Zeroing the Instrument:}

- A clean sample cell was filled with a DI water blank (DI cell).

- The DR/890 colorimeter was turned on.

- The exterior of the DI cell was wiped clean with a light duty wipe. The DI cell was loaded into the chamber of colorimeter and covered with the lid. The orientation of the DI cell was noted.

- $\quad$ PGRM 95 was entered.

- The ZERO button was pressed, zeroing the instrument, showing 0 NTU before continuing.

\section{Reading Turbidity:}

1. The instrument was zeroed to a DI blank, as seen above.

2. The sample cell was filled with $70 \%$ ethanol, capped, and shaken vigorously.

3. If a yellow color was noted in the ethanol after shaking, step 2 was repeated.

4. The sample cell was filled with 5-25 mL of DI, capped, and shaken vigorously. Waste was discarded in a proper receptacle.

5. Step 4 was repeated 3 times.

6. The sample cell was filled with 5-25 mL of sample, swirled and discarded.

7. The sample cell was then filled with at least $5 \mathrm{~mL}$ of sample to be measured.

8. A light-duty wipe was used to clean the exterior of the sample cell. The sample cell was then loaded into the chamber of colorimeter, and covered with the lid.

9. The READ button was pressed and turbidity was recorded as NTU.

10. Contents of the sample cell were discarded into a proper receptacle. 
11. Repeat Steps 2-10 for each sample.

12. At the end of sampling, steps 2-4 were repeated for cleanliness.

\subsubsection{Total Chlorine}

The HACH DR/890 Colorimeter and HACH method 10070 were used to measure chlorine levels. Total chlorine concentrations tested in this study usually fell between 0 and $8 \mathrm{mg} / \mathrm{L}$; however, some readings exceeded the upper limit of the test $(10 \mathrm{mg} / \mathrm{L})$. HACH methods allow for dilution of samples, as long as proper concentration correction is made after reading. All chlorine readings in this study were carried out using a 1:1 dilution. This was achieved by filling sample vials with double the recommended amount of sample before adding the reagent pack. All chlorine readings have been corrected in data tables and the body of this document.

\section{Total Chlorine Materials:}

- $\mathrm{DR} / 890$ Colorimeter (1)

- DPD Total Chlorine High Concentration reagent pillow packs (1 per sample)

- 10-25 mL cylindrical sample cell with cap (1)

- Serological pipette (1 per sample)

- DI Water

- $70 \%$ Ethanol in DI Water

- Light-Duty chemistry wipes 


\section{Total Chlorine Procedure:}

Before sampling, put on proper PPE, including gloves to prevent smudging of sample cell exterior.

1. A sample cell was filled with $70 \%$ ethanol, capped, and shaken vigorously. Ethanol was poured into waste container.

2. If a yellow color was noted in the ethanol after shaking, step 2 was repeated.

3. The sample cell was filled with 5-25 mL of DI, capped, and shaken vigorously. Waste was discarded in a proper receptacle.

4. 5-25 $\mathrm{mL}$ of sample were added to the sample cell, swirled and discarded.

5. The sample cell was filled with $10 \mathrm{~mL}$ of sample [double the recommended 5 $\mathrm{mL}]$.

6. The DR/890 colorimeter was turned on.

7. PGRM 12 was entered.

8. A light-duty wipe was used to clean the exterior of the sample cell. The sample cell was then loaded into the chamber of colorimeter, and covered with the lid.

9. The instrument was zeroed by pressing the ZERO button. Before sampling the screen would read $0.0 \mathrm{mg} / \mathrm{L} \mathrm{Cl}_{2}$.

10. The sample cell was removed from the colorimeter, and add the contents of one HACH DPD Total Chlorine High Range reagent pillow pack were added to the cell.

11. A 3-mintue reaction timer was started.

12. The sample was swirled vigorously until all reagent dissolved. Undissolved reagent does not interfere with the result of the test. 
13. After the 3-minute reaction period, the sample cell was loaded back into the sample chamber with the same orientation as when it was zeroed. The sample cell was tapped gently to ensure that there were no bubbles in the sample.

14. The READ button was pressed, and data were recorded as $\mathrm{mg} / \mathrm{L} \mathrm{Cl}_{2}$. Note: True Chlorine concentrations are double that of what the machine reads.

15. Waste was discarded into a proper receptacle.

16. Steps 1-15 were repeated for each sample.

17. At the end of sampling, steps 1-3 were repeated for cleanliness.

\subsubsection{Cyanuric Acid Turbidimetric Measurement}

The materials and methods for the turbidimetric analysis of CYA are outlined below. The method consists of sample cell cleaning, a precipitation reaction between melamine and cyanuric acid, and turbidimetric measurement using a HACH DR/890 Colorimeter.

\section{Cyanuric Acid Materials:}

- $\mathrm{DR} / 890$ Colorimeter (1)

- Cyanuric Acid 2 Reagent Powder Pillow (1 per sample)

- $25 \mathrm{~mL}$ cylindrical sample cell with cap (1)

- Serological pipette (1 per sample)

- DI WATER

- $70 \%$ Ethanol in DI Water

- Light-Duty chemistry wipes 


\section{Cyanuric Acid Procedure:}

Experimenters used proper PPE, including gloves to prevent smudging of sample cell exterior.

1. A sample cell was filled with $70 \%$ ethanol, capped, and shaken vigorously. Ethanol was poured into a waste container.

2. If a color or cloudiness was noted in the ethanol after shaking, step 1 was repeated.

3. The sample cell was filled with 5-25 mL of DI, capped, and shaken vigorously. Waste was discarded in a proper receptacle. (repeat $3 \mathrm{x}$ )

4. The sample cell was loaded with 5-25 mL of sample, swirled, and discarded.

5. A sample cell was filled with 5-25 $\mathrm{mL}$ of sample and diluted to $25 \mathrm{~mL}$. Dilution factors were recorded. (Note: the range of the test is 7-55 $\mathrm{mg} / \mathrm{L}$.)

6. The colorimeter was turned on.

7. PGRM 24 was entered.

8. A light-duty wipe was used to clean the exterior of the sample cell. The sample cell was then loaded into the chamber of colorimeter, and covered with the lid.

9. The instrument was zeroed by pressing the ZERO button. Before reading, the screen would read $0 \mathrm{mg} / \mathrm{L} \mathrm{CYACD.}$

10. The sample cell was removed, and the contents of one $\mathrm{HACH}$ Cyanuric Acid 2 Reagent Powder Pillow were added to the cell.

11. A 3-minute reaction timer was started.

12. The sample was swirled vigorously until all reagent dissolved, then the sample was left to rest for the remainder of the timer. 
13. After the 3-minute reaction period, the sample cell was loaded back into the sample chamber with the same orientation as when it was zeroed. The sample cell was tapped gently to ensure that there were no bubbles in the sample.

14. The READ button was then pressed. Data were recorded (as mg/L CYA) and adjusted for dilution.

15. Waste was discarded into a proper receptacle, and the sample cell was quickly rinsed with DI water.

16. The interior of sample cell was scrubbed with a light-duty wipe if a white film formed.

17. Steps 1-16 were repeated for each sample.

18. At the end of sampling, the interiors of any used sample cells were cleaned with light-duty wipes and 70\% ethanol followed by $3 x$ DI rinse.

\subsubsection{HPLC Analysis of CYA}

The HPLC system used to measure CYA was an Agilent 1100 series with the components listed in Table 3-1. Chemstation software was used for data collection and analysis.

Table 3-1: HPLC Components

\begin{tabular}{lll}
\hline Component & Model Number & Serial Number \\
\hline Vacuum Degasser & G1322A & JP63205331 \\
Quaternary Pump & G1311A & US70601733 \\
Autosampler & G1313A & US70201655 \\
UV/Vis Detector & G1314A & JP64202932 \\
\hline
\end{tabular}


Two columns used were the Dionex Acclaim Trinity P1 HILIC column, and Waters XBridge C18 column. Column details can be found in Table 3-2.

Table 3-2: HPLC Columns

\begin{tabular}{|c|c|c|c|c|c|c|c|}
\hline Column & Mode & $\begin{array}{l}\text { Particle } \\
\text { Size }\end{array}$ & $\begin{array}{l}\text { Column } \\
\text { Dimensions }\end{array}$ & $\begin{array}{l}\mathrm{pH} \\
\text { Range }\end{array}$ & $\begin{array}{l}\text { Flow } \\
\text { Rate }\end{array}$ & $\begin{array}{l}\text { Max } \\
\text { Pressure }\end{array}$ & $\begin{array}{l}\text { Suggested } \\
\text { Mobile } \\
\text { Phase }\end{array}$ \\
\hline $\begin{array}{l}\text { Acclaim } \\
\text { Trinity } \\
\text { P1 }\end{array}$ & $\begin{array}{l}\text { Reversed } \\
\text { Phase/ } \\
\text { HILIC }\end{array}$ & $5 \mu \mathrm{m}$ & $\begin{array}{l}150 \mathrm{~mm} x \\
3 \mu \mathrm{m}\end{array}$ & $\begin{array}{l}2.5- \\
7.0\end{array}$ & $\begin{array}{l}0.3-1.5 \\
\mathrm{~mL} / \mathrm{min}\end{array}$ & 400 bar & $\begin{array}{l}\mathrm{NH}_{4} \mathrm{Ac} \\
\text { buffered } \\
\mathrm{AcN} \text {, or } \\
\mathrm{KH}_{2} \mathrm{PO}_{4} \\
\text { buffered } \\
\text { water }\end{array}$ \\
\hline $\begin{array}{l}\text { Waters } \\
\text { XBridge } \\
\text { C18 }\end{array}$ & $\begin{array}{l}\text { Reversed } \\
\text { Phase }\end{array}$ & $5 \mu \mathrm{m}$ & $\begin{array}{l}100 \mathrm{~mm} x \\
3 \mu \mathrm{m}\end{array}$ & $1-12$ & $\mathrm{n} / \mathrm{a}$ & 400 bar & $\begin{array}{l}\mathrm{KH}_{2} \mathrm{PO}_{4} \\
\text { buffered } \\
\text { water and } \\
\text { methanol }\end{array}$ \\
\hline
\end{tabular}

The Waters XBridge C18 column was used in conjunction with a 2-cm Waters XBridge C18 guard column in the reversed phase mode. A method was developed, Table 3-3, which resolves the cyanuric acid peak from other nitrogenous species, specifically nitrate and nitrite.

Table 3-3: HPLC Parameters

\begin{tabular}{ll}
\hline Parameter & Value \\
\hline Column & Waters XBridge C18 \\
Mobile Phase & $1 \%$ methanol \\
& $69.5 \% 50 \mathrm{mM} \mathrm{KH}_{2} \mathrm{PO}_{4}$ buffer $(\mathrm{pH} 5.70)$ in DI water \\
& $29.5 \%$ distilled water \\
Flow Rate & $0.300 \mathrm{~mL} / \mathrm{min}$ \\
Injection volume & $1 \mathrm{uL}$ \\
\hline
\end{tabular}


Detection wavelength

Temperature

Sample Run Time
$213 \mathrm{~nm}$

$18-20^{\circ} \mathrm{C}$ (ambient)

5 minutes

Since the HPLC system does not have a column heater, elution times and peak areas are subject to variations in room-temperature. After discovery of this issue, a four-point calibration curve, including a DI blank, was incorporated at the beginning of each sequence of samples.

\section{Sample Collection and Preparation Materials:}

- Serological pipette or graduated transfer pipette (1 per sample)

- $50 \mathrm{~mL}$ beaker (1 per sample +1 additional)

- $3 \mathrm{~mL}$ syringe (1)

- Non-sterile syringe filter, $13 \mathrm{~mm}$ diameter, $0.2 \mu \mathrm{m}$ pore-size, $\mathrm{PVDF}$ or nylon (1 per sample)

- $\quad 12 \times 32 \mathrm{~mm}(2 \mathrm{~mL})$, clear, crimp-top vial (1 per sample)

- $11 \mathrm{~mm}$ aluminum seal with TFE/rubber septum (1 per sample)

- $\mathrm{GC} / \mathrm{LC} 11 \mathrm{~mm}$ vial crimper

- DI Water

- $70 \%$ Ethanol in DI Water

- Permanent Marker 


\section{Syringe Cleaning Procedure:}

1. A syringe was filled with Alconox soap solution, and the plunger was depressed 34 times over a waste container.

2. The syringe was then rinsed with DI water $3 x$, depressing plunger 3-4 times over waste container.

3. The plunger was drawn back fully, and remaining water was shaken out.

4. The plunger was depressed once more and blotted dry on a paper towel.

5. These methods were repeated after every unique sample.

\section{Sampling Preparation Procedure:}

1. Transfer pipettes were rinsed with $70 \%$ ethanol and stored in a beaker with tips submerged in ethanol.

2. At least $1.5 \mathrm{~mL}$ of sample were pipetted into a $50 \mathrm{~mL}$ beaker.

3. A $0.22 \mu \mathrm{m}$ syringe filter was attached to a cleaned syringe, and at least $0.5 \mathrm{~mL}$ of sample were drawn through the filter.

4. The filter was removed and discarded into a waste receptacle.

5. Filtered sample was then loaded into a $2 \mathrm{~mL}$ crimp-top vial.

6. The vial was then capped, crimped, and labeled.

\section{Column Flush Procedure:}

1. Column flushing was performed before any set of samples was run. Flushing procedure was also run if pressure began drifting upwards, or if the baseline drifted.

2. Eluent was set to $0.7 \mathrm{~mL} / \mathrm{min}$; $95 \%$ methanol, $5 \%$ phosphate buffer for 15 minutes. 
3. Eluent was set to $0.7 \mathrm{~mL} / \mathrm{min} ; 5 \%$ methanol, $95 \%$ phosphate buffer for 20 minutes.

4. Eluent was set to $0.7 \mathrm{~mL} / \mathrm{min}$; desired operating mobile phase for 15 minutes, or until steady baseline absorbance was reached.

\subsubsection{Bacterial Plating}

Section 3.1.5 details the materials and methods for bacterial plating and performing plate counting. All bacterial plating was carried out using Plate Count Agar at $35^{\circ} \mathrm{C}$. All materials and instruments were autoclaved before use, to ensure aseptic conditions. Since bacterial typically attach to each other and germinate into one indistinguishable colony, bacteria are typically enumerated as Colony Forming Units. The statistical significance of a plate count is between 30 and 300 CFU (Sanders 2012).

\section{Bacterial Plating Materials:}

- Petri dishes (about 50 dishes per 1 Liter of agar prepared)

- Dry Agar Mix (quantity varies by type)

- 2 Liter Erlenmeyer Flask

- Aluminum Foil

- Autoclave Tape

- Laboratory Labeling Tape

- Autoclave Tape

- DI Water

- Electronic Balance 
- Laminar Flow Hood (optional UV lamp)

- Paraffin Wax

\section{Bacterial Plating Procedures:}

1. Dry Plate Count Agar was measured and add to a 2L flask.

2. 1 Liter of DI water was added to flask and swirled to dissolve media.

3. The flask was then covered with aluminum foil, and the foil was taped into place. (A gap was left gas to escape during autoclaving.)

4. The media was autoclaved for 20 minutes at $121^{\circ} \mathrm{C}$ and $15-20$ psig.

5. Petri dishes were placed in a laminar flow hood, and the UV lamp was turned on for 15 minutes.

6. The flask of agar was then placed in a $55^{\circ} \mathrm{C}$ bath plates were ready to be poured.

7. One Petri dish was partially uncovered, to avoid contamination, and agar was gently poured into the plate until the entire bottom of the plate was covered in agar.

8. The plate was capped and gently moved to the side.

9. Steps 9 and 10 were repeated until agar was expended.

10. Agar was allowed to solidify in the Petri dishes before plating bacteria.

11. If any agar was spilled, it was allowed to solidify before wiping up with a paper towel.

12. Unused plates were refrigerated, inverted. 


\section{Performing Bacterial Plate Count:}

1. A sterile serological pipette or transfer pipette was used to transfer $1 \mathrm{~mL}$ of sample to $9 \mathrm{~mL}$ of autoclaved DI water, creating a $10^{-1}$ dilution.

2. $1 \mathrm{~mL}$ of the $10^{-1}$ dilution was added to $9 \mathrm{~mL}$ of autoclaved water creating a $10^{-2}$ dilution.

3. This method was repeated to prepare dilutions down to $10^{-15}$ for strong bacterial solutions and $10^{-12}$ for weak solutions.

4. 20-50 uL was poured onto a sterile agar plate (see plate preparation instructions above).

5. 10-20 sterile glass spreading beads were also added to the plate.

6. The plate was then covered and swirled, so that the beads spread inoculum across the entirety of the plate's surface.

7. The used beads were poured off into a $70 \%$ ethanol waste container. (Note: some sample is removed on the surface of the beads; however, this amount is minimal compared to the plated volume.)

8. The agar plate was then capped and labeled, with researcher's name, date, dilution, type of agar, sample source, and expected bacterial strain (if known).

9. Steps 4-8 were repeated for each dilution prepared.

10. Plates were incubated, inverted, for 48 hours at $35^{\circ} \mathrm{C}$.

11. Plates were removed and CFU were enumerated if there were between 30 and 300 individual colonies. 


\subsubsection{Scanning Electron Microscopy}

The SEM used in this study is an SEM FEI Quanta 200, equipped with a Peltier cooling stage, Electron Dispersive Spectroscopy (EDS), and Electron Backscatter Diffraction (EBSD). The Peltier cooling stage prevents samples from being damaged by the electron beam. EDS provides analysis of heavier elements from Boron to Uranium. EBSD allows for the mapping and microstructural analysis of crystalline samples. The EBSD function was used in this study, as surface structure was the only desired attribute. For this study, Dr. Trevor Harding, PhD., operated the SEM in order to expedite the collection of images.

\section{SEM Sample Collection and Preparation:}

1. Samples were collected $(<0.5 \mathrm{~g})$ by scraping a used filter with pipette tip and loaded into $1 \mathrm{~mL}$ centrifuge tube.

2. Samples were freeze dried for 24 hours at $100 \mu \mathrm{mHg}$ in plastic centrifuge tube holder. (Note: Do not use cardboard or other natural/porous material, as it elongates the freeze drying process.)

3. Samples were mounted on the SEM stage by breaking particles up with forceps and placing them on adhesive surface of stage.

Table 3-4: Scanning Electronic Microscope Operating Parameters

\begin{tabular}{ll}
\hline Parameter & Value \\
\hline Electron Beam Voltage & $10 \mathrm{kV}$ \\
Pressure & $90 \mathrm{~Pa}$ \\
Spot Size & 3.0 \\
\hline
\end{tabular}




\subsubsection{UV Absorbance Measurement}

A spectrophotometer was used in experiments II-1 and II-1.1 to measure absorbance of samples at specific wavelengths. These experiments were performed before the HACH Colorimeter became available.

\section{UV Absorbance Materials:}

- Shimadzu UV-1700 Pharmaspec

- 2 mL Rectangular Cuvette (1 per sample)

- DI Water for Reference Cell

- $5 \mathrm{~mL}$ Transfer Pipettes

- $\quad$ Light-Duty Chemistry Wipes

\section{UV Absorbance Methods:}

1. The spectrophotometer was turned on, and the UV lamp was allowed to warm up.

2. A sample was collected with $5 \mathrm{~mL}$ transfer pipette, and at least $1 \mathrm{~mL}$ of sample was loaded into a $2 \mathrm{~mL}$ cuvette.

3. The desired mode of measurement was selected (spectrum or single wavelength).

4. The DI reference cell was filled with DI water and loaded into its proper compartment.

5. The sample cuvette was loaded into the spectrophotometer.

6. The machine was then prompted to read absorbance.

7. Absorbance values were recorded, and the sample cell was removed. 
8. Steps 5 through 7 were repeated as needed, for each sample.

9. The spectrophotometer was turned off, using the command prompts, not simply the mechanical switch.

\subsubsection{Preparing CYA Solution}

1. Cyanuric acid was added to DI water at a desired concentration of no more than $3 \mathrm{~g} / \mathrm{L}$.

2. The solution was heated to $50^{\circ} \mathrm{C}$ and stirred until all CYA dissolved (5 to 30 minutes, depending on concentration).

\subsubsection{Preparing Growth Media}

1. Desired media constituents were added to DI water, from highest to lowest concentration.

2. Media was then stirred to mix, and heated if necessary.

3. Growth media was then covered with aluminum foil and weighed.

4. The growth media and additional DI water in a separate container were then autoclaved for 20 minutes at $121^{\circ} \mathrm{C}$.

5. Growth media was then re-weighed and any evaporated volume was replenished with autoclaved DI water. 


\subsubsection{Preparing HPLC Mobile Phase}

1. $1 \mathrm{~L}$ of DI Water was added to a volumetric flask along with a magnetic stir bar.

2. Desired masses of buffer constituents were added, and the flask was stirred to dissolve.

3. Any residual buffer solution was discarded, and the reagent bottle was rinsed with a small volume of new buffer solution

4. Add new mobile phase to reagent bottle and flush the mobile phase through the HPLC system for at least 20 column volumes.

\subsubsection{Dosing Chlorine}

Experiments in this study were carried out using household bleach containing $\mathrm{NaOCl}$. The theoretical dose required to obtain the desired mass equivalent of chlorine, measured as $\mathrm{Cl}_{2}$, can be calculated as follows:

$$
\mathrm{V}_{\text {bleach }}=\mathrm{C}_{\mathrm{Cl} 2} / \mathrm{C}_{\mathrm{OCl}} * \mathrm{~V}_{\text {container }} * \mathrm{MM}_{\mathrm{OCl}} / \mathrm{MM}_{\mathrm{Cl} 2}
$$

Where:

$\mathrm{V}_{\text {bleach }}=$ Volume of bleach to be dosed $[\mathrm{mL}]$

$\mathrm{C}_{\mathrm{Cl} 2}=$ Desired chlorine concentration as $\mathrm{Cl}_{2}[\mathrm{mg} / \mathrm{L}]$

CoCl- $=$ Concentration of $\mathrm{OCl}^{-}$in the bleach used $\left[\mathrm{mgOCl}_{\mathrm{OCL}} / \mathrm{mL}_{\text {Bleach }}\right]$

$\mathrm{V}_{\text {container }}=$ Volume of the container being dosed with bleach $[\mathrm{L}]$

MMocl- $=$ Molar mass of $\mathrm{OCl}^{-}[\mathrm{g} / \mathrm{mol}]$

$\mathrm{MM}_{\mathrm{Cl} 2}=$ Molar mass of $\mathrm{Cl}_{2}[\mathrm{~g} / \mathrm{mol}]$ 
1. Desired volume of bleach was pipetted into destination container. When dosing an aquarium, bleach was added to different areas of the tank, including the filter if present.

2. Water within the container was swirled or stirred to mix.

\subsubsection{Dosing Sunscreen}

1. Desired mass of sunscreen was weighed into a large plastic weigh boat.

2. Approximately $5 \mathrm{~mL}$ of DI water was added to the sunscreen.

3. Sunscreen and water were mixed by vigorously stirring with a $200 \mu \mathrm{L}$ pipette tip to fully homogenize sunscreen with water.

4. Steps 2 and 3 were repeated with increasing volumes of water, two to three times.

5. Diluted sunscreen was then poured into the desired container.

6. A serological pipette was used to draw media from the desired container and rinse residual sunscreen from the weigh boat into the container.

7. The container was then swirled or stirred to mix.

\subsubsection{Inoculating Shaker Flasks}

1. For liquid cultures, a sterile serological pipette was used to collect desired volume of inoculum.

2. For dry products, weighing-paper was used to measure and transfer product.

3. Products were then added to desired flask containing growth medium. 
4. Flasks were then capped and swirled to mix.

5. $70 \%$ ethanol was then used to sanitize workspace.

\subsubsection{Inoculating Aquaria}

1. For liquid cultures, a sterile serological pipette was used to collect desired volume of inoculum.

2. For dry products, a plastic weigh boat was used to measure and transfer inoculums. 20-50 $\mathrm{mL}$ of liquid from the destination container were then used to hydrate the sample.

3. When using aquarium filters, hydrated inoculum was added to the interior of the filter, upstream of the filter media bag.

4. When not using aquarium filters, hydrated inoculum was added to the aquarium and a serological pipette was used to mix the solution.

5. After addition of the inoculum, a serological pipette was used to rinse residual inoculum from the weigh boat into the aquarium, using inoculated growth media.

6. The entire volume of aquarium was stirred using a serological pipette. 


\subsection{Task I - Determination of Clarification Mechanism}

\subsubsection{Experiment I-1 Effect of Thai FOG on Turbidity, with Mechanical Filtration}

A 10-gallon aquarium was washed with bleach and air-dried. The tank was then filled with $30 \mathrm{~L}$ of tap water. An aquarium filter was washed with bleach and installed on the aquarium, positioned so that the filter spout was centered on the long side of the tank.

The Tetra Whisper PF10 filter operates with a fibrous "filter bag" containing activated carbon followed by an aeration media. Both the aeration media and the activated carbon were removed from the system, leaving just the filter bag, which more closely mimics pool filter conditions.

A thermometer strip was installed on the tank's exterior, and a heating element was bleached, dried, installed, and set to $30^{\circ} \mathrm{C}$. Temperature was allowed to stabilize overnight, before inoculation.

A 3.0-gram sample of Thai FOG was added to the tank. Turbidity was measured using the method outlined above. 3.0 grams of sunscreen were then added to the tank according to the method, as described above. Chlorine was dosed at 3-4 mg/L according to the method outlined above. Total chlorine was measured using the method detailed above, to confirm chlorine residual levels. 
Turbidity and total chlorine were measured daily according to methods described above. Chlorine was re-dosed at 3-4 mg/L after each day's measurements according to the methods described above.

All components of the tank, heater, and filter were disassembled and washed in bleach and soap water. Equipment was allowed to air dry before reuse.

\subsubsection{Experiment I-2 Effects of BiOWiSH on Turbidity with Sodium Azide Control}

Three 10-gallon aquaria were set up identically to the methods of Experiment I-1, with contents detailed in Table 3-5. Sodium azide was added at $0.5 \%$ as a bacterial inhibitor. The control treatment was not chlorinated, due to incompatibility between sodium azide and chlorine.

Table 3-5: Experiment I-2 Experimental Setup

\begin{tabular}{ll}
\hline Treatment & Contents \\
\hline Thai FOG & $100 \mathrm{mg} / \mathrm{L}$ Sunscreen, $100 \mathrm{mg} / \mathrm{L}$ Thai FOG \\
US FOG & $100 \mathrm{mg} / \mathrm{L}$ Sunscreen, $100 \mathrm{mg} / \mathrm{L}$ US FOG \\
Control & $100 \mathrm{mg} / \mathrm{L}$ Sunscreen, $0.5 \% \mathrm{w} / \mathrm{w}$ Sodium Azide \\
\hline
\end{tabular}

Turbidity and Total Chlorine were measured daily using methods described above, for each. Chlorine was re-dosed at 3-4 $\mathrm{mg} / \mathrm{L}$ to the Thai FOG and US FOG tanks daily. Evaporative losses were mitigated by refilling each tank with tap water, daily. 
At the end of the experiment, the control tank contents and filter bag were disposed of in a hazardous waste container, due to its sodium azide content.

\subsubsection{Experiment I-3 Effects of BiOWiSH on Turbidity with Re-Dosed Sunscreen}

Four aquaria were filled with 33 Liters of tap water. The additional water was added in order to prevent splashing of tank contents into other tanks. Filters and heating elements were installed identically to Experiment I-1. Table 3-6, below, details the contents of each tank.

Table 3-6: Experiment I-3 Experimental Setup

\begin{tabular}{ll}
\hline Treatment & Inoculum \\
\hline US FOG & $33 \mathrm{mg} / \mathrm{L} \mathrm{US} \mathrm{FOG}$ \\
Thai FOG & $100 \mathrm{mg} / \mathrm{L}$ Thai FOG \\
US Rice Bran & $100 \mathrm{mg} / \mathrm{L}$ US Rice Bran \\
Control & N/A \\
\hline
\end{tabular}

Tanks were inoculated with products according to the methods detailed above. Tanks were dosed with $100 \mathrm{mg} / \mathrm{L}$ of sunscreen at $\mathrm{T}=0, \mathrm{~T}=3, \mathrm{~T}=7, \mathrm{~T}=10$, and $\mathrm{T}=16$ Days, according to the methods detailed above. The sunscreen dosing schedule was chosen semi-arbitrarily based on the clarity of the control tank.

Similar to Experiment I-2, turbidity and Total Chlorine levels were measured each day, and tanks were refilled and re-chlorinated to 3-4 $\mathrm{mg} / \mathrm{L} \mathrm{Cl}_{2}$ after measurement. Tanks were not sampled, refilled, or re-chlorinated on Day 11, due to experimenter oversight. At T=12 Days, the normal daily schedule was resumed. 
At the end of the experiment, filter bags were discarded. Tanks and components were cleaned with bleach and soap water.

\subsubsection{Experiment I-4 Comparison of Re-Dosed US FOG to Single Dosed Products}

Five aquaria were set up as in Experiment I-3, with contents detailed in Table 3-7. A sample of Thai FOG was inactivated by gamma irradiation in an external laboratory.

Table 3-7: Experiment I-4 Experimental Setup

\begin{tabular}{ll}
\hline Treatment & Inoculum \\
\hline US FOG Re-Dose & $5 \mathrm{mg} / \mathrm{L}$ US FOG with each \\
& Sunscreen Re-dose \\
US FOG & $50 \mathrm{mg} / \mathrm{L}$ US FOG \\
Thai FOG & $100 \mathrm{mg} / \mathrm{L}$ Thai FOG \\
Thai FOG Irradiated & $100 \mathrm{mg} / \mathrm{L}$ Irradiated Thai FOG \\
Control & N/A \\
\hline
\end{tabular}

Treatments were dosed with $100 \mathrm{mg} / \mathrm{L}$ of sunscreen at $\mathrm{T}=0$ Days and multiple times thereafter. Due to experimenter oversight and clerical errors, the data tables containing the exact dosing schedule and readings were lost.

Turbidity and Total Chlorine were measured, daily. After each sampling event, treatments were dosed with 3-5 mg/L Total Chlorine and refilled with tap water. 


\subsubsection{Experiment I-5 Effects of BiOWiSH Products on Re-Dosed Sunscreen}

Six aquaria were filled with 33 Liters of tap water and set up identically to Experiment I-

3. The contents of each treatment are listed in Table 3-8, below.

Table 3-8: Experiment I-5 Experimental Setup

\begin{tabular}{ll}
\hline Treatment & Inoculum \\
\hline US FOG & $50 \mathrm{mg} / \mathrm{L}$ US FOG \\
Mix \#1 & $50 \mathrm{mg} / \mathrm{L}$ US FOG, $100 \mathrm{mg} / \mathrm{L}$ Irradiated Thai FOG \\
Mix \#1 & $50 \mathrm{mg} / \mathrm{L}$ US FOG, $100 \mathrm{mg} / \mathrm{L}$ Irradiated Thai FOG \\
IR Thai FOG & $100 \mathrm{mg} / \mathrm{L}$ Irradiated Thai FOG \\
Premix & $100 \mathrm{mg} / \mathrm{L}$ Premix \\
BMT SS & $100 \mathrm{mg} / \mathrm{L}$ BMT Remediate \\
\hline
\end{tabular}

Sunscreen was added to each aquarium according to the methods above, at $\mathrm{T}=0, \mathrm{~T}=2, \mathrm{~T}=8$, and $\mathrm{T}=16$ Days. Treatments were chlorinated, daily, to 6-9 $\mathrm{mg} / \mathrm{L}$ of Total Chlorine, because residuals dropped to $0 \mathrm{mg} / \mathrm{L}$ overnight. Between $\mathrm{T}=16.1$ and $\mathrm{T}=27$ days, the aquaria were not sampled from, chlorinated, or refilled.

\subsubsection{Experiment I-6 Investigation of Solid Substrate Products' Effects on Turbidity}

Seven aquaria were set up identically to Experiment I-3. Each tank's contents are listed in Table 3-9, below.

Table 3-9: Experiment I-6 Experimental Setup

\begin{tabular}{ll}
\hline Treatment & Inoculum \\
\hline Manure/Odor & $50 \mathrm{mg} / \mathrm{L}$ Manure/Odor Control \\
\hline
\end{tabular}




\begin{tabular}{ll}
\hline Premix & $100 \mathrm{mg} / \mathrm{L}$ Premix \\
BS-AQ-001 & $100 \mathrm{mg} / \mathrm{L}$ BS-AQ-001 \\
BS-AQ-002 & $100 \mathrm{mg} / \mathrm{L}$ BS-AQ-002 \\
BS-AQ-003 & $100 \mathrm{mg} / \mathrm{L}$ BS-AQ-003 \\
Thai Rice Bran & $100 \mathrm{mg} / \mathrm{L}$ Thai Rice Bran \\
US Rice Bran & $100 \mathrm{mg} / \mathrm{L}$ US Rice Bran \\
\hline
\end{tabular}

Sunscreen was dosed to each aquarium according to the methods above, at $\mathrm{T}=0$ and $\mathrm{T}=1$ Days. Daily measurements, chlorination, and refilling were carried out identically to Experiment I-3.

\subsubsection{Experiment I-7 Effects of BiOWiSH Products on Re-Dosed Turbidity}

Seven aquaria were set up identically to Experiment I-3. The contents of each tank are detailed below in Table 3-10. A sample of Thai Rice Bran was inactivated by gamma irradiation in an external laboratory.

Table 3-10: Experiment I-7 Experimental Setup

\begin{tabular}{ll}
\hline Treatment & Inoculum \\
\hline Fruit Wash & $50 \mathrm{mg} / \mathrm{L}$ Fruit Wash \\
Premix & $100 \mathrm{mg} / \mathrm{L}$ Premix \\
AP 001 & $100 \mathrm{mg} / \mathrm{L}$ AP 001 \\
AP 002 & $100 \mathrm{mg} / \mathrm{L}$ AP 002 \\
AP 003 & $100 \mathrm{mg} / \mathrm{L}$ AP 003 \\
Thai Rice Bran & $100 \mathrm{mg} / \mathrm{L}$ Thai Rice Bran \\
Irradiated Thai Rice Bran & $100 \mathrm{mg} / \mathrm{L}$ Irradiated Thai Rice Bran \\
\hline
\end{tabular}

Daily measurements, chlorination, and refilling were carried out identically to Experiment I-3. 


\subsubsection{Experiment I-8 Effects of Thai BiOWiSH Products on Re-Dosed Turbidity}

Seven aquaria were set up identically to Experiment I-3. The contents of each aquarium are detailed in Table 3-11, below.

Table 3-11: Experiment I-8 Experimental Setup

\begin{tabular}{ll}
\hline Treatment & Inoculum \\
\hline Premix 1 & $100 \mathrm{mg} / \mathrm{L}$ Premix \\
Premix 2 & $100 \mathrm{mg} / \mathrm{L}$ Premix \\
Thai FOG 1 & $100 \mathrm{mg} / \mathrm{L}$ Thai FOG \\
Thai FOG 2 & $100 \mathrm{mg} / \mathrm{L}$ Thai FOG \\
IR Thai FOG 1 & $100 \mathrm{mg} / \mathrm{L}$ Irradiated Thai FOG \\
IR Thai FOG 2 & $100 \mathrm{mg} / \mathrm{L}$ Irradiated Thai FOG \\
Control & N/A \\
\hline
\end{tabular}

Tanks were dosed with $100 \mathrm{mg} / \mathrm{L}$ of sunscreen at $\mathrm{T}=0, \mathrm{~T}=3, \mathrm{~T}=7, \mathrm{~T}=10$, and $\mathrm{T}=16$ Days, according to the methods detailed above. Daily measurements and tank refilling were carried out identically to Experiment I-3. Tanks were chlorinated to at least $5 \mathrm{mg} / \mathrm{L}$, daily, per the above-detailed methods.

At the end of the experiment, samples were taken from Premix 1, Thai FOG 1, IR Thai FOG 1, and the Control for bacterial plating in Experiment III-2. Contents of each tank were then discarded down the sink, and all aquaria and components were cleaned identically to Experiment I-3. 


\subsubsection{Experiment I-9 Experiment I-9 Effects of Vegetative Bacterial Cultures on Turbidity}

Six aquaria were set up identically to Experiment I-3. The contents of each aquarium are detailed in Table 3-12, below.

Table 3-12: Experiment I-9 Experimental Setup

\begin{tabular}{lllll}
\hline Treatment & $\begin{array}{l}\text { Sunscreen, } \\
\text { re-dosed }\end{array}$ & CYA & Inoculum & Chlorination \\
\hline Tank 1 & $100 \mathrm{mg} / \mathrm{L}$ & $100 \mathrm{mg} / \mathrm{L}$ & Activated CAR & None \\
Tank 2 & $100 \mathrm{mg} / \mathrm{L}$ & None & Activated CAR & $1-5 \mathrm{mg} / \mathrm{L}$ \\
Tank 3 & $100 \mathrm{mg} / \mathrm{L}$ & $100 \mathrm{mg} / \mathrm{L}$ & Activated CAR & $1-5 \mathrm{mg} / \mathrm{L}$ \\
Tank 4 & $100 \mathrm{mg} / \mathrm{L}$ & $100 \mathrm{mg} / \mathrm{L}$ & Activated CAR & $1-5 \mathrm{mg} / \mathrm{L}$ \\
Tank 5 & None & $100 \mathrm{mg} / \mathrm{L}$ & Activated CAR & None \\
Tank 6 & $100 \mathrm{mg} / \mathrm{L}$ & $100 \mathrm{mg} / \mathrm{L}$ & $\begin{array}{l}\text { Biology from Used } \\
\text { None }\end{array}$ & Filter Media \\
& & & & \\
\hline
\end{tabular}

The Activated CAR product was prepared by incubating OBAAG-KLB, LCM, OBWWT\#1, and MBWWT\#1 in four separate flasks of modified growth media. LCM was grown in Difco ${ }^{\mathrm{TM}}$ Lactobacillus MRS Broth prepared according to the package labeling. OBAAG-KLB, OBWWT\#1 and MBWWT\#1 were grown in Potato Dextrose Broth (PDB) prepared at half of the suggested concentration with an additional $10 \mathrm{~g} / \mathrm{L}$ of dextrose. The PDB was prepared at $12 \mathrm{~g} / \mathrm{L}$ rather than $24 \mathrm{~g} / \mathrm{L}$ to avoid a $\mathrm{pH}$ drop that would inhibit bacterial growth, and the dextrose was added to make up the deficiency in carbon. To prepare the inoculum from a used recreational pool filter, A $105 \mathrm{in}^{2}$ segment was collected from a used pleated cartridge filter from a swimming pool and added to $1 \mathrm{~L}$ of $12 \mathrm{~g} / \mathrm{L}$ 
PDB/dextrose growth medium, defined previously. All CYA stock solutions were prepared according to the methods detailed above.

The "Activated CAR" product was created by pipetting $10 \mathrm{~mL}$ of each stock culture into an Erlenmeyer flask. Once the temperature of each aquarium had stabilized at $30^{\circ} \mathrm{C}, 4 \mathrm{~mL}$ of the "Activated CAR" were added to tanks 1 through 5, using the method outlined in previous methods. Tank 6 was inoculated with $4 \mathrm{~mL}$ of the used recreational pool filter stock culture using the same dosing method.

Sunscreen was dosed to Tanks $1,2,3$, and 4 at $\mathrm{T}=0$ Days. The sunscreen dosing schedule was changed at $\mathrm{T}=1$ Day to include dosing to Tank 6 . Sunscreen was dosed to tanks listed in Table 3-12 at $\mathrm{T}=1, \mathrm{~T}=4, \mathrm{~T}=7$, and $\mathrm{T}=12$ Days.

Turbidity and Total Chlorine measurements were recorded each day and after re-dosing of sunscreen. Samples were collected at $\mathrm{T}=1, \mathrm{~T}=3, \mathrm{~T}=5, \mathrm{~T}=6, \mathrm{~T}=14$, and $\mathrm{T}=15$ Days for HPLC analysis of CYA. After sampling, each tank was re-chlorinated and refilled to its original level with tap water. Tank 1 was accidentally chlorinated at $\mathrm{T}=1.1$ Days, and $\mathrm{T}=4.1$ Days. 


\subsection{Task II - Efficacy of BiOWiSH Clarifying Oils from Swimming Pools}

\subsubsection{Experiment II-1 Water Clarification by Thai FOG}

Aquaria were filled with $30 \mathrm{~L}$ at $30^{\circ} \mathrm{C}$ as in Task I. Mechanical filtration was not used in this experiment, to investigate the clarifying effects of BiOWiSH products, un-agitated. The contents of each tank are listed in Table 3-13, below.

Table 3-13: Experiment II-1 Experimental Setup

\begin{tabular}{ll}
\hline Tank \# & Contents \\
\hline 1 & $500 \mathrm{mg} / \mathrm{L}$ Sunscreen \\
2 & $250 \mathrm{mg} / \mathrm{L}$ Thai FOG \\
3 & $500 \mathrm{mg} / \mathrm{L}$ Sunscreen, $250 \mathrm{mg} / \mathrm{L}$ Thai FOG \\
4 & Tap Water \\
\hline
\end{tabular}

Sunscreen was dosed to Tank 1 by direct addition and did not dissolve completely. Before dosing sunscreen to Tank 3, the method in Section 3.2.2.5 was developed. Thai FOG was added, dry, to the surfaces of Tanks 2 and 3.

Since no filtration was used in the experimental setup, tanks were not agitated beyond the convective currents caused by heating elements. During sampling, care was taken not to disturb the settled layer of sunscreen and biomass on the bottom of each tank. Samples for turbidity measurement were collected using $10 \mathrm{~mL}$ serological pipettes. 
Samples were loaded into test tubes and transferred to $2 \mathrm{~mL}$ cuvettes for absorbance measurement in spectrophotometer at $470 \mathrm{~nm}$, relative to a DI blank.

The contents of the aquarium were disposed of down the sink. All components of the tank, heater, and filter were disassembled and washed in bleach and soap water. Equipment was allowed to air dry before reuse.

\subsubsection{Experiment II-1.1 Absorbance Calibration Curve for Sunscreen}

Serial dilutions of sunscreen dissolved in DI water were created in $25 \mathrm{~mL}$ test tubes. Calibration was carried out from $437.5 \mathrm{mg} / \mathrm{L}$ down to $10 \mathrm{mg} / \mathrm{L}$.

Samples were and pipetted from the test tubes into $2 \mathrm{~mL}$ cuvettes for analysis in the spectrophotometer. Absorbance was read at $520 \mathrm{~nm}$. A calibration curve was created relating absorbance to concentration of sunscreen.

\subsubsection{Experiment II-1.2 Investigation of Growth Media Compatibility with Sunscreen}

Four autoclaved flat-bottomed boiling flasks were filled with $200 \mathrm{~mL}$ of water and growth media, detailed in Table 3-14, below. 
Table 3-14: Experiment II-1.2 Experimental Setup

\begin{tabular}{|c|c|}
\hline Flask \# & Contents \\
\hline 1 & $\begin{array}{l}1 \mathrm{~g} / \mathrm{L} \text { 20-20-20 fertilizer"; } \\
5 \mathrm{~g} / \mathrm{L} \text { dextrose }\end{array}$ \\
\hline 2 & $55 \mathrm{~g} / \mathrm{L}$ MRS Broth \\
\hline 3 & $\begin{array}{l}1 \mathrm{~g} / \mathrm{L} \mathrm{K}_{2} \mathrm{HPO}_{4} ; \\
1 \mathrm{~g} / \mathrm{L} \mathrm{KH}_{2} \mathrm{PO}_{4} ; \\
1 \mathrm{~g} / \mathrm{L} \text { glucose; } \\
0.1 \mathrm{~g} / \mathrm{LNNO}_{3} ; \\
\text { Trace } \mathrm{FeSO}_{4} ; \\
\text { Trace } \mathrm{CaCl}_{2} ;\end{array}$ \\
\hline 4 & DI Water \\
\hline
\end{tabular}

Each flask was chlorinated to with $5 \mathrm{mg} / \mathrm{L}$ of total chlorine, and covered aerobically. Total chlorine was measured at $\mathrm{T}=0, \mathrm{~T}=1$, and $\mathrm{T}=72$ hours, according to the method described in Section 3.1.2. Samples for total chlorine tests were collected using non-sterile $5 \mathrm{~mL}$ graduated transfer pipettes.

\subsubsection{Experiment II-2 Chlorine Decay with BiOWiSH Products}

Twelve $500 \mathrm{~mL}$ flat-bottomed boiling flasks were cleaned with soap water, rinsed with DI, and autoclaved. Flasks 1 through 8,11, and 12 were filled with $200 \mathrm{~mL}$ of DI water. Flasks 9 and 10 were filled with the minimal growth described in Table 3-15. 
Table 3-15: Experiment II-2 Minimal Media Composition

\begin{tabular}{ll}
\hline Component & Concentration \\
\hline Glucose & $2 \mathrm{~g} / \mathrm{L}$ \\
K2HPO4 & $1.5 \mathrm{~g} / \mathrm{L}$ \\
KH2PO4 & $0.75 \mathrm{~g} / \mathrm{L}$ \\
NH4NO3 & $0.2 \mathrm{~g} / \mathrm{L}$ \\
FeSO4 & $20 \mathrm{mg} / \mathrm{L}$ \\
MnSO4 & Trace \\
\hline
\end{tabular}

Flasks 1 through 8 were dosed with $125 \mathrm{mg} / \mathrm{L}$ of the products listed in Table 3-16. Flask 10 was dosed with $525 \mathrm{mg} / \mathrm{L}$ of sunscreen, and Flask 11 was dosed with $536 \mathrm{mg} / \mathrm{L}$ of sunscreen. Sunscreen dosing varied from the methods detailed, due to the small volume of sunscreen being added. Sunscreen was dosed directly to the flasks without dilution. The flasks were then swirled vigorously to fully dissolve sunscreen. Each treatment was then dosed with 3-4 mg/L of total chlorine, and capped aerobically.

Table 3-16: Experiment II-2 Flask Setup

\begin{tabular}{ll}
\hline Flask \# & Product \\
\hline 1 & Osprey MPB 5 \\
2 & Osprey BPB 100 \\
3 & Osprey Waste Water \\
4 & US Aqua \\
5 & Us FOG \\
6 & MDG Petro \\
7 & MDG Waste Water \\
8 & Thai FOG \\
9 & Minimal Media \\
10 & sunscreen + Media $525 \mathrm{mg} / \mathrm{L}$ \\
11 & sunscreen + Water $536 \mathrm{mg} / \mathrm{L}$ \\
12 & Tap Water \\
\hline
\end{tabular}


Total Chlorine was measured at $\mathrm{T}=0, \mathrm{~T}=4.5$, and $\mathrm{T}=25$ Hours.

\subsubsection{Experiment II-3 Turbidity Reduction by BiOWiSH Products}

Ten aquaria were set up identically to Experiment II-1 and inoculated with the products listed in Table 3-17, below.

Table 3-17: Experiment II-3 Aquarium Contents

\begin{tabular}{ll}
\hline Tank & Product \\
\hline 1 & Osprey- MPB 5 \\
2 & Osprey BPB 100 \\
3 & Osprey WW \\
4 & MDG Petro \\
5 & MDG Wastewater \\
6 & BMT Wastewater \\
7 & Thai FOG \\
8 & US FOG \\
9 & Fruit Wash \\
10 & Control - DI Water \\
\hline
\end{tabular}

Turbidity and total chlorine were measured daily. Chlorine was re-dosed each day to obtain a residual of 0.2 to $0.6 \mathrm{mg} / \mathrm{L} \mathrm{TC}$.

\subsubsection{Experiment II-4 Agitated vs. Un-Agitated Turbidity Reduction by BiOWiSH Products}

Eight tanks were set up identically to Experiment II-1. Each tank's inoculum is listed in Table 3-18, below. Tanks 2, 3, 4, 5, 6, and 7 received $100 \mathrm{mg} / \mathrm{L}$ of inoculum. Tank 8 was accidentally dosed with $200 \mathrm{mg} / \mathrm{L}$ of product. 
Table 3-18: Experiment II-4 Experimental Setup

\begin{tabular}{ll}
\hline Tank & Contents \\
\hline 1 & Control \\
2 & Thai FOG \\
3 & Food Wash I \\
4 & Food Wash II \\
5 & BMT WW1 I \\
6 & BMT WW1 II \\
7 & BMT WW2 I \\
8 & BMT WW2 II \\
\hline
\end{tabular}

Each tank was dosed to a theoretical TC content of $2.66 \mathrm{mg} / \mathrm{L}$ as $\mathrm{Cl}_{2}$, but readings immediately dropped to between 0.6 and $1.9 \mathrm{mg} / \mathrm{L}$. Thai FOG showed the most chlorine scouring, so it was dosed with additional chlorine, multiple times. After each chlorine dose, TC dropped to around $1.8 \mathrm{mg} / \mathrm{L}$. Chlorination was stopped at a theoretical dose of 3.5 $\mathrm{mg} / \mathrm{L}$.

Daily turbidity and TC measurements were taken. Chlorine was then re-dosed to a residual of $2.0 \mathrm{mg} / \mathrm{L} \mathrm{TC}$ as $\mathrm{Cl}_{2}$.

\subsubsection{Experiment II-5 Turbidity Reduction by BiOWiSH Products}

Ten aquaria were prepared identically to Experiment II-3 and dosed with the products listed in Table 3-19. 
Table 3-19: Experiment II-5 Experimental Setup

\begin{tabular}{lll}
\hline Tank & Label & Inoculum $[\mathrm{mg} / \mathrm{L}]$ \\
\hline 1 & Control & 0 \\
2 & Thai FOG & 125 \\
3 & LCM 1 & 125 \\
4 & LCM 2 & 125 \\
5 & BMT WW1 & 125 \\
6 & BMT WW2 & 125 \\
7 & BMT KLB Mix I & 62.5 , and 4.2, respectively \\
8 & BMT KLB Mix II & 62.5, and 4.2, respectively \\
9 & KLB I & 8.3 \\
10 & KLB II & 8.3 \\
\hline
\end{tabular}

Daily turbidity and TC were measured daily. Chlorine was re-dosed each day to a residual of $3.0 \mathrm{mg} / \mathrm{L}$ TC as $\mathrm{Cl}_{2}$. Only Tanks $1,2,7$, and 8 were continued past $\mathrm{T}=50$ Hours, due to time constraints. Treatments were not chlorinated between $\mathrm{T}=68$ Hours and $\mathrm{T}=113$ Hours.

\subsubsection{Experiment II-6 Effect of BiOWiSH Products on Turbidity with Dextrose}

Each of seventeen $500 \mathrm{~mL}$ flat-bottomed shaker flasks were cleaned with bleach water and allowed to air dry. Flasks were filled $300 \mathrm{~mL}$ of DI water and $200 \mathrm{mg} / \mathrm{L}$ of dextrose as a carbon source. Flasks were then dosed with the products and concentrations detailed in Table 3-20.

Table 3-20: Experiment II-6 Experimental Setup

\begin{tabular}{ll}
\hline Flask & Concentration \\
\hline Control & N/A \\
Osprey MPB-5 & $100 \mathrm{mg} / \mathrm{L}$ \\
Osprey BPB-100 & $100 \mathrm{mg} / \mathrm{L}$ \\
Osprey MPB-5 Liq & $125 \mathrm{mg} / \mathrm{L}$ \\
\hline
\end{tabular}




\begin{tabular}{ll}
\hline BMT WW 1 & $100 \mathrm{mg} / \mathrm{L}$ \\
BMT WW 2 & $100 \mathrm{mg} / \mathrm{L}$ \\
MBWWT\#1 & $100 \mathrm{mg} / \mathrm{L}$ \\
MDG Petro & $100 \mathrm{mg} / \mathrm{L}$ \\
MDG Micro-N & $100 \mathrm{mg} / \mathrm{L}$ \\
Crop & $100 \mathrm{mg} / \mathrm{L}$ \\
Fruit Wash & $100 \mathrm{mg} / \mathrm{L}$ \\
LCM & $100 \mathrm{mg} / \mathrm{L}$ \\
Thai FOG & $100 \mathrm{mg} / \mathrm{L}$ \\
Thai Aqua & $100 \mathrm{mg} / \mathrm{L}$ \\
US Aqua & $100 \mathrm{mg} / \mathrm{L}$ \\
US FOG & $100 \mathrm{mg} / \mathrm{L}$ \\
KLB & $100 \mathrm{mg} / \mathrm{L}$ \\
\hline
\end{tabular}

Each flask was agitated before daily turbidity and TC measurement. Chlorine was re-dosed each day to a residual of 3-5 $\mathrm{mg} / \mathrm{L} \mathrm{TC}$ as $\mathrm{Cl}_{2}$. At the end of the experiment, samples were collected from the US FOG, KLB, and Thai FOG treatments for plating in Experiment III-1.

\subsubsection{Experiment II-7 Effect of BiOWiSH Products on Turbidity with Sunscreen}

Seventeen treatments, identical to those in Experiment II-6, were prepared. Where dextrose was used in Experiment II-6, this experiment substituted $200 \mathrm{mg} / \mathrm{L}$ sunscreen. See Table 3-20, above, for treatment details.

Each flask was agitated before daily turbidity and TC measurement. Chlorine was re-dosed each day to a residual of $3-5 \mathrm{mg} / \mathrm{L} \mathrm{TC}$ as $\mathrm{Cl}_{2}$. 


\subsection{Task III - Isolation and Identification of Bacteria}

\subsubsection{Experiment III-1 Bacterial Plating of Experiment II-6}

45 PCA plates were prepared according to the method detailed above. Samples were collected from the treatments of MDG Micro Nutrient, Thai FOG, US FOG, and KLB from Experiment II-6. All samples were stored and transported in $25 \mathrm{~mL}$ test tubes, covered with paraffin wax. Each sample was plated at dilutions of $10^{-1}, 10^{-2}, 10^{-3}, 10^{-4}, 10^{-6}, 10^{-8}, 10^{-10}$, and $10^{-12}$.

A control plate containing no inoculum and a blank plate containing DI water used for dilution were incubated alongside the samples. The control plate was included to indicate the cleanliness of the media and plates used, and the blank plate was included to indicate the cleanliness of plating methods.

All plates were incubated at $35^{\circ} \mathrm{C}$ for 48 hours before enumeration. After enumeration, all plates were discarded in a waste receptacle designated for Petri dishes.

\subsubsection{Experiment III-2 Bacterial Plating of Experiment I-8}

PCA plates were prepared according to the method detailed above. Samples were collected from Experiment I-8, Tanks 1, 3, 5, and 7, and stored in $25 \mathrm{~mL}$ test tubes, covered with paraffin wax. 
Each sample was plated at dilutions of, $10^{-16}, 10^{-20}$, and $10^{-28}$. Due to experimenter oversight, the water used for dilution was not autoclaved. (This resulted in contamination of almost every plate.) All plates were incubated at $35^{\circ} \mathrm{C}$ for 48 hours before enumeration. After enumeration, all plates were discarded in a waste receptacle designated for Petri dishes containing microbiology.

\subsection{Task IV - Biodegradation of Cyanuric Acid}

\subsubsection{Experiment IV-1 CYA Biodegradation in a Respirometer}

Experiment IV-1 was developed to investigate $\mathrm{CO}_{2}$ production by BiOWiSH Thai FOG and US FOG in the presence of glucose and CYA. Due to repeated electrical and mechanical failures, the experiment was omitted from this study. The respirometer was not used in subsequent experiments.

\subsubsection{Experiment IV-2 CYA Adsorption to Irradiated Thai FOG}

A stock solution of CYA was prepared at $100 \mathrm{mg} / \mathrm{L}$ in DI water. The solution was added to each of five autoclaved $250 \mathrm{~mL}$ threaded shaker flasks. Flasks were dosed with concentrations of Irradiated Thai FOG shown in Table 3-21.

Table 3-21: Experiment IV-2 Irradiated Thai FOG Concentrations

\begin{tabular}{ll}
\hline Bottle \# & Contents \\
1 & $50 \mathrm{mg} / \mathrm{L}$ \\
2 & $75 \mathrm{mg} / \mathrm{L}$ \\
3 & $100 \mathrm{mg} / \mathrm{L}$ \\
\hline
\end{tabular}




\begin{tabular}{ll}
\hline 4 & $150 \mathrm{mg} / \mathrm{L}$ \\
5 & $300 \mathrm{mg} / \mathrm{L}$ \\
\hline
\end{tabular}

After inoculation, flasks were capped anaerobically, swirled to mix, and left on the laboratory bench to react at ambient temperature, $18-22^{\circ} \mathrm{C}$. Before daily turbidimetric analysis of CYA, each flask was swirled to mix.

\subsubsection{Experiment IV-3 Anaerobic Degradation of CYA in DI Water}

Ten $250 \mathrm{~mL}$ threaded shaker flasks and caps were washed and autoclaved. Each flask was filled with the contents detailed below, in Table 3-22.

Table 3-22: Experiment IV-3 Flask Labels and Contents

\begin{tabular}{lll}
\hline Flask \# & Flask Label & Contents \\
\hline 1 & US-200 Glucose & $\begin{array}{l}\text { DI Water } 200 \mathrm{~mL} ; \text { CYA } 50 \mathrm{mg} / \mathrm{L}, \text { Glucose } 200 \mathrm{mg} / \mathrm{L}, \\
\text { US Aqua } 50 \mathrm{mg} / \mathrm{L}\end{array}$ \\
2 & US-200 Glucose & $\begin{array}{l}\text { DI Water } 200 \mathrm{~mL} ; \text { CYA } 50 \mathrm{mg} / \mathrm{L}, \text { Glucose } 200 \mathrm{mg} / \mathrm{L}, \\
\text { US Aqua } 50 \mathrm{mg} / \mathrm{L}\end{array}$ \\
3 & US-50 Glucose & $\begin{array}{l}\text { DI Water } 200 \mathrm{~mL} ; \text { CYA } 50 \mathrm{mg} / \mathrm{L}, \text { Glucose } 50 \mathrm{mg} / \mathrm{L}, \\
\text { US Aqua } 50 \mathrm{mg} / \mathrm{L}\end{array}$ \\
4 & US-50 Glucose & $\begin{array}{l}\text { DI Water } 200 \mathrm{~mL} ; \text { CYA } 50 \mathrm{mg} / \mathrm{L}, \text { Glucose } 50 \mathrm{mg} / \mathrm{L}, \\
\text { US Aqua } 50 \mathrm{mg} / \mathrm{L}\end{array}$ \\
5 & Thai-200 Glucose & $\begin{array}{l}\text { DI Water } 200 \mathrm{~mL} ; \text { CYA } 50 \mathrm{mg} / \mathrm{L}, \text { Glucose } 200 \mathrm{mg} / \mathrm{L}, \\
\text { Thai FOG } 50 \mathrm{mg} / \mathrm{L}\end{array}$ \\
& & $\begin{array}{l}\text { DI Water } 200 \mathrm{~mL} ; \text { CYA } 50 \mathrm{mg} / \mathrm{L}, \text { Glucose } 200 \mathrm{mg} / \mathrm{L}, \\
\text { Thai FOG } 50 \mathrm{mg} / \mathrm{L}\end{array}$ \\
& Thai-200 Glucose &
\end{tabular}




\begin{tabular}{lll}
\hline 7 & Thai-200 Sunscreen & $\begin{array}{l}\text { DI Water 200 mL; CYA } 50 \mathrm{mg} / \mathrm{L}, \text { Sunscreen } 200 \\
\mathrm{mg} / \mathrm{L}, \text { Thai FOG } 200 \mathrm{mg} / \mathrm{L}\end{array}$ \\
8 & US-200 Sunscreen & $\begin{array}{l}\text { DI Water } 200 \mathrm{~mL} ; \text { CYA } 50 \mathrm{mg} / \mathrm{L}, \text { Sunscreen } 200 \\
\text { mg/L, US Aqua } 50 \mathrm{mg} / \mathrm{L}\end{array}$ \\
9 & Cyanuric & DI Water $200 \mathrm{~mL}, 50 \mathrm{mg} / \mathrm{L} \mathrm{CYA}$ \\
10 & Water & DI Water $200 \mathrm{~mL}$ \\
\hline
\end{tabular}

Instead of a stock solution, CYA was dosed to each flask, dry. After observing the inconsistencies introduced by this method, addition of CYA via stock solution was adopted as the standard method beginning with Experiment IV-5.

Flasks reacted at ambient temperatures ranging from $18-22^{\circ} \mathrm{C}$. Flasks were only agitated when swirled to mix, immediately before daily turbidimetric analysis of CYA.

\subsubsection{Experiment IV-4 Anaerobic Degradation of CYA in Minimal Media}

Ten treatments were prepared identically to Experiment IV-3 using minimal media, rather than DI Water.

Table 3-23: Experiment IV-4 Flask Labeling and Contents

\begin{tabular}{lll}
\hline Flask \# & Flask Label & Contents \\
\hline 1 & US-200 Glucose & $\begin{array}{l}\text { Growth Media 200 mL; CYA } 50 \mathrm{mg} / \mathrm{L}, \\
\text { Glucose 200 mg/L, US Aqua } 50 \mathrm{mg} / \mathrm{L}\end{array}$ \\
2 & US-200 Glucose & $\begin{array}{l}\text { Growth Media 200 mL; CYA } 50 \mathrm{mg} / \mathrm{L}, \\
\text { Glucose 200 mg/L, US Aqua } 50 \mathrm{mg} / \mathrm{L}\end{array}$ \\
\hline
\end{tabular}




\begin{tabular}{lll}
\hline Flask \# & Flask Label & Contents \\
\hline 3 & US-50 Glucose & $\begin{array}{l}\text { Growth Media 200 mL; CYA } 50 \mathrm{mg} / \mathrm{L}, \\
\text { Glucose } 50 \mathrm{mg} / \mathrm{L}, \text { US Aqua } 50 \mathrm{mg} / \mathrm{L}\end{array}$ \\
4 & US-50 Glucose & $\begin{array}{l}\text { Growth Media } 200 \mathrm{~mL} ; \text { CYA } 50 \mathrm{mg} / \mathrm{L}, \\
\text { Glucose } 50 \mathrm{mg} / \mathrm{L}, \text { US Aqua } 50 \mathrm{mg} / \mathrm{L}\end{array}$ \\
5 & Thai-200 Glucose & $\begin{array}{l}\text { Growth Media } 200 \mathrm{~mL} ; \text { CYA } 50 \mathrm{mg} / \mathrm{L}, \\
\text { Glucose } 200 \mathrm{mg} / \mathrm{L}, \text { Thai FOG } 50 \mathrm{mg} / \mathrm{L}\end{array}$ \\
6 & Thai-200 Glucose & $\begin{array}{l}\text { Growth Media } 200 \mathrm{~mL} ; \text { CYA } 50 \mathrm{mg} / \mathrm{L}, \\
\text { Glucose } 200 \mathrm{mg} / \mathrm{L}, \text { Thai FOG } 50 \mathrm{mg} / \mathrm{L}\end{array}$ \\
7 & Thai-200 Sunscreen & $\begin{array}{l}\text { Growth Media } 200 \mathrm{~mL} ; \text { CYA } 50 \mathrm{mg} / \mathrm{L}, \\
\text { Sunscreen } 200 \mathrm{mg} / \mathrm{L}, \text { Thai FOG } 200 \mathrm{mg} / \mathrm{L}\end{array}$ \\
8 & US-200 Sunscreen & $\begin{array}{l}\text { Growth Media } 200 \mathrm{~mL} ; \text { CYA } 50 \mathrm{mg} / \mathrm{L}, \\
\text { Sunscreen } 200 \mathrm{mg} / \mathrm{L}, \mathrm{US} \mathrm{Aqua} 50 \mathrm{mg} / \mathrm{L}\end{array}$ \\
9 & Cyanuric & DI Water $200 \mathrm{~mL}, 50 \mathrm{mg} / \mathrm{L} \mathrm{CYA}$ \\
10 & Water & DI Water $200 \mathrm{~mL}$ \\
\hline
\end{tabular}

Minimal media was prepared with the concentrations in Table 3-24. Media was autoclaved before addition to the $250 \mathrm{~mL}$ shaker flasks.

Table 3-24: Experiment IV-4 Growth Medium

\begin{tabular}{ll}
\hline Constituent & Concentration \\
\hline $\mathrm{K}_{2} \mathrm{HPO}_{4}$ & $1 \mathrm{~g} / \mathrm{L}$ \\
$\mathrm{KH}_{2} \mathrm{PO}_{4}$ & $1 \mathrm{~g} / \mathrm{L}$ \\
Dextrose (Anhydrous) & $1 \mathrm{~g} / \mathrm{L}$ \\
$\mathrm{KNO}_{3}$ & $0.1 \mathrm{~g} / \mathrm{L}$ \\
$\mathrm{FeSO}_{4}$ & Trace \\
$\mathrm{CaCl}_{2}$ & Trace \\
\hline
\end{tabular}


CYA was added to each flask in granular form. After addition, each flask was capped and shaken to dissolve CYA. Dry bacterial mixes and additional glucose were then added to each flask. After bacterial inoculation, flasks were loaded into an incubator shaker at $30^{\circ} \mathrm{C}$ and 75 RPM. Flasks were swirled to mix immediately before daily analysis of CYA. CYA was measured turbidimetrically.

\subsubsection{Experiment IV-5 Effect of Activated Thai FOG Supernatant on CYA}

Thai FOG was added to $1 \mathrm{~L}$ of DI water at $750 \mathrm{mg} / \mathrm{L}$ and incubated, aerobically, for 24 hours at $30^{\circ} \mathrm{C}$ and $75 \mathrm{RPM}$. A stock solution of $62.5 \mathrm{mg} / \mathrm{L} \mathrm{CYA} \mathrm{was} \mathrm{prepared.} \mathrm{One}$

treatment of $390 \mathrm{~mL} \mathrm{CYA} \mathrm{stock} \mathrm{solution} \mathrm{was} \mathrm{inoculated} \mathrm{with} 10 \mathrm{~mL}$ of the supernatant of the activated Thai FOG. The inoculated treatment was capped anaerobically and incubated at $30^{\circ} \mathrm{C}$ and 75 RPM. Daily turbidimetric CYA measurements were taken.

\subsubsection{Experiment IV-6 Effects of US FOG and Activated Thai FOG on CYA}

Six $500 \mathrm{~mL}$ threaded shaker flasks were autoclaved then filled with $400 \mathrm{~mL}$ of $60 \mathrm{mg} / \mathrm{L}$ CYA stock solution. Each flask was dosed with $250 \mathrm{mg} / \mathrm{L}$ glucose. CYA was tested turbidimetrically for each flask before the addition of any biological inoculum.

Treatments were set up in triplicate. Three flasks were dosed with $100 \mathrm{~mL}$ DI water and $250 \mathrm{mg} / \mathrm{L}$ of US FOG. The other three flasks were dosed with $100 \mathrm{~mL}$ of supernatant from a solution of $1 \mathrm{~g} / \mathrm{L}$ Thai FOG. The Thai FOG solution had been activated at $30^{\circ} \mathrm{C}$ and 75 
RPM for 24 hours, inverted and agitated, then allowed to settle for 2 minutes. CYA was tested turbidimetrically for each flask, each day.

\subsubsection{Experiment IV-7 Turbidimetric CYA Calibration}

Serial dilutions were created from a stock CYA. Each dilution was turbidimetrically, and a linear regression model was fit to the resulting data.

\subsubsection{Experiment IV-8 Standard Preparation for HPLC}

A stock solution of CYA was prepared. Dilutions were prepared in $2 \mathrm{~mL}$ crimp-top vials for HPLC analysis. Concentrations were recorded and written on the exterior of each vial for ease of reference.

\subsubsection{Experiment IV-9 HPLC Calibration of CYA}

The standard solutions prepared in Experiment IV-8 were tested in the HPLC using the method described in Table 3-25, below. The purge valve was maintained partially open throughout HPLC analysis, which heavily influenced elution time and peak area.

Table 3-25: Experiment IV-9 HPLC Operating Parameters

\begin{tabular}{ll}
\hline Parameter & Value \\
\hline Column & Acclaim Trinity P1 \\
Mobile Phase & $20 \%$ methanol \\
& $80 \% 50 \mathrm{mM} \mathrm{K}_{2} \mathrm{HPO}_{4}$ buffer \\
Flow Rate & $0.500 \mathrm{~mL} / \mathrm{min}$ \\
Injection volume & $20 \mu \mathrm{L}$ \\
\hline
\end{tabular}




\begin{tabular}{ll}
\hline Detection wavelength & $213 \mathrm{~nm}$ \\
Temperature & $22^{\circ} \mathrm{C}$ (ambient) \\
Sample Run Time & 12 minutes \\
Operating Pressure & $350 \mathrm{bar}$ \\
\hline
\end{tabular}

\subsubsection{Experiment IV-10 HPLC Calibration using Thai FOG}

A stock solution of $50 \mathrm{mg} / \mathrm{L}$ CYA was prepared. Thai FOG was added to DI water at 110 $\mathrm{mg} / \mathrm{L}$ and activated at $30^{\circ} \mathrm{C}$ and $75 \mathrm{RPM}$ for 24 hours. All samples were filtered through $0.22 \mu \mathrm{m}$ filters before addition to $2 \mathrm{~mL}$ vials at concentrations listed in Table 3-26, below. The $40 \mathrm{mg} / \mathrm{L}$ standard CYA vial from Experiment IV-8 was also analyzed.

Table 3-26: Experiment IV-10 HPLC Vial Contents

\begin{tabular}{ll}
\hline Vial & Contents \\
\hline 1 & CYA $50 \mathrm{mg} / \mathrm{L}$ \\
2 & Thai FOG $110 \mathrm{mg} / \mathrm{L}$ \\
3 & $\begin{array}{l}\text { CYA } 25 \mathrm{mg} / \mathrm{L} ; \\
\text { Thai FOG } 55.3 \mathrm{mg} / \mathrm{L}\end{array}$ \\
4 & $40 \mathrm{mg} / \mathrm{L} \mathrm{CYA} \mathrm{Standard}$ \\
\hline
\end{tabular}

HPLC analysis was carried out with the parameters in Table 3-27. The purge valve was maintained partially open, due to high operating pressure. 
Table 3-27: Experiment IV-10 HPLC Operating Parameters

\begin{tabular}{ll}
\hline Parameter & Value \\
\hline Column & Acclaim Trinity P1 \\
Mobile Phase & $20 \%$ methanol \\
& $80 \% 50 \mathrm{mM} \mathrm{K}_{2} \mathrm{HPO}_{4}$ buffer \\
Flow Rate & $0.500 \mathrm{~mL} / \mathrm{min}$ \\
Injection volume & $20 \mathrm{uL}$ \\
Detection wavelength & $213 \mathrm{~nm}$ \\
Temperature & $21^{\circ} \mathrm{C}$ (ambient) \\
Sample Run Time & 12 minutes \\
Operating Pressure & 360 bar \\
\hline
\end{tabular}

\subsubsection{Experiment IV-11 Method Development of HPLC using Thai FOG and CYA}

A shaker flask was dosed with $100 \mathrm{mg} / \mathrm{L}$ Thai FOG and $60 \mathrm{mg} / \mathrm{L}$ CYA. The inoculated solution was placed on a heat plate and stirred with a magnetic stir-bar until all CYA had dissolved. The flask was then incubated in a shaker at $30^{\circ} \mathrm{C}$ and 75 RPM for the duration of the experiment.

Samples were collected for HPLC analysis according to the methods detailed above. HPLC operating parameters were identical to those in Experiment IV-10 and are laid out in Table 3-27, above.

\subsubsection{Experiment IV-12 Investigation of Products' Effects on CYA}

Eight $500 \mathrm{~mL}$ shaker flasks were autoclaved and filled with $300 \mathrm{~mL}$ of DI water and the contents listed in Table 3-28, below. After inoculation, treatments were capped and incubated at $30^{\circ} \mathrm{C}$ and $75 \mathrm{RPM}$ for the duration of the experiment. 
Table 3-28: Experiment IV-12 Experimental Setup

\begin{tabular}{llll}
\hline Bottle & $\begin{array}{l}\text { Cya } \\
{[\mathrm{mg} / \mathrm{L}]}\end{array}$ & Inoculum & $\begin{array}{l}\text { Glucose } \\
{[\mathrm{mg} / \mathrm{L}]}\end{array}$ \\
\hline 1 & 50 & $\mathrm{x}$ & $\mathrm{x}$ \\
2 & 50 & Thai FOG & 250 \\
3 & 50 & Thai FOG & $\mathrm{x}$ \\
4 & 50 & IR TF & 250 \\
5 & 50 & Premix & 250 \\
6 & 50 & 35 mg Osp Liq & 250 \\
7 & 50 & Osp Solid & 250 \\
8 & 50 & US FOG & 250 \\
\hline
\end{tabular}

Samples were collected daily, for HPLC analysis. HPLC operating parameters were identical to those in Experiments IV-10 and IV-11 and are detailed in Table 3-27, above.

\subsubsection{Experiment IV-13 HPLC Method Development - Inconclusive Mobile Phase Adjustment}

Many mobile phases were tested, and none provided improved separation of CYA peaks from nitrate peaks.

Mobile phases tested include:

$90 \%$ acetonitrile, $5 \%$ methanol, $5 \% 17.5 \mathrm{mM} \mathrm{K}_{2} \mathrm{HPO}_{4}$ buffer

95\% acetonitrile, $5 \% 17.5 \mathrm{mM} \mathrm{K}_{2} \mathrm{HPO}_{4}$ buffer

$15 \%$ acetonitrile, $85 \% 50 \mathrm{mM} \mathrm{K}_{2} \mathrm{HPO}_{4}$ buffer

$85 \%$ acetonitrile, $15 \% 20 \mathrm{mM}$ ammonium acetate buffer 


\subsubsection{Experiment IV-14 HPLC Method Development - High Injection Volume}

High injected concentrations of CYA led to column clogging during analysis. No meaningful data were collected in this experiment.

\subsubsection{Experiment IV-15 Investigation of C:N:P Ratios on CYA Degradation}

A minimal growth medium, with concentrations detailed in Table 3-29, was autoclaved.

Table 3-29: Experiment IV-15 Minimal Media Composition

\begin{tabular}{ll}
\hline Component & Concentration $[\mathrm{mg} / \mathrm{L}]$ \\
\hline Cyanuric Acid & 276.4 \\
$\mathrm{NH}_{4} \mathrm{NO}_{3}$ & 28.6 \\
$\mathrm{~K}_{2} \mathrm{HPO}_{4}$ & 56.1 \\
\hline
\end{tabular}

US Aqua and dextrose were combined at a ratio of $44 \%$ US Aqua and $56 \%$ dextrose. This mixture was added to the minimal media, which was stirred to dissolve additives. Additional dextrose was added to each treatment to obtain desired carbon content. Table 3-30 details the components of each treatment.

Table 3-30: Experiment IV-15 Carbon, Nitrogen, and Phosphorus Concentrations

\begin{tabular}{llllll}
\hline Ratio of C:N:P & $\begin{array}{l}\text { Product } \\
{[\mathrm{mg} / \mathrm{L}]}\end{array}$ & $\begin{array}{l}\text { Dextrose } \\
{[\mathrm{mg} / \mathrm{L}]}\end{array}$ & $\begin{array}{l}\mathrm{CYA} \\
{[\mathrm{mg} / \mathrm{L}]}\end{array}$ & $\begin{array}{l}\mathrm{NH}_{4} \mathrm{NO}_{3} \\
{[\mathrm{mg} / \mathrm{L}]}\end{array}$ & $\begin{array}{l}\mathrm{K}_{2} \mathrm{HPO}_{4} \\
{[\mathrm{mg} / \mathrm{L}]}\end{array}$ \\
\hline 100:10:01 & 100 & 2264.3 & 276.4 & 28.6 & 56.1 \\
60:10:01 & 100 & 1264.3 & 276.4 & 28.6 & 56.1 \\
50:10:01 & 100 & 1014.3 & 276.4 & 28.6 & 56.1 \\
10:10:01 & 100 & 764.3 & 276.4 & 28.6 & 56.1 \\
50:10:01 & 100 & 14.3 & 276.4 & 28.6 & 56.1 \\
\hline
\end{tabular}


After inoculation, treatments 1 through 5 and the control were capped anaerobically. Treatments 6 and 7 were covered with aerobic caps. All treatments were placed in an incubator shaker at $30^{\circ} \mathrm{C}$ and $75 \mathrm{RPM}$.

Daily sample collection and preparation for HPLC was carried out according to the methods detailed above. HPLC analysis was performed with the operating parameters laid out in Table 3-31, below.

Table 3-31: Experiment IV-15 HPLC Operating Parameters

\begin{tabular}{ll}
\hline Parameter & Value \\
\hline Column & Acclaim Trinity P1 \\
Mobile Phase & $95 \% 17.5 \mathrm{mM}$ Phosphate buffer, \\
& $5 \%$ methanol \\
Flow Rate & $0.400 \mathrm{~mL} / \mathrm{min}$ \\
Injection volume & $150 \mathrm{uL}$ \\
Detection wavelength & $213 \mathrm{~nm}$ \\
Temperature & $22^{\circ} \mathrm{C}$ (ambient) \\
Sample Run Time & 12 minutes \\
Operating Pressure & $250 \mathrm{bar}$ \\
\hline
\end{tabular}

\subsubsection{Experiment IV-16 Hour-by-Hour Time-Point CYA Degradation}

A growth solution containing $500 \mathrm{mg} / \mathrm{L} \mathrm{CYA}, 500 \mathrm{mg} / \mathrm{L}$ dextrose, and $100 \mathrm{mg} / \mathrm{L}$ ammonium nitrate was autoclaved. Six $500 \mathrm{~mL}$ shaker flasks were filled with $300 \mathrm{~mL}$ of growth solution. Isolated vegetative bacteria from Thai FOG were provided by BiOWiSH for inoculation in this experiment. Three of the six flasks were inoculated with $100 \mathrm{mg} / \mathrm{L}$ of vegetative bacterial suspension. 
HPLC analysis was carried out identically to Experiment IV-15, with operating parameters identical to those in Table 3-31, above.

\subsubsection{Experiment IV-17 Effect of CAR on CYA Concentration}

A $200 \mathrm{mg} / \mathrm{L}$ stock solution of CYA was prepared. Six $500 \mathrm{~mL}$ threaded shaker flasks and caps were autoclaved, and each was filled with $300 \mathrm{~mL}$ of CYA solution.

A stock solution of BiOWiSH CAR product was prepared at $10 \mathrm{~g} / \mathrm{L}$. Two control flasks were not inoculated. Two flasks were dosed to $5 \mathrm{mg} / \mathrm{L}$ of CAR solution. Two flasks were dosed to $50 \mathrm{mg} / \mathrm{L}$ of CAR solution. HPLC sample collection, preparation, and analysis were carried out according to the methods and operating parameters detailed earlier.

\subsubsection{Experiment IV-18 Effect of CAR on CYA with $\mathrm{K}_{2} \mathrm{HPO}_{4}$, Varied Glucose}

Growth media containing $100 \mathrm{mg} / \mathrm{L}$ CYA and trace $\mathrm{K}_{2} \mathrm{HPO}_{4}$. Before addition of the CYA solution to each of six $200 \mathrm{~mL}$ shaker flasks, the stock solution was sparged with $\mathrm{N}_{2}$ gas to create anaerobic conditions from $\mathrm{T}=0$ hours. Bottles were filled to the brim with between 249 and $257 \mathrm{~mL}$ of growth media, CAR product, and additional glucose. Treatments can be found in Table 3-32, below. 
Table 3-32: Experiment IV-18 Flask Contents

\begin{tabular}{lllll}
\hline Flask & $\begin{array}{l}\text { Volume Growth } \\
\text { Media }[\mathrm{mL}]\end{array}$ & $\begin{array}{l}\text { CAR Product } \\
{[\mathrm{mg} / \mathrm{L}]}\end{array}$ & $\begin{array}{l}\text { Added Glucose } \\
{[\mathrm{mg} / \mathrm{L}]}\end{array}$ & $\begin{array}{l}\text { Total Glucose } \\
{[\mathrm{mg} / \mathrm{L}]}\end{array}$ \\
\hline Control 1 & 250 & 0 & 0 & 0 \\
Control 2 & 250 & 0 & 0 & 0 \\
CAR1 & 249 & 50.0 & 0 & 47 \\
CAR2 & 253 & 49.8 & 0 & 46.8 \\
CAR+GLU1 & 250 & 50.3 & 50 & 97.3 \\
CAR+GLU2 & 257 & 50.0 & 50 & 96.3 \\
\hline
\end{tabular}

After inoculation, shaker flasks were capped anaerobically and incubated at $30^{\circ} \mathrm{C}$ and 75 RPM.

HPLC sample collection, preparation, and analysis were carried out according to the methods and operating parameters detailed above, using non-sterile graduated transfer pipettes. A 3-point calibration was run at the beginning of $\mathrm{HPLC}$ analysis at $\mathrm{T}=6, \mathrm{~T}=8$, and $\mathrm{T}=9$ Days, to provide a daily calibration check. This method was used in future experiments to provide accurate conversion of peak area to CYA concentration.

No appreciable bacterial growth was seen within biological treatments after 6 days. To stimulate growth, a solution of $1 \mathrm{~g} / \mathrm{L} \mathrm{CAR}$ in Lactobacillus Broth was activated for 24 hours at $30^{\circ} \mathrm{C}$ and $75 \mathrm{rpm}$. The activated product was dosed at $1 \mathrm{~mL}$ per flask to all four biological treatments on day 7. HPLC measurement was continued, but at increased intervals. 


\subsubsection{Experiment IV-19 Effect of Activated CAR on CYA, Varying Dextrose}

A stock solution of $50 \mathrm{mg} / \mathrm{L} \mathrm{CYA} \mathrm{was} \mathrm{prepared.} \mathrm{The} \mathrm{activated} \mathrm{cultures} \mathrm{of} \mathrm{OBAAG-KLB,}$ LCM, OBWWT\#1, and MBWWT\#1 from Experiment I-9 were combined in equal parts to create the "Activated CAR" product. Six $250 \mathrm{~mL}$ shaker flasks were filled with $250 \mathrm{~mL}$ of CYA solution.

Two control flasks were not inoculated. Two flasks received $15 \mathrm{~mL}$ of Activated CAR and $50 \mathrm{mg} / \mathrm{L}$ of dextrose, and two flasks received $15 \mathrm{~mL}$ of Activated CAR and $287 \mathrm{mg} / \mathrm{L}$ of dextrose, as shown in Table 3-33. After inoculation, each treatment was capped anaerobically and incubated at $30^{\circ} \mathrm{C}$ and $75 \mathrm{RPM}$.

Table 3-33: Experiment IV-19 Experimental Setup

\begin{tabular}{lll}
\hline & & Additional \\
Bottle & Activated CAR [mL] & Dextrose [mg/L] \\
\hline Control 1 & 0 & 0 \\
Control 2 & 0 & 0 \\
CYA + Dex 50 ppm 1 & 15 & 50 \\
CYA + Dex 50 ppm 2 & 15 & 50 \\
CYA + Dex 287 ppm 1 & 15 & 287 \\
CYA + Dex 287 ppm 2 & 15 & 287 \\
\hline
\end{tabular}

HPLC sample collection, preparation, and analysis were carried out according to the methods and operating parameters detailed above. A four-point calibration was run at the beginning of each analysis event to provide accurate conversion of peak area to CYA concentration. 


\subsubsection{Experiment IV-20 Effect of Activated CAR and Filter Media on CYA}

A minimal growth media was prepared with composition found in Table 3-34, below.

Table 3-34: Experiment IV-20 Minimal Media Composition

\begin{tabular}{ll}
\hline Component & Concentration \\
\hline Glucose & $2 \mathrm{~g} / \mathrm{L}$ \\
K2HPO4 & $1.5 \mathrm{~g} / \mathrm{L}$ \\
KH2PO4 & $0.75 \mathrm{~g} / \mathrm{L}$ \\
NH4NO3 & $0.2 \mathrm{~g} / \mathrm{L}$ \\
FeSO4 & $20 \mathrm{mg} / \mathrm{L}$ \\
MnSO4 & Trace \\
\hline
\end{tabular}

A stock solution of CYA was prepared at $3.00 \mathrm{~g} / \mathrm{L}$. Each flask was dosed with $5 \mathrm{~mL}$ stock CYA solution before dilution with DI water or activated culture broth and growth medium. Total volume of each flask was $300 \mathrm{~mL}$, creating a final concentration of $50 \mathrm{mg} / \mathrm{L} \mathrm{CYA}$ in each treatment.

Three sets of duplicate treatments were prepared in $250 \mathrm{~mL}$ Erlenmeyer flasks. Flasks were filled to $300 \mathrm{~mL}$ in order to prevent oxygen introduction from an air void volume. $15 \mathrm{~mL}$ of stock inoculum were added to each flask, as listed in Table 3-35, below.

Table 3-35: Experiment IV-20 Flask Setup

\begin{tabular}{lll}
\hline Treatment & Solution & Inoculation \\
\hline 1 & DI Water + CYA & None \\
2 & DI Water + CYA & None \\
3 & Minimal Media + CYA & Activated Thai FOG \\
4 & Minimal Media + CYA & Activated Thai FOG \\
\hline
\end{tabular}




$5 \quad$ Minimal Media + CYA Activated Pool Filter Media

6 Minimal Media + CYA Activated Pool Filter Media

After the addition of CYA, growth medium, and inoculum, flasks were capped anaerobically and placed in a shaker incubator at $30^{\circ} \mathrm{C}$ and $75 \mathrm{RPM}$ to ensure proper mixing. Sampling for HPLC was carried out according to the method and operating parameters outlined above. An additional $1.6 \mathrm{~g} / \mathrm{L}$ of dextrose were added to Thai FOG 1, Thai FOG 2, Filter Media 1, and Filter Media 2 at T=7 days. 


\section{CHAPTER 4 - RESULTS AND DISCUSSION}

\subsection{Task I - Determination of Clarification Mechanism}

\subsubsection{Experiment I-1 Efficacy of Thai FOG Removing Turbidity, with Mechanical Filtration}

At $\mathrm{T}=0$ hours, $100 \mathrm{mg} / \mathrm{L}$ of Coppertone Sunscreen was dosed to $30 \mathrm{~L}$ of tap water in a 10gallon aquarium with mechanical filtration. At $\mathrm{T}=0.25$ hours, $100 \mathrm{mg} / \mathrm{L}$ of Thai FOG was added to the tank. The tank was chlorinated to with Clorox concentrated bleach to 3-4 mg/L of total chlorine as $\mathrm{Cl}_{2}$, daily.

After a slight increase in turbidity due to the addition of Thai FOG an $82 \%$ decrease in turbidity was observed over 18 hours (Figure 4-1). The turbidity reduction continued, at a diminished rate, throughout the experiment.

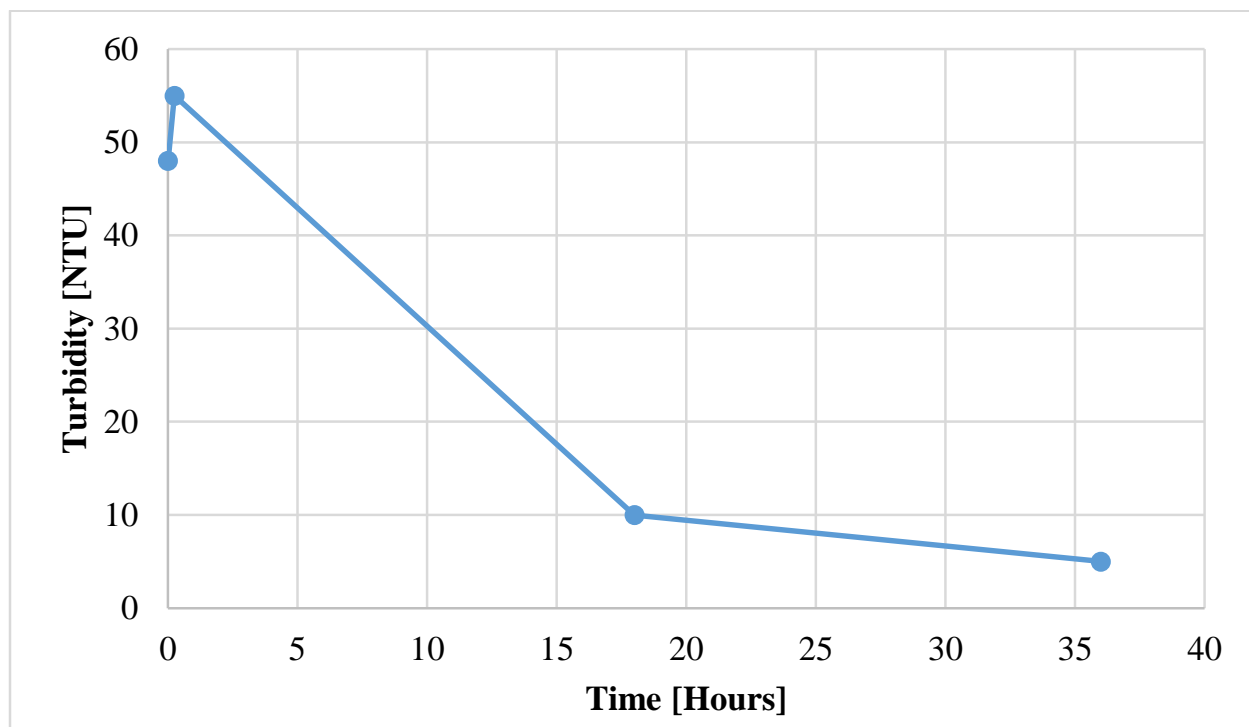

Figure 4-1: Experiment I-1 Turbidity vs. Time, BiOWiSH Thai FOG, Tap Water at $30^{\circ} \mathrm{C}$, Mechanical Filtration 
The rate of water clarification of water indicated the potential for $\mathrm{BiOWiSH}$ to remove turbidity caused by sunscreen. The mechanism by which is unknown, so further research is necessary to determine why turbidity is reduced.

\subsubsection{Experiment I-2 Effects of BiOWiSH on Turbidity with Sodium Azide Control}

Experiment I-2 replicated the methods of Experiment I-1 with additional treatments including US FOG and an abiotic control. Sodium azide was added to the control tank as a microbial inhibitor.

Each treatment resulted in a sharp decrease in turbidity over the first 18 hours (Figure 42). Thai FOG, US FOG, and the Control displayed 66\%, $77 \%$, and $85 \%$ reductions in turbidity, respectively.

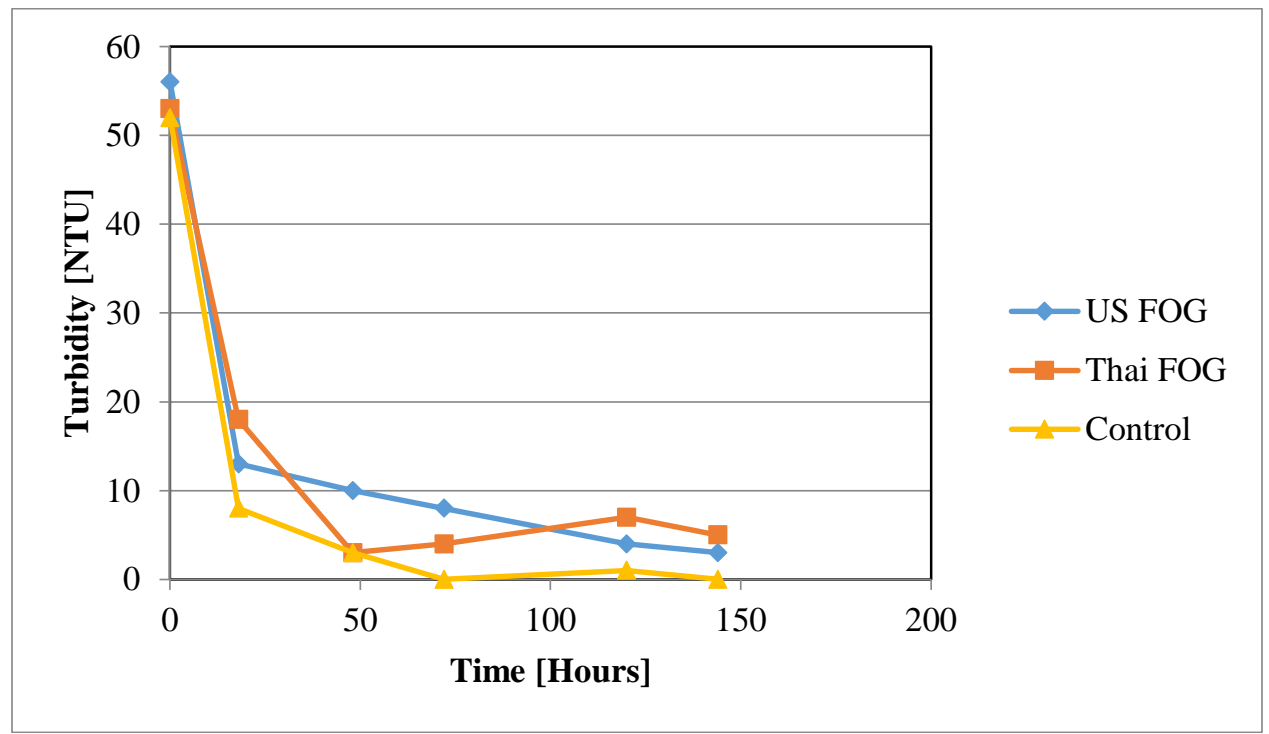

Figure 4-2: Experiment I-2 Turbidity vs. Time, US FOG and Thai FOG, Tap Water at $30^{\circ} \mathrm{C}$, Mechanical Filtration 
No improvement of clarification over the control treatment was seen by Thai FOG or US FOG. Increased turbidity relative to the control is most likely due to the introduction of particulate matter in each product.

Use of sodium azide as a bacterial inhibitor was discontinued after this experiment due to its high toxicity and splashing caused by filters. To prevent splashing of filters, subsequent treatments were filled with an additional $3 \mathrm{~L}$ of water. The additional water provided a gentler re-entry of filter effluent to each tank, minimizing splashing.

\subsubsection{Experiment I-3 Effects of BiOWiSH on Turbidity with Re-Dosed Sunscreen}

Experiment I-3 was the first experiment in which sunscreen was re-dosed periodically. Additionally a treatment of rice bran was introduced as a control compared to the rice bran used in Thai FOG. Sunscreen was re-dosed at $100 \mathrm{mg} / \mathrm{L}$ whenever the turbidity of the control tank leveled out. Residual TC dropped close to zero each day, so each tank was chlorinated to 3-4 mg/L TC as $\mathrm{Cl}_{2}$, daily.

Each aquarium showed a sharp decrease in turbidity one day after each sunscreen re-dose (Figure 4-3). Initial doses of sunscreen were clarified at different rates by each treatment. Thai FOG reduced turbidity by the greatest amount in the first 24 hours, followed by the control and US FOG. Rice bran showed the highest turbidity throughout the experiment, because the fine particles of the substrate did not settle out of suspension, nor were they removed by the filter. 
Turbidity reduction of Thai FOG was poor between 1 and 11 days, and turbidity increased after the $\mathrm{T}=12$ Days time-point. This is attributed to an accidental lapse in chlorination at $\mathrm{T}=11$ Days. The Bacillus species in Thai FOG were able to proliferate, and continued chlorination did not halt microbial growth. A shock dose of chlorine was considered as an option to stop the bacteria from growing as quickly. For consistency among trials and comparability to future experiments, the regular chlorine dosing schedule was maintained.

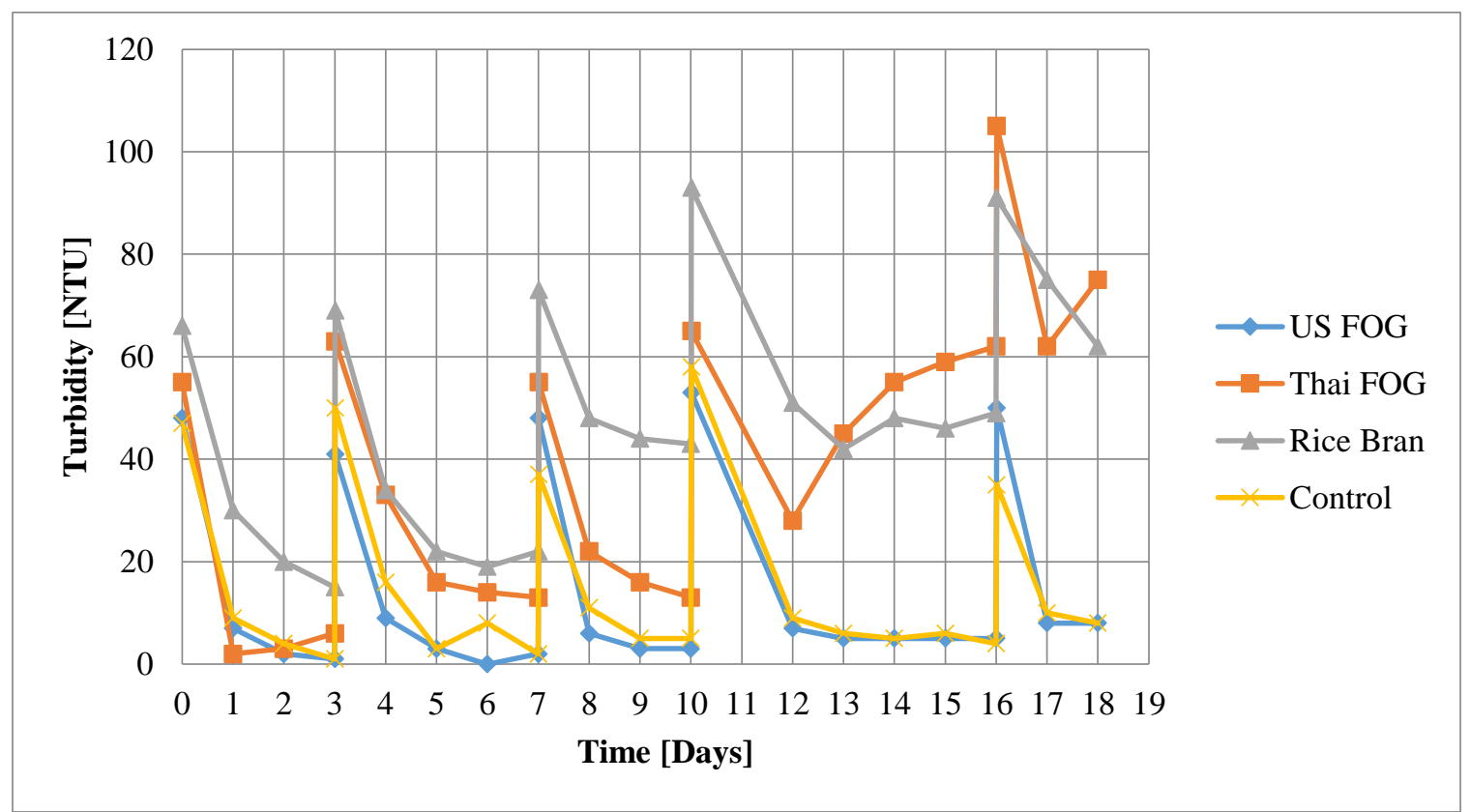

Figure 4-3: Experiment I-3 Turbidity vs. Time, Tap Water at $30^{\circ} \mathrm{C}$, Re-dosed Sunscreen, Mechanical Filtration

Thai FOG displayed greater activity than the soluble-diluent US FOG, the abiotic treatments of "Rice Bran" and the Control. Further investigation is necessary to determine whether the microbes in Thai FOG are degrading sunscreen within the first 24 hours, or if the physical properties of the substrate lead to adsorption or improved filtration of sunscreen. 
Since the rice bran treatment did not settle out of solution, it cannot be considered analogous to an abiotic form of the substrate of Thai FOG. Experiments I-4, I-5, I-7, and I-8 utilize an irradiated sample of Thai FOG as an abiotic control instead of the rice bran. This control is expected to reveal the effects of the solid substrate without interference by microorganisms.

The results suggest that mechanical removal (either filtration or adsorption) plays a dominant role in the clarification of sunscreen from solution; however, other mechanisms of clarification, such as biodegradation, cannot be ruled out.

\subsubsection{Experiment I-5 Effects of BiOWiSH Products on Re-Dosed Sunscreen}

Experiment I-5 was designed to compare US FOG and irradiated Thai FOG to a mixture of US FOG and irradiated Thai FOG, among other treatments. Irradiated Thai FOG was used as an abiotic treatment containing solid substrate. US FOG was used as a treatment containing biology and a soluble substrate. Two treatments of US FOG mixed with irradiated Thai FOG were prepared to mimic the bacteria of US FOG mounted to a solid substrate. Proprietary surfactants and the KLB strain of Bacillus are added to Thai FOG during production. To observe the effects of a solid substrate, the Thai FOG substrate was used post-fermentation without additives. This product was called Premix. BMT Remediate, called "BMT SS" in this experiment, was tested because it contains a mix of Rhodococcus and Arthobacter bacteria, rather than the Bacillus and Lactobacillus of US FOG and Thai FOG. 
Chlorine was dosed by adding concentrated bleach between 6 and $9 \mathrm{mg} / \mathrm{L} \mathrm{TC}$, which immediately dropped to between 2.1 and $3.0 \mathrm{mg} / \mathrm{L}$ in each aquarium. To combat the drop in TC, an additional dose of 6 to $9 \mathrm{mg} / \mathrm{L}$ TC was added to each tank. Residuals consistently dropped to around $\sim 1 \mathrm{mg} / \mathrm{L} \mathrm{Cl}_{2}$ overnight. On Day $5,23 \mathrm{mg} / \mathrm{L}$ of CYA were added to each of the tanks in an effort to maintain residual chlorine. However, no change in TC residual was noted. CYA only protects chlorine from being photodegraded by UV radiation, and there are no windows in the lab through which UV radiation could affect chlorine levels in the aquaria.

Sampling and chlorination were discontinued between the final re-dose on Day 16.1 and the final sampling event on Day 27.

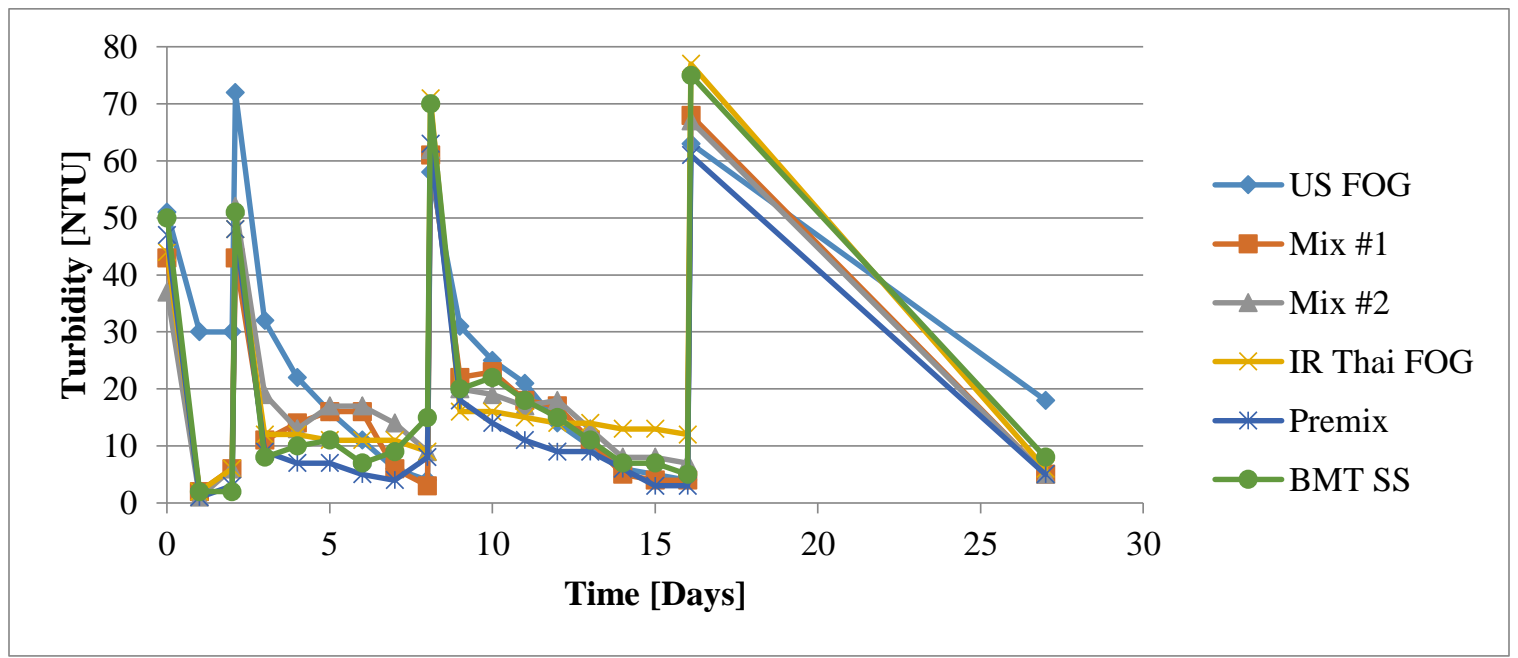

Figure 4-4: Experiment I-5 Turbidity vs. Time, Tap Water at $30^{\circ} \mathrm{C}$, Re-dosed Sunscreen, Mechanical Filtration

Between $\mathrm{T}=0$ Days and $\mathrm{T}=1$ Days, the turbidity of US FOG only dropped by $41 \%$, whereas each other treatment reduced turbidity by $95-98 \%$. This is attributed to improper 
installation of the filter bag, which caused water to bypass the filter and reduced overall filtration. This mistake shows that without mechanical filtration, clarification is much slower in the first 24 hours of this type of experiment. Additionally, the results of this experiment confirm the results of Experiments I-2 and I-3, which suggest that mechanical filtration is responsible for significantly reduced sunscreen in each treatment, over the first day.

When compared to similar time-points in the control tanks of Experiments I-2 and I-3, "IR Thai FOG" data suggest that the solid substrate does not provide additional removal of sunscreen after re-dosing. This suggests that the majority of clarification during re-doses stems from mechanical filtration, rather than adsorption to the substrate.

\subsubsection{Experiment I-4 Comparison of Re-Dosed US FOG to Single Dosed Products}

This experiment was designed to compare a treatment which received a single dose of 50 $\mathrm{mg} / \mathrm{L}$ US FOG to a re-dosed treatment which received $5 \mathrm{mg} / \mathrm{L}$ of US FOG each time sunscreen was re-dosed. Additionally, a sample of Thai FOG was irradiated to inhibit biological effects on clarification, if present. The "Irradiated Thai FOG" treatment was compared to a treatment with unaltered Thai FOG.

Due to clerical and experimenter error, the data for $\mathrm{T}=0$ Days through $\mathrm{T}=23$ Days were lost. The trials in this experiment received multiple re-doses of sunscreen before the Day 24 time-point. This experiment highlights each treatment's ability to reduce turbidity after repeated addition of sunscreen. 
None of the treatments improved turbidity reduction compared to the control (Figure 4-6).

The "US FOG Re-Dose" resulted in the highest turbidity until the Day 31 time-point (Figure 4-7).

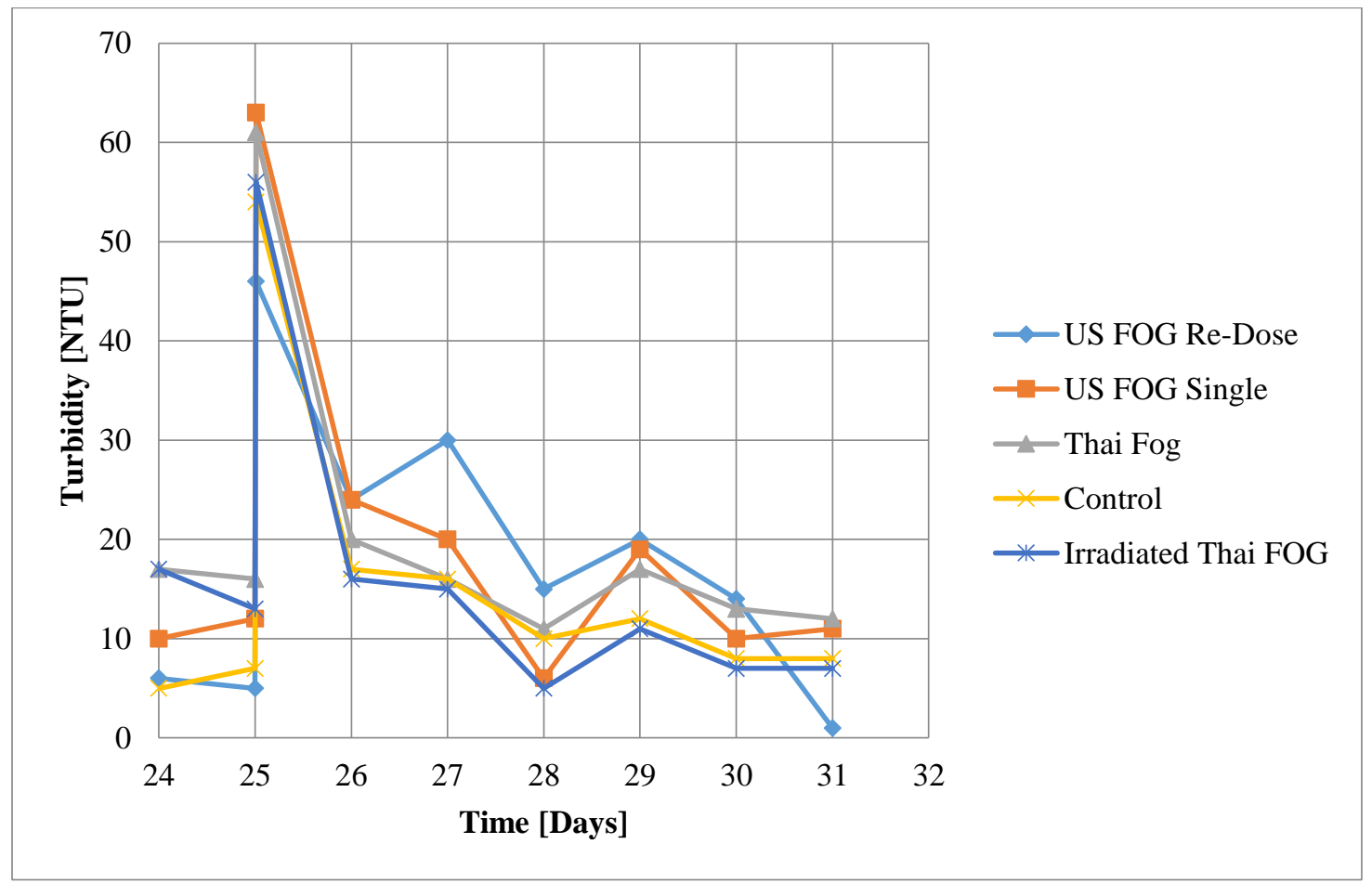

Figure 4-5: Experiment I-4 Turbidity vs. Time, Tap Water at $30^{\circ} \mathrm{C}$, Re-dosed Sunscreen Between 24 and 31 Days, Mechanical Filtration

Irradiated Thai FOG showed lower turbidity than the unaltered Thai FOG treatment. This is consistent with the assumption that irradiation deactivated all microbes in the "Irradiated Thai FOG" treatment, and there was minimal bacterial contribution to turbidity in the irradiated product.

By Day 24, the "US FOG Re-Dose" contained a similar quantity of bacteria to "US FOG Single", as microbes in each had been was provided the same amount of substrate in the 
form of sunscreen. Results show that re-dosing US FOG is not advantageous over a single dose.

\subsubsection{Experiment I-6 Effects of Additional Solid Substrate Products on Turbidity}

Building from the findings of Experiment I-5, Experiment I-6 was designed to test a number of additional solid substrate Bacillus products. The rice bran which is fermented to create Premix was used in one treatment to investigate the effects of fermentation on the rice bran to remove turbidity from solution. Additionally, the proprietary Manure and Odor Control (Manure/ Odor) product was tested as a treatment containing soluble diluent.

After dosing sunscreen, a significant drop in turbidity was noted in the first day of the experiment for all treatments. Premix showed the greatest drop in turbidity between $\mathrm{T}=0$ and $\mathrm{T}=1$ Days. After the re-dose, Premix again showed the lowest turbidity of all treatments. Beyond T=5 Days, however, Premix showed steadily increasing turbidity.

The prototype BS-AQ products (BS-AQ-001, BS-AQ-002, and BS-AQ-003) performed similarly to each other, showing a decrease in turbidity after the re-dose followed by minimal change in turbidity until $\mathrm{T}=5$ Days. After this time, each product showed a slight increase in turbidity. 


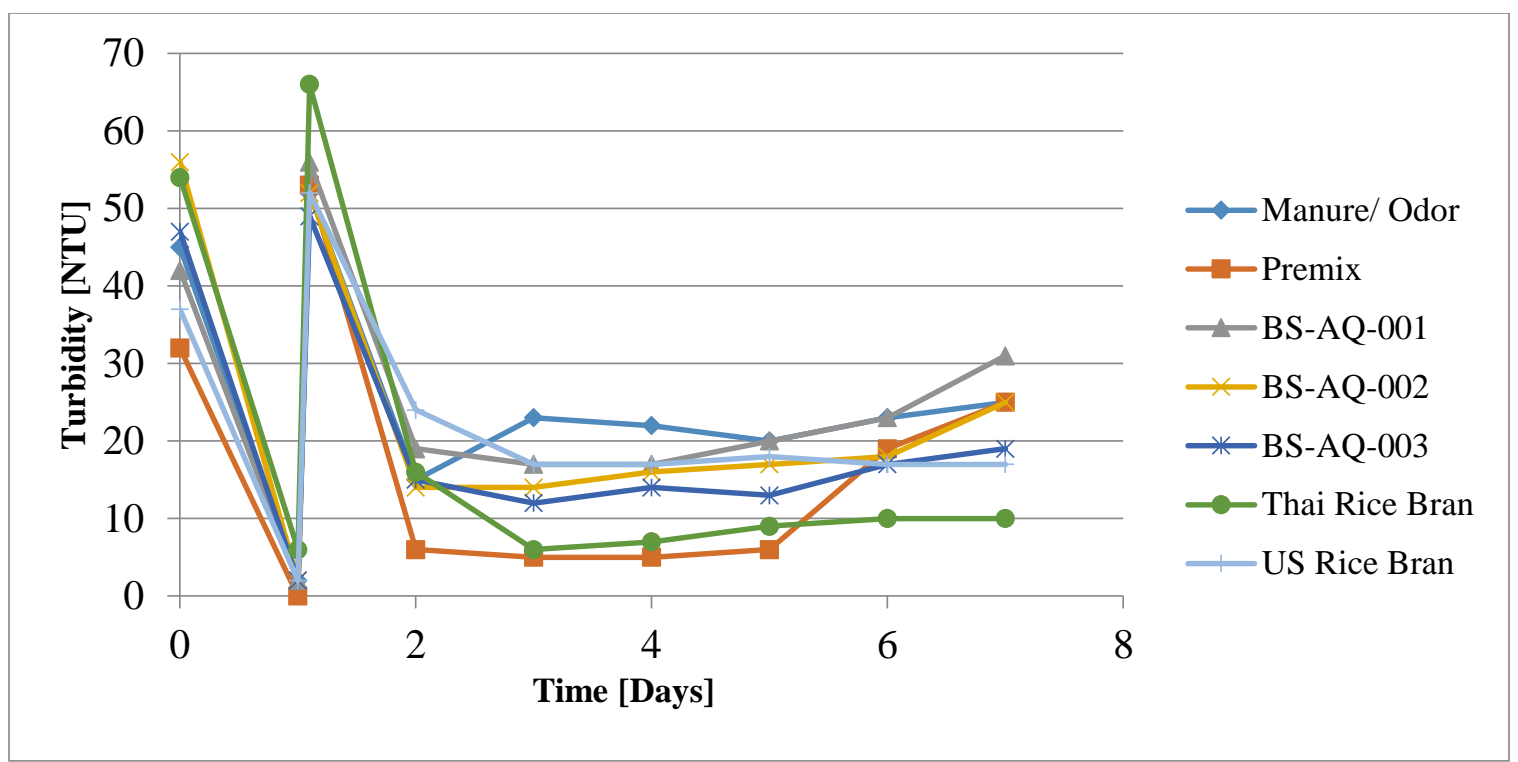

Figure 4-6: Experiment I-6 Turbidity vs. Time, Tap Water at $30^{\circ} \mathrm{C}$, Re-dosed Sunscreen, Mechanical Filtration

The Manure/Odor treatment showed an increase in turbidity, relative to the other treatments, starting between $\mathrm{T}=2$ Days and $\mathrm{T}=3$ Days. Premix and Thai rice bran treatments showed the lowest turbidities following the second dose of sunscreen, but apparently bacteria native to the Premix continued to grow, causing an increase in turbidity after $\mathrm{T}=5$ Days. Thai rice bran initially performed similarly to Premix, but Thai rice bran has not been fermented in the presence bacterial starter cultures, so it did not show the same increase in turbidity shown by Premix.

\subsubsection{Experiment I-7 Effects of BiOWiSH Products on Re-Dosed Turbidity}

Experiment I-7 investigated the effects of various BiOWiSH products, listed in Table 4-1, on re-dosed turbidity in the form of sunscreen. 
Table 4-1 Experiment I-7 List of Treatments

\begin{tabular}{ll}
\hline Tank & Treatment \\
\hline 1 & Fruit Wash \\
2 & Premix \\
3 & AP 001 \\
4 & AP 002 \\
5 & AP 003 \\
6 & Thai Rice Bran \\
7 & Irradiated Thai Bran \\
\hline
\end{tabular}

The greatest reductions in turbidity throughout the experiment were seen by Premix (Figure 4-7). No improved reduction of turbidity was seen over time between the solid substrate product, Premix, and the soluble diluent product, Fruit Wash.

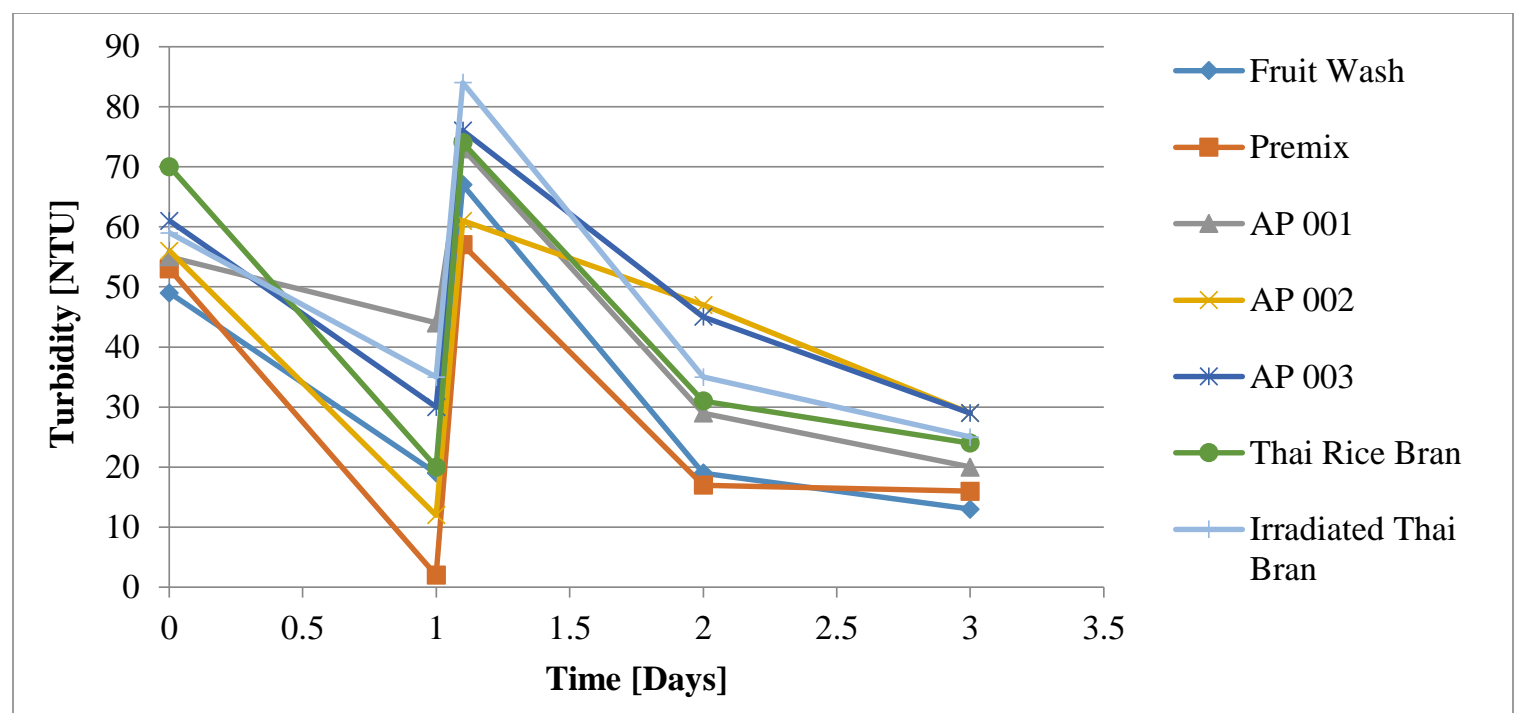

Figure 4-7: Experiment I-7 Turbidity vs. Time, Tap Water at $30^{\circ} \mathrm{C}$, Re-dosed Sunscreen, Mechanical Filtration

After the first dose of sunscreen, Thai rice bran reduced turbidity by $71 \%$, whereas Irradiated Thai rice bran reduced turbidity by $40 \%$. This difference is probably not due to the native biology present in Thai rice bran, as no other experiments have shown significant 
differences between biological treatments and abiotic treatments in the first 24 hours. The differences in clarification could be due to preexisting differences between the two batches of Thai rice bran, prior to irradiation.

The products AP 001, AP 002, and AP 003 displayed very high turbidity relative to Premix and Fruit Wash, due to particulate matter remaining in suspension. These products were not used in subsequent experiments.

\subsubsection{Experiment I-8 Effects of Thai BiOWiSH Products on Re-Dosed Turbidity}

Experiment I-8 investigated different Thai products relative to a control tank, including Premix, Thai FOG, and Irradiated Thai FOG. The control treatment was run to confirm the effects of mechanical filtration on sunscreen-induced turbidity without additives. Treatments were chlorinated daily to at least $3 \mathrm{mg} / \mathrm{L}$ of total chlorine.

For the first two doses of sunscreen, each product out-performed the control in terms of clarification, as shown in Figure 4-8. After the third dose of sunscreen, the best-performing treatment was the control; a trend which continued through to the termination of the experiment. As shown in Figure 4-8, the control tank consistently showed lower turbidity than the averages of the treatments after $\mathrm{T}=2.1$ Days. 




Figure 4-8: Experiment I-8 Averaged Turbidity vs. Time, Thai Products in Duplicate, Tap Water at $30^{\circ} \mathrm{C}$, Re-dosed Sunscreen, Mechanical Filtration

The early removal of turbidity by all products confirms previous findings that solid substrate is able to assist in filtration or adsorption of sunscreen, without the assistance of bacteria. As time progressed and more sunscreen was added to each system, results for the treatments suggested that the products added turbidity to the water. The similar results for the various treatments suggest that effects on turbidity were independent of both the bacteria contained in the products and the post-fermentation additives present in Thai FOG and Irradiated Thai FOG.

The long-term results of this experiment, from $\mathrm{T}=3$ Days until the termination of the experiment, coincide with those of Experiment I-3, in which the control consistently showed lower turbidity than treatments containing solid substrate after two doses of 
sunscreen. In the short term, the control treatment showed less reduction than solid substrate materials.

There is a high chance that tanks received cross-contamination from each other, considering the length of the experiment and the fact that aquaria were set up side-by-side with open surfaces and filters that splashed when water levels ran low. Additionally, the tanks were dosed with chlorine levels that are low, relative to those needed for complete bacterial inactivation.

It is likely that the solid substrate materials are growing microbes and the turbidity created by the production of bacterial cells masks any biodegradation of sunscreen. The control tank showed improved turbidity reduction over time, relative to the other treatments.

At the end of the experiment, samples were collected and plated for bacterial quantification and colony morphology analysis (see Experiment III-2). Improper plating methods led to contamination and inconclusive results. Solid substrate was also collected from the filters of Premix 1 and Thai FOG 1 to be imaged with Scanning Electron Microscopy.

Products were imaged using SEM before and after use in this experiment. Images were captured between 400x and 20,000x magnification. Figures 4-9 and 4-10 provide an overview of the differences between the appearances of the two substrates before and after use. Additional SEM images can be found in Appendix D. Prior to use, Thai FOG showed surface structure containing many rounded and jagged particles (Figure 4-9, Left). The 
quantity and size of these particles is similar throughout the field of view, indicating homogeneity of surface structure within the immediate area on the sample. After use in the experiment, Thai FOG showed less distinct surface structure (Figure 4-9, Right). Filamentous material can be seen attached to both the flat and the jagged portions of the sample, which may be indicative of sunscreen adsorbing to surfaces of the particles. The Premix material showed a similar coated-looking surface structure, relative to its starting appearance (Figure 4-10). The electron microscopy provides more evidence that adsorption of sunscreen to the solid substrate is occurring.
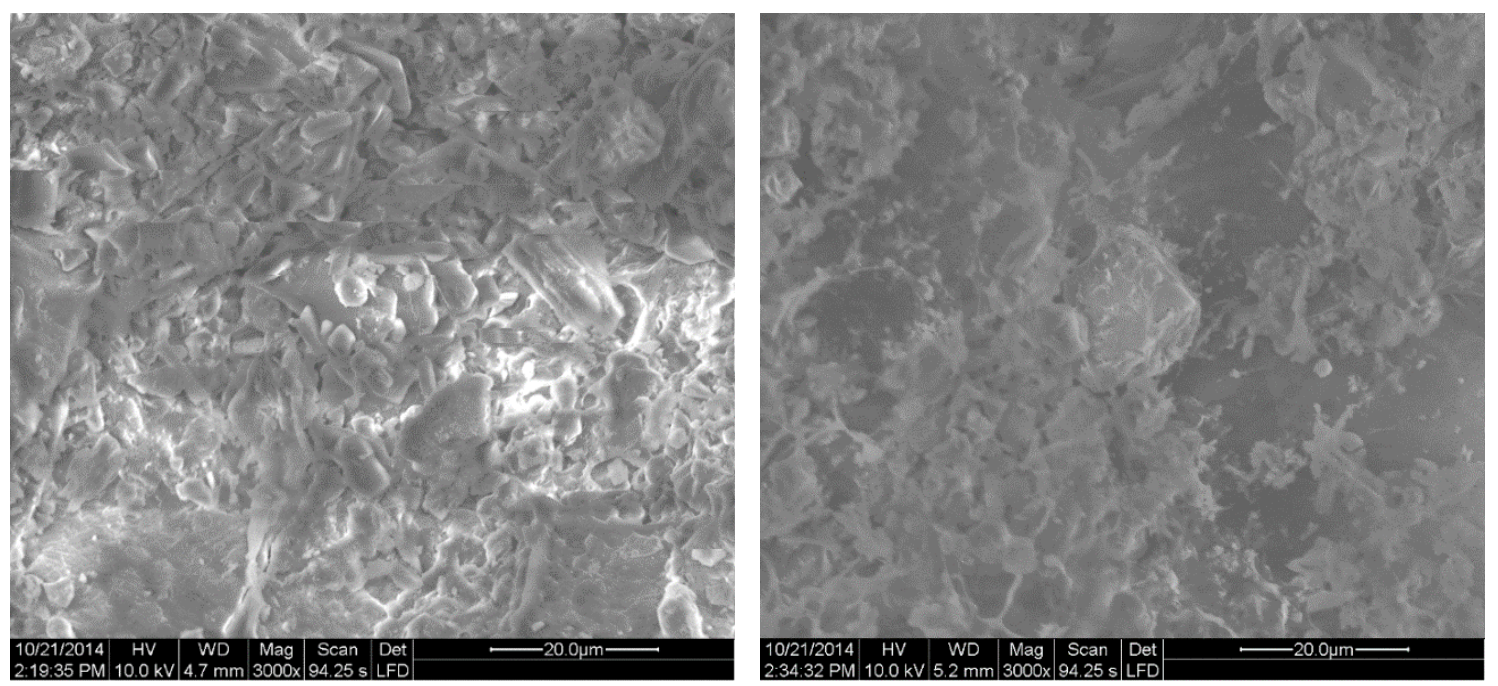

Figure 4-9: Thai FOG New (Left) and Used (Right) 3000x Magnification 

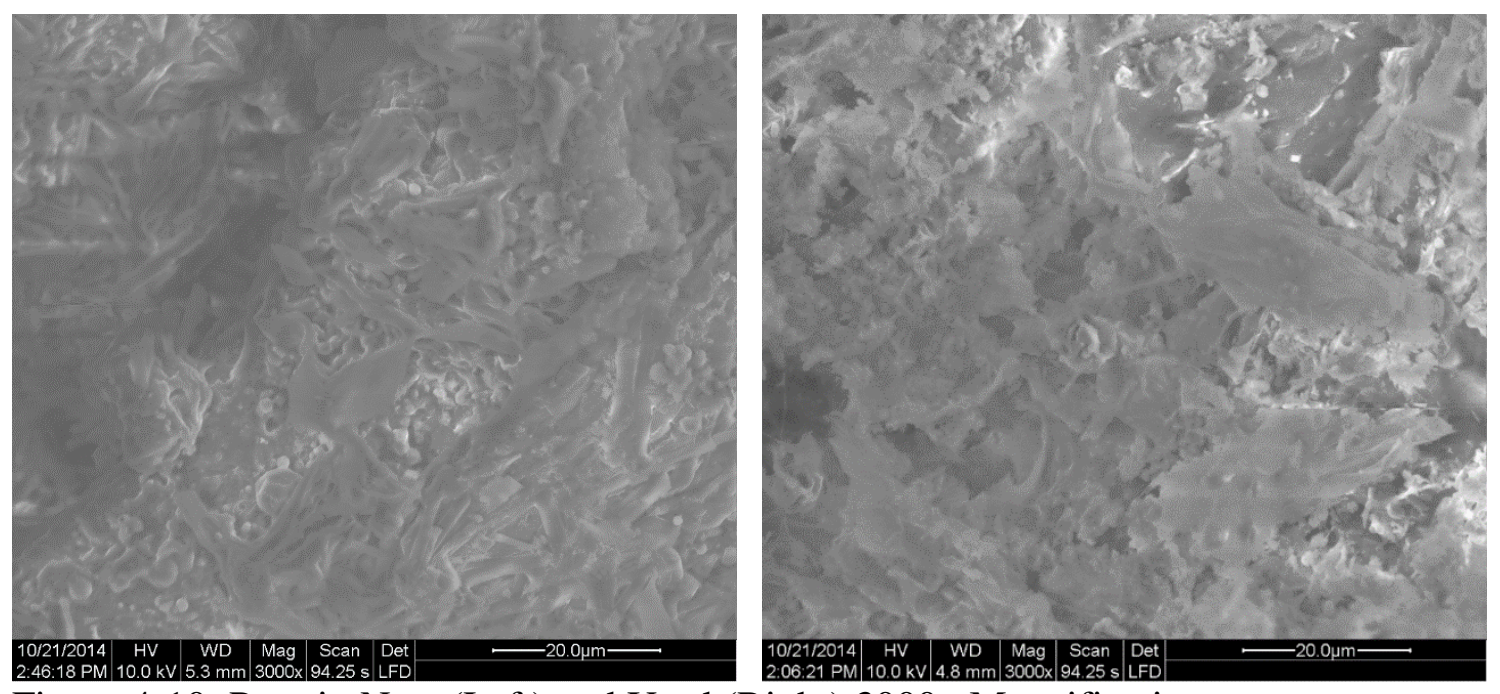

Figure 4-10: Premix New (Left) and Used (Right) 3000x Magnification

\subsubsection{Experiment I-9 Effects of Vegetative Bacterial Cultures on Turbidity}

Experiment I-9 was developed to investigate the effects of the biological components of BiOWiSH Cyanuric Acid Reducer (CAR) on turbidity with repeated dosing of sunscreen. Treatments were carried out in chlorinated and unchlorinated environments both with and without CYA. Additionally, one treatment was inoculated with a culture of the microflora collected from a spent swimming pool filter.

During incubation of the pool filter and manufactured bacterial cultures, intense gas production and turbidity increases were observed in all cases. This indicates successful activation and proliferation of the microbes.

The most effective and consistent treatment in reducing turbidity was the "Filter Media + CYA" control, as shown in Figure 4-11. This treatment was not dosed with sunscreen at $\mathrm{T}=0$, but it was included in all subsequent re-doses. Its efficacy at removing sunscreen from 
solution relative to other treatments is attributed to the assumed high biodiversity encountered on the swimming pool filter media. Highly diverse microbial populations will utilize multiple metabolic pathways and will use nutrients more quickly and effectively.

After T=7.1 Days, both of the non-chlorinated treatments which received sunscreen, "CAR + CYA" and "Filter Media + CYA", displayed the greatest reduction in turbidity. This could be attributed to microbial inhibition in chlorinated environments, which could result in slower rates of growth and thus fewer suspended bacteria to contribute to turbidity (Camper and McFeters 1979).

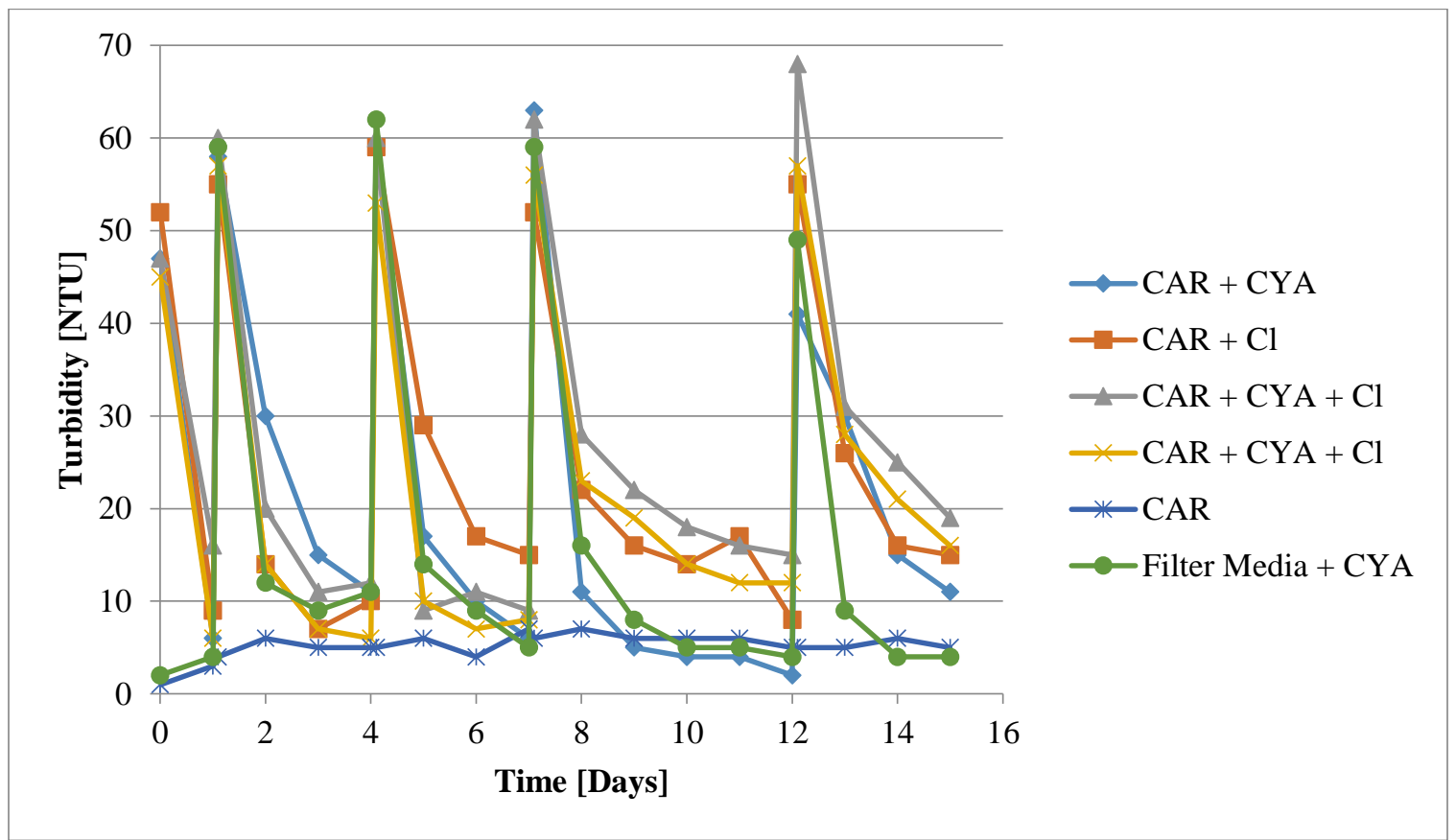

Figure 4-11: Experiment I-9 Turbidity vs. Time, Tap Water at $30^{\circ} \mathrm{C}$, Re-dosed Sunscreen, Mechanical Filtration, with and without CYA

As shown in Figure 4-11, the "CAR + CYA" treatment showed less turbidity removal than other treatments during the re-doses at $\mathrm{T}=1.1$ and $\mathrm{T}=12.1$ Days. At these time-points, the 
system was accidentally chlorinated by experimenters. The decreased response to turbidity was not expected, because each other chlorinated treatment showed steep reduction in turbidity at $\mathrm{T}=1.1$ and $\mathrm{T}=12.1$ Days.

Samples were periodically collected from each tank and analyzed with HPLC to track any changes in CYA concentration over time. Each tank containing CYA showed an increase in concentration between $\mathrm{T}=0$ and $\mathrm{T}=2$ Days (Figure 4-11). This is attributed to the stock solutions of CYA not being fully dissolved when dosed to each aquarium and the resulting continued dissolution of CYA. Due to the drift in CYA can be seen in Figure 4-12, no conclusions were made regarding the degradation or adsorption of CYA.

Two data-points (Tank 2, T=3 Days; and Tank 5, T=5 Days) were omitted from Figure 412, due to contamination in sampling. 


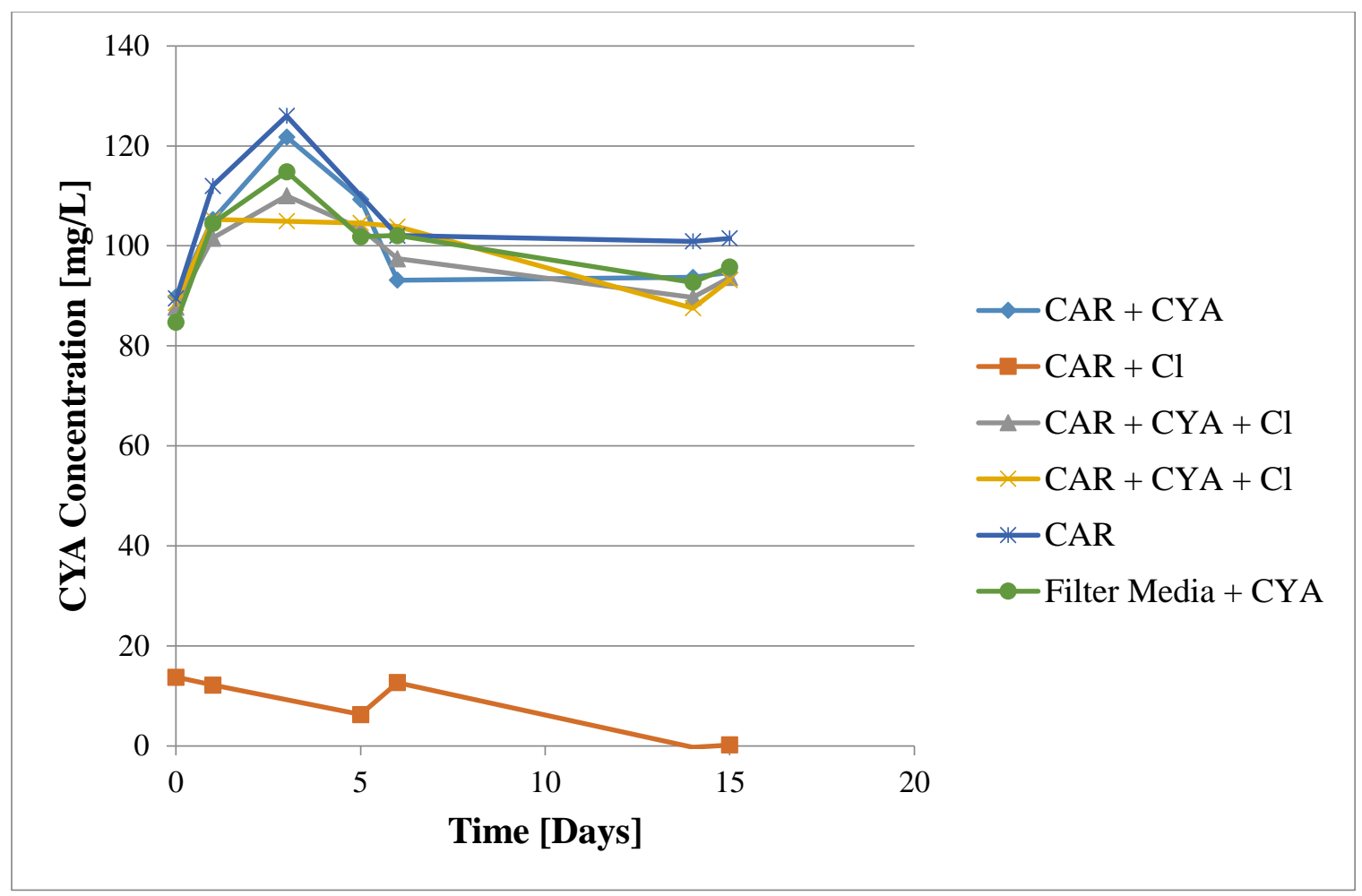

Figure 4-12: Experiment I-9 CYA Concentration vs. Time, Tap Water at $30^{\circ} \mathrm{C}$, No CYA in Tank 2, Mechanical Filtration

Total Chlorine residuals were measured between 0.2 to $0.6 \mathrm{mg} / \mathrm{L}$ after the addition of CYA. Baseline TC was measured at $0.2 \mathrm{mg} / \mathrm{L}$ in the treatment without CYA, so it was determined that the CYA did not contribute significantly to the residual chlorine levels. This is to be expected, because CYA is mainly attributed to protecting chlorine from UV degradation. This experiment was run in a laboratory without windows, so UV radiation from the Sun was not a factor in chlorine reduction. All decreases in chlorine were likely from interaction with oxygen in the atmosphere or with microbes and sunscreen within the aquaria. Subsequent experiments were not dosed with CYA as a means of maintaining chlorine residuals. 


\subsubsection{Turbidity Reduction for All Experiments at $T=1$ and $T=3$ Days}

Initial turbidity reduction data were compiled to show the relative effects of each product at $\mathrm{T}=1$ Day in Figure 4-13. Early data points can be compared, because each experiment received the same initial dose of sunscreen. The only experiment excluded from this compilation is $\mathrm{I}-4$ because $\mathrm{T}=0$ data were not available.

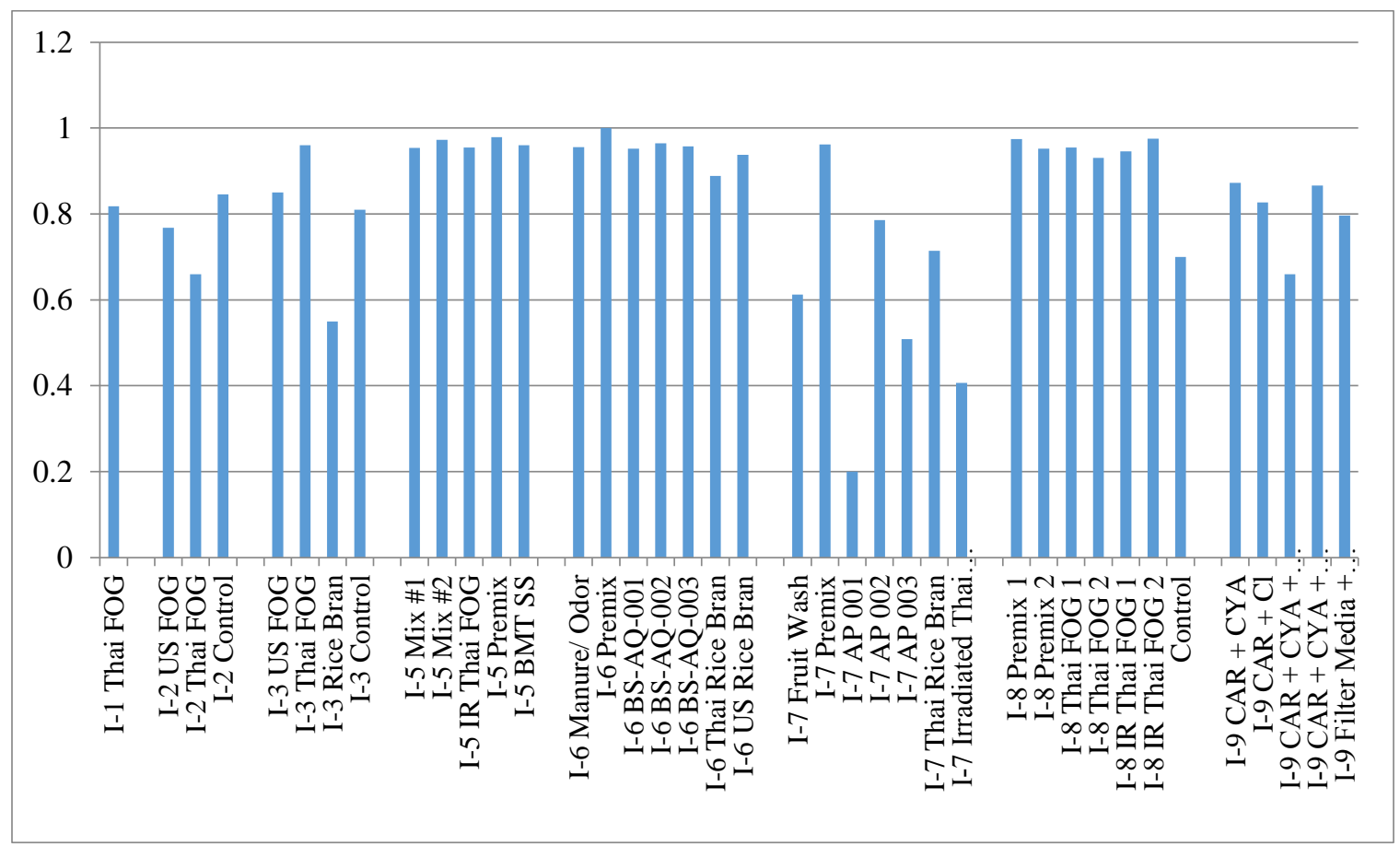

Figure 4-13: Compiled Percent Reduction in Turbidity Across Experiments, One Day after $1^{\text {st }}$ Sunscreen Dose, Mechanical Filtration

Figure 4-13, above, shows that each control tank exhibited at least $70 \%$ removal of turbidity in the first day. When the effects of "Irradiated Thai FOG" treatments are compiled and compared to those of the control treatments, the additive effect of solid substrate on clarification can be observed. The average 1-Day percent removal of turbidity by control treatments is $79 \%$, whereas the average 1-Day clarification by solid substrate products is $86 \%$. Excluding the prototype products AP 001, AP002, and AP003, the 
average 1-Day turbidity reduction increases to $90 \%$. It can be concluded that the solid substrate of BiOWiSH products provides an additional 11\% 1-Day reduction of turbidity over pure mechanical filtration.

The average initial reduction of turbidity by soluble diluent products is $79 \%$. This is identical to the average percent reduction by pure mechanical filtration, indicating that products without a solid substrate do not enhance initial turbidity reduction.

For each experiment including a re-dose, the time-point one day past the second dose of sunscreen was also compiled to compare percent reduction of turbidity by each product tested. The experiments which are included in this comparison are I-3, I-5, I-6, I-7, and I9 , because they were dosed sunscreen on consecutive days at $\mathrm{T}=0$ and $\mathrm{T}=1$. 


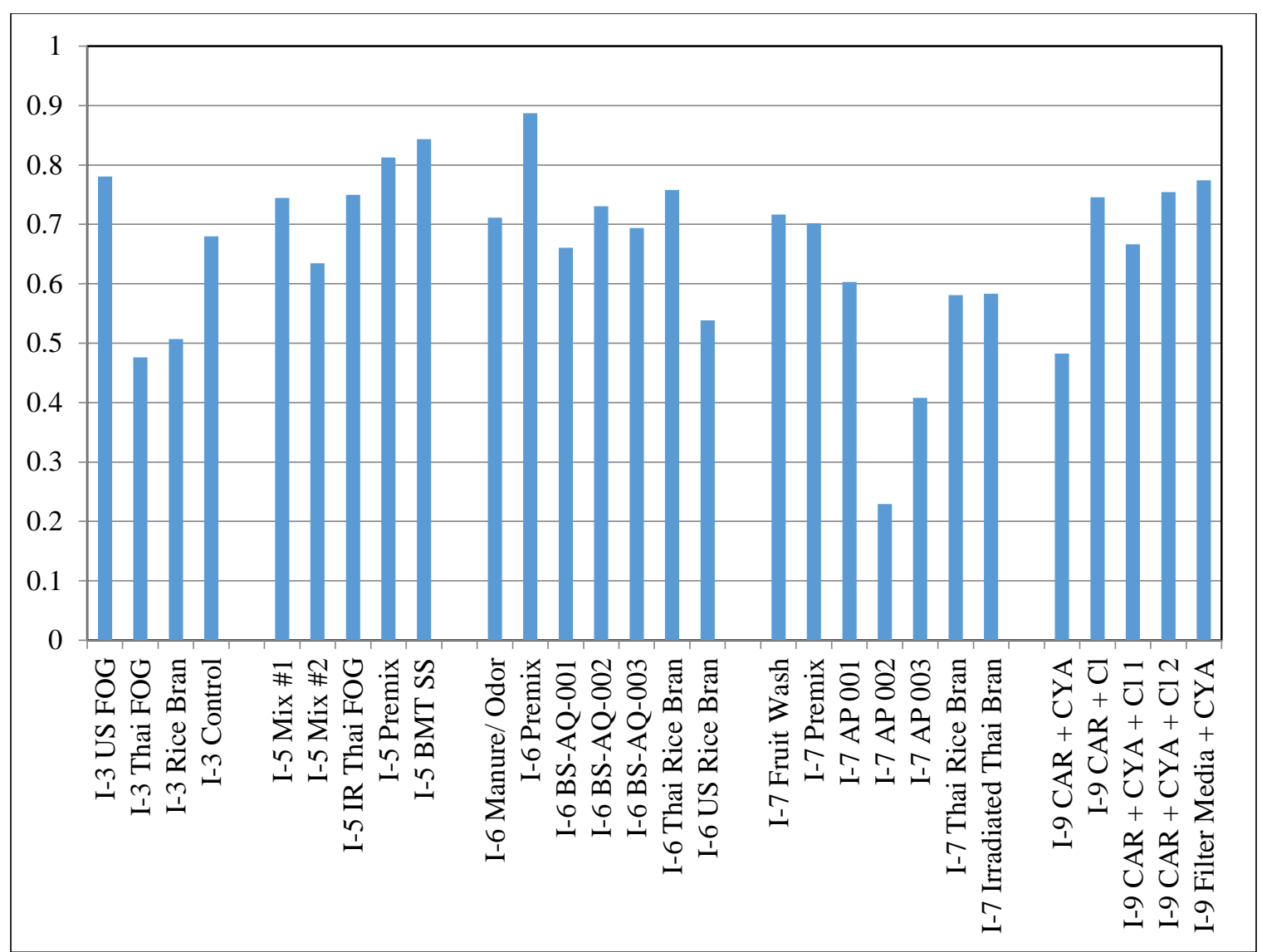

Figure 4-14: Compiled Percent Reduction of Turbidity, One Day after $2^{\text {nd }}$ Sunscreen Dose, Tap Water at $30^{\circ} \mathrm{C}$, Mechanical Filtration

The mechanism by which this added reduction occurs is probably mechanical, through adsorption to the substrate or enhanced filtration due to reduced filter pore size. As shown in the SEM images from Experiment I-8 (Figure 4-9 and Figure 4-10) it is apparent that adsorption plays a role in the mechanical removal of sunscreen by the solid substrate. Experiments I-3, I-4, and I-8 showed that solid substrate products did not provide additional clarification after the second dose of sunscreen, possibly due to bacterial growth contributing to turbidity. Adsorption is likely the driving mechanism of additional turbidity removal provided by the solid substrate of $\mathrm{BiOWiSH}$ products. 


\subsection{Task II - Efficacy of BiOWiSH for Clarifying Oils from Swimming Pools}

\subsubsection{Experiment II-1 Water Clarification by Thai FOG, No Mechanical Filtration}

Experiment II-1 was an investigation of water clarification by Thai FOG used to investigate the product's ability to grow in aqueous solution and remove turbidity induced by sunscreen without mechanical filtration. The colorimeter was not available at the time of this experiment, so UV absorbance was measured instead of turbidity. No change was seen in UV absorbance of the Thai FOG + Sunscreen treatment, relative to the Sunscreen treatment without Thai FOG. Additionally, biomass production interfered with optical density readings at $470 \mathrm{~nm}$.

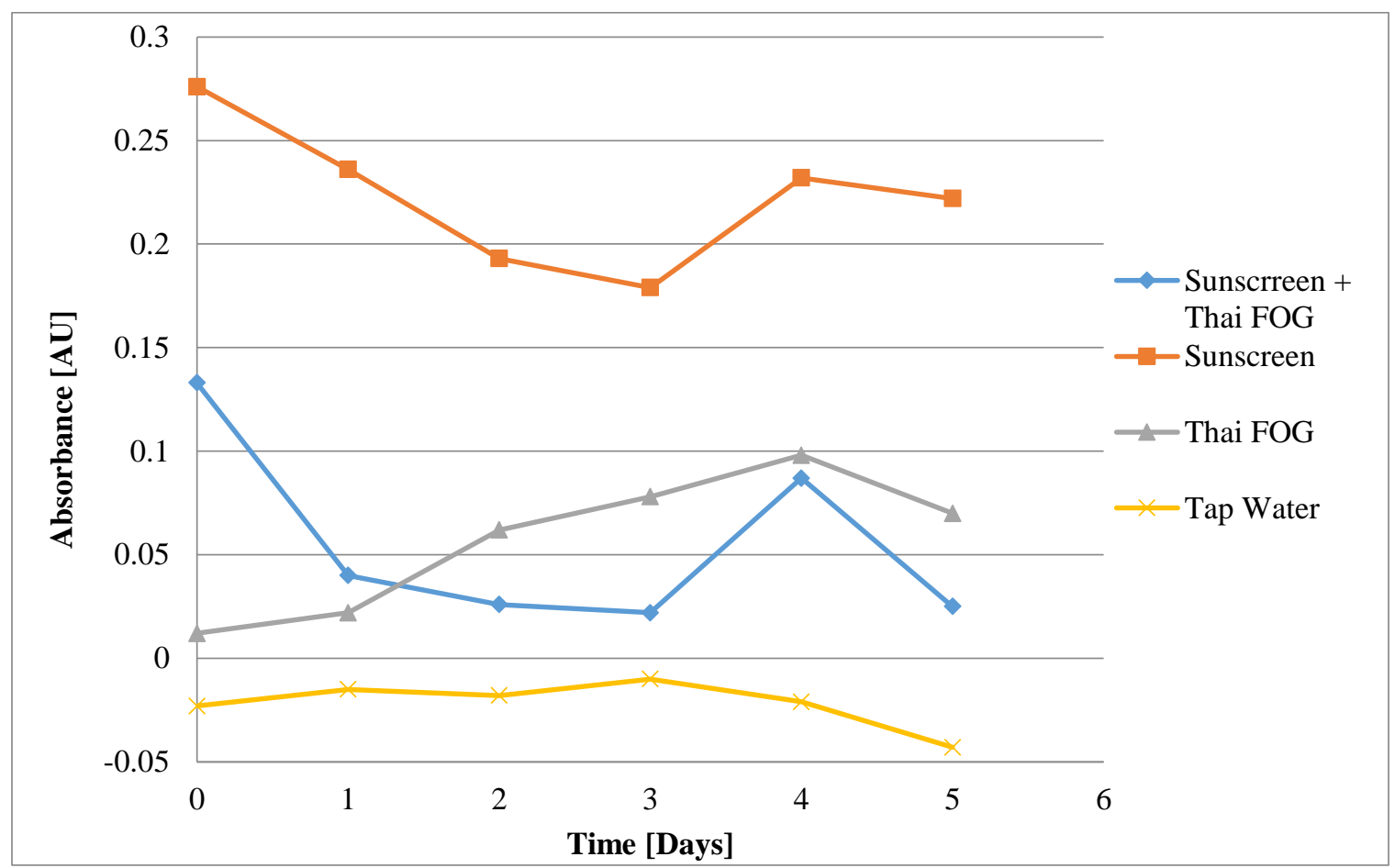

Figure 4-15: Experiment II-1 Absorbance vs. Time at $470 \mathrm{~nm}$, Tap Water at $30^{\circ} \mathrm{C}$, Single Dose of Sunscreen, No Mechanical Filtration 
Sunscreen dosed to Tank 1 did not completely dissolve, leading to a much lower starting turbidity than the other tanks. To prevent this issue, Tanks 2 and 3 were dosed sunscreen that had been dissolved into a small volume $(10-50 \mathrm{~mL})$ of the respective tank's water within a plastic weigh boat. The aqueous sunscreen mixture showed much greater level of dissolution with the tanks. This method was adopted for all subsequent sunscreen additions.

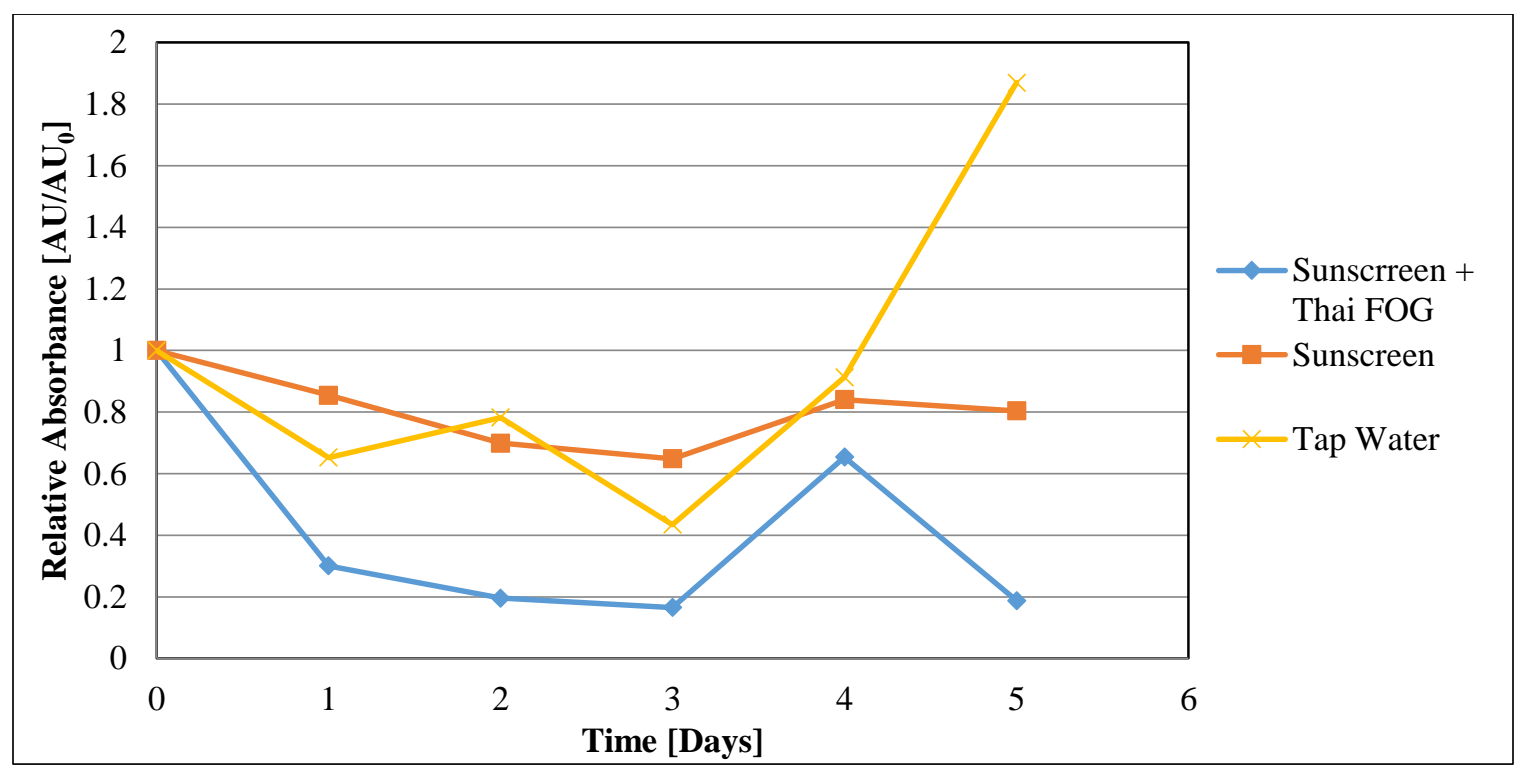

Figure 4-16: Experiment II-1 Normalized Absorbance vs. Time at $470 \mathrm{~nm}$, Excluding Thai FOG, Tap Water at $30^{\circ} \mathrm{C}$, Single Dose of Sunscreen, No Mechanical Filtration

Thai FOG showed a change in color and an increase in turbidity. The increased turbidity can probably be attributed to suspended particles in the form of microbial growth. The suspension of substrate was ruled out as a contributor to turbidity, because tanks were not agitated through the duration of the experiment.

An important finding from Experiment II-1 is that the Thai FOG product affects turbidity within the first 24 hours of inoculation. Thai FOG was able to reduce turbidity from sunscreen relative to a treatment of sunscreen without inoculum within the first 24 hours. 
This result suggests that either the biology or the substrate of Thai FOG causes reduction of turbidity.

\subsubsection{Experiment II-1.1 Absorbance Calibration Curve for Sunscreen}

A calibration curve was developed for sunscreen in tap water at $520 \mathrm{~nm}$ (Figure 4-17). A baseline absorbance of 0.09 AU was observed.

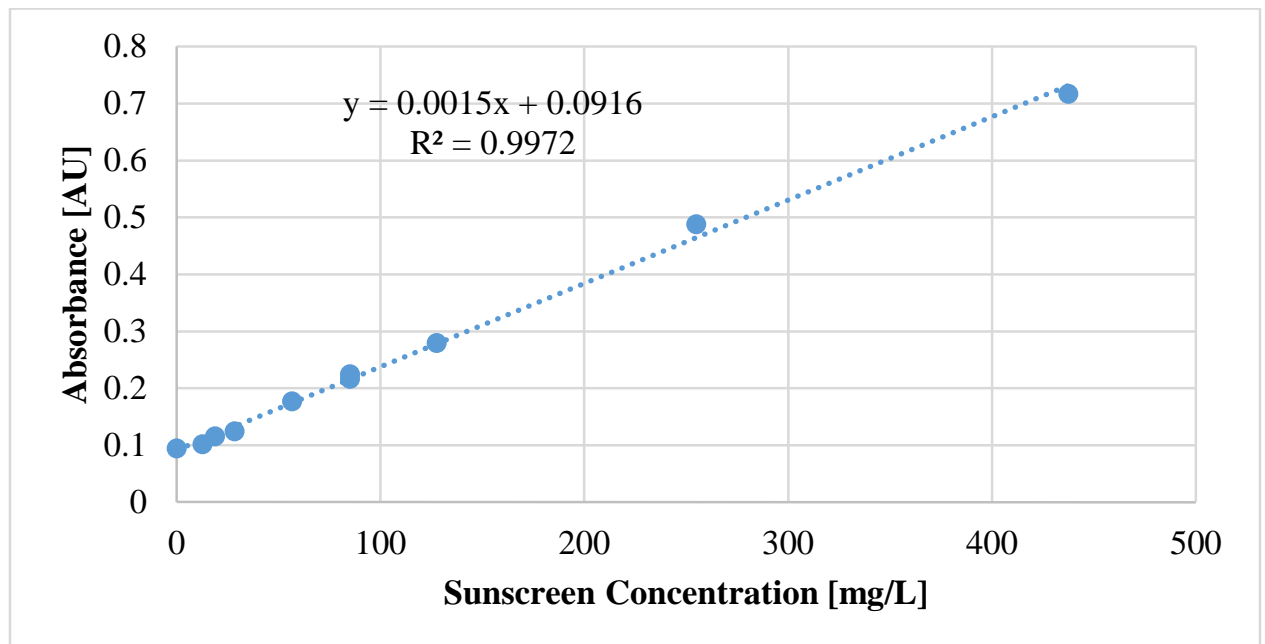

Figure 4-17: Experiment II-1.1 Absorbance vs. Concentration of Sunscreen at $520 \mathrm{~nm}$

Due to the observed interference of BiOWiSH products and bacterial cells on optical density at $520 \mathrm{~nm}$, this calibration curve can only be used to determine concentrations of abiotic trials. Turbidity was determined to be a more valuable indicator of water clarity than absorbance of pure sunscreen. Therefore, this calibration curve was not utilized in any analyses. 


\subsubsection{Experiment II-1.2 Investigation of Growth Media Compatibility with Chlorine}

In order to determine which medium would be best to use in chlorinated experiments, three growth media were tested for compatibility with chlorine alongside tap water. Total chlorine as $\mathrm{Cl}_{2}$ readings were taken over time. The 20-20-20 Fertilizer and MRS broth were ruled out as viable growth media, due to rapid scouring of chlorine. Based on 72-hour chlorine residual, tap water was the least interfering growth solution (Figure 4-18). Minimal media was also determined to be a suitable growth solution in chlorinated environments.



Figure 4-18: Experiment II-1.2 Chlorine Concentration vs. Time in Varying Growth Media, DI Water at $20^{\circ} \mathrm{C}$

Hypochlorite is a strong oxidizing agent which readily reacts with organic and nitrogenous material. The fertilizer and MRS broth both have high carbon and nitrogen content, which 
interferes with residual hypochlorite. It would be disadvantageous to utilize the fertilizer or MRS broth in chlorinated experiments.

Minimal media showed less interaction with chlorine than fertilizer or MRS broth; however it still caused a substantial decrease in chlorine relative to tap water. Tap water had an original chlorine content of $0.66 \mathrm{mg} / \mathrm{L}$, indicating no chlorine demand and contributing to the higher residual over time. The use of municipal water closely mimics the method of pool filling for many domestic and professional pool operators.

BiOWiSH products contain sufficient glucose and substrate to support bacterial growth when added to tap water. Additional growth media may be advantageous but will not be required in subsequent experiments.

\subsubsection{Experiment II-2 Chlorine Decay with BiOWiSH Products}

A variety of products were placed in chlorinated environments to determine their effects on chlorine residuals. Total chlorine was measured at $\mathrm{T}=0,4.5,25$ hours. Many treatments showed a decrease in chlorine concentration at $\mathrm{T}=0$ after initial dosing of $3-4 \mathrm{mg} / \mathrm{L} \mathrm{Cl}_{2}$. At $\mathrm{T}=4.5$ Hours, the only treatments which had not decreased below $0.5 \mathrm{mg} / \mathrm{L}$ were tap water and minimal growth media. At $\mathrm{T}=25$ Hours, all chlorine concentrations had decreased to below $0.5 \mathrm{mg} / \mathrm{L}$. 
Every treatment reduced total chlorine concentration by a greater amount than tap water, because hypochlorite reacts with and oxidizes organic material. Minimal media showed the lowest drop in chlorine relative to tap water.

Increases in total chlorine concentrations were observed in several treatments, including those with sunscreen. These increases are attributed to noise in measurements from incomplete cleaning of the sample cell used. Samples containing sunscreen were noted to leave a residue on the interior of the sample cell. Subsequent experiments incorporated a light-duty tissue to wipe away sunscreen residue.

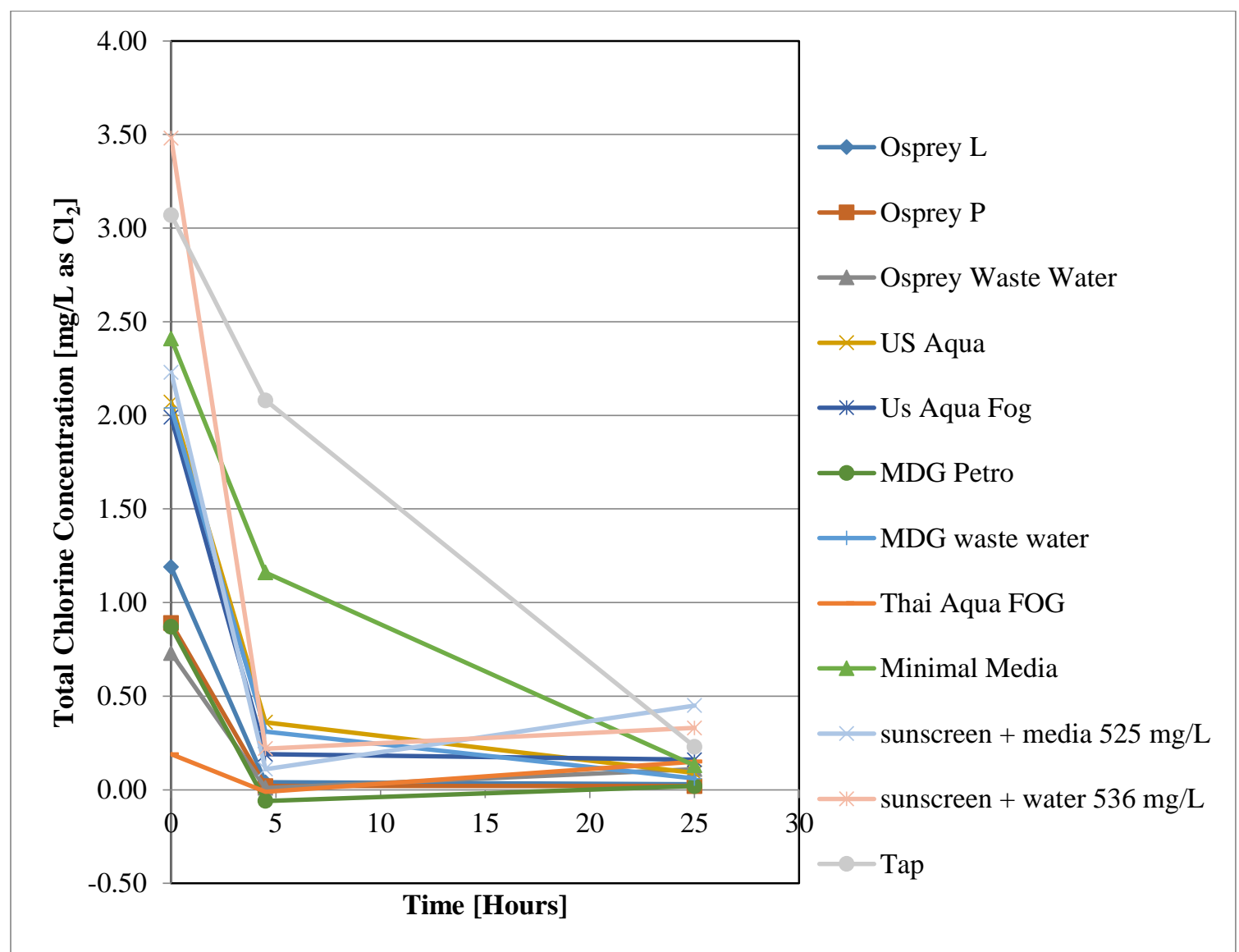

Figure 4-19: Experiment II-2 Chlorine Concentration vs. Time, DI Water at $20^{\circ} \mathrm{C}$, Covered with Gas-Permeable Membrane, Single dose of Chlorine 
The sharp decrease in chlorine for all treatments indicates that future experiments need to be chlorinated daily if residual chlorine is to be maintained at a certain level. Additionally, trials containing BiOWiSH products may require an initial dose of chlorine that is greater than subsequent daily dosing levels. Further investigation is necessary to determine daily doses of chlorine required for consistent residual levels.

\subsubsection{Experiment II-3 Turbidity Reduction by Various BiOWiSH Products without Mechanical Filtration}

Ten aquaria, each containing $250 \mathrm{mg} / \mathrm{L}$ of sunscreen and $125 \mathrm{mg} / \mathrm{L}$ of the BiOWiSH product listed below in Table 4-2, were maintained at $30^{\circ} \mathrm{C}$ for 5 days.

Table 4-2: Experiment II-3 Aquaria Contents

\begin{tabular}{ll}
\hline Tank No. & Product \\
\hline 1 & Osprey- Liquid \\
2 & Osprey- Powder \\
3 & Osprey- Wastewater Treatment \\
4 & MDG Petro \\
5 & MDG Wastewater \\
6 & BMT WW \\
7 & Thai FOG \\
8 & BUS FOG \\
9 & Fruit Wash \\
10 & Control - DI Water \\
\hline
\end{tabular}


Each tank, including the control, showed a decrease in turbidity over time (Figure 4-20). The greatest turbidity drop relative to starting turbidity, $70 \%$, was observed for the Thai FOG product, which greatly outperformed all other treatments. The control displayed a $37 \%$ reduction in turbidity. This was probably due to settling of material and the formation of an oily film on the surface of the tank. Osprey Liquid and Osprey WWT showed a smaller drop in turbidity than the control. BMT WW showed more clarification than the control early in the trial, but at $\mathrm{T}=114$ hours, turbidity of BMT WW rose above that of the control. The $\mathrm{T}=68$ Hours time-point showed a spike in turbidity from the Osprey Wastewater Treatment due to accidental agitation of the settled material at the bottom of the tank.

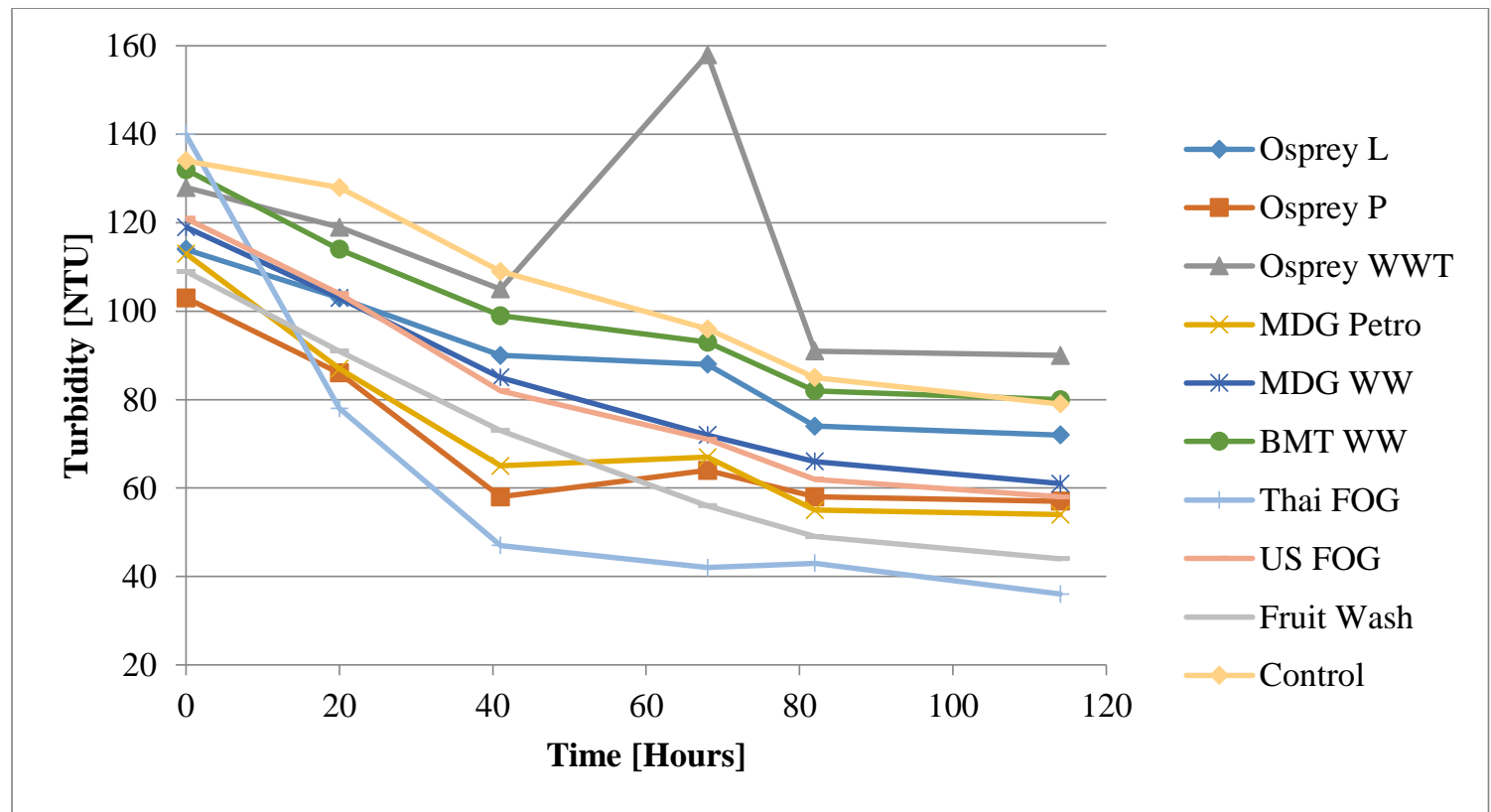

Figure 4-20: Experiment II-3 Turbidity vs. Time, Tap Water at $30^{\circ} \mathrm{C}$, Single Dose of 250 $\mathrm{mg} / \mathrm{L}$ Sunscreen, No Mechanical Filtration

The best-performing treatment was Thai FOG, followed by Fruit Wash, MDG Petro, and US FOG. Thai FOG is being phased out by BiOWiSH. As a result, it will not be considered 103 
as a viable product for clarification of recreational pool waters. Instead, it was used as a positive control to which the performance of other products can be compared.

Every treatment, including control, showed a decrease in turbidity. This can be attributed to the hydrophobic nature of many components of sunscreen and its natural tendency to settle out from solution. The formation of an oily film on the surface of many tanks, coupled with large deposits on the bottom of each tank, indicate that settling plays a large role in clarification.

Chlorine was dosed daily at 0.2 to $0.6 \mathrm{mg} / \mathrm{L}$ per tank, which is below the required $1.0 \mathrm{mg} / \mathrm{L}$ available hypochlorite found in Title 22 Standards (California Code of Regulations 2015). Since there is no retention agent to provide lasting chlorine residual, all chlorine readings were close to zero by the following day. Previous experiments showed that biomass interferes with turbidity readings if growth is not inhibited by constant chlorination. Therefore, in subsequent experiments, chlorine was dosed at higher concentrations to ensure that a suitable residual is retained overnight.

\subsubsection{Experiment II-4 Agitated vs. Un-Agitated Turbidity Reduction by BiOWiSH Products}

Replicate treatments of the best-performing treatments from Experiment II-3, Thai FOG and Fruit Wash, were tested in this experiment to provide confirmation of previous results. Additionally, different batches of BMT WW (BMT WW1 and BMT WW2) were compared to Thai FOG and an un-amended control. Duplication of treatments was deemed important 
due to potential heterogeneity of each product, the risk of contamination, and variability in day-to-day readings.

\begin{abstract}
Altering methods from Experiment II-3, daily turbidity readings were taken before and after settled material was agitated. This was intended to provide a direct comparison within treatments with and without settling. Measuring turbidity after agitation and re-suspension of settled material showed an increase in turbidity of the Thai FOG treatment and a small decrease in turbidity of other treatments (Figure 4-22). No trends in turbidity were observed for any treatment.
\end{abstract}

Table 4-3: Experiment II-4 Treatments, Duplicated

\begin{tabular}{ll}
\hline Tank & Treatment \\
\hline 1 & Control \\
2 & Thai FOG \\
3 & Fruit Wash II \\
4 & Fruit Wash II \\
5 & BMT WW1- I \\
6 & BMT WW1- II \\
7 & BMT WW2 - I \\
8 & BMT WW2- II \\
\hline
\end{tabular}




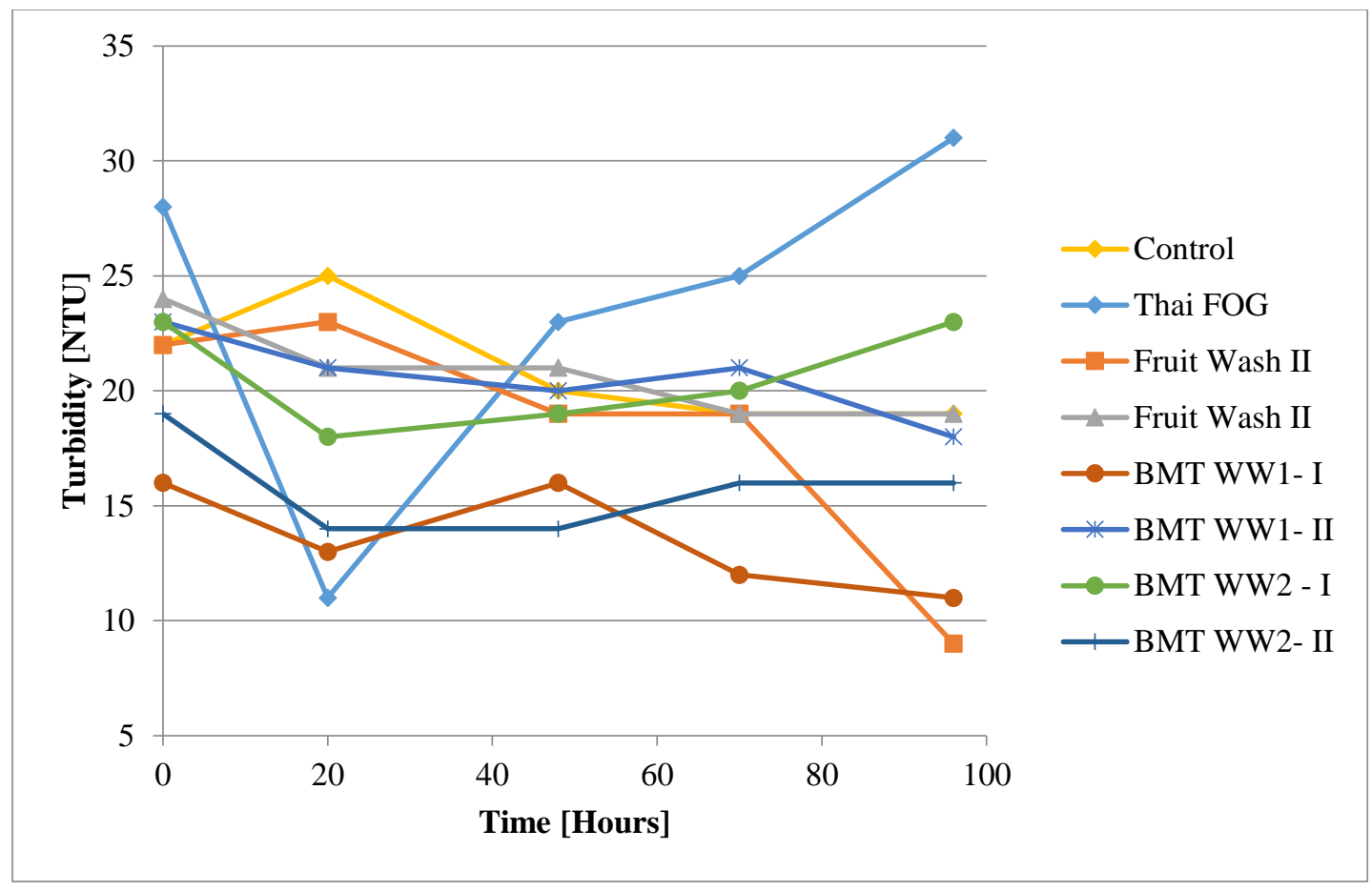

Figure 4-21: Experiment II-4 Turbidity vs. Time, Tap Water at $30^{\circ} \mathrm{C}$, Un-Agitated, Single Dose of Sunscreen, No Mechanical Filtration

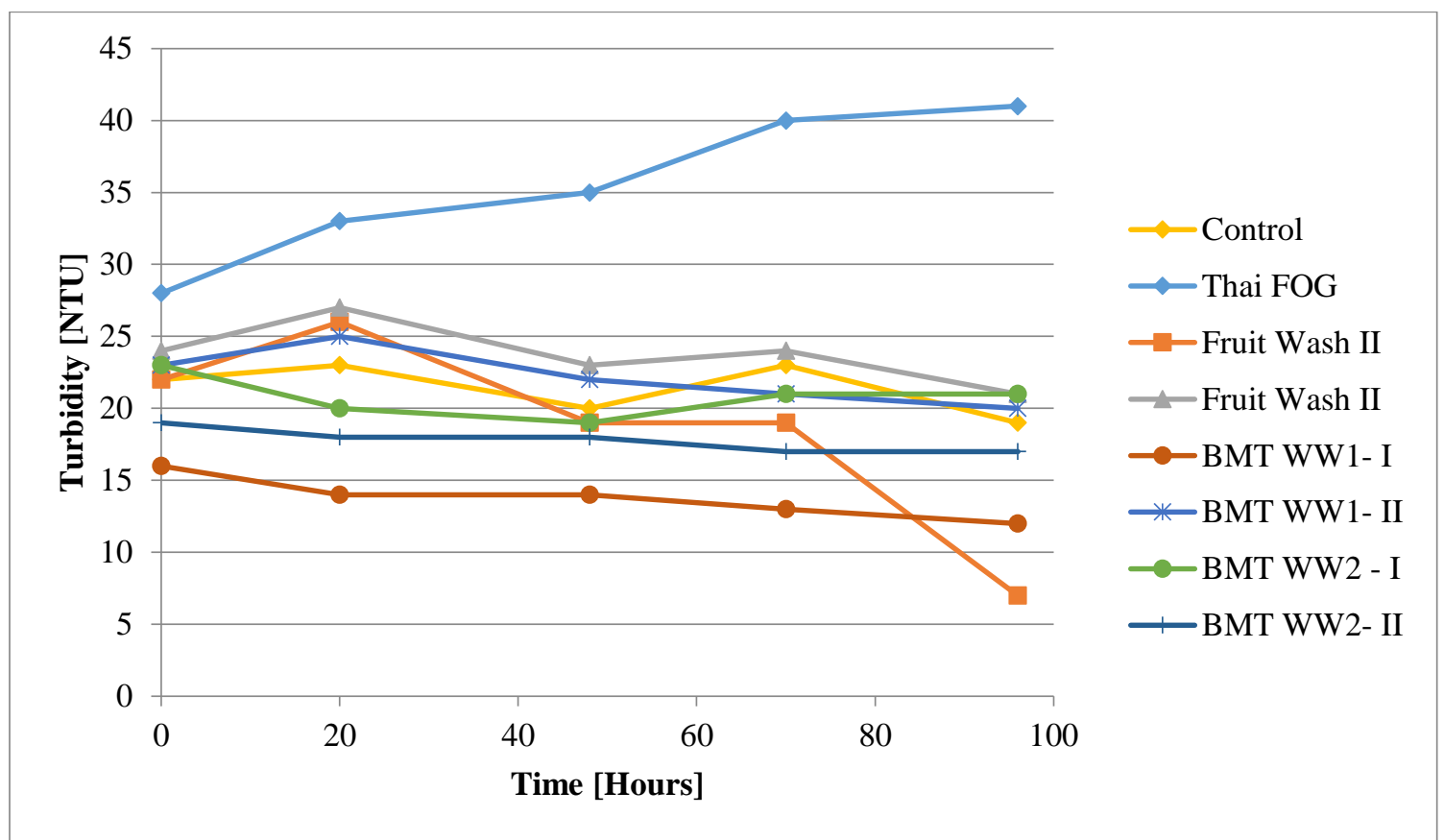

Figure 4-22: Experiment II-4 Turbidity vs. Time, Tap Water at $30^{\circ} \mathrm{C}$, Agitated, Single Dose of Sunscreen, No Mechanical Filtration 
Table 4-4 shows the turbidity difference between agitated and un-agitated treatments for each time-point. Positive values indicate an increase in turbidity with agitation. The data show that settling accounts for a larger portion of turbidity reduction early in the trial, at $\mathrm{T}=20$ hours. By $\mathrm{T}=70$ and $\mathrm{T}=96$ hours, agitation only contributes a small amount to turbidity of each treatment. Therefore, throughout the trial, material that can originally be suspended in solution is either removed or converted into material that does not re-suspend in solution. This, along with the slight downward trend in turbidity, may indicate that the biological components of $\mathrm{BiOWiSH}$ products are able to convert sunscreen into bacterial cells.

Table 4-4: Experiment II-4 Turbidity Change by Agitation

\begin{tabular}{llllll}
\hline & \multicolumn{5}{c}{ Change in Turbidity [NTU] } \\
\cline { 2 - 6 } Tank & $\begin{array}{l}\mathrm{T}=0 \\
\text { hours }\end{array}$ & $\begin{array}{l}\mathrm{T}=20 \\
\text { hours }\end{array}$ & $\begin{array}{l}\mathrm{T}=48 \\
\text { hours }\end{array}$ & $\begin{array}{l}\mathrm{T}=70 \\
\text { hours }\end{array}$ & $\begin{array}{l}\mathrm{T}=96 \\
\text { hours }\end{array}$ \\
\hline Control & 0 & -2 & 0 & 4 & 0 \\
Thai FOG & 0 & 22 & 12 & 15 & 10 \\
Fruit Wash II & 0 & 3 & 0 & 0 & -2 \\
Fruit Wash II & 0 & 6 & 2 & 5 & 2 \\
BMT WW1- I & 0 & 1 & -2 & 1 & 1 \\
BMT WW1- II & 0 & 4 & 2 & 0 & 2 \\
BMT WW2 - I & 0 & 2 & 0 & 1 & -2 \\
BMT WW2- II & 0 & 4 & 4 & 1 & 1 \\
\hline
\end{tabular}

During initial chlorination, of each tank was dosed to an expected residual of $2.66 \mathrm{mg} / \mathrm{L}$ as $\mathrm{Cl}_{2}$. Readings ranged from of 0.6 to $1.9 \mathrm{mg} / \mathrm{L}$ as $\mathrm{Cl}_{2}$ depending on the level of chlorine scouring displayed by each product. The following day, as tanks were re-dosed with chlorine, enough chlorine was added to reach a $2.0 \mathrm{mg} / \mathrm{L}$ minimum in each tank. 
The Thai FOG treatment, which displayed the lowest initial chlorine residual, exerts a high chlorine demand. Chlorine was dosed to an expected concentration of $3.5 \mathrm{mg} / \mathrm{L}$ as $\mathrm{Cl}_{2}$, but readings were consistently close to $1.8 \mathrm{mg} / \mathrm{L}$. The low chlorine levels may partially explain why Thai FOG showed a consistent increase in turbidity after the first day.

During turbidity sampling, it was noted that sunscreen builds up on the interior of the sample cell. A DI water rinse was employed between samples in this experiment. It was noted that loading the sample cell with DI water would read as high as 8 NTU, which accounted for between $19.5 \%$ and $114 \%$ of raw data turbidity readings. The sample cell cleaning method was modified to include $70 \%$ ethanol rinse and internal wipe with a lightduty tissue soaked in $70 \%$ ethanol, followed by a rinse with DI water.

\subsubsection{Experiment II-5 Turbidity Reduction by BiOWiSH Products}

Experiment II-5 was performed to investigate the effects on turbidity caused by the Lactic Mix product, BMT WW 1 and 2, pure spores of KLB, and KLB added to the BMT WW product. A positive control was run containing Thai FOG, and a negative control was run containing no inoculum. Due to time constraints, only four treatments were carried out past the T=50 hour time-point: Control, BMT KLB Mix I, BMT KLB Mix II, and Thai FOG.

Thai FOG showed the greatest level of clarification (87\%), even after starting with the highest turbidity. The BMT KLB mix treatments returned inconsistent results. One treatment showed a $19 \%$ reduction in turbidity, while the other reduced turbidity by $48 \%$. 




Figure 4-23: Experiment II-5 Turbidity vs. Time, Tap Water at $30^{\circ} \mathrm{C}$, Single Dose of Chlorine, Combined Products, No Mechanical Filtration

This experiment showed that KLB mixed with BMT WW does not provide significant reduction of turbidity caused by sunscreen, relative to a control treatment. The treatment of Thai FOG was the only solid substrate-mounted product in the experiment, and it significantly out-performed all other treatments. This is consistent with previous findings, suggesting that biological effects on turbidity are minimal, and that the main effects of BiOWiSH on turbidity are due to solid substrate interacting with the sunscreen.

\subsubsection{Experiment II-6 Effect of BiOWiSH Products on Turbidity with Dextrose}

Experiment II-6 was performed to investigate the effects of product growth on turbidity. The data showed no trends in turbidity change for any product, relative to a control over 5 days of incubation (Figures 4-24 and 4-25). In a chlorinated aerobic environment with 
dextrose as a carbon source, no product showed a consistent or significant change in turbidity.

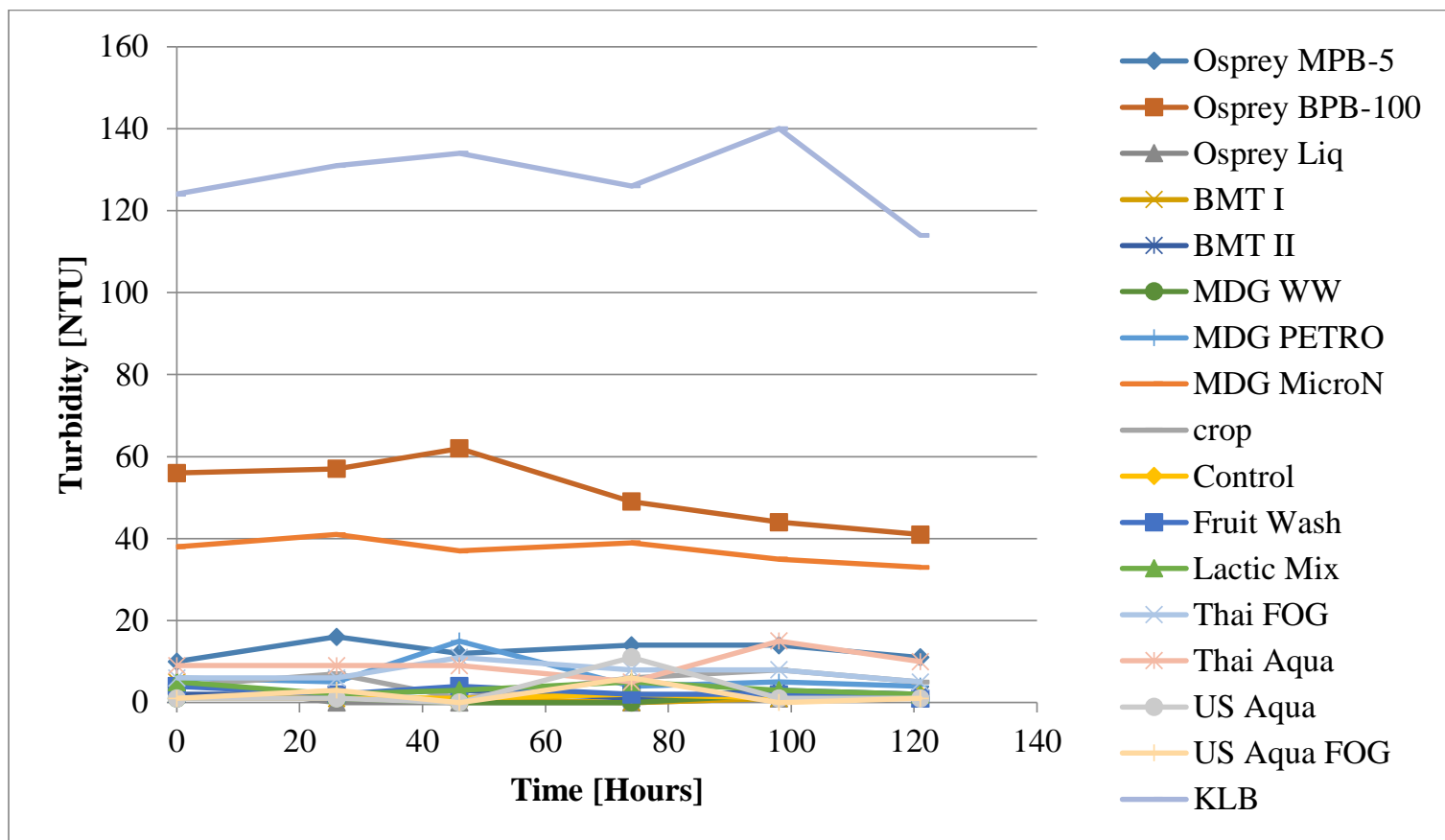

Figure 4-24: Experiment II-6 Turbidity vs. Time, DI Water and Dextrose at $20^{\circ} \mathrm{C}$, No Sunscreen, No Agitation 


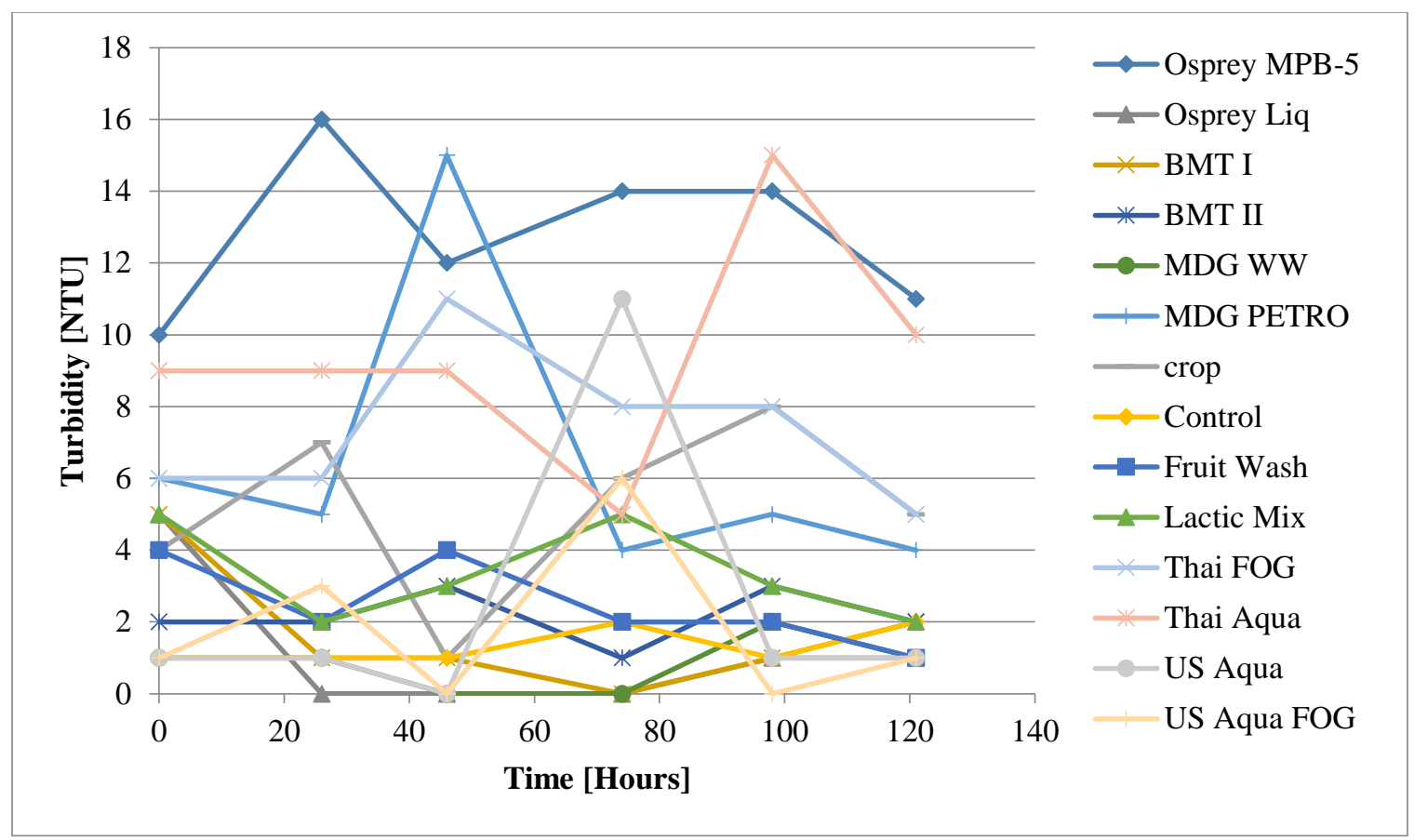

Figure 4-25: Experiment II-6 Turbidity vs. Time Excluding KLB, Osprey BPB-100, and MDG Micro-N, DI Water and Dextrose at $20^{\circ} \mathrm{C}$, No Sunscreen, No Agitation

The experiment was carried out in $500 \mathrm{~mL}$ shaker flasks with low buffering capacity for fluctuations in temperature and chlorination. Without the nutrients necessary for growth, it is likely that many of the bacterial cultures did not propagate.

Previously, Experiment II-4 showed that the Bacillus in Thai FOG can flourish using just the solid substrate that the microbes are mounted on. This growth was not seen in the presence of constant chlorination at 3-5 ppm TC. It was noted that in swimming pools, free chlorine concentrations are usually no higher than $1 \mathrm{mg} / \mathrm{L}$; therefore, this experiment was considered as a worst-case scenario for bacterial survival in chlorinated environments.

Samples from the US FOG, KLB, and Thai FOG treatments were plated for bacterial quantification and colony morphology investigation in Experiment III-1. 


\subsubsection{Experiment II-7 Effect of BiOWiSH Products on Turbidity with Sunscreen}

Experiment II-7 was performed identically to Experiment II-6, but the carbon source (200 $\mathrm{mg} / \mathrm{L}$ dextrose) was replaced with $200 \mathrm{mg} / \mathrm{L}$ sunscreen. Figure 4-5 shows an increase in turbidity over time for each flask, except the MDG Micro-N. The control showed one of the greatest increases in turbidity, relative to its starting value.

Table 4-5: Experiment II-7 List of Treatments

\begin{tabular}{ll}
\hline Flask & Label \\
\hline 1 & Control \\
2 & Osprey MPB-5 \\
3 & Osprey BPB-100 \\
4 & Osprey MPB-5 Liq \\
5 & BMT WW 1 \\
6 & BMT WW 2 \\
7 & MBWWT\#1 \\
8 & MDG Petro \\
9 & MDG Micro-N \\
10 & Crop \\
11 & Fruit Wash \\
12 & LCM \\
13 & Thai FOG \\
14 & Thai Aqua \\
15 & US Aqua \\
16 & US Aqua FOG \\
17 & KLB \\
\hline
\end{tabular}






Figure 4-26: Experiment II-7 Turbidity vs. Time, DI Water at $20^{\circ} \mathrm{C}$, Single Dose of Sunscreen, Aerobic

Each flask was agitated before sampling to ensure representative collection of samples from each treatment. Components of sunscreen typically separate from solution, but agitation prevented. The increase in turbidity of the control flask is probably due to more complete emulsion and dissolution of sunscreen components over time.

The re-suspension of particulate matter masked settling as a potential mechanism of clarification. Since each treatment showed a smaller increase in turbidity than the control, it is possible that the biology within each flask was able to metabolize sunscreen. The MDG Micro-N treatment showed a decrease in turbidity. The most feasible explanation is that the flask became contaminated during sampling and bacteria encountered the proper nutrients required for degradation of sunscreen without a sizeable increase in turbidity. While contamination is very likely, degradation cannot be confirmed as a mechanism of clarification at this point. 


\subsection{Task III - Isolation and Identification of Bacteria}

\subsubsection{Experiment III-1 Bacterial Plating of Experiment II-6}

Flasks from Experiment II-6 which demonstrated an increase in turbidity over five days of chlorinated incubation were plated at dilutions ranging from $10^{-1}$ to $10^{-12}$. Plates were enumerated after 48 hours of incubation at $35^{\circ} \mathrm{C}$.

A control plate resulted in zero colonies, denoting uncontaminated agar. One dish was plated with an undiluted sample from the Micro Nutrient flask, which returned $1.4 \times 10^{4}$ CFU per $100 \mathrm{~mL}$. This flask was expected to be abiotic, which raises questions regarding the sterility of chlorination and sampling or the purity of the available Micro Nutrient product.

Table 4-6: Experiment III-1 Plate Count CFU per 100 mL after 48 hours, PCA

\begin{tabular}{|c|c|c|c|c|c|c|c|c|}
\hline \multirow[b]{2}{*}{ Treatment } & \multicolumn{8}{|c|}{ CFU/100 mL at each Dilution } \\
\hline & $10^{-1}$ & $10^{-2}$ & $10^{-3}$ & $10^{-4}$ & $10^{-6}$ & $10^{-8}$ & $10^{-10}$ & $10^{-12}$ \\
\hline Thai FOG & $1.2 \times 10^{6}$ & $8.5 \times 10^{5}$ & $3.5 \times 10^{6}$ & $9.0 \times 10^{7}$ & $5.0 \times 10^{9}$ & $5.5 \times 10^{11}$ & $2.0 \times 10^{13}$ & $1.0 \times 10^{15}$ \\
\hline US FOG & $9.5 \times 10^{4}$ & $5.6 \times 10^{6}$ & $1.5 \times 10^{8}$ & $4.3 \times 10^{8}$ & $3.1 \times 10^{10}$ & $9.9 \times 10^{12}$ & $5.8 \times 10^{14}$ & $2.5 \times 10^{15}$ \\
\hline KLB & $4.0 \times 10^{4}$ & $4.5 \times 10^{5}$ & $3.8 \times 10^{7}$ & $6.0 \times 10^{7}$ & $5.0 \times 10^{9}$ & $5.0 \times 10^{11}$ & $2.5 \times 10^{13}$ & $1.0 \times 10^{15}$ \\
\hline
\end{tabular}

The same two types of bacterial cultures were seen predominantly in each flask, with several anomalous colonies forming. Due to the high biodiversity and unknown composition of Thai FOG, little can be said regarding the bacterial species of each colony 
which formed. The fact that the monoculture of KLB showed multiple colonies indicates cross-contamination from other flasks.

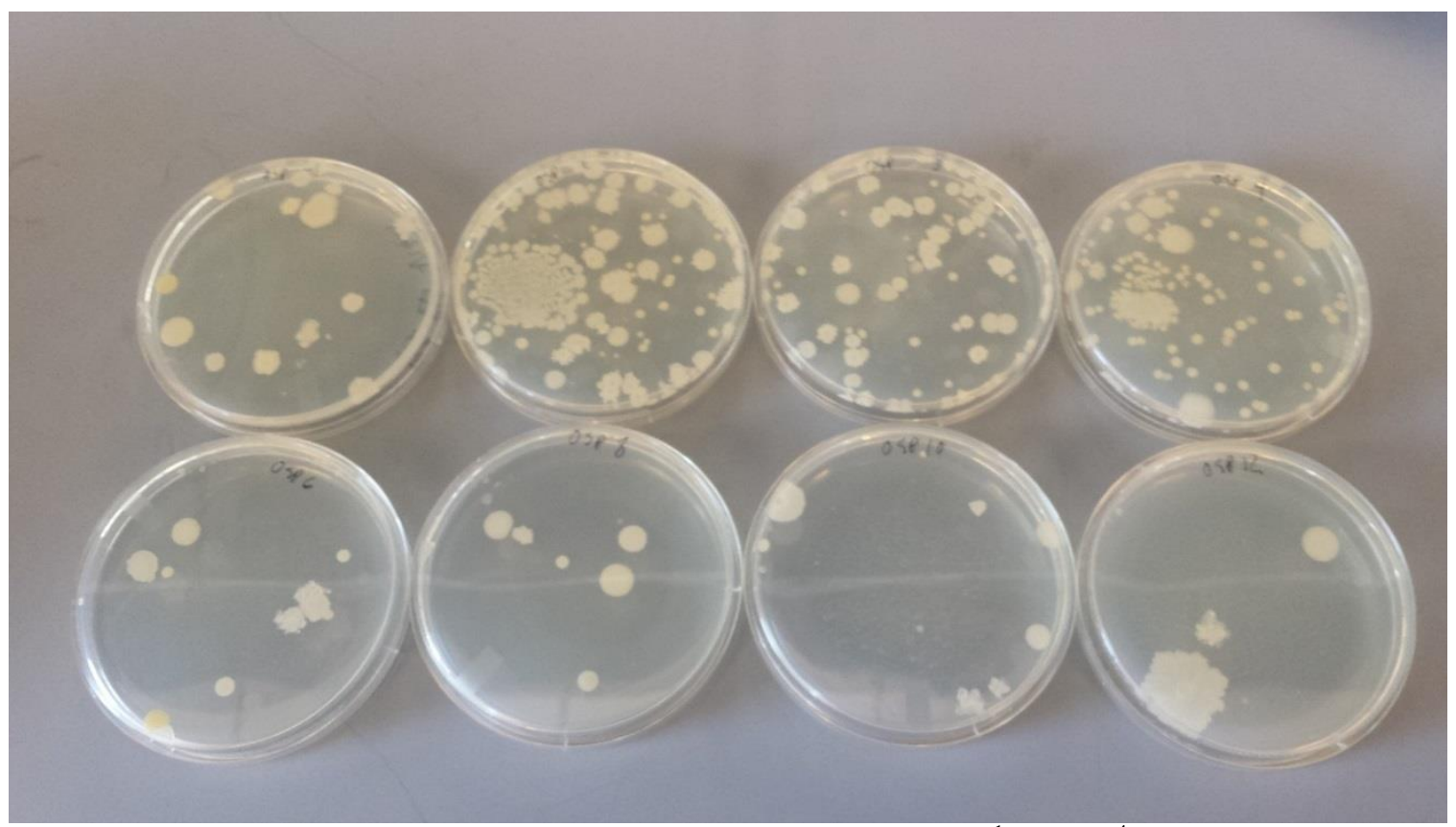

Figure 4-27: Experiment III-1 Osprey MBP-5 Dilutions $10^{-1}$ to $10^{-4}$ (Top Row, Left to Right), $10^{-6}$ to $10^{-12}$ (Bottom Row, Left to Right) 


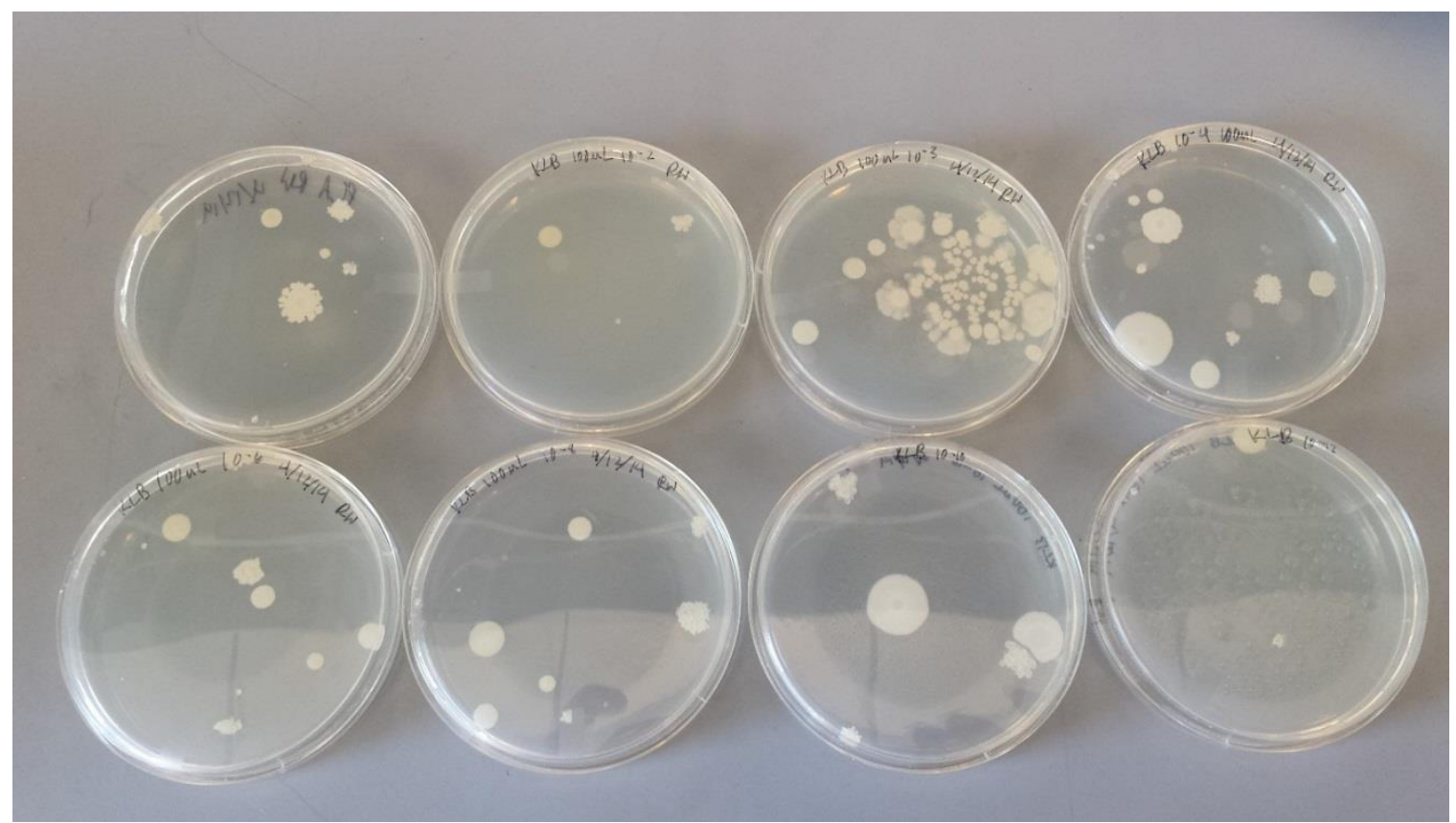

Figure 4-28: Experiment III-1 KLB Dilutions $10^{-1}$ to $10^{-4}$ (Top Row, Left to Right), $10^{-6}$ to $10^{-12}$ (Bottom Row, Left to Right)



Figure 4-29: Experiment III-1 US FOG Dilutions $10^{-1}$ to $10^{-4}$ (Top Row, Left to Right), $10^{-6}$ to $10^{-12}$ (Bottom Row, Left to Right) 


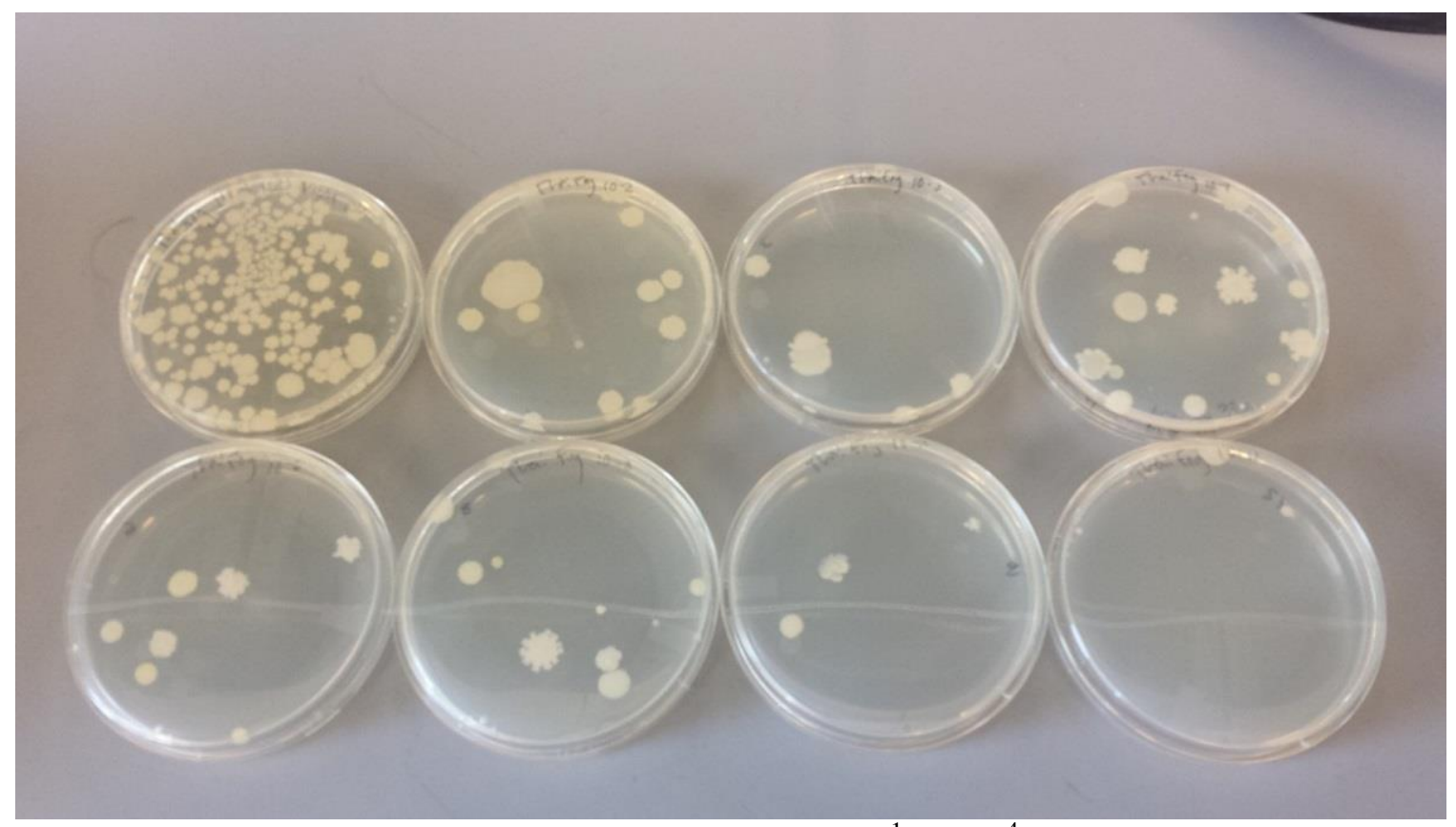

Figure 4-30: Experiment III-1 Thai FOG Dilutions $10^{-1}$ to $10^{-4}$ (Top Row, Left to Right), $10^{-6}$ to $10^{-12}$ (Bottom Row, Left to Right)

Each plate, including the monoculture of KLB, had two distinct types of colonies growing.

Figure 4-31 shows the Thai FOG $10^{-4}$ and US FOG $10^{-1}$ plates side-by-side. The prevalence of multiple bacterial colony types indicates contamination between treatments. 


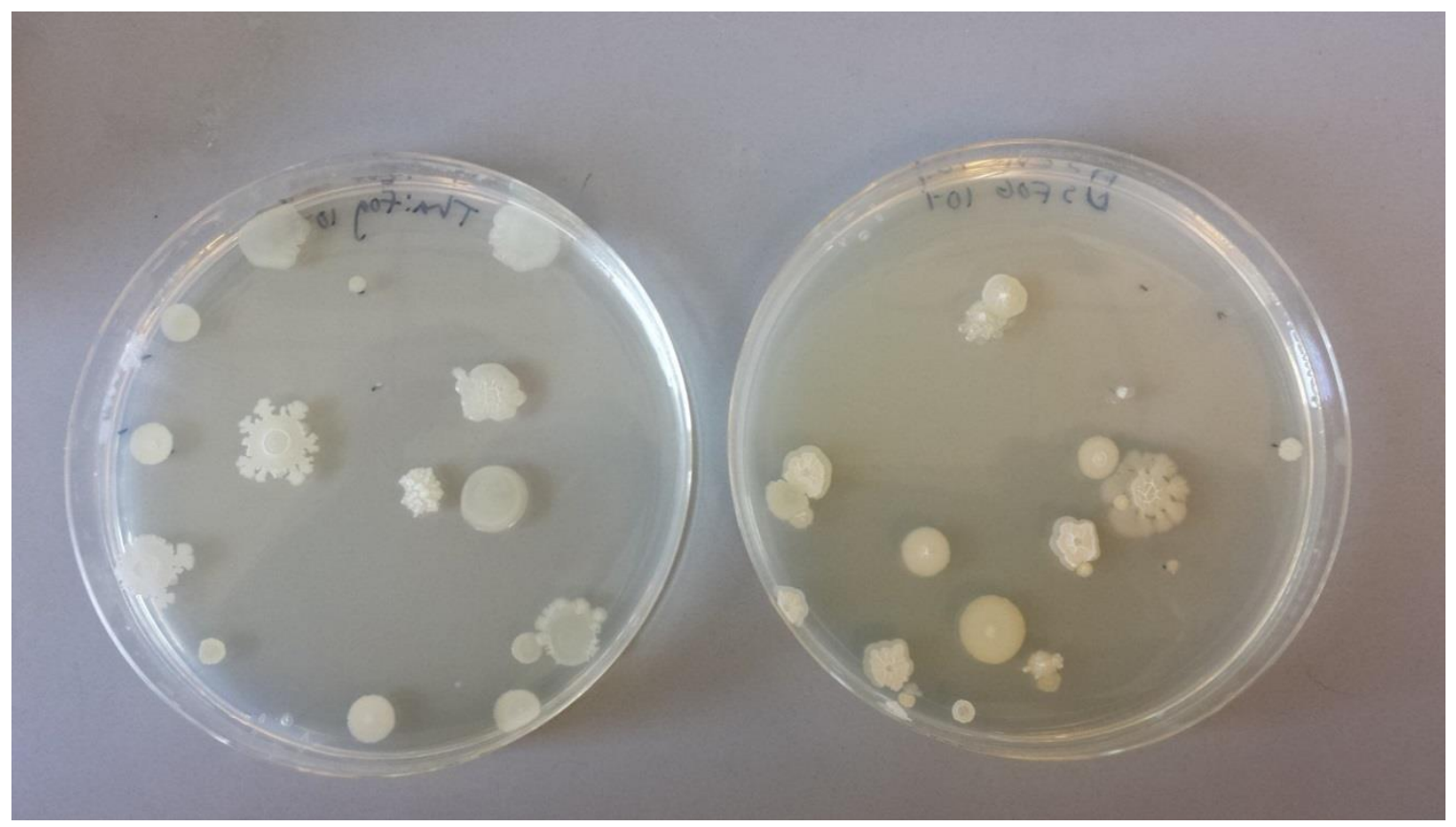

Figure 4-31: Experiment III-1 Comparison of Varied Colony Structure in Thai FOG (Left) and US FOG (Right)

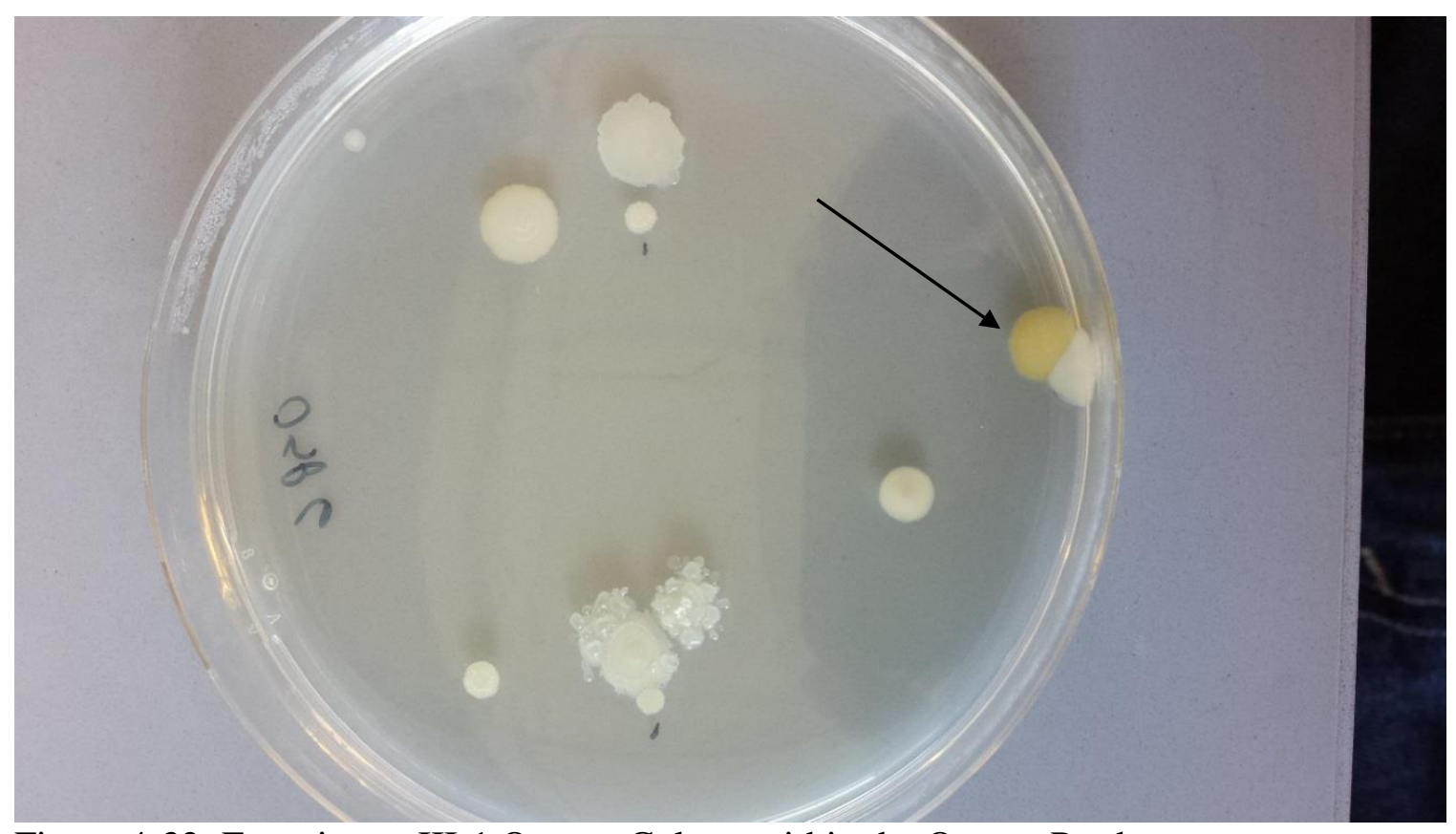

Figure 4-32: Experiment III-1 Orange Colony within the Osprey Product. 




Figure 4-33: Experiment III-3 Several Globular Colonies in Osprey 10 $0^{-1}$ Dilution

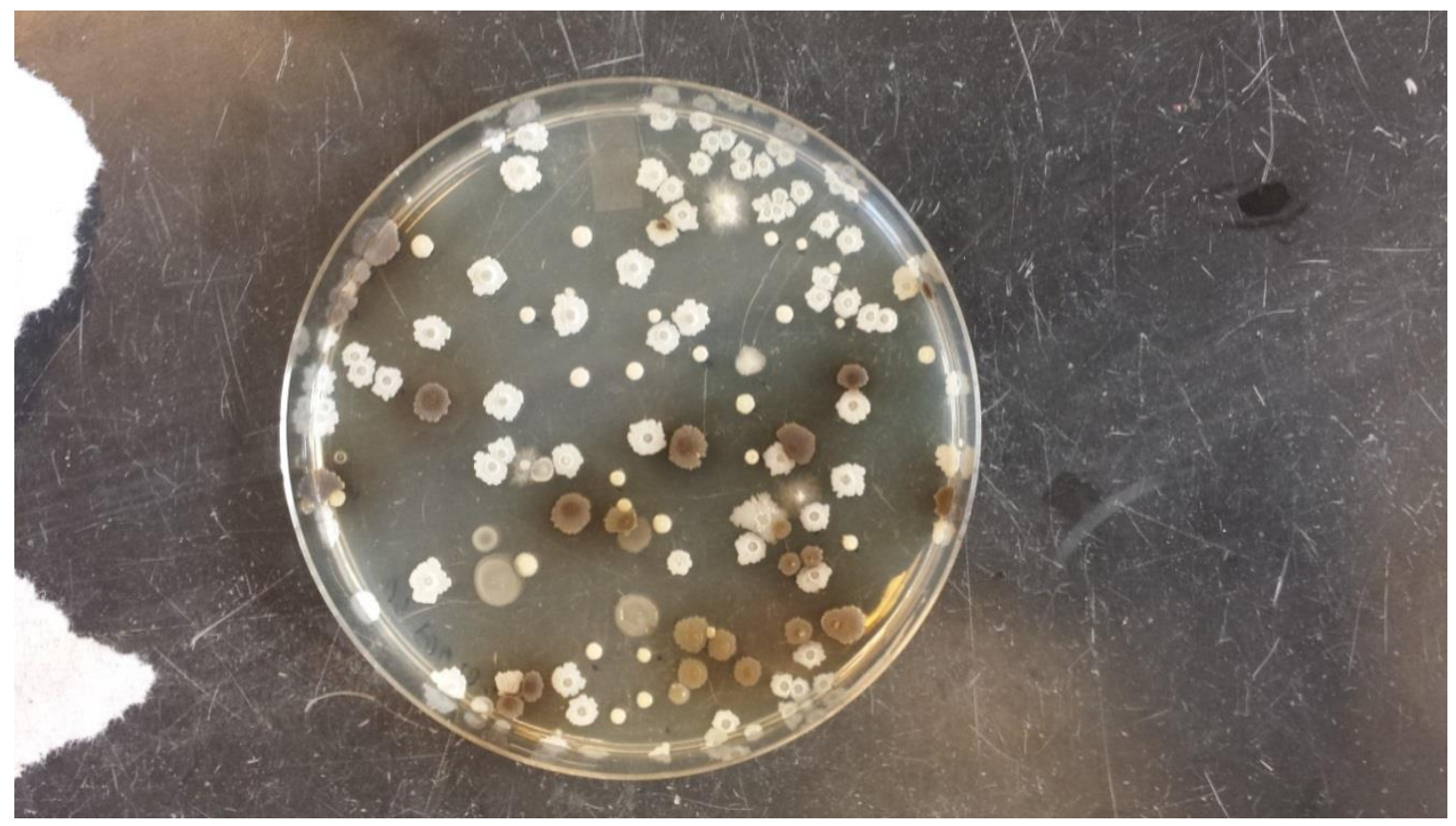

Figure 4-34: Experiment III-1 Black Colonies after 4 Days' Incubation at $35^{\circ} \mathrm{C}$ 


\subsubsection{Experiment III-2 Bacterial Plating of Experiment I-8}

Samples from treatments of Premix, Thai FOG, Irradiated Thai FOG and Control were plated on PCA and incubated for 48 hours. DI Water used for dilution and plating was not autoclaved. The control plate resulted in $2.5 \times 10^{4} \mathrm{CFU}$ per $100 \mathrm{~mL}$, invalidating the test.

Table 4-7: Experiment III-2 Plate Count Results

\begin{tabular}{llll}
\hline & \multicolumn{3}{c}{ Plate Count } \\
\cline { 2 - 4 } Tank & $10^{-16}$ & $10^{-20}$ & $10^{-28}$ \\
\hline 1 & TNTC & TNTC & TNTC \\
3 & TNTC & TNTC & TNTC \\
5 & 3 & TNTC & TNTC \\
7 & TNTC & TNTC & TNTC \\
Control & 0 & 0 & 0 \\
DI Blank & 25 & & \\
\hline
\end{tabular}

Figure 4-35: Experiment III-2 Control Treatment, Plate 10-28 Dilution

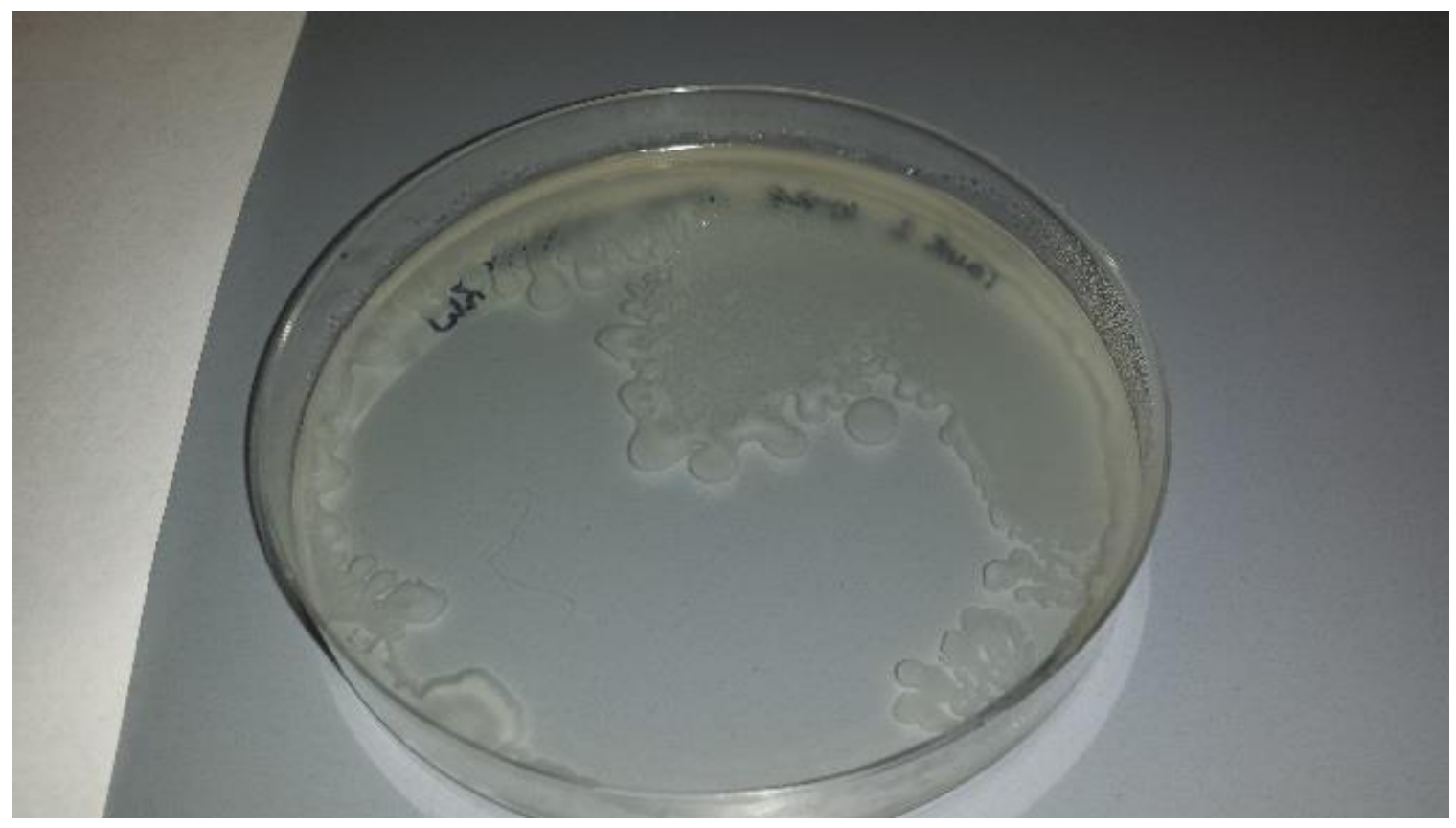




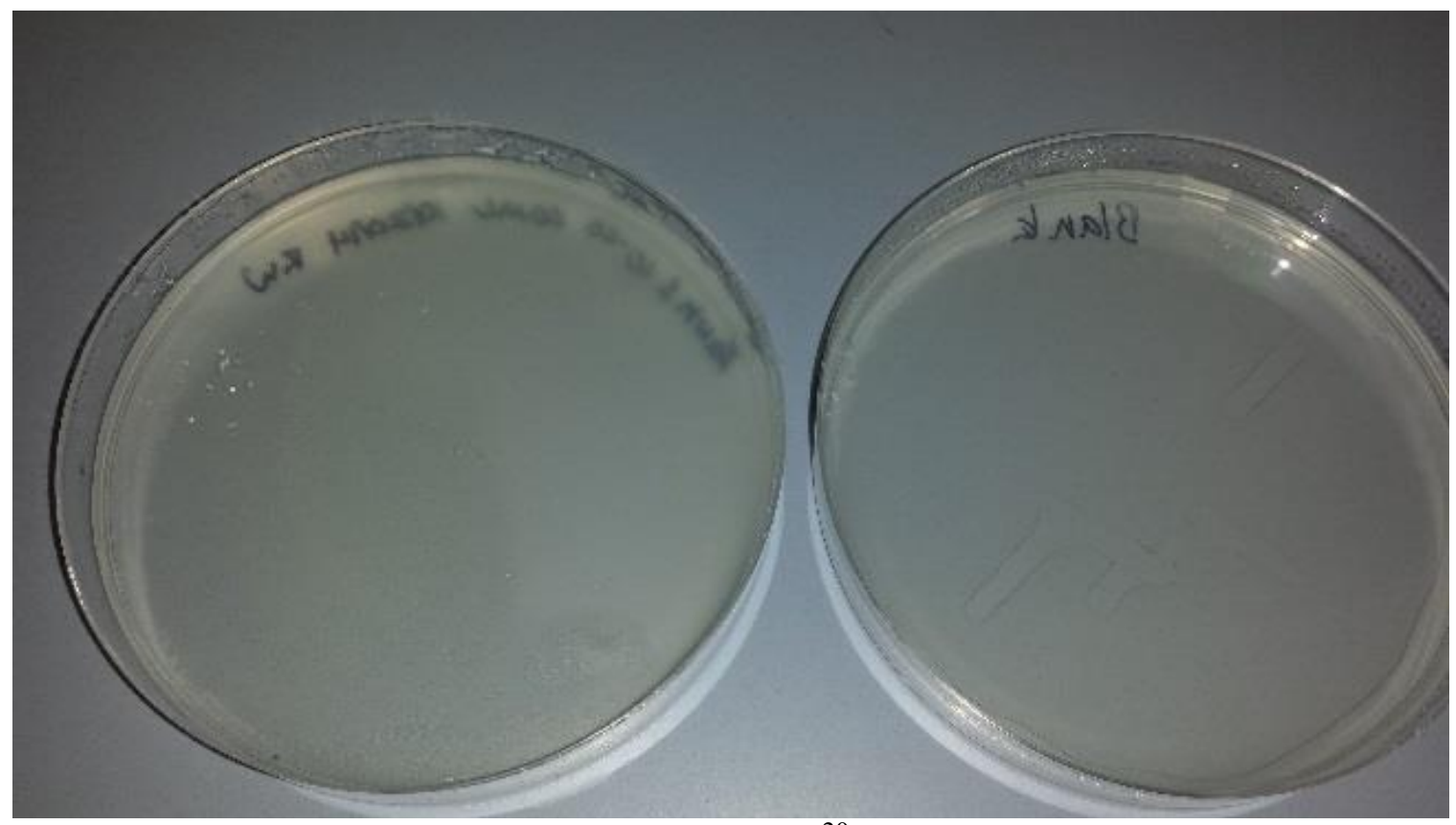

Figure 4-36: Experiment III-2 Thai FOG, Plate 10-20 Dilution Compared to Blank

No conclusions were drawn, due to the contamination of the test. 


\subsection{Task IV - Biodegradation of Cyanuric Acid}

\subsubsection{Experiment IV-1 CYA Biodegradation in a Respirometer}

Experiment IV-1 was developed to investigate $\mathrm{CO}_{2}$ production by BiOWiSH Thai FOG and US FOG in the presence of glucose and CYA. Due to repeated electrical and mechanical failures, no meaningful data were collected in this experiment. The respirometer was not used in subsequent experiments.

\subsubsection{Experiment IV-2 CYA Adsorption to Irradiated Thai FOG}

The purpose of Experiment IV-2 was to record the reduction of CYA over time by the substrate of Irradiated Thai FOG, independent of biological interactions. Irradiated Thai FOG was added to each of 5 shaker flasks at concentrations ranging from $50 \mathrm{mg} / \mathrm{L}$ to 300 $\mathrm{mg} / \mathrm{L}$.

A weak trend in CYA concentrations was observed over 72 hours with respect to irradiated Thai FOG concentration (Figure 4-37). The $300 \mathrm{mg} / \mathrm{L}$ Thai FOG treatment maintained the lowest CYA concentration among trials, and the $50 \mathrm{mg} / \mathrm{L}$ Thai FOG treatment displayed the highest CYA concentration throughout the experiment. An initial drop of CYA was seen in treatments of $100 \mathrm{mg} / \mathrm{L}$ and higher, but each treatment (other than $50 \mathrm{mg} / \mathrm{L}$ ) showed an increase in CYA concentration after the 24-hour time-point. 


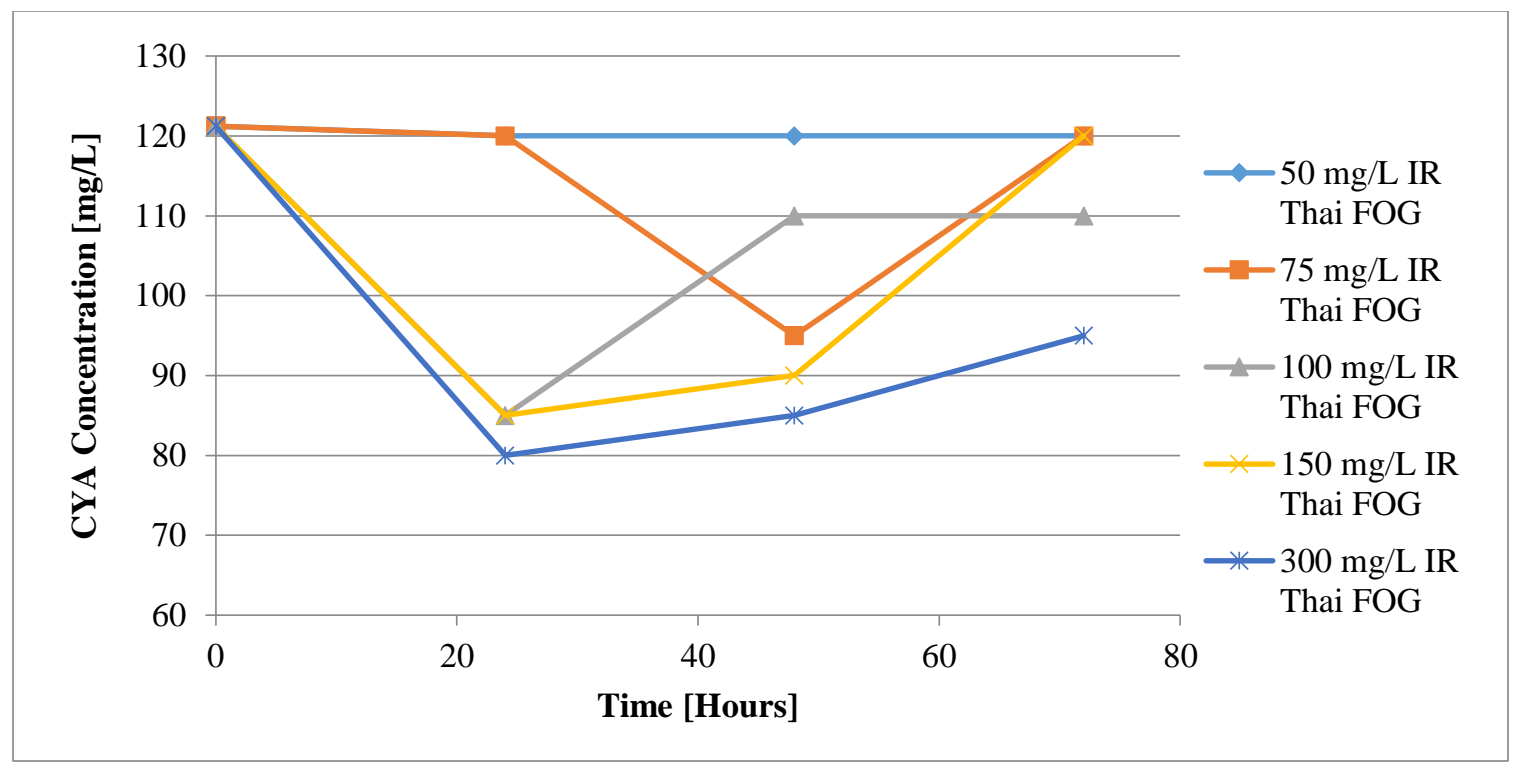

Figure 4-37: Experiment IV-2 CYA Concentration vs. Time, Turbidimetric Measurement, Varied Irradiated Thai FOG Concentrations, DI Water at $18-20^{\circ} \mathrm{C}$, No Agitation, Anaerobic

Samples were diluted by a factor of 5 to avoid surpassing the limit of the test $(60 \mathrm{mg} / \mathrm{L})$. Variation in CYA readings showcased the inaccuracy of the test when compounding low resolution (+/-1 mg/L) with sample dilution.

The fact that the highest and lowest concentrations of Irradiated Thai FOG showed the lowest and highest CYA concentrations, respectively, indicates some form of concentration-dependent interaction between the two substances. Different methods of CYA measurement would be necessary to differentiate between true adsorption and noise in measurement. At this point, the HPLC system was not functional. 


\subsubsection{Experiment IV-3 Anaerobic Degradation of CYA in DI Water}

Each treatment, excluding the control, was dosed with $50 \mathrm{mg} / \mathrm{L}$ of CYA. BiOWiSH products were dosed dry, at $50 \mathrm{mg} / \mathrm{L}$. DI water was used in order to prevent interaction between CYA and residual chlorine found in tap water. Table 4-8 shows data for one hour post-inoculation and after 9 days. The experiment was carried out anaerobically on a lab bench at ambient temperature which varied between $18^{\circ} \mathrm{C}$ and $22^{\circ} \mathrm{C}$.

Since only two data points were collected for each trial, no definitive conclusions can be drawn from the results. US FOG amended with $200 \mathrm{mg} / \mathrm{L}$ glucose showed an average of 66\% difference in CYA compared to US FOG with $50 \mathrm{mg} / \mathrm{L}$ glucose which showed an average of $32 \%$ difference. This implies that glucose, as a carbon source, may act as a limiting factor in the biodegradation of CYA.

Table 4-8: Experiment IV-3 CYA Raw Data

\begin{tabular}{llll}
\hline & & \multicolumn{2}{l}{$\begin{array}{l}\text { Cyanuric Acid } \\
\text { Concentration }[\mathrm{mg} / \mathrm{L}]\end{array}$} \\
\cline { 3 - 4 } Flask & Flask Contents & 35 & 7.5 \\
\cline { 2 - 3 } 2 & US FOG, $200 \mathrm{mg} / \mathrm{L}$ Glucose & $\mathrm{T}=9$ Days \\
2 & US FOG, $200 \mathrm{mg} / \mathrm{L}$ Glucose & 37.5 & 17.5 \\
3 & US FOG, $50 \mathrm{mg} / \mathrm{L}$ Glucose & 37.5 & 25 \\
4 & US FOG, $50 \mathrm{mg} / \mathrm{L}$ Glucose & 40 & 27.5 \\
5 & Thai FOG, $200 \mathrm{mg} / \mathrm{L}$ Glucose & 19 & 2.5 \\
6 & Thai FOG, $200 \mathrm{mg} / \mathrm{L}$ Glucose & 46 & 2.5 \\
7 & Thai FOG, $200 \mathrm{mg} / \mathrm{L}$ Sunscreen & 37.5 & 30 \\
8 & US FOG, 200 mg/L Sunscreen & 40 & 25 \\
9 & Cyanuric Acid & 65 & 67.5 \\
10 & Water & 0 & 0 \\
\hline
\end{tabular}


Initial CYA measurements varied across treatments, between 19 and $65 \mathrm{mg} / \mathrm{L}$. This is attributed to the low sensitivity of turbidimetric CYA measurement and the inconsistency of individually preparing low-concentration CYA solutions for each treatment. The variation in initial concentrations is not due to adsorption of CYA. Three treatments of Thai FOG showed varying starting values of CYA, even though they contained the same concentrations of Thai FOG. Additionally, the five treatments of US FOG showed reduced levels of CYA without containing the solid substrate that would be responsible for adsorption.

Starting with Experiment IV-5, stock solutions of CYA will be prepared and added to each treatment, providing more consistent initial concentrations and readings.

\subsubsection{Experiment IV-4 Anaerobic Degradation of CYA in Minimal Media}

Experiment IV-4 replicated Experiment IV-3, but a minimal growth media was used, rather than DI water. Similar to Experiment IV-3, a high degree of variation was observed in initial CYA values. Each treatment was dosed with $15 \mathrm{mg}$ of CYA and shaken, but they were not heated to expedite CYA dissolution. As a result, four of the nine treatments containing CYA showed an increase in CYA concentration over the first day of incubation. This is attributed to the remainder of CYA dissolving during 24 hours at elevated temperature and shaking at $75 \mathrm{rpm}$. Turbidimetric readings of CYA were taken over 14 days (Figure 4-38). 


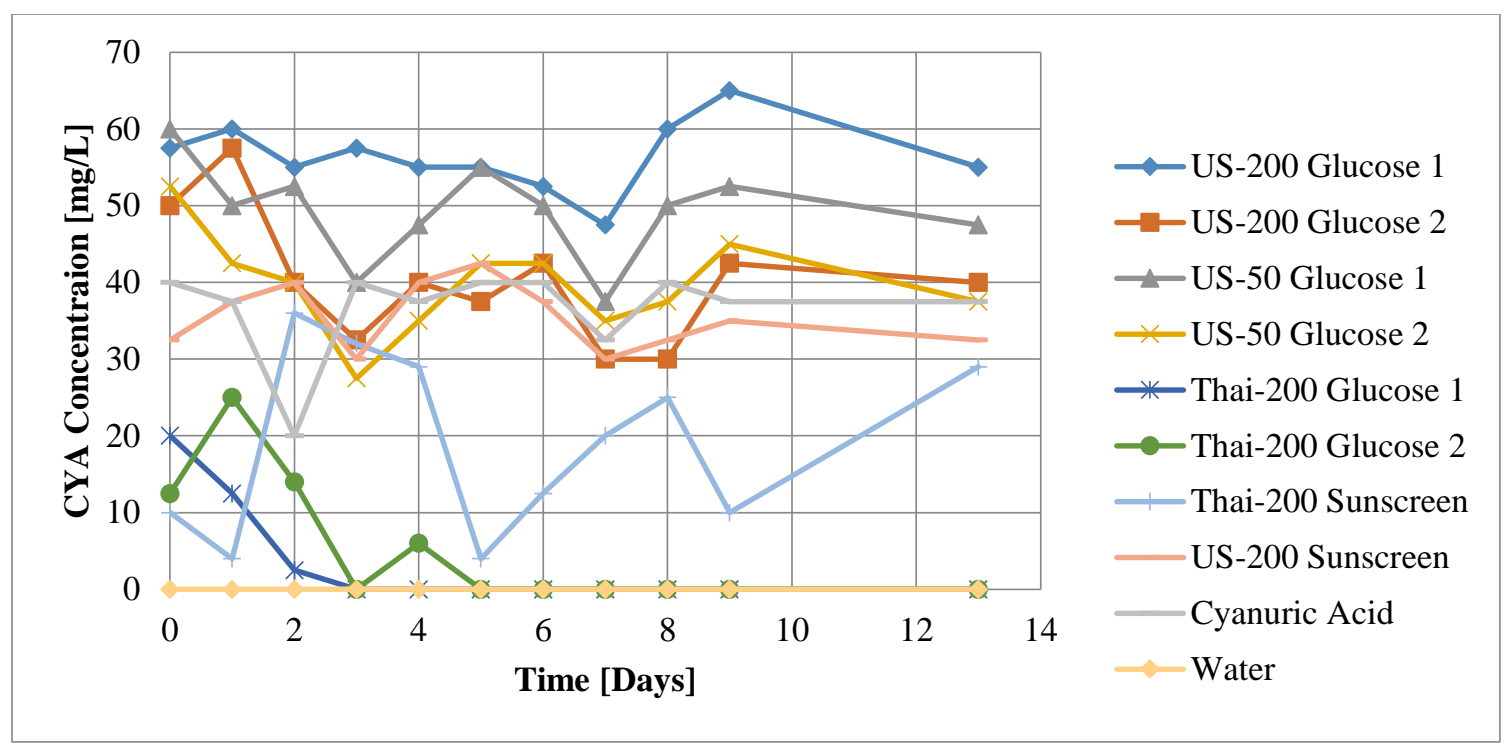

Figure 4-38: Experiment IV-4 CYA Concentration vs. Time, Turbidimetric Measurement, Minimal Media at $30^{\circ} \mathrm{C}$ and $75 \mathrm{RPM}$, Anaerobic

Treatments of "US- 50 Glucose" showed 21-29\% reduction in CYA from start to finish. Conversely, treatments of "US- 200 Glucose" reduced CYA by $4 \%$ and $20 \%$. This contrasts the effect seen in Experiment IV-3, in which US FOG showed greater reduction in CYA with higher glucose concentrations.

The "Thai- 200 Glucose 1" treatment showed a steady decrease in CYA over time and remained at zero after $\mathrm{T}=3$ days. "Thai- 200 Glucose 2 " showed similar reduction of CYA but also displayed higher variation across readings. The increase in CYA seen for "Thai200 Glucose 2 " between $\mathrm{T}=0$ and $\mathrm{T}=1$ day is attributed to incomplete dissolution of CYA at initial sampling. These data are in agreement with Experiment IV-3 regarding the efficacy of Thai FOG in removing CYA from solution.

Levels of CYA in the control treatment varied from 32.5 to $40 \mathrm{mg} / \mathrm{L}$, with an outlier of 20 $\mathrm{mg} / \mathrm{L}$. The mode of the readings was $40 \mathrm{mg} / \mathrm{L}$. Excluding the individual reading of 20 126 
$\mathrm{mg} / \mathrm{L}$, most CYA readings were within 1-2 mg/L prior to correction for dilution. This level of noise in measurement is to be expected, so it was concluded that the concentration of CYA did not change over time in the control treatment.

CYA levels for the "Thai- 200 Sunscreen" treatment varied widely throughout the duration of the experiment. CYA readings for "US- 200 Sunscreen" did not vary as much as those of "Thai- 200 Sunscreen", and CYA readings for "US- 200 Sunscreen" fell in-line with both treatments of "US- 50 Glucose". Therefore, interference of sunscreen with turbidimetric CYA measurement was ruled out as a reason for variation in readings.

\subsubsection{Experiment IV-5 Effect of Activated Thai FOG Supernatant on CYA}

The supernatant of a solution of Thai FOG (after 24 hours of incubation) was added to 62.5 $\mathrm{mg} / \mathrm{L}$ of CYA and incubated at $30^{\circ} \mathrm{C}$ and $75 \mathrm{RPM}$. No consistent change in CYA was observed over time. Readings varied between 70 and $82.5 \mathrm{mg} / \mathrm{L} \mathrm{CYA}$, which can be attributed to the low test resolution magnified by a dilution factor of 2.5 for each reading. 




Figure 4-39: Experiment IV-5 CYA Concentration vs. Time, Turbidimetric Measurement, Thai FOG Supernatant in $62.5 \mathrm{mg} / \mathrm{L} \mathrm{CYA}$ at $30^{\circ} \mathrm{C}$ and $75 \mathrm{RPM}$, Anaerobic

No change was seen in CYA concentration, so it is postulated that the mechanism of CYA reduction by Thai FOG (seen in Experiments IV-2, IV-3, and IV-4) is dependent upon the solid substrate. The fermented rice bran and soy meal which makes up the majority of Thai FOG (98-99\%) has a highly porous surface structure as seen in the SEM imagery of Experiment I-8, Figures 4-9 and 4-10. The product's porous surface seems to provide a high degree of adsorption of sunscreen and may contribute to adsorption of CYA.

\subsubsection{Experiment IV-6 Effects of US FOG and Activated Thai FOG on CYA}

Experiment IV-6 was designed to investigate the efficacy of CYA reduction by US FOG and the supernatant from incubated Thai FOG. Treatments were carried out in triplicate to avoid potential inconsistencies in turbidimetric CYA analysis. 
Prior to dosing, the flask containing activated Thai FOG was inverted and agitated then allowed to settle for 2 minutes before collecting supernatant material. When collected for dosing, the supernatant was more turbid than before agitation. Increased turbidity indicates that finer particles from the solid substrate of Thai FOG were collected along with vegetative cells.

CYA readings were taken before and after inoculation to capture the initial CYA drop which is characteristic of Thai FOG. Values in Figure 4-40 have been corrected for dilution caused by the addition of $100 \mathrm{~mL}$ of inoculum to each flask. Figure 4-40 shows a significant drop in CYA by Thai FOG after inoculation. Due to a clerical error, glucose was not added until $\mathrm{T}=1$ Days.

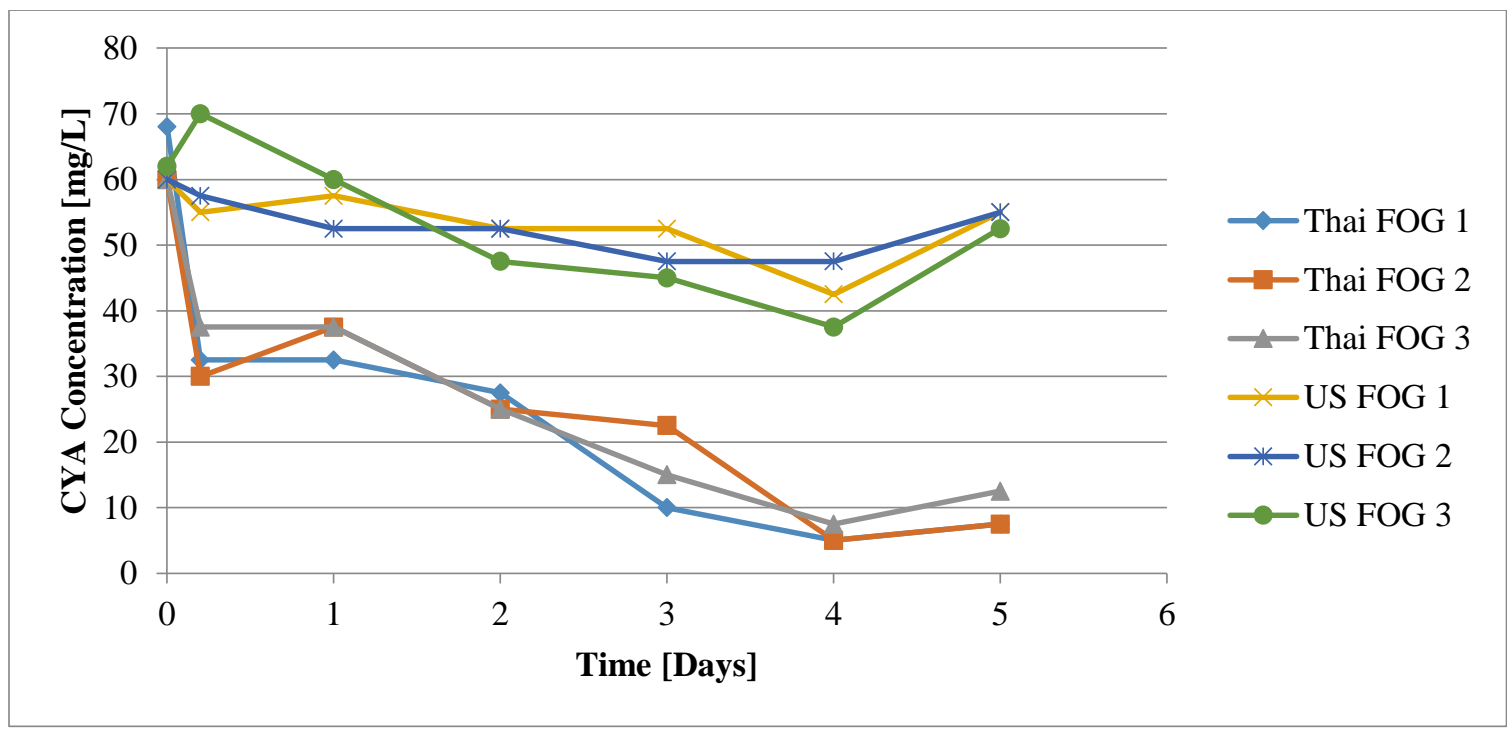

Figure 4-40: Experiment IV-6 CYA Concentration vs. Time, Turbidimetric Measurement, Thai FOG and US FOG in Triplicate, DI Water with Glucose at $30^{\circ} \mathrm{C}$ and 75 RPM, Anaerobic

Solid substrate material was dosed with the inoculum of each Thai FOG treatment. A 47\% drop in CYA was observed at $\mathrm{T}=0.2$ Days by Thai FOG. Results indicate that the Thai 129 
FOG substrate is responsible for the substantial decrease in CYA measurement using turbidimetric measurement.

US FOG showed a $30 \%$ reduction of CYA between $\mathrm{T}=0$ Days and $\mathrm{T}=4$ Days. Over the same time-period, Thai FOG showed a 90\% reduction in CYA. Discrepancies in dilution methods between experimenters during measurement of CYA caused an increase in CYA

at $\mathrm{T}=5$ Days. The consistent grouping of treatments indicates precision in CYA measurement between treatments. Accuracy of measurement was not confirmed, preventing definitive conclusions from being drawn.

Baseline CYA reduction was not confirmed in this experiment, because a control flask was not included in the treatments. Experiments IV-3 and IV-4 showed no change in CYA over time for control treatments, so it is assumed that no change would have been seen in a control flask.

\subsubsection{Experiment IV-7 Turbidimetric CYA Calibration}

A calibration curve for serial dilutions of CYA was developed using the turbidimetric method. The results show high linearity and are fit to a linear regression model with $\mathrm{R}^{2}=$ 0.916 (Figure 4-41). 


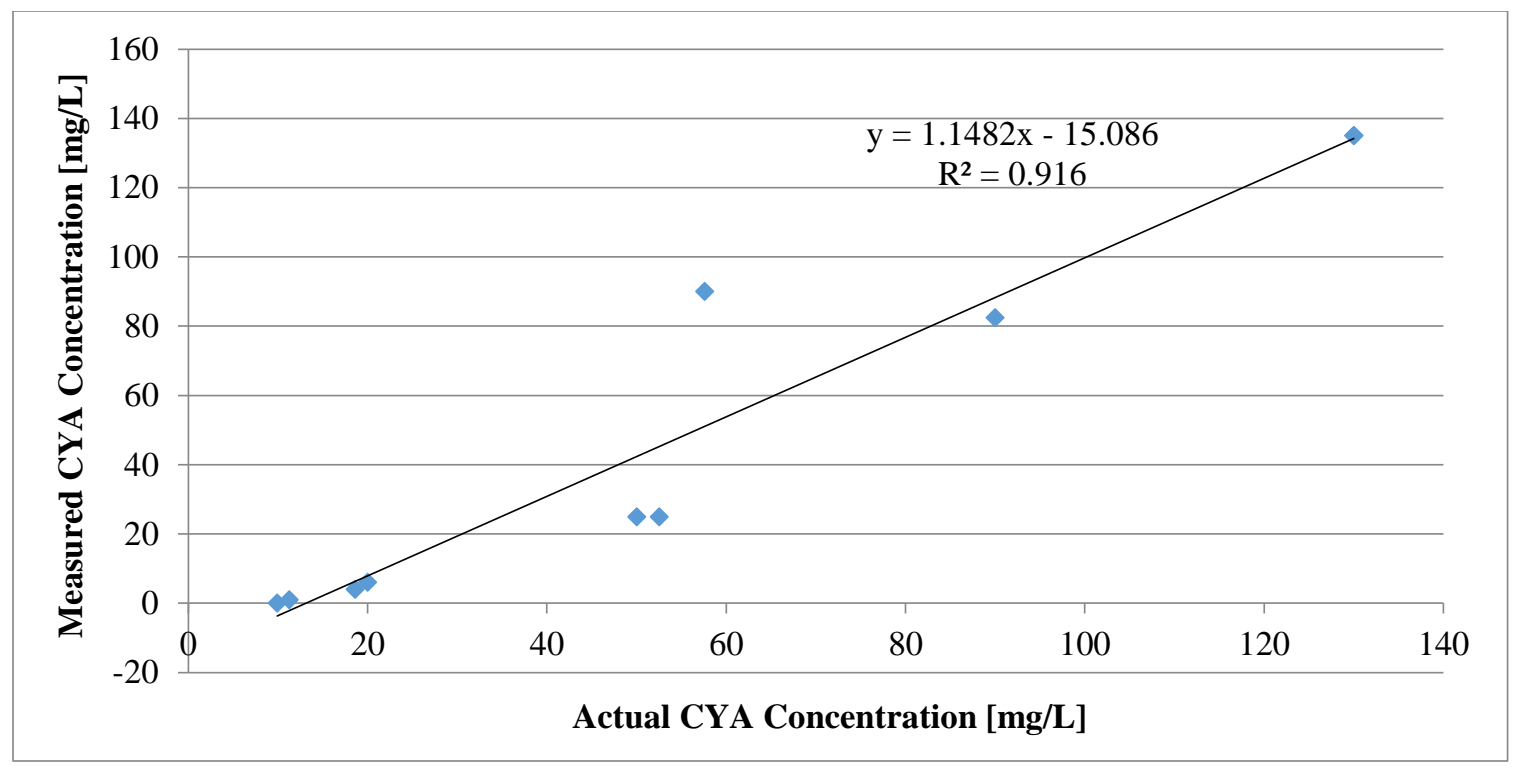

Figure 4-41: Calibration of Turbidimetric Method for CYA Measurement, Turbidimetric Measurement

\subsubsection{Experiment IV-8 Standard Preparation for HPLC}

Standards of CYA were prepared in $2 \mathrm{~mL}$ glass vials. According to the standard method for HPLC analysis of CYA, prepared samples are stable for $>69$ days at $25^{\circ} \mathrm{C}$ (Tucker 1994).

\subsubsection{Experiment IV-9 HPLC Calibration of CYA}

Two HPLC analyses of CYA returned linear calibration curves with highly varied slopes. System pressure was noted to exceed 400 bar when the purge valve was tightened fully. Due to improper experimenter training, the HPLC was run with the purge valve partially open for both standard curves. A portion of the mobile phase flow was allowed to leak from the purge valve. Low pressure corresponded to low eluent flow rate through the 
column, wide peaks, and large integrated area. Higher pressure corresponded to higher eluent flow rate, narrower peaks, and smaller integrated area.

Preliminary analysis was run with $\mathrm{P}=145$ bar. Peaks eluted between 14.8 minutes at low concentrations and 8.1 minutes at high concentrations. Changing elution times indicate inconsistency in analyte retention by the system. To combat this issue, a subsequent analysis was carried out at 350 bar. CYA peaks were much narrower and more uniform than before. The linear regression showed a much shallower slope (Figure 4-42). The yintercept was fixed at zero, and an $\mathrm{R}^{2}$ value of 0.9988 was acquired, indicating strong linearity.

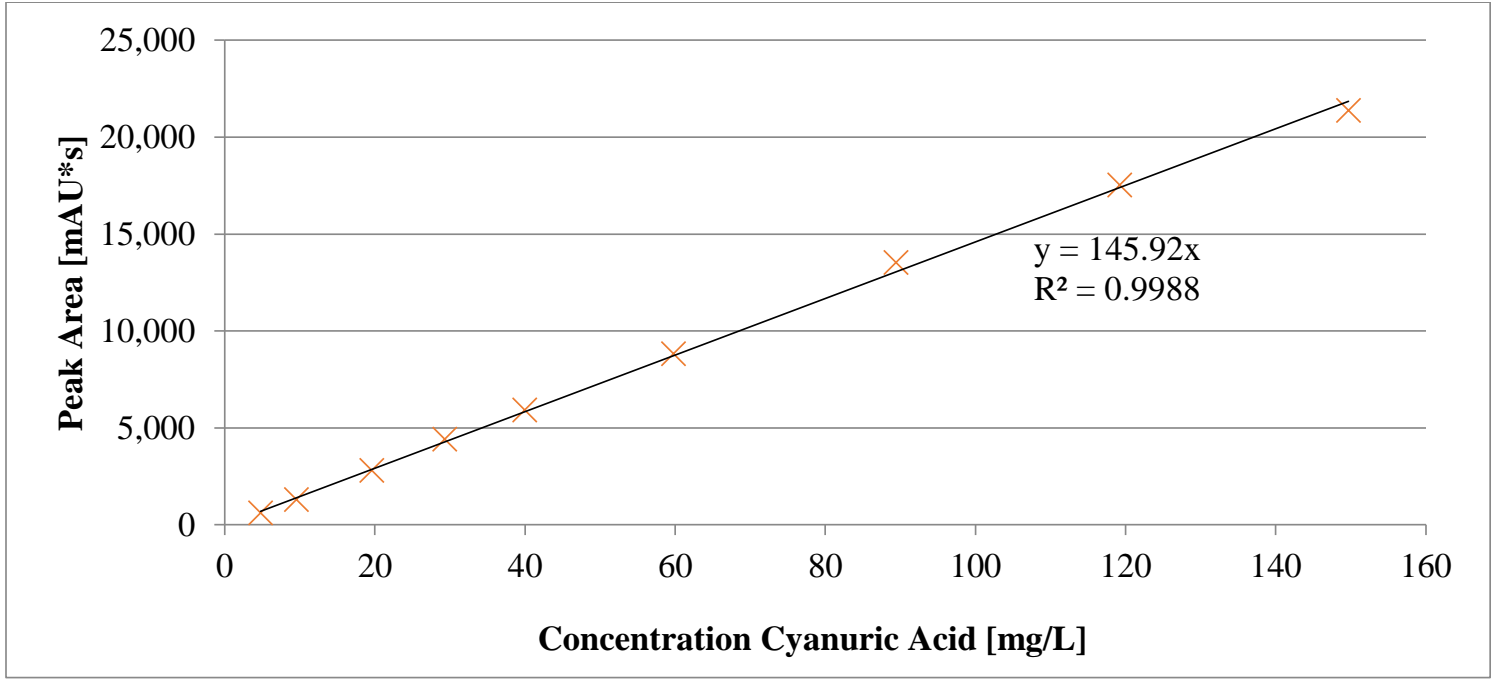

Figure 4-42: Experiment IV-9 Peak Area vs. CYA Concentration Calibration, HPLC Measurement, $\mathrm{P}=350$ bar

System maintenance performed after Experiment IV-12 showed that the purge valve frit had fouled and was occluding mobile phase flow. The problem was not rectified until after Experiment IV-17. 
The slope of calibration curve created in this experiment is dependent upon more variables than pressure alone, including temperature, guard column condition, and cleanliness of the purge valve frit. Therefore, results from future experiments cannot be converted to concentration based upon these calibrations.

\subsubsection{Experiment IV-10 HPLC Calibration using Thai FOG}

The supernatant from an activated Thai FOG solution and a prepared CYA sample were analyzed using HPLC. All samples were filtered through $0.22 \mu \mathrm{m}$ filter prior to analysis. Peak areas, listed in Table 4-9, show that Thai FOG does not interfere with HPLC analysis of CYA.

Table 4-9: Experiment IV-10 CYA and Thai FOG Peak Areas

\begin{tabular}{lll}
\hline Vial Contents & Peak Area [mAU*s] & $\begin{array}{l}\text { Expected Peak Area } \\
\text { Based on 40 mg/L }\end{array}$ \\
\hline CYA $50 \mathrm{mg} / \mathrm{L}$ & 11620 & 9157.5 \\
Thai FOG $110 \mathrm{mg} / \mathrm{L}$ & -128 & 0 \\
CYA $25 \mathrm{mg} / \mathrm{L} ;$ & 5792 & 4578.75 \\
Thai FOG 55.3 mg/L & & \\
$40 \mathrm{mg} / \mathrm{L} \mathrm{CYA} \mathrm{Standard}$ & 7326 & 7326 \\
\hline
\end{tabular}

The percent difference between the samples containing CYA at $50 \mathrm{mg} / \mathrm{L}$ and $25 \mathrm{mg} / \mathrm{L}$, when corrected for dilution, was $0.3 \%$. This confirms that the HPLC method provides substantially linear results across diluted samples. 
Peak areas of samples were also compared to that of the $40 \mathrm{mg} / \mathrm{L}$ standard prepared in Experiment IV-8. Percent differences were calculated by comparing observed peak of the prepared CYA samples areas to expected peak areas based on the $40 \mathrm{mg} / \mathrm{L}$ standard. The $50 \mathrm{mg} / \mathrm{L} \mathrm{CYA}$ and $25 \mathrm{mg} / \mathrm{L}$ CYA samples were $26.9 \%$ and $26.5 \%$ different from expected values, respectively, indicating that the CYA solution was diluted accurately, but not prepared accurately.

\subsubsection{Experiment IV-11 Method Development of HPLC using Thai FOG and CYA}

Thai FOG was added at $100 \mathrm{mg} / \mathrm{L}$ to a solution of $60 \mathrm{mg} / \mathrm{L} \mathrm{CYA}$. The mixture was heated and stirred until all CYA had dissolved. Peak areas were analyzed over time to investigate relative change in CYA concentration due to adsorption or biodegradation. The turbidimetric method of CYA analysis showed significant decrease of CYA over time by Thai FOG (Experiments IV-5 and IV-6), so a change was expected to be observed. Contrary to previous results, no change in CYA peak area was noted. 


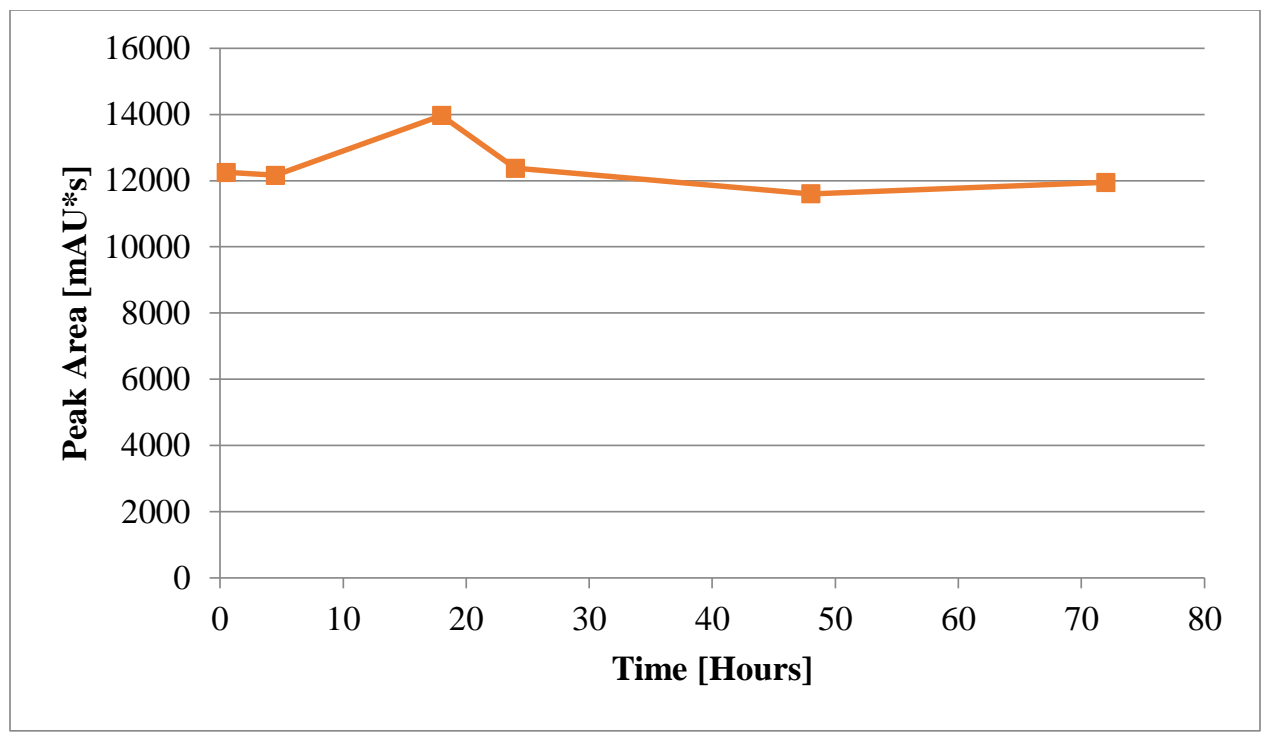

Figure 4-43: Experiment IV-11 CYA Peak Area vs. Time, HPLC Measurement, Thai FOG in $60 \mathrm{mg} / \mathrm{L} \mathrm{CYA}$, DI Water at $30^{\circ} \mathrm{C}$ and $75 \mathrm{RPM}$, Anaerobic

According to the results, CYA peak area is stable in the presence of Thai FOG, over time.

\subsubsection{Experiment IV-12 Investigation of Products' Effects on CYA}

Treatments in this experiment each contained $50 \mathrm{mg} / \mathrm{L}$ of CYA to observe effects of various BiOWiSH products on CYA in the presence of additional glucose. Inoculums and additional glucose are laid out in Table 4-10, below. 
Table 4-10: Experiment IV-12 Experimental Setup

\begin{tabular}{llll}
\hline Bottle & $\begin{array}{l}\text { Cya } \\
{[\mathrm{mg} / \mathrm{L}]}\end{array}$ & Inoculum & $\begin{array}{l}\text { Glucose } \\
{[\mathrm{mg} / \mathrm{L}]}\end{array}$ \\
\hline 1 & 50 & $\mathrm{x}$ & $\mathrm{x}$ \\
2 & 50 & Thai FOG & 250 \\
3 & 50 & Thai FOG & $\mathrm{x}$ \\
4 & 50 & IR TF & 250 \\
5 & 50 & Premix & 250 \\
6 & 50 & 35 mg Osp Liq & 250 \\
7 & 50 & Osp Solid & 250 \\
8 & 50 & US FOG & 250 \\
\hline
\end{tabular}

Samples were analyzed using HPLC alongside a standard of $60 \mathrm{ppm} \mathrm{CYA,} \mathrm{which} \mathrm{was} \mathrm{used}$ to correct measurements for daily variation in peak elution time. Elution time varied between 2.0 and 2.5 minutes depending on temperature and the amount of eluent diverted by the partially-open purge valve. Glucose was analyzed separately for UV absorbance at $213 \mathrm{~nm}$, and no notable peaks were observed.

In the first 48 hours, all treatments showed a decrease in CYA relative to the standard. The remainder of the experiment displayed a consistent increase in CYA measurement for each trial, with the exception of US FOG. 


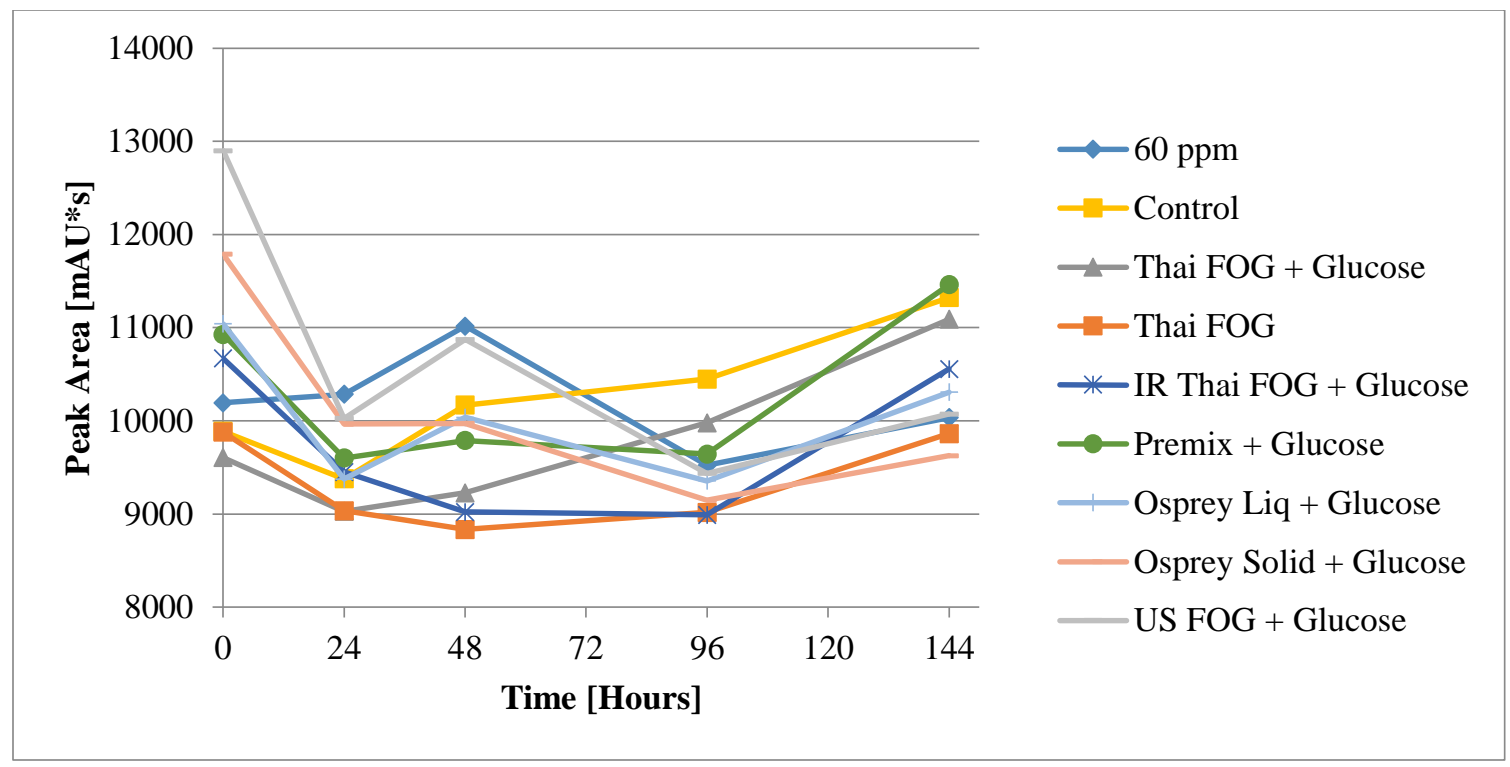

Figure 4-44: Experiment IV-12 Peak Area vs. Time, HPLC Measurement, DI Water at $30^{\circ} \mathrm{C}$ and $75 \mathrm{RPM}$, Anaerobic

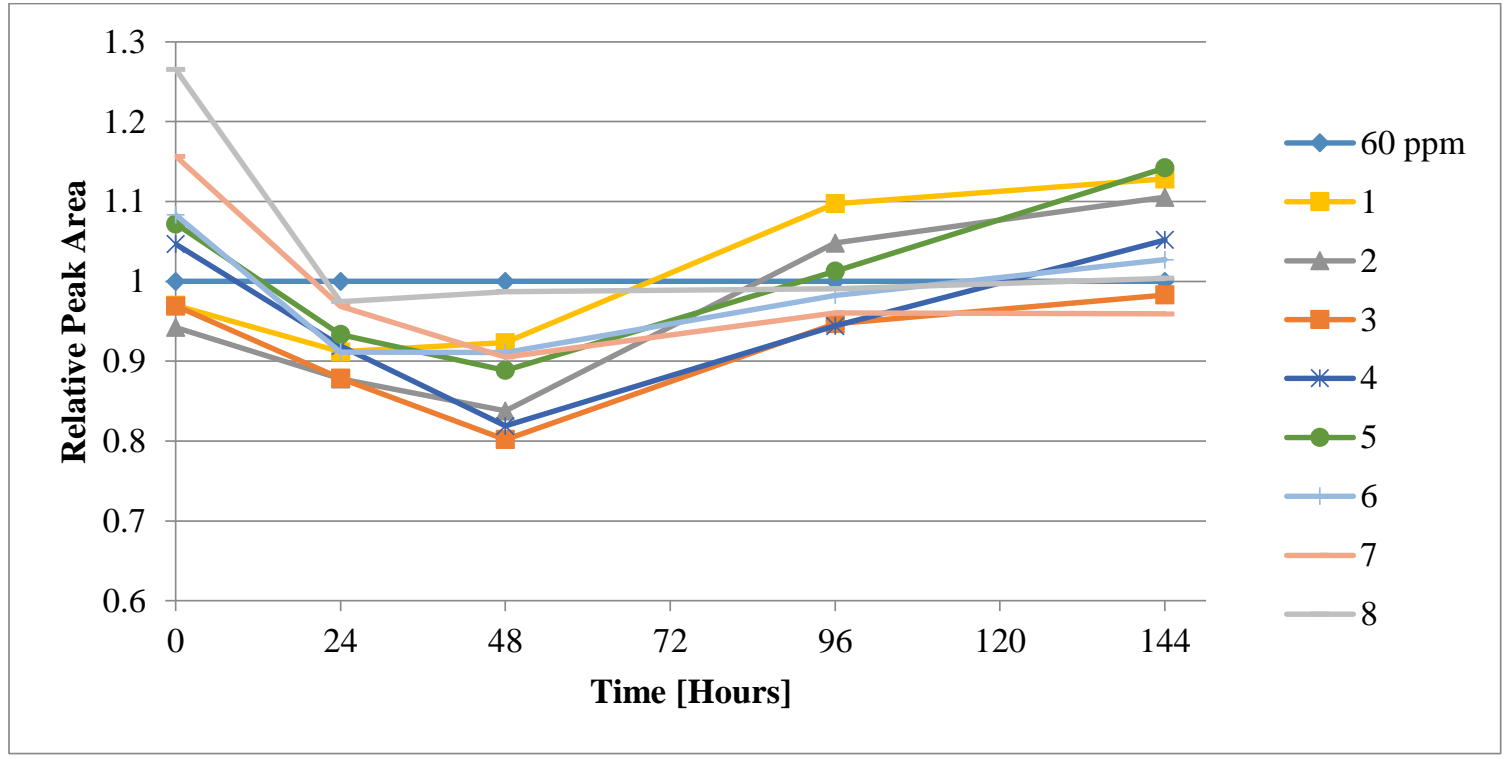

Figure 4-45: Experiment IV-12 Relative Peak Area vs. Time, Corrected to 60 PPM Standard, HPLC Measurement, DI Water at $30^{\circ} \mathrm{C}$ and 75 RPM, Anaerobic 
CYA peaks showed systematic error with all samples changing by a similar amount, relative to control, throughout sampling events. As noted before, the issue stemmed from a clogged purge valve frit which was not discovered until after Experiment IV-16.

\subsubsection{Experiment IV-13 HPLC Method Development - Inconclusive Mobile Phase Adjustment}

Experiment 4-13 is omitted, due to inconclusive changes in HPLC method. Mobile phase adjustments are summarized in Section 3.5.11.

\subsubsection{Experiment IV-14 HPLC Method Development - High Injection Volume}

High injected concentrations of CYA led to column clogging during analysis. Peak areas eluted in excess of 4,000 mAU. It was determined that smaller volumes of CYA would be necessary for accurate analysis. No meaningful data were collected in this experiment.

\subsubsection{Experiment IV-15 Investigation of C:N:P Ratios Effects on CYA Degradation}

Experiment IV-15 was designed to highlight differences in CYA degradation with varying ratios of carbon to nitrogen and phosphorous. The inoculum was a combination of US Aqua and dextrose.

Method development demonstrated that the mobile phase used in this experiment did not separate nitrate from CYA. UV absorbance of nitrate at $213 \mathrm{~nm}$ is much stronger than that 
of CYA, so ammonium nitrate within the growth media masked any changes in CYA concentration in this experiment.

Table 4-11: Experiment IV-15 Carbon:Nitrogen:Phosphorus Ratios

\begin{tabular}{ll}
\hline Bottle & C:N:P Ratio \\
\hline 1 & $100: 10: 1$ \\
2 & $60: 10: 1$ \\
3 & $50: 10: 1$ \\
4 & $40: 10: 1$ \\
5 & $10: 10: 1$ \\
6 & $50: 10: 1$ Aerobic \\
7 & $50: 10: 1$ Aerobic \\
& + Headspace \\
\hline
\end{tabular}

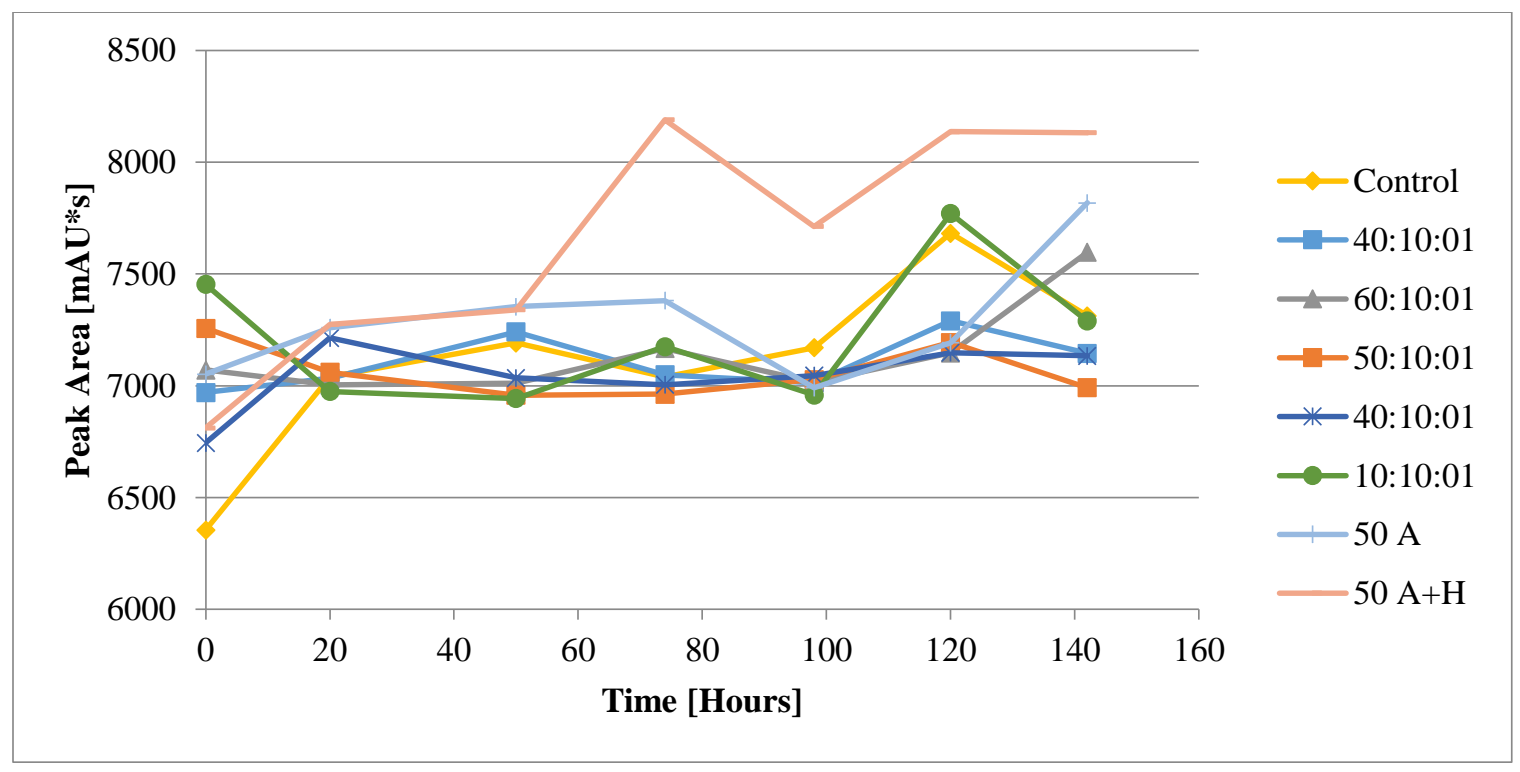

Figure 4-46: Experiment IV-15 Peak Area vs. Time, HPLC Measurement, Minimal Growth Media at $30^{\circ} \mathrm{C}$ and 75 RPM, Varying C:N:P Ratios, Aerobic and Anaerobic Treatments

Due to the interference of nitrate peaks with those of CYA, data in Figure 4-46 cannot be utilized for the analysis of CYA concentrations. 


\subsubsection{Experiment IV-16 Hour-by-Hour Time-Point CYA Degradation}

Hour-by-hour time-point CYA degradation was carried out using vegetative cultures suspended in Phosphate Buffered Saline in a growth solution. The HPLC method was not able to resolve nitrate peaks from CYA peaks. Due to the interference of peaks, no meaningful data were obtained.

\subsubsection{Experiment IV-17 Effect of Cyanuric Acid Reducer on CYA Concentration}

Experiment IV-17 investigated the effects of BiOWiSH Cyanuric Acid Reducer (CAR) product on CYA. The product is primarily composed of dextrose amended with isolated bacterial cells. In order to dose $5 \mathrm{mg} / \mathrm{L}$ and $50 \mathrm{mg} / \mathrm{L}$ of CAR to $200 \mathrm{~mL}$ of growth solution, a stock solution of CAR was used.

Starting at T=19 Hours, a standard of CYA at $97 \mathrm{mg} / \mathrm{L}$ and DI water were analyzed with each sampling event as a two-point calibration. An example calibration can be found in Appendix BXX.

All treatments, including the controls, showed drift in peak area with tight grouping after $\mathrm{T}=2$ Hours. This is attributed to diurnal temperature fluctuation. Elution time fluctuations could be prevented with a column heater. 
After T $=65$ hours, low to no bacterial growth was seen. $500 \mathrm{mg} / \mathrm{L}$ of glucose was dosed to the non-control flasks to stimulate bacterial growth and potential CYA degradation. Even with the addition of glucose, no consistent trends relative to controls were seen.

Figure 4-47, the raw peak area data, shows strong systematic error in the form of peak area drift between sampling events. This indicates that the developed method does not consistently measure CYA, and needs further refining. Temperature control with a column heater is the first change which could make a significant impact on peak area stability.

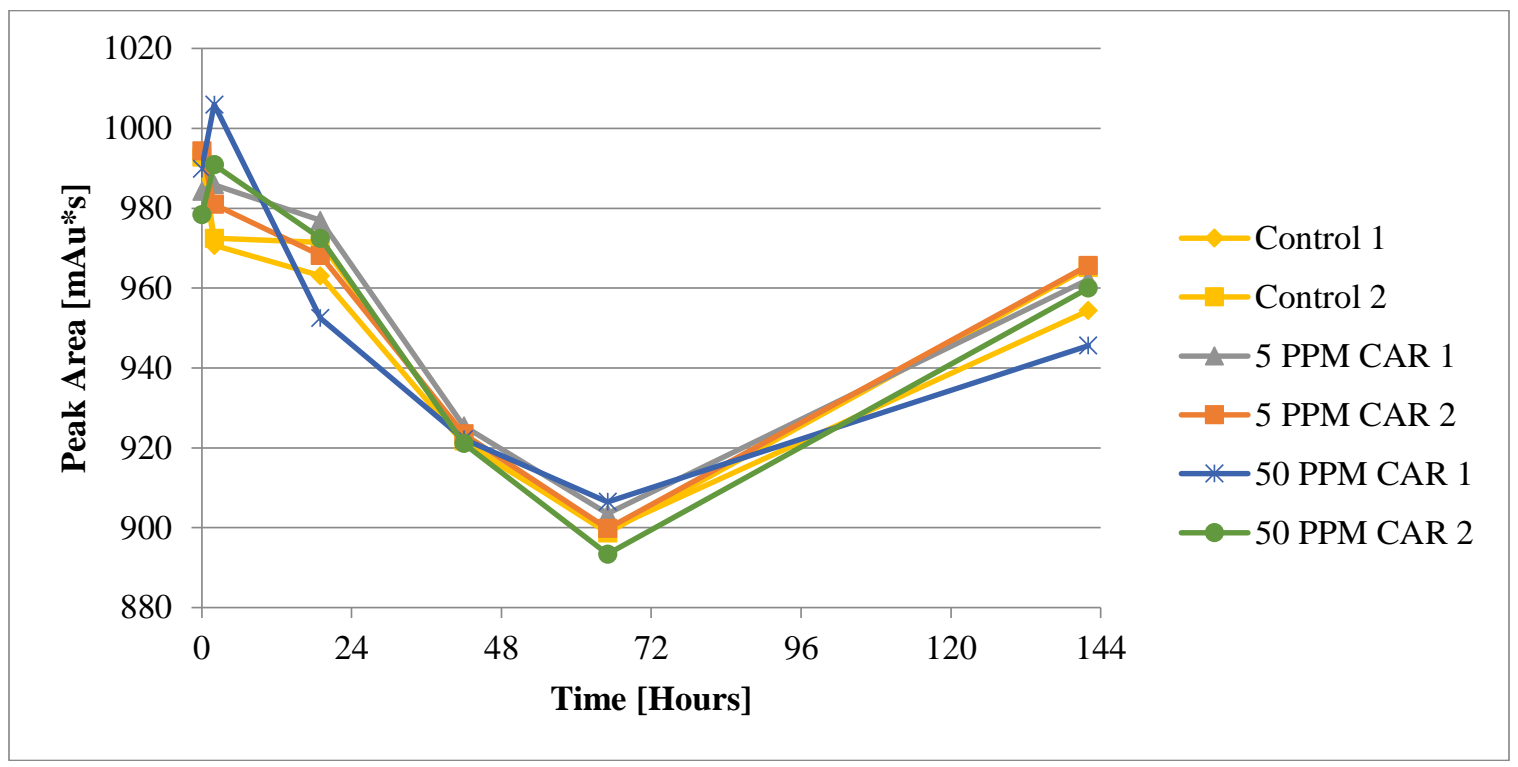

Figure 4-47: Experiment Iv-17 Peak Area vs. Time, HPLC Measurement, CAR Product at $5 \mathrm{mg} / \mathrm{L}$ and $50 \mathrm{mg} / \mathrm{L}$, DI Water with Dextrose at $30^{\circ} \mathrm{C}$ and $75 \mathrm{RPM}$, Anaerobic 


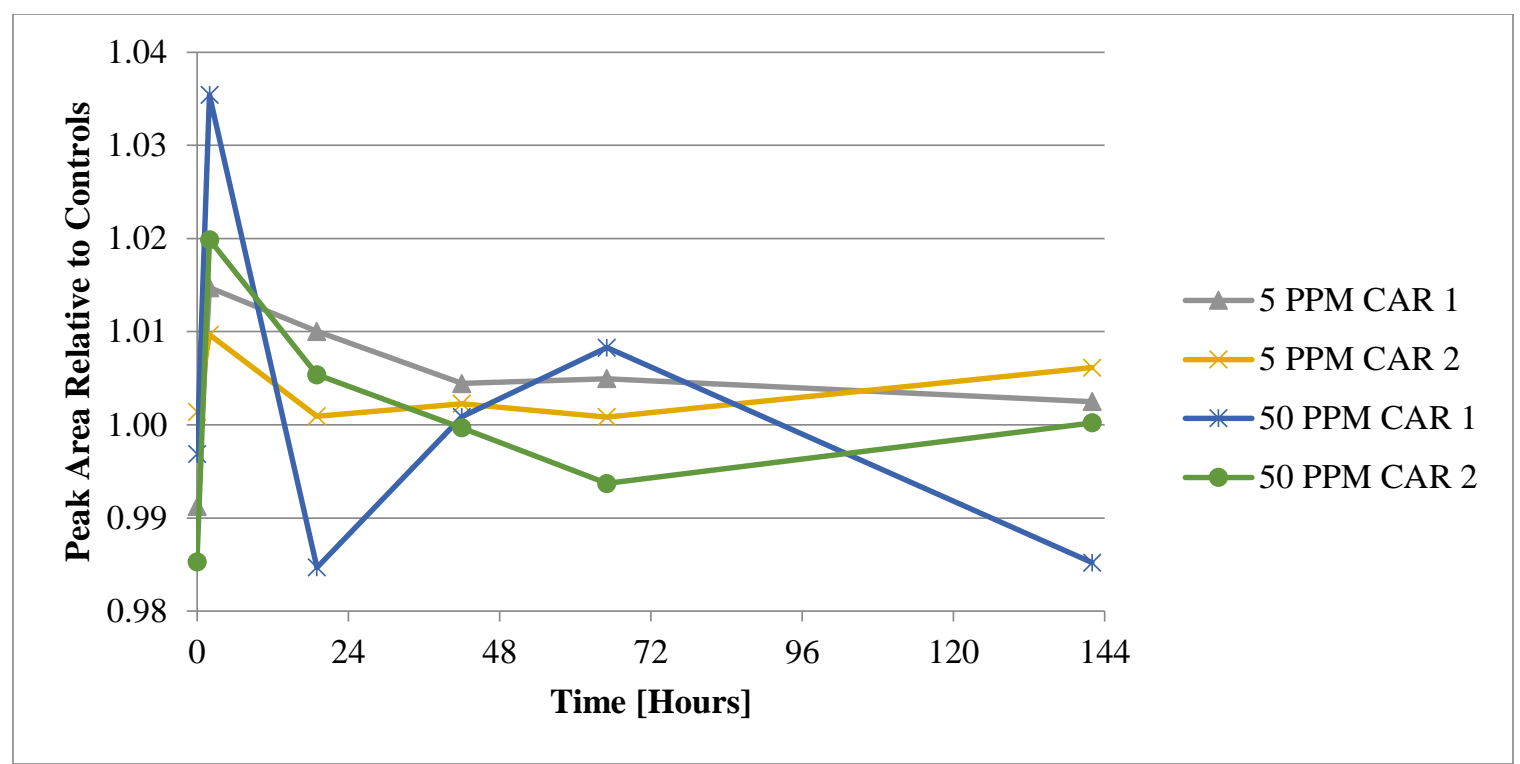

Figure 4-48: Experiment IV-17 Peak Area vs. Time Relative to Averaged Controls, HPLC Measurement, CAR Product at $5 \mathrm{mg} / \mathrm{L}$ and $50 \mathrm{mg} / \mathrm{L}$, DI Water with Dextrose and at 30oC and 75 RPM, Anaerobic

Peak area varied from the average of the controls by no more than $4 \%$ in either direction throughout the experiment for each treatment Figure 4-48. Results show that up to $50 \mathrm{ppm}$ of CAR had no measureable effect on CYA concentration.

\subsubsection{Experiment IV-18 Effect of CAR on CYA with $\mathrm{K}_{2} \mathrm{HPO}_{4}$, Varied Glucose}

Experiment IV-18 was developed to investigate the effects of CAR on CYA with varying concentrations of glucose and trace $\mathrm{K}_{2} \mathrm{HPO}_{4}$. Prior to inoculation, growth media was autoclaved then sparged with $\mathrm{N}_{2}$ gas in order to remove dissolved oxygen and promote anaerobic metabolism.

After T=1 Days, the HPLC guard column was changed. As a result, operating pressure decreased, peak elution time stabilized marginally, and peak areas dropped significantly. 
Figure 4-49 excludes readings from $\mathrm{T}=0$ and $\mathrm{T}=1$ Days, because they are not relatable to the remainder of the data.

Results showed no change in CYA concentrations relative to the controls in the first 6 days. Similarly, no appreciable bacterial growth was seen within biological treatments. A solution of $1 \mathrm{~g} / \mathrm{L} \mathrm{CAR}$ in Lactobacillus Broth was activated for 24 hours at $30^{\circ} \mathrm{C}$ and 75 rpm. The activated product was then dosed at $1 \mathrm{~mL}$ per flask to all four biological treatments at $\mathrm{T}=7$ Days.

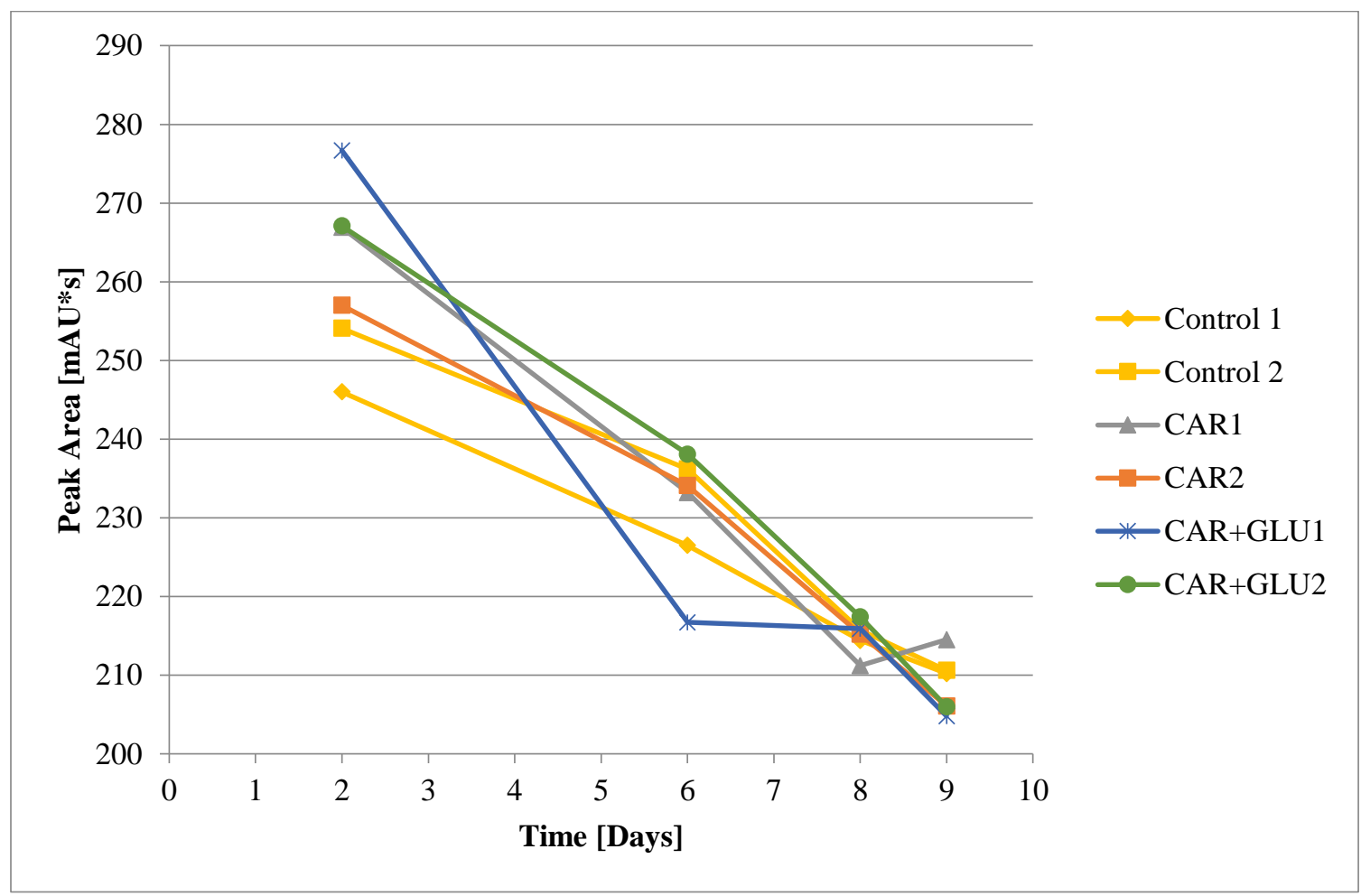

Figure 4-49: Experiment IV-18 Peak Area vs. Time HPLC Measurement, CAR Product and Varied Glucose, DI Water with $\mathrm{K}_{2} \mathrm{HPO}_{4}$ at $30^{\circ} \mathrm{C}$ and $75 \mathrm{RPM}$, Anaerobic

A 3-point calibration was run at the beginning of $\mathrm{HPLC}$ analysis at $\mathrm{T}=6, \mathrm{~T}=8$, and $\mathrm{T}=9$ Days. An example of the procedure for calibration and conversion of peak area to $\mathrm{mg} / \mathrm{L}$ of 
CYA can be found in Appendix C. The results were not included in this experiment, because it was not used consistently from the onset of the experiment. Subsequent experiments will utilize the three-point or four-point calibration at the beginning of HPLC analyses.

\subsubsection{Experiment IV-19 Effect of Activated CAR on CYA, Varying Dextrose}

Experiment IV-19 was developed to investigate the effects of the activated bacterial components of BiOWiSH CAR product on CYA, in varying concentrations of dextrose. Prior to inoculation, each bottle of autoclaved CYA solution was sparged with $\mathrm{N}_{2}$ gas in order to promote anaerobic conditions from the onset of the experiment.

A four-point calibration was run before each sampling event to correct for temperaturedependent peak area variations. A sample calibration can be found in Appendix BXX. It was assumed that the calibration curve created for a sampling event remained valid throughout the sampling event, as temperature did not change significantly during HPLC analysis of each set of samples (maximum of 2 hours). Figure 4-50 shows minimal change in CYA concentration over time.

After $\mathrm{T}=3$ Days, the HPLC guard column was changed. Starting at $\mathrm{T}=4$ Days, the clean guard column provided much more distinct peaks with less tailing, and CYA readings became much more closely grouped between treatments. In Figure 4-50, the final timepoint excludes the "Control 2" treatment, as contamination was suspected to have been introduced to the treatment. 


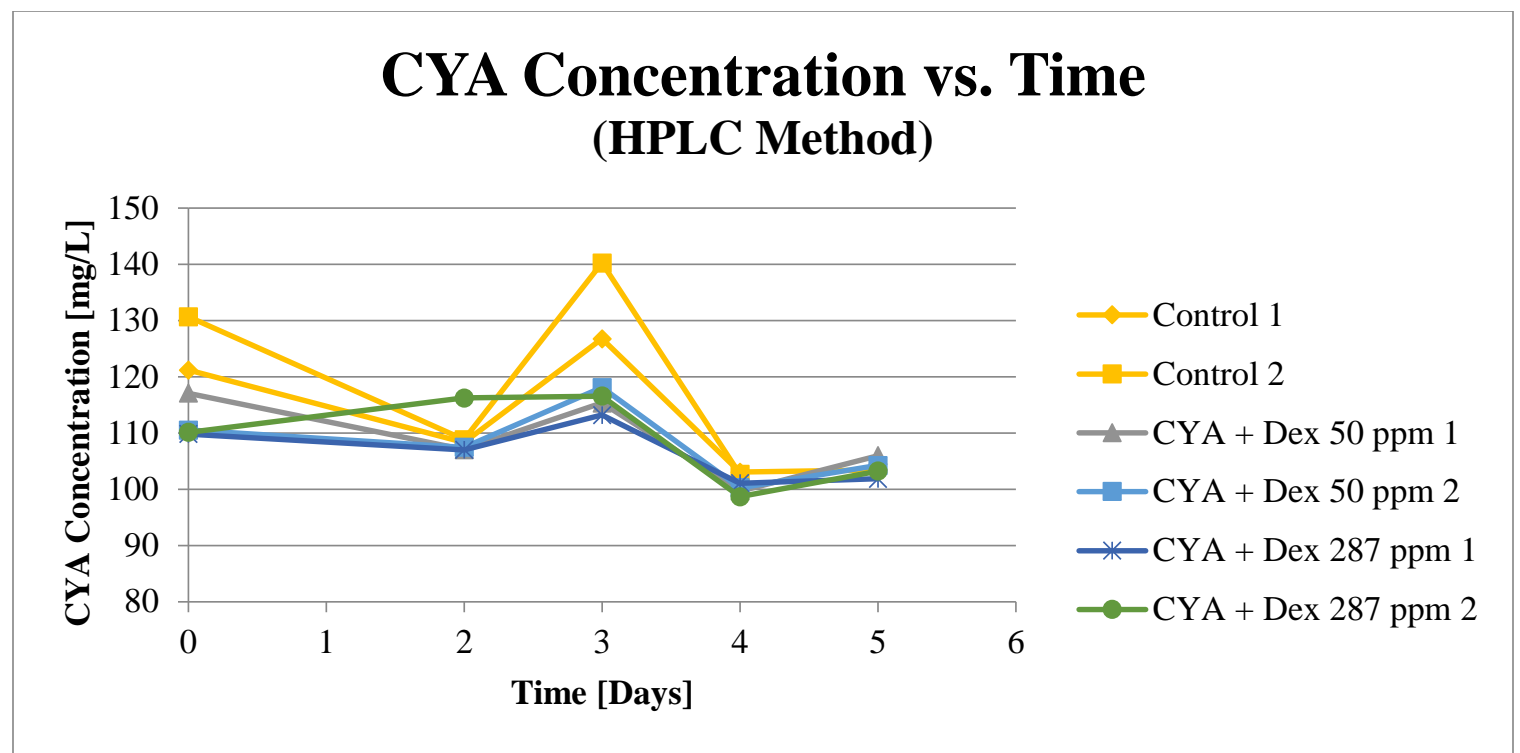

Figure 4-50: Experiment IV-19 CYA Concentration vs. Time, HPLC Measurement, Vegetative Bacterial Inoculums, DI Water with Dextrose at $30^{\circ} \mathrm{C}$ and $75 \mathrm{RPM}$, Anaerobic

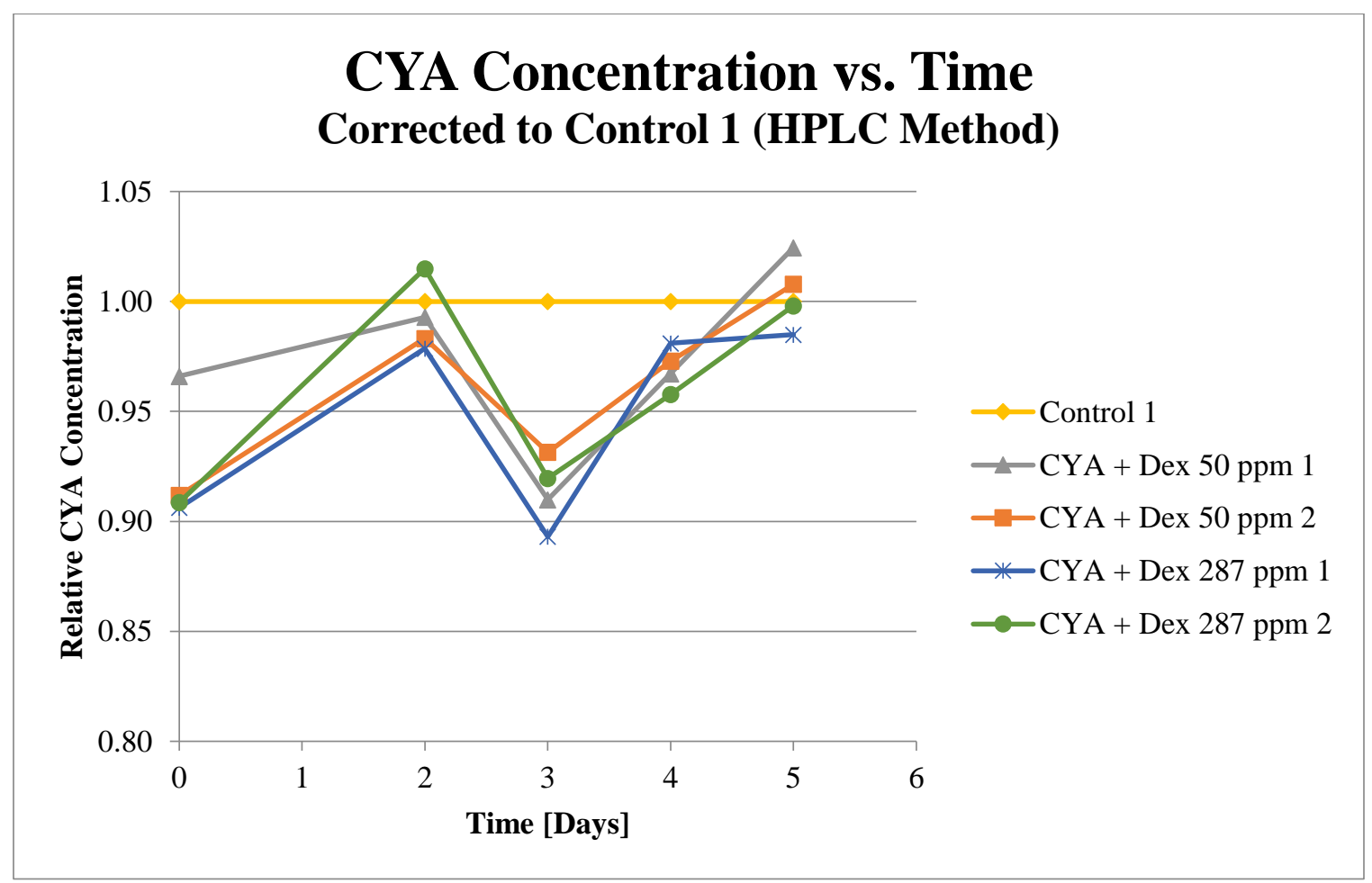

Figure 4-51: Experiment IV-19 CYA Concentration vs. Time Corrected to Control 1, HPLC Measurement, Vegetative Bacterial Inoculums, DI Water with Dextrose at $30^{\circ} \mathrm{C}$ and 75 RPM, Anaerobic 
Data corrected to "Control 1" (Figure 4-51) showed systematic error similar to that seen in Experiment IV-17. The systematic error caused the test to be inconclusive; however the data suggest that there is no change in CYA relative to the control treatment. CYA concentrations did not vary by more than $11 \%$ from the control before the guard column was changed. After the guard column was changed, CYA concentrations differed from "Control 1" by no more than $5 \%$.

\subsubsection{Experiment IV-20 Effect of Activated CAR and Filter Media on CYA}

Experiment IV-20 sought to stimulate the degradation of CYA by introducing vegetative Thai FOG supernatant to a minimal growth media containing CYA. Additionally, a section of swimming pool media filter was incubated in growth media, and the activated cultures were added to flasks containing minimal growth media and CYA.

Nitrate in the minimal media caused interference with initial HPLC measurement of CYA, so apparent CYA concentrations at $\mathrm{T}=0$ Days were artificially high (Figure 4-52). After three days of anaerobic incubation, it was assumed that all nitrate had been biodegraded from the samples, and that peak areas of CYA were indicative of true concentrations. Chromatograms showed similar levels of absorbance between nitrate and CYA with sufficient separation of peaks (Appendix E).

Significant bacterial growth and gas production were noted within the first three days of incubation. An existing crack in the flask containing the "Thai FOG 2" treatment propagated vertically through the bottle, due to increased pressure. This caused half of the 146 
growth media to be extruded from the flask. It is assumed that air was introduced to the system, preventing a fully anaerobic environment from forming. Therefore, "Thai FOG 2" was not included in the chart of averaged CYA concentrations, Figure 4-52.

Gas production by each treatment slowed significantly after $\mathrm{T}=3$ days. An additional 1.6 g/L of dextrose were added to "Thai FOG 1," "Thai FOG 2," "Filter Media 1," and "Filter Media 2" at T=7 days. Gas production continued alongside visible sedimentation/settling of bacterial cells.

When treatments and controls were averaged, no appreciable or consistent change was seen in CYA concentration relative to the control (Figure 4-53).



Figure 4-52: Experiment IV-20 Anaerobic CYA Concentration vs. Time, Excluding T=0, Vegetative Bacteria, Minimal Media at $30^{\circ} \mathrm{C}$ and $75 \mathrm{RPM}$, Anaerobic 


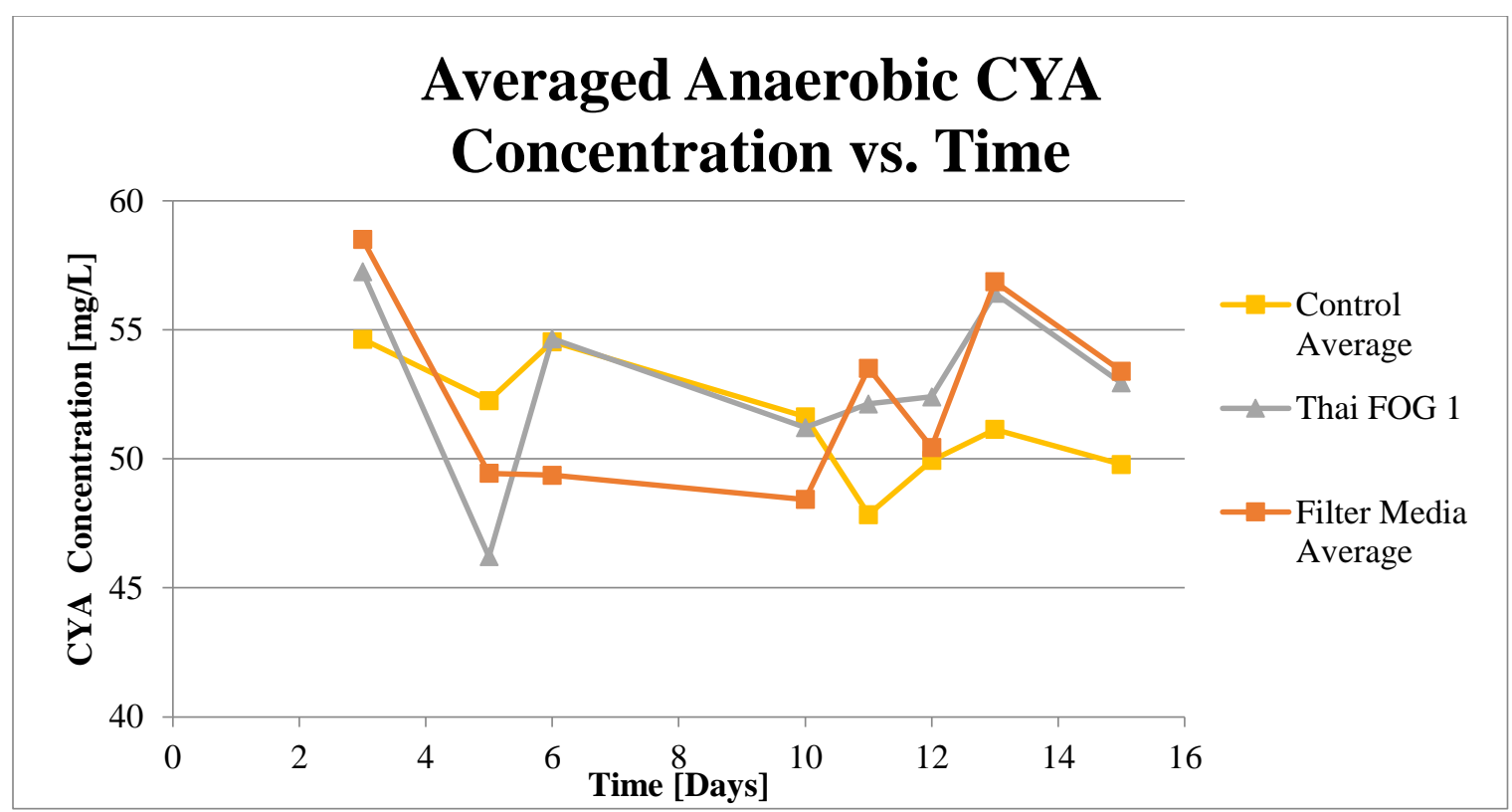

Figure 4-53: Experiment IV-20 Averaged CYA Concentration vs. Time, Excluding T=0, Excluding Thai FOG 2, Vegetative Bacteria, Minimal Media at $30^{\circ} \mathrm{C}$ and $75 \mathrm{RPM}$, Anaerobic

Similar levels of variation were seen between all trials in Figure 4-52. No degradation of CYA was seen by Thai FOG or the Filter Media treatments using the developed method. The averaged trials in Figure 4-53 show a relatively high reading of CYA at $\mathrm{T}=3$ Days, which is probably due to continued interference by nitrate. The inability of the method to resolve high nitrate peaks from CYA prevents definitive conclusions from being made. 


\section{CHAPTER 5 - CONCLUSIONS}

\subsection{Results of the Determination of Clarification Mechanism}

- Solid substrate products provide enhanced clarification in the first 24 hours, compared to un-amended mechanical filtration. (Section 4.1.10)

- Thai FOG, active or irradiated, provides the greatest enhancement of initial clarification with mechanical filtration, relative to un-amended mechanical filtration. (Section 4.1.10)

- Adsorption is the driving mechanism of additional turbidity removal provided by the solid substrate of BiOWiSH products. (Experiments I-5 and I-8, Section 4.1.10)

- Control tanks with just sunscreen commonly showed levels of turbidity reduction on-par or more effective than BiOWiSH products. (Experiments I-2, I-3, I-4, and I8)

- Improved turbidity reduction over time is observed in control treatments which became contaminated during long-term clarification experiments. Biodegradation may be the cause of turbidity reduction, but the true mechanism remains unconfirmed. (Experiment I-8)

\subsection{Results Regarding the Efficacy of BiOWiSH Clarifying Oils from Swimming Pools}

- Without mechanical filtration, Thai FOG reduces turbidity caused by sunscreen within 24 hours of dosing the dry product. (Experiments II-1 and II-5) 
- Chlorine is scoured by all BiOWiSH products and growth media. (Experiments II1.2 , II-2, II-3, and II-4)

- Physical separation (floating and settling of material) accounts for a large portion of turbidity reduction. (Experiment II-4)

- In flasks, no reduction of turbidity induced by sunscreen, was seen relative to control treatments. (Experiments II-6 and II-7)

\subsection{Results Regarding the Isolation and Identification of Bacteria}

- Two predominant types of bacterial colonies are present when samples of used BiOWiSH products are plated. This is most likely due to cross-contamination of treatments. (Experiments III-1 and III-2)

\subsection{Results Regarding the Biodegradation of Cyanuric Acid}

- Results suggest that there is no measureable change in CYA via biodegradation or adsorption by $\mathrm{BiOWiSH}$ products in bench-scale tests, however; the low accuracy of the developed method prevents definitive conclusions from being drawn. (Experiments IV-11, IV-12, IV-15, and IV-17 through IV-20)

- Thai FOG appears to interfere with the turbidimetric precipitation assay of CYA measurement. CYA reduction was observed by the solid substrate of Thai FOG using the turbidimetric method, but not through HPLC. (Experiment IV-2, IV-4, and IV-6) 
- Without a column heater, peak areas vary significantly, between analysis sequences. To convert peak area to concentration, a 4-point calibration should be run before each set of samples is analyzed. (Experiments IV-17 through IV-20)

- Using the available Agilent 1100 HPLC system, a method for replicable measurement of CYA was not achieved.

- Separation of CYA from nitrate/nitrite was achieved with the method which follows in Table 5-1, below.

Table 5-1: Final HPLC Method for separation of Nitrate/Nitrite from CYA

\begin{tabular}{ll}
\hline Parameter & Value \\
\hline Column & Waters XBridge C18 \\
Mobile Phase & $1 \%$ methanol \\
& $69.5 \% 50 \mathrm{mM} \mathrm{KH}_{2} \mathrm{PO}_{4}$ buffer (pH 5.70) in DI water \\
& $29.5 \%$ distilled water \\
Flow Rate & $0.300 \mathrm{~mL} / \mathrm{min}$ \\
Injection volume & $1 \mathrm{uL}$ \\
Detection wavelength & $213 \mathrm{~nm}$ \\
Temperature & $18-20^{\circ} \mathrm{C}$ (ambient) \\
Sample Run Time & 5 minutes \\
\hline
\end{tabular}

- The best resolution of CYA through HPLC analysis was observed at peak areas between 100 and $200 \mathrm{mAU}^{*}$ s, which corresponds with peak heights less than 20 mAU. 


\subsection{Future Research}

- Analyze CYA with HPLC at a constant temperature, to determine whether the systematic error in measurement is indeed temperature-induced.

- Perform an experiment which confirms both the biodegradation of CYA and the ability of HPLC method to measure the reduction of CYA, using a bacteria spp. which has been proven to degrade CYA.

- Clarification with controls in separate laboratory to prevent contamination of the control.

- Test clarification rates in aerated and strictly anaerobic environments in order to gauge the difference in clarification rates. 


\section{REFERENCES}

American Elements. 2015. "Zinc Oxide Nanopowder." American Elements;

Nanomaterials Database. http://www.americanelements.com/nanomaterialsnanoparticles-nanotechnology.html.

Badia-Fabregat, Marina, Carlos E. Rodríguez-Rodríguez, Pablo Gago-Ferrero, Alba Olivares, Benjamí Piña, M. Silvia Díaz-Cruz, Teresa Vicent, Damià Barceló, e, and Glòria Caminal. 2012. "Degradation of UV filters in sewage sludge and 4MBC in liquid medium by the ligninolytic fungus Trametes versicolor." Journal of Environmental Management 104 (Aug): 114-20. doi:10.1016/j.jenvman.2012.03.039. http://www.sciencedirect.com/science/article/pii/S0301479712001582.

Baron S, Salton MRJ, Kim KS. 1996. “Structure.” Baron's Medical Microbiology (4th ed.). University of Texas Medical Branch. ISBN 0-9631172-1-1.

Breakwell, Donald, Christopher Woolverton, Bryan MacDonald, Kyle Smith, and Richard Robison. 2007. "Colony Morphology Protocol." American Society for Microbiology MicrobeLibrary. http://www.microbelibrary.org/component/resource/laboratory-test/3136-colonymorphology-protocol.

California Code of Regulations. 2015. "Title 22, Division 4, Chapter 20. Public Swimming Pools." California Code of Regulations. https:/govt.westlaw.com/calregs/Browse/Home/California/CaliforniaCodeofRegu lations?guid=I6C51CF80D4BA11DE8879F88E8B0DAAAE\&originationContext $=$ documenttoc $\&$ transitionType $=$ Default $\&$ contextData $=($ sc. Default $)$.

Camper, A.K., and G.A. McFeters. 1979. "Chlorine injury and the enumeration of waterborne coliform bacteria." American Society for Microbiology Applied and Environmental Microbiology 37 (3) (March): 633-641. http://aem.asm.org/content/37/3/633.short.

Cantú, Ricardo, Otis Evans, Fred K. Kawahara, Larry J. Wymer, and Alfred P. Dufour. 2001. "HPLC Determination of Cyanuric Acid in Swimming Pool Waters Using Phenyl and Confirmatory Porous Graphitic Carbon Columns." Analytical Chemistry 73 (14) (June): 3358-3364. doi: 10.1021/ac001412t. http://pubs.acs.org/doi/full/10.1021/ac001412t. 
Caspi, Ron, Tomer Altman, Richard Billington, Kate Dreher, Hartmut Foerster, Carol A. Fulcher, Timothy A. Holland, Ingrid M. Keseler, Anamika Kothari, Aya Kubo, Markus Krummenacker, Mario Latendresse, Lukas A. Mueller, Quang Ong, Suzanne Paley, Pallavi Subhraveti, Daniel S. Weaver, Deepika Weerasinghe, Peifen Zhang, and Peter D. Karp. 2014. "The MetaCyc database of metabolic pathways and enzymes and the BioCyc collection of Pathway/Genome Databases." Nucleic Acids Research 42 (1) (Jan): D459-71. doi: 10.1093/nar/gkt1103. http://nar.oxfordjournals.org/content/42/D1/D459.

CDC. 2009. “Chlorine Residual Testing Factsheet.” Centers for Disease Control SWS Project. http://www.cdc.gov/safewater/publications_pages/chlorineresidual.pdf.

CDC. 2010. "Violations Identified from Routine Swimming Pool Inspections --- Selected States and Counties, United States, 2008." Centers for Disease Control and Prevention, Morbidity and Mortality Weekly Report (MMWR). http://www.cdc.gov/mmwr/preview/mmwrhtml/mm5919a2.htm.

CDC. 2014. "Healthy Swimming Fast Facts." Centers for Disease Control and Prevention. http://www.cdc.gov/healthywater/swimming/.

Cheng, Gang, Nir Shapir, Michael J. Sadowsky, and Lawrence P. Wackett. 2005. "Allophanate Hydrolase, Not Urease, Functions in Bacterial Cyanuric Acid Metabolism." Applied Environmental Microbiology 71 (8) (Aug): 4437-45. doi: 10.1128/AEM.71.8.4437-4445.2005. http://www.ncbi.nlm.nih.gov/pmc/articles/PMC1183272/.

Cooke, Rosa-lee. 2000. "Chlorination Chemistry." Mountain Empire Community College; Water/Wastewater Distance Learning Website. http://water.me.vccs.edu/concepts/chlorchemistry.html.

DailyMed. 2012. “COPPERTONE SPORT HIGH PERFORMANCE SPF 30avobenzone, homosalate, octisalate and octocrylene lotion." DailyMed Drug Label Info Database.

http://dailymed.nlm.nih.gov/dailymed/drugInfo.cfm?setid=1a9c97c8-7f50-41afaf39-feb78378789f.

EPA. 2012. "Turbidity." United States Environmental Protection Agency. http://water.epa.gov/type/rs1/monitoring/vms55.cfm.

HACH. 2009. "DR/820, DR/850, and DR/890 Portable Datalogging Colorimeter Instrument Manual." HACH Industries Product Downloads Website. http://www.hach.com/dr-890-portable-colorimeter/productdownloads?id=7640439041. 
Kotharu, Prasad. 2014. "Cyanuric acid Pathway Map.” EAWAG

Biocatalyst/Biodegradation Database. http://eawagbbd.ethz.ch/cya/cya_map.html.

Linhart, Jason. 2014. "Pool Filter Comparison." Trouble Free Pool Database. http://www.troublefreepool.com/content/160-pool-filter-comparison.

Lloyd, David. 1993. "Aerobic denitrification in soils and sediments: From fallacies to facts." Trends in Ecology and Evolution 8 (10) (Oct): 352-356. doi: 10.1016/0169-5347(93)90218-E. http://www.sciencedirect.com/science/article/pii/016953479390218E.

Osborne, Jeffrey P., and Joseph Planer. 2013. "Nitrate (anaerobic) Pathway Map." EAWAG Biocatalyst/Biodegradation Database. http://eawagbbd.ethz.ch/nit/nit_map.html.

Ou, J.P., and Duan, Z.D. 2005. "Low Vacuum Scanning Electron Microscope." Structural Health Monitoring and Intelligent Infrastructure 2: 901. CRC Press. ISBN 9780415396523.

P.K. Data, Inc. 2013. US Swimming Pool and Hot Tub Market 2013.” P.K. Data, Inc. http://apsp.org/portals/0/images/APSP\%20statistics\%202013.jpg.

Pennsylvania Department of Public Health.2015. "Fact Sheet on Cyanuric Acid and Stabilized Chlorine Products" Pennsylvania Department of Public Health. http://www.portal.state.pa.us/portal/server.pt/community/environmental_health/1 4143/fact_sheet_on_cyanuric_acid_and_stabilized_chlorine_products/556676.

Rovner, Sophie L. 2008. "Anatomy of a Pet Food Catastrophe." Chemical and Engineering News 86 (18) (May): 41-43. https://pubs.acs.org/cen/science/86/8619sci3.html.

Saldick, Jerome. 1974. "Biodegradation of Cyanuric Acid." Applied Microbiology 28 (6) (Dec): 1004-8. http://aem.asm.org/content/28/6/1004.full.pdf

Sanders, E. R. 2012. “Aseptic Laboratory Techniques: Plating Methods.” Journal of Visualized Experiments. (63): e3064. doi: 10.3791/3064. http://www.jove.com/video/3064/aseptic-laboratory-techniques-plating-methods.

Schlumpf, M., Cotton, B., Conscience, M., Haller, V., Steinmann, B., \& Lichtensteiger, W. 2001. "In Vitro and in Vivo Estrogenicity of UV Screens: Response." Environmental Health Perspectives: A359-A61. http://www.ncbi.nlm.nih.gov/pmc/articles/PMC1240241/pdf/ehp0109000239.pdf. 
Shields, J.M., Arrowood M.J., Hill V.R., and Beach M.J. 2009. "The effect of cyanuric acid on the disinfection rate of Cryptosporidium parvum in 20-ppm free chlorine." Journal of Water Health (1) March: 109-14. doi: 10.2166/wh.2009.008. http://www.ncbi.nlm.nih.gov/pubmed/18957779.

Stern, Robert S., Weinstein, Milton C., Baker, Stuart G. 1986. "Risk Reduction for Nonmelanoma Skin Cancer With Childhood Sunscreen Use." JAMA Dermatology. 122 (5):537-45. doi:10.1001/archderm.1986.01660170067022. http://archderm.jamanetwork.com/article.aspx?articleid=547163.

Tran, BN, Okoniewski. R, Storm. R, Jansing. R, and Aldous. KM. 2010. "Use of methanol for the efficient extraction and analysis of melamine and cyanuric acid residues in dairy products and pet foods." Journal of Agricultural and Food Chemistry 58 (1) (Jan): 101-7. doi: 10.1021/jf903040z. http://www.ncbi.nlm.nih.gov/pubmed/19904985.

Tucker, Samuel P. 1994. “Cyanuric Acid 5030.” NIOSH Manual of Analytic Methods (4th ed.). http://www.cdc.gov/niosh/docs/2003-154/pdfs/5030.pdf.

WHO. 2006. "Guidelines for safe recreational water environments." Geneva: World Health Organization. http://www.who.int/water_sanitation_health/bathing/srwe2full.pdf.

Wojtowicz, John A. 2001. "Relative Bactericidal Effectiveness of Hypochlorous Acid and Chloroisocyanurates." Journal of the Swimming Pool and Spa Industry 2 (1): 34-41. http://jspsi.poolhelp.com/articles/jspsi_v2n1_pp34-41.pdf.

Zwiener, Christian, Susan D. Richardson, David M. De Marini, Tamara Grummt, Thomas Glauner, and Fritz H. Frimmel. 2007. "Drowning in Disinfection Byproducts? Assessing Swimming Pool Water." Environmental Science \& Technology 41 (2): 363-72. doi: 10.1021/es062367v. http://pubs.acs.org/doi/full/10.1021/es062367v. 


\section{APPENDICES}

\section{Appendix A: Data Tables}

Table 7-1: Experiment I-1 Raw Turbidity Data

\begin{tabular}{lllll}
\hline & \multicolumn{4}{c}{ Turbidity [NTU] } \\
\cline { 2 - 5 } & $\mathrm{T}=0$ & $\mathrm{~T}=0.25$ & $\mathrm{~T}=18$ & $\mathrm{~T}=36$ \\
Treatment & Hours & Hours & Hours & Hours \\
\hline Thai FOG & 48 & 55 & 10 & 5 \\
\hline
\end{tabular}

Table 7-2: Experiment I-2 Raw Turbidity Data

\begin{tabular}{llllllll}
\hline & \multicolumn{7}{c}{ Turbidity [NTU] } \\
\cline { 2 - 8 } Treatment & $\mathrm{T}=0$ & $\mathrm{~T}=18$ & $\mathrm{~T}=48$ & $\mathrm{~T}=72$ & $\mathrm{~T}=96$ & $\mathrm{~T}=120$ & $\mathrm{~T}=144$ \\
& Hours & Hours & Hours & Hours & Hours & Hours & Hours \\
\hline US FOG & 56 & 13 & 10 & 8 & 0 & 4 & 3 \\
Thai FOG & 53 & 18 & 3 & 4 & 0 & 7 & 5 \\
Control & 52 & 8 & 3 & 0 & 0 & 1 & 0 \\
\hline
\end{tabular}

Table 7-3: Experiment I-3 Raw Turbidity Data

\begin{tabular}{lllll}
\hline & \multicolumn{4}{c}{ Turbidity [NTU] } \\
\cline { 2 - 5 } & US & Thai & US Rice \\
Day & FOG & FOG & Bran & Control \\
\hline 0 & 48 & 55 & 66 & 47 \\
1 & 7 & 2 & 30 & 9 \\
2 & 2 & 3 & 20 & 4 \\
3 & 1 & 6 & 15 & 1 \\
3.01 & 41 & 63 & 69 & 50 \\
4 & 9 & 33 & 34 & 16 \\
5 & 3 & 16 & 22 & 3 \\
6 & 0 & 14 & 19 & 8 \\
7 & 2 & 13 & 22 & 2 \\
7.01 & 48 & 55 & 73 & 37 \\
8 & 6 & 22 & 48 & 11 \\
9 & 3 & 16 & 44 & 5 \\
\hline
\end{tabular}




\begin{tabular}{lllll}
\hline 10 & 3 & 13 & 43 & 5 \\
10.01 & 53 & 65 & 93 & 58 \\
12 & 7 & 28 & 51 & 9 \\
13 & 5 & 45 & 42 & 6 \\
14 & 5 & 55 & 48 & 5 \\
15 & 5 & 59 & 46 & 6 \\
16 & 5 & 62 & 49 & 4 \\
16.01 & 50 & 105 & 91 & 35 \\
17 & 8 & 62 & 75 & 10 \\
18 & 8 & 75 & 62 & 8 \\
\hline
\end{tabular}

Table 7-4: Experiment I-4 Raw Turbidity Data

\begin{tabular}{llllll}
\hline & \multicolumn{5}{c}{ Turbidity (NTU) } \\
\cline { 2 - 6 } Day & US FOG & US FOG & & Thai FOG & \\
\hline 24 & 6 & 10 & 17 & 17 & Control \\
25 & 5 & 12 & 16 & 13 & 7 \\
25.01 & 46 & 63 & 61 & 56 & 54 \\
26 & 24 & 24 & 20 & 16 & 17 \\
27 & 30 & 20 & 16 & 15 & 16 \\
28 & 15 & 6 & 11 & 5 & 10 \\
29 & 20 & 19 & 17 & 11 & 12 \\
30 & 14 & 10 & 13 & 7 & 8 \\
31 & 1 & 11 & 12 & 7 & 8 \\
\hline
\end{tabular}

Table 7-5: Experiment I-5 Raw Turbidity Data

\begin{tabular}{llllllll}
\hline & \multicolumn{6}{c}{ Turbidity [NTU] } \\
\cline { 2 - 7 } Day & US FOG & Mix \#1 & Mix \#2 & FOG & Premix & BMT SS \\
\hline 0 & 51 & 43 & 37 & 44 & 47 & 50 \\
1 & 30 & 2 & 1 & 2 & 1 & 2 \\
2 & 30 & 6 & 6 & 6 & 3 & 2 \\
2.1 & 72 & 43 & 52 & 48 & 48 & 51 \\
3 & 32 & 11 & 19 & 12 & 9 & 8 \\
4 & 22 & 14 & 13 & 12 & 7 & 10 \\
\hline
\end{tabular}




\begin{tabular}{lllllll}
\hline 5 & 16 & 16 & 17 & 11 & 7 & 11 \\
6 & 11 & 16 & 17 & 11 & 5 & 7 \\
7 & 6 & 6 & 14 & 11 & 4 & 9 \\
8 & 4 & 3 & 9 & 9 & 8 & 15 \\
8.1 & 58 & 61 & 62 & 71 & 63 & 70 \\
9 & 31 & 22 & 20 & 16 & 18 & 20 \\
10 & 25 & 23 & 19 & 16 & 14 & 22 \\
11 & 21 & 18 & 17 & 15 & 11 & 18 \\
12 & 14 & 17 & 18 & 14 & 9 & 15 \\
13 & 10 & 11 & 13 & 14 & 9 & 11 \\
14 & 6 & 5 & 8 & 13 & 6 & 7 \\
15 & 5 & 4 & 8 & 13 & 3 & 7 \\
16 & 4 & 4 & 7 & 12 & 3 & 5 \\
16.1 & 63 & 68 & 67 & 77 & 61 & 75 \\
27 & 18 & 5 & 5 & 6 & 5 & 8 \\
\hline
\end{tabular}

Table 7-6: Experiment I-6 Raw Turbidity Data

\begin{tabular}{llllllll}
\hline & \multicolumn{7}{c}{ Turbidity (NTU) } \\
\cline { 2 - 7 } Day & Manure/ & Odor & Premix & BS-AQ- & BS-AQ- & BS-AQ- & Thai Rice \\
US Rice \\
Bran & Bran \\
\hline 0 & 45 & 32 & 42 & 56 & 47 & 54 & 37 \\
1 & 2 & 0 & 2 & 2 & 2 & 6 & 2 \\
1.1 & 52 & 53 & 56 & 52 & 49 & 66 & 52 \\
2 & 15 & 6 & 19 & 14 & 15 & 16 & 24 \\
3 & 23 & 5 & 17 & 14 & 12 & 6 & 17 \\
4 & 22 & 5 & 17 & 16 & 14 & 7 & 17 \\
5 & 20 & 6 & 20 & 17 & 13 & 9 & 18 \\
6 & 23 & 19 & 23 & 18 & 17 & 10 & 17 \\
7 & 25 & 25 & 31 & 25 & 19 & 10 & 17 \\
\hline
\end{tabular}


Table 7-7: Experiment I-7 Raw Data Turbidity

\begin{tabular}{llllllll}
\hline & \multicolumn{7}{c}{ Turbidity [NTU] } \\
\cline { 2 - 8 } Day & $\begin{array}{l}\text { Fruit } \\
\text { Wash }\end{array}$ & Premix & AP 001 & AP 002 & AP 003 & $\begin{array}{l}\text { Thai } \\
\text { Bran }\end{array}$ & Rice \\
& & & & & $\begin{array}{l}\text { Irradiated Thai } \\
\text { Rice Bran }\end{array}$ \\
\hline 0 & 49 & 53 & 55 & 56 & 61 & 70 & 59 \\
1 & 19 & 2 & 44 & 12 & 30 & 20 & 35 \\
1.1 & 67 & 57 & 73 & 61 & 76 & 74 & 84 \\
2 & 19 & 17 & 29 & 47 & 45 & 31 & 35 \\
3 & 13 & 16 & 20 & 29 & 29 & 24 & 25 \\
\hline
\end{tabular}

Table 7-8: Experiment I-8 Raw Turbidity Data

\begin{tabular}{llllllll}
\hline & \multicolumn{7}{c}{ Turbidity [NTU] } \\
\cline { 2 - 7 } Day & Premix & Premix & Thai & Thai & IR Thai & IR Thai \\
& 1 & 2 & FOG 1 & FOG 2 & FOG 1 & FOG 2 & Control \\
\hline 0 & 39 & 42 & 44 & 43 & 37 & 40 & 50 \\
1 & 1 & 2 & 2 & 3 & 2 & 1 & 15 \\
1.1 & 56 & 57 & 55 & 55 & 58 & 52 & 58 \\
2 & 12 & 11 & 15 & 16 & 15 & 13 & 17 \\
2.1 & 68 & 62 & 71 & 71 & 69 & 65 & 65 \\
3 & 27 & 27 & 39 & 41 & 35 & 30 & 25 \\
4 & 18 & 14 & 17 & 18 & 17 & 16 & 12 \\
5 & 22 & 17 & 16 & 17 & 27 & 17 & 7 \\
6 & 18 & 14 & 15 & 18 & 22 & 19 & 2 \\
7 & 16 & 14 & 13 & 16 & 20 & 18 & 2 \\
8 & 13 & 13 & 15 & 15 & 17 & 16 & 3 \\
9 & 9 & 10 & 14 & 12 & 13 & 14 & 4 \\
10 & 8 & 9 & 11 & 13 & 12 & 15 & 6 \\
10.1 & 59 & 63 & 69 & 65 & 55 & 64 & 56 \\
11 & 41 & 58 & 54 & 43 & 32 & 31 & 15 \\
12 & 26 & 38 & 35 & 33 & 23 & 24 & 10 \\
13 & 20 & 28 & 26 & 29 & 20 & 18 & 7 \\
\hline
\end{tabular}


Table 7-9: Experiment I-9 Raw Turbidity Data

\begin{tabular}{|c|c|c|c|c|c|c|}
\hline \multirow[b]{2}{*}{ Day } & \multicolumn{6}{|c|}{ Turbidity [NTU] } \\
\hline & $\begin{array}{l}\text { CAR + } \\
\text { CYA }\end{array}$ & $\mathrm{CAR}+\mathrm{Cl}$ & $\begin{array}{l}\mathrm{CAR}+ \\
\mathrm{CYA}+\mathrm{Cl}\end{array}$ & $\begin{array}{l}\mathrm{CAR}+ \\
\mathrm{CYA}+\mathrm{Cl}\end{array}$ & CAR & $\begin{array}{l}\text { Filter Media } \\
+ \text { CYA }\end{array}$ \\
\hline 0 & 47 & 52 & 47 & 45 & 1 & 2 \\
\hline 1 & 6 & 9 & 16 & 6 & 3 & 4 \\
\hline 1.1 & 58 & 55 & 60 & 57 & 4 & 59 \\
\hline 2 & 30 & 14 & 20 & 14 & 6 & 12 \\
\hline 3 & 15 & 7 & 11 & 7 & 5 & 9 \\
\hline 4 & 11 & 10 & 12 & 6 & 5 & 11 \\
\hline 4.1 & 59 & 59 & 60 & 53 & 5 & 62 \\
\hline 5 & 17 & 29 & 9 & 10 & 6 & 14 \\
\hline 6 & 10 & 17 & 11 & 7 & 4 & 9 \\
\hline 7 & 6 & 15 & 9 & 8 & 7 & 5 \\
\hline 7.1 & 63 & 52 & 62 & 56 & 6 & 59 \\
\hline 8 & 11 & 22 & 28 & 23 & 7 & 16 \\
\hline 9 & 5 & 16 & 22 & 19 & 6 & 8 \\
\hline 10 & 4 & 14 & 18 & 14 & 6 & 5 \\
\hline 11 & 4 & 17 & 16 & 12 & 6 & 5 \\
\hline 12 & 2 & 8 & 15 & 12 & 5 & 4 \\
\hline 12.1 & 41 & 55 & 68 & 57 & 5 & 49 \\
\hline 13 & 30 & 26 & 31 & 28 & 5 & 9 \\
\hline 14 & 15 & 16 & 25 & 21 & 6 & 4 \\
\hline 15 & 11 & 15 & 19 & 16 & 5 & 4 \\
\hline
\end{tabular}

Table 7-10: Experiment I-9 CYA Concentration vs. Time

\begin{tabular}{lrrrrrrr}
\hline & \multicolumn{7}{c}{ CYA Concentration [mg/L] } \\
\cline { 2 - 8 } Tank & Days $=0$ & Days & Days & Days & Days & Days & Days \\
\hline 1 & 90 & 105 & 122 & 109 & 93 & 94 & 95 \\
2 & 14 & 12 & 67 & 6 & 13 & 0 & 0 \\
3 & 88 & 102 & 110 & 103 & 97 & 90 & 94 \\
4 & 89 & 105 & 105 & 105 & 104 & 88 & 93 \\
5 & 89 & 112 & 126 & 210 & 102 & 101 & 102 \\
6 & 85 & 105 & 115 & 102 & 102 & 93 & 96 \\
\hline
\end{tabular}


Table 7-11: Compiled Percent Reduction after 1 Day, for Each Experiment

\begin{tabular}{ll}
\hline $\begin{array}{l}\text { Treatment, Grouped } \\
\text { by Experiment }\end{array}$ & $\begin{array}{l}\text { Percent Turbidity } \\
\text { Reduction at Day 1 }\end{array}$ \\
\hline I-1 Thai FOG & 82 \\
& \\
I-2 US FOG & 77 \\
I-2 Thai FOG & 66 \\
I-2 Control & 85 \\
& \\
I-3 US FOG & 85 \\
I-3 Thai FOG & 96 \\
I-3 Rice Bran & 55 \\
I-3 Control & 81 \\
& \\
I-5 Mix \#1 & 95 \\
I-5 Mix \#2 & 97 \\
I-5 IR Thai FOG & 95 \\
I-5 Premix & 98 \\
I-5 BMT SS & 96 \\
& \\
I-6 Manure/ Odor & 96 \\
I-6 Premix & 100 \\
I-6 BS-AQ-001 & 95 \\
I-6 BS-AQ-002 & 96 \\
I-6 BS-AQ-003 & 96 \\
I-6 Thai Rice Bran & 89 \\
I-6 US Rice Bran & 94 \\
& \\
I-7 Fruit Wash & 61 \\
I-7 Premix & 96 \\
I-7 AP 001 & 20 \\
I-7 AP 002 & 79 \\
I-7 AP 003 & 51 \\
I-7 Thai Rice Bran & 71 \\
I-7 Irradiated Thai Bran & 41 \\
& \\
I-8 Premix 1 & 97 \\
I-8 Premix 2 & 95 \\
I-8 Thai FOG 1 & 95 \\
I-8 Thai FOG 2 & 93 \\
\hline
\end{tabular}




\begin{tabular}{ll}
\hline $\begin{array}{l}\text { Treatment, Grouped } \\
\text { by Experiment }\end{array}$ & $\begin{array}{l}\text { Percent Turbidity } \\
\text { Reduction at Day 1 }\end{array}$ \\
\hline I-8 IR Thai FOG 1 & 95 \\
I-8 IR Thai FOG 2 & 98 \\
Control & 70 \\
& \\
I-9 CAR + CYA & 87 \\
I-9 CAR + Cl & 83 \\
I-9 CAR + CYA + Cl 1 & 66 \\
I-9 CAR + CYA + Cl 2 & 87 \\
I-9 Filter Media + CYA & 80 \\
\hline
\end{tabular}

Table 7-12: Experiment II-1 Raw Absorbance Data at $470 \mathrm{~nm}$

\begin{tabular}{lllll}
\hline & \multicolumn{4}{c}{ Absorbance [AU] } \\
\cline { 2 - 5 } Day & $\begin{array}{l}\text { Sunscreen }+ \\
\text { Thai FOG }\end{array}$ & Sunscreen & Thai FOG & Tap Water \\
\hline 0 & 0.133 & 0.276 & 0.012 & -0.023 \\
1 & 0.040 & 0.236 & 0.022 & -0.015 \\
2 & 0.026 & 0.193 & 0.062 & -0.018 \\
3 & 0.022 & 0.179 & 0.078 & -0.01 \\
4 & 0.087 & 0.232 & 0.098 & -0.021 \\
5 & 0.025 & 0.222 & 0.07 & -0.043 \\
\hline
\end{tabular}

Table 7-13: Experiment II-1.2 Chlorine Compatibility Raw Data

\begin{tabular}{llll}
\hline & \multicolumn{3}{l}{ Total Chlorine $[\mathrm{mg} / \mathrm{L}]$} \\
\cline { 2 - 4 } Treatment & Hours & Hours & Hours \\
\hline $20-20-20$ & 5 & 0.42 & $\mathrm{x}$ \\
MRS & 5 & 0.65 & $\mathrm{x}$ \\
Minimal & 5 & 3.85 & 0.02 \\
Tap Water & 5 & 4.59 & 1.66 \\
\hline
\end{tabular}


Table 7-14: Experiment II-2 Raw Total Chlorine Data

\begin{tabular}{llll}
\hline & \multicolumn{3}{c}{ Chlorine (mg/L) } \\
\cline { 2 - 4 } Product & $\begin{array}{l}\mathrm{T}=0 \\
\text { hours }\end{array}$ & $\begin{array}{l}\mathrm{T}=4.5 \\
\text { hours }\end{array}$ & $\begin{array}{l}\mathrm{T}=25 \\
\text { hours }\end{array}$ \\
\hline Osprey MPB 5 & 1.19 & 0.04 & 0.03 \\
Osprey BPB 100 & 0.89 & 0.02 & 0.02 \\
Osprey Waste Water & 0.73 & 0.01 & 0.11 \\
US Aqua & 2.07 & 0.36 & 0.09 \\
Us FOG & 1.99 & 0.19 & 0.16 \\
MDG Petro & 0.87 & -0.06 & 0.02 \\
MDG Waste Water & 2.04 & 0.31 & 0.06 \\
Thai FOG & 0.19 & -0.01 & 0.15 \\
Minimal Media & 2.41 & 1.16 & 0.13 \\
sunscreen + Media 525 mg/L & 2.23 & 0.11 & 0.45 \\
sunscreen + Water 536 mg/L & 3.48 & 0.22 & 0.33 \\
Tap Water & 3.07 & 2.08 & 0.23 \\
\hline
\end{tabular}

Table 7-15: Experiment II-4 Raw Turbidity Data, Un-Agitated

\begin{tabular}{llllll}
\hline & \multicolumn{5}{c}{ Turbidity [NTU] } \\
\cline { 2 - 6 } Tank & $\begin{array}{l}\mathrm{T}=0 \\
\text { hours }\end{array}$ & $\begin{array}{l}\mathrm{T}=20 \\
\text { hours }\end{array}$ & $\begin{array}{c}\mathrm{T}=48 \\
\text { hours }\end{array}$ & $\begin{array}{l}\mathrm{T}=70 \\
\text { hours }\end{array}$ & $\begin{array}{l}\mathrm{T}=96 \\
\text { hours }\end{array}$ \\
\hline Control & 22 & 25 & 20 & 19 & 19 \\
Thai FOG & 28 & 11 & 23 & 25 & 31 \\
Fruit Wash II & 22 & 23 & 19 & 19 & 9 \\
Fruit Wash II & 24 & 21 & 21 & 19 & 19 \\
BMT WW1- I & 16 & 13 & 16 & 12 & 11 \\
BMT WW1- II & 23 & 21 & 20 & 21 & 18 \\
BMT WW2 - I & 23 & 18 & 19 & 20 & 23 \\
BMT WW2- II & 19 & 14 & 14 & 16 & 16 \\
\hline
\end{tabular}


Table 7-16: Experiment II-5 Turbidity Raw Data

\begin{tabular}{llllll}
\hline & \multicolumn{5}{c}{ Turbidity [NTU] } \\
\cline { 2 - 6 } Tank & T=0 & $\mathrm{T}=20$ & $\mathrm{~T}=50$ & $\mathrm{~T}=68$ & $\mathrm{~T}=113$ \\
\hline Thai FOG & 70 & 20 & 17 & 22 & 9 \\
LCM 1 & 61 & 58 & 62 & $\mathrm{x}$ & $\mathrm{x}$ \\
LCM 2 & 63 & 59 & 57 & $\mathrm{x}$ & $\mathrm{x}$ \\
BMT WW1 & 62 & 56 & 55 & $\mathrm{x}$ & $\mathrm{x}$ \\
BMT WW2 & 59 & 56 & 56 & $\mathrm{x}$ & $\mathrm{x}$ \\
BMT KLB Mix I & 60 & 57 & 53 & 57 & 31 \\
BMT KLB Mix II & 68 & 64 & 57 & 54 & 55 \\
KLB I & 65 & 62 & 61 & $\mathrm{x}$ & $\mathrm{x}$ \\
KLB II & 66 & 63 & 62 & $\mathrm{x}$ & $\mathrm{x}$ \\
Control & 62 & 58 & 56 & 49 & 61 \\
\hline
\end{tabular}

Table 7-17: Experiment II-6 Raw Turbidity Data

\begin{tabular}{lllllll}
\hline & \multicolumn{5}{c}{ Turbidity [NTU] } \\
\cline { 2 - 6 } Flask & $\mathrm{T}=0$ & $\mathrm{~T}=26$ & $\mathrm{~T}=46$ & $\mathrm{~T}=74$ & $\mathrm{~T}=98$ & $\mathrm{~T}=121$ \\
\hline Osprey MPB-5 & Hours & Hours & Hours & Hours & Hours & Hours \\
Osprey BPB-100 & 56 & 16 & 12 & 14 & 14 & 11 \\
Osprey MPB-5 Liq & 5 & 57 & 62 & 49 & 44 & 41 \\
BMT WW 1 & 5 & 0 & 0 & 0 & 1 & 1 \\
BMT WW 2 & 2 & 1 & 1 & 0 & 1 & 2 \\
MBWWT\#1 & 1 & 1 & 3 & 1 & 3 & 2 \\
MDG Petro & 6 & 5 & 15 & 0 & 2 & 1 \\
MDG Micro-N & 38 & 41 & 37 & 39 & 5 & 4 \\
Crop & 4 & 7 & 1 & 6 & 8 & 53 \\
Control & 1 & 1 & 1 & 2 & 1 & 2 \\
Fruit Wash & 4 & 2 & 4 & 2 & 2 & 1 \\
LCM & 5 & 2 & 3 & 5 & 3 & 2 \\
Thai FOG & 6 & 6 & 11 & 8 & 8 & 5 \\
Thai Aqua & 9 & 9 & 9 & 5 & 15 & 10 \\
US Aqua & 0 & 1 & 0 & 11 & 1 & 1 \\
US Aqua FOG & 0 & 3 & 0 & 6 & 0 & 1 \\
KLB & 124 & 131 & 134 & 126 & 140 & 114 \\
\hline
\end{tabular}


Table 7-18: Experiment II-7 Raw Data

\begin{tabular}{|c|c|c|c|c|c|c|c|c|c|}
\hline \multirow[b]{3}{*}{ \# } & \multirow[b]{3}{*}{ Flask Label } & \multicolumn{8}{|c|}{ Turbidity [NTU] } \\
\hline & & $\mathrm{T}=0$ & $\mathrm{~T}=18$ & $\mathrm{~T}=38$ & $\mathrm{~T}=70$ & $\mathrm{~T}=94$ & $\mathrm{~T}=115$ & $\mathrm{~T}=139$ & $\mathrm{~T}=154$ \\
\hline & & Hrs & Hrs & Hrs & Hrs & Hrs & Hrs & Hrs & Hrs \\
\hline 1 & Control & 130 & 142 & 143 & 142 & 146 & 148 & 154 & 166 \\
\hline 2 & Osprey MPB-5 & 130 & 145 & 149 & 154 & 143 & 144 & 148 & 151 \\
\hline 3 & Osprey BPB-100 & 164 & 170 & 177 & 177 & 178 & 181 & 184 & 193 \\
\hline 4 & Osprey MPB-5 Liq & 90 & 94 & 95 & 84 & 81 & 91 & 92 & 90 \\
\hline 5 & BMT WW 1 & 117 & 116 & 123 & 119 & 118 & 107 & 124 & 121 \\
\hline 6 & BMT WW 2 & 163 & 156 & 166 & 167 & 153 & 163 & 166 & 167 \\
\hline 7 & MBWWT\#1 & 126 & 123 & 131 & 131 & 127 & 127 & 132 & 130 \\
\hline 8 & MDG Petro & 124 & 124 & 126 & 125 & 126 & 125 & 129 & 128 \\
\hline 9 & MDG Micro-N & 149 & 139 & 139 & 129 & 123 & 130 & 132 & 133 \\
\hline 10 & Crop & 114 & 124 & 125 & 176 & 124 & 130 & 140 & 145 \\
\hline 11 & Fruit Wash & 109 & 115 & 118 & 117 & 112 & 113 & 116 & 118 \\
\hline 12 & LCM & 119 & 125 & 121 & 125 & 116 & 127 & 129 & 132 \\
\hline 13 & Thai FOG & 125 & 127 & 130 & 133 & 134 & 135 & 146 & 149 \\
\hline 14 & Thai Aqua & 128 & 131 & 134 & 134 & 132 & 137 & 137 & 148 \\
\hline 15 & US Aqua & 117 & 126 & 106 & 193 & 125 & 123 & 129 & 133 \\
\hline 16 & US Aqua FOG & 126 & 132 & 134 & 153 & 136 & 137 & 143 & 153 \\
\hline 17 & KLB & 206 & 236 & 239 & 233 & 232 & 248 & 255 & 258 \\
\hline
\end{tabular}

Table 7-19: Experiment IV-2 CYA Concentration vs. Time Raw Data

\begin{tabular}{lllll}
\hline & \multicolumn{4}{c}{ Cyanuric Acid Concentration $\mathrm{mg} / \mathrm{L}$} \\
\cline { 2 - 5 } $\begin{array}{l}\text { Thai FOG } \\
{[\mathrm{mg} / \mathrm{L}]}\end{array}$ & $\mathrm{T}=0$ & $\mathrm{~T}=24$ & $\mathrm{~T}=48$ & $\mathrm{~T}=72$ \\
\hline 50 & 121 & 120 & 120 & 120 \\
75 & 121 & 120 & 95 & 120 \\
100 & 121 & 85 & 110 & 110 \\
150 & 121 & 85 & 90 & 120 \\
300 & 121 & 80 & 85 & 95 \\
\hline
\end{tabular}


Table 7-20: Experiment IV-4 Raw CYA vs. Time Data

\begin{tabular}{|c|c|c|c|c|c|c|c|c|c|c|c|}
\hline \multirow[b]{2}{*}{ Flask } & \multicolumn{11}{|c|}{ CYA Concentration [mg/L] } \\
\hline & $\mathrm{T}=0$ & $\mathrm{~T}=1$ & $\mathrm{~T}=2$ & $\mathrm{~T}=3$ & $\mathrm{~T}=4$ & $\mathrm{~T}=5$ & $\mathrm{~T}=6$ & $\mathrm{~T}=7$ & $\mathrm{~T}=8$ & $\mathrm{~T}=9$ & $\mathrm{~T}=14$ \\
\hline Label & Day & Day & Day & Day & Day & Day & Day & Day & Day & Day & Day \\
\hline US-200 & 57.5 & 60 & 55 & 57.5 & 55 & 55 & 52.5 & 47.5 & 60 & 65 & 55 \\
\hline $\begin{array}{l}\text { Glucose } \\
\text { US-200 }\end{array}$ & 50 & 57.5 & 40 & 32.5 & 40 & 37.5 & 42.5 & 30 & 30 & 445 & \\
\hline Glucose & & & & & & & & & & & \\
\hline $\begin{array}{l}\text { US-50 } \\
\text { Glucose }\end{array}$ & 60 & 50 & 52.5 & 40 & 47.5 & 55 & 50 & 37.5 & 50 & 52.5 & 47.5 \\
\hline $\begin{array}{l}\text { US-50 } \\
\text { Glucose }\end{array}$ & 52.5 & 42.5 & 40 & 27.5 & 35 & 42.5 & 42.5 & 35 & 37.5 & 45 & 37.5 \\
\hline $\begin{array}{l}\text { Thai-200 } \\
\text { Glucose }\end{array}$ & 20 & 12.5 & 22 & 0 & 0 & 0 & 0 & 0 & 0 & 0 & 0 \\
\hline $\begin{array}{l}\text { Thai-200 } \\
\text { Glucose }\end{array}$ & 12.5 & 25 & 2.5 & 0 & 6 & 0 & 0 & 0 & 0 & 0 & 0 \\
\hline $\begin{array}{l}\text { Thai-200 } \\
\text { Sunscreen }\end{array}$ & 10 & 4 & 36 & 32 & 29 & 4 & 12.5 & 20 & 25 & 10 & 29 \\
\hline $\begin{array}{l}\text { US-200 } \\
\text { Sunscreen }\end{array}$ & 32.5 & 37.5 & 40 & 30 & 40 & 42.5 & 37.5 & 30 & 32.5 & 35 & 32.5 \\
\hline $\begin{array}{l}\text { Cyanuric } \\
\text { Acid }\end{array}$ & 40 & 37.5 & 20 & 40 & 37.5 & 40 & 40 & 32.5 & 40 & 37.5 & 37.5 \\
\hline Water & 0 & 0 & 0 & 0 & 0 & 0 & 0 & 0 & 0 & 0 & 0 \\
\hline
\end{tabular}

Table 7-21: Experiment IV-5 Raw CYA vs. Time Data

\begin{tabular}{ll}
\hline $\begin{array}{l}\text { Time } \\
{[\text { Hours }]}\end{array}$ & $\begin{array}{l}\text { CYA } \\
{[\mathrm{mg} / \mathrm{L}]}\end{array}$ \\
\hline 0 & 82.5 \\
0.1 & 85 \\
1 & 82.5 \\
2 & 80 \\
2.1 & 77.5 \\
3 & 70 \\
4 & 82.5 \\
5 & 70 \\
9 & 80 \\
\hline
\end{tabular}


Table 7-22: Experiment IV-6 Raw CYA vs. Time Data

\begin{tabular}{llllllll}
\hline & \multicolumn{7}{c}{ CYA Concentration } \\
\cline { 2 - 8 } Treatment & $\mathrm{T}=0$ & $\mathrm{~T}=0.2$ & $\mathrm{~T}=1$ & $\mathrm{~T}=2$ & $\mathrm{~T}=3$ & $\mathrm{~T}=4$ & $\mathrm{~T}=5$ \\
\hline Thai FOG 1 & 68 & 32.5 & 32.5 & 27.5 & 10 & 5 & 7.5 \\
Thai FOG 2 & 60 & 30 & 37.5 & 25 & 22.5 & 5 & 7.5 \\
Thai FOG 3 & 60 & 37.5 & 37.5 & 25 & 15 & 7.5 & 12.5 \\
US FOG 1 & 60 & 55 & 57.5 & 52.5 & 52.5 & 42.5 & 55 \\
US FOG 2 & 60 & 57.5 & 52.5 & 52.5 & 47.5 & 47.5 & 55 \\
US FOG 3 & 62 & 70 & 60 & 47.5 & 45 & 37.5 & 52.5 \\
\hline
\end{tabular}

Table 7-23: Experiment IV-11 CYA Peak Area Raw Data

\begin{tabular}{ll}
\hline Time (Hours) & $\begin{array}{l}\text { Peak Area } \\
{\left[\mathrm{mAU}^{*} \mathrm{~s}\right]}\end{array}$ \\
\hline 0.5 & 12251 \\
4.5 & 12160 \\
18 & 13966 \\
24 & 12376 \\
48 & 11603 \\
72 & 11947 \\
\hline
\end{tabular}

Table 7-24: Experiment IV-12 CYA Peak Area Raw Data

\begin{tabular}{|c|c|c|c|c|c|c|}
\hline \multirow[b]{3}{*}{ Flask } & \multirow[b]{3}{*}{ Label } & \multicolumn{5}{|c|}{ Peak Area [mAU*s] } \\
\hline & & $\mathrm{T}=0$ & $\mathrm{~T}=24$ & $\mathrm{~T}=48$ & $\mathrm{~T}=96$ & $\mathrm{~T}=144$ \\
\hline & & Hours & Hours & Hours & Hours & Hours \\
\hline $60 \mathrm{ppm}$ & Standard & 10194 & 10286 & 11017 & 9523 & 10035 \\
\hline 1 & Control & 9887 & 9378 & 10170 & 10448 & 11323 \\
\hline 2 & Thai FOG & 9606 & 9029 & 9228 & 9978 & 11091 \\
\hline 3 & Thai FOG, no Glucose & 9879 & 9036 & 8835 & 9017 & 9863 \\
\hline 4 & Irradiated Thai FOG & 10670 & 9452 & 9022 & 8990 & 10556 \\
\hline 5 & Premix & 10928 & 9601 & 9789 & 9644 & 11462 \\
\hline 6 & Osprey Liq & 11041 & 9375 & 10037 & 9356 & 10307 \\
\hline 7 & Osprey BPB 100 & 11788 & 9966 & 9972 & 9146 & 9625 \\
\hline 8 & US FOG & 12899 & 10025 & 10874 & 9436 & 10072 \\
\hline
\end{tabular}


Table 7-25: Experiment IV-15 CYA Peak Area Raw Data

\begin{tabular}{lllllllll}
\hline & \multicolumn{7}{c}{ Peak Area [mAU*s] } \\
\cline { 2 - 9 } Flask & Hours & Hours & Hours & Hours & Hours & Hours & Hours & Hours \\
\hline Control & 6355.3 & 7038.9 & 7191.7 & 7039.5 & 7170.7 & 7682 & 7313.2 & 7406.6 \\
40:10:01 & 6970.3 & 7033.4 & 7241.6 & 7049.8 & 7013.9 & 7291.2 & 7145.4 & 7423.8 \\
60:10:01 & 7071.2 & 7004.2 & 7010.8 & 7166.6 & 7015.7 & 7147 & 7597.2 & 7291.8 \\
50:10:01 & 7257.3 & 7060.5 & 6957.7 & 6962.9 & 7027.9 & 7193.9 & 6992 & 7547.6 \\
40:10:01 & 6744.6 & 7214.7 & 7035.3 & 7004.7 & 7046 & 7148.5 & 7134.3 & 7622.6 \\
10:10:01 & 7453.8 & 6975.3 & 6942.8 & 7175.4 & 6959.2 & 7770.3 & 7289.6 & 8698.9 \\
50 A & 7052.2 & 7259.7 & 7354.5 & 7380.8 & 6992 & 7192.7 & 7817.8 & 7581.9 \\
50 A+H & 6811.9 & 7274.6 & 7339.9 & 8189.9 & 7712.9 & 8136.4 & 8132.3 & 7439.8 \\
\hline
\end{tabular}

Table 7-26: Experiment IV-17 CYA Peak Area Raw Data

\begin{tabular}{lllllll}
\hline & \multicolumn{5}{c}{ Peak Area [mAU*s] } \\
\cline { 2 - 7 } Treatment & $\mathrm{T}=0$ & $\mathrm{~T}=2$ & $\mathrm{~T}=19$ & $\mathrm{~T}=42$ & $\mathrm{~T}=65$ & $\mathrm{~T}=142$ \\
\hline Control 1 & Hours & Hours & Hours & Hours & Hours & Hours \\
Control 2 & 992.8 & 970.7 & 963.1 & 921.1 & 899.4 & 954.4 \\
5 PPM CAR 1 & 984.3 & 985.5 & 971.5 & 921.7 & 898.7 & 965.2 \\
5 PPM CAR 2 & 994.4 & 981 & 977 & 925.5 & 903.5 & 962.2 \\
50 PPM CAR 1 & 989.9 & 1006 & 958.2 & 923.5 & 899.8 & 965.7 \\
50 PPM CAR 2 & 978.4 & 990.9 & 972.5 & 922.2 & 906.5 & 945.6 \\
CYA 97 & $\mathrm{x}$ & $\mathrm{x}$ & 829.6 & 784.8 & 893.4 & 960 \\
\hline
\end{tabular}

Table 7-27: Experiment IV-18 CYA Peak Area Raw Data

\begin{tabular}{lllllll}
\hline & \multicolumn{5}{c}{ Peak Area [mAU*s] } \\
\cline { 2 - 7 } Treatment & Days & Days & Days & Days & Days & Days \\
\hline Control 1 & 889.6 & 922.1 & 246 & 226.5 & 214.4 & 210.2 \\
Control 2 & 895.4 & 983 & 254.1 & 236.2 & 215.7 & 210.6 \\
CAR1 & 893 & 961.7 & 266.9 & 233.2 & 211.2 & 214.5 \\
CAR2 & 892.4 & 933.2 & 257 & 234.1 & 215.2 & 206.1 \\
\hline
\end{tabular}




\begin{tabular}{lllllll}
\hline CAR+GLU1 & 888.4 & 926.2 & 276.7 & 216.7 & 215.9 & 204.8 \\
CAR+GLU2 & 900.6 & 929.1 & 267.1 & 238.1 & 217.4 & 206 \\
CYA 97 & 788.7 & 818.5 & 244 & 206.7 & $x$ & $x$ \\
\hline
\end{tabular}

Table 7-28: Experiment IV-19 CYA Concentration Raw Data

\begin{tabular}{lrrrrr}
\hline & \multicolumn{5}{c}{ CYA Concentration [mg/L] } \\
\cline { 2 - 6 } Treatment & $\mathrm{T}=0$ Days & $\mathrm{T}=2$ Days & $\mathrm{T}=3$ Days & $\mathrm{T}=4$ Days & $\mathrm{T}=5$ Days \\
\hline Control 1 & 121 & 108 & 127 & 103 & 103 \\
Control 2 & 131 & 109 & 140 & 103 & 173 \\
CYA + Dex 50 ppm 1 & 117 & 107 & 115 & 100 & 106 \\
CYA + Dex 50 ppm 2 & 111 & 107 & 118 & 100 & 104 \\
CYA + Dex 287 ppm 1 & 110 & 107 & 113 & 101 & 102 \\
CYA + Dex 287 ppm 2 & 110 & 116 & 117 & 99 & 103 \\
\hline
\end{tabular}

Table 7-29: Experiment IV-20 Raw CYA Data

\begin{tabular}{llllllllll}
\hline & \multicolumn{8}{c}{ CYA Concentration [mg/L] } \\
\cline { 2 - 10 } Treatment & $\mathrm{T}=0$ & $\mathrm{~T}=3$ & $\mathrm{~T}=5$ & $\mathrm{~T}=6$ & $\mathrm{~T}=10$ & $\mathrm{~T}=11$ & $\mathrm{~T}=12$ & $\mathrm{~T}=13$ & $\mathrm{~T}=15$ \\
\hline Control 1 & 46 & 54 & 49 & 52 & 52 & 47 & 51 & 51 & 51 \\
Control 2 & 46 & 55 & 56 & 57 & 52 & 49 & 48 & 51 & 49 \\
Thai FOG 1 & $276^{*}$ & 57 & 46 & 55 & 51 & 52 & 52 & 56 & 53 \\
Thai FOG 2 & $281^{*}$ & 63 & 64 & 53 & 53 & 54 & 51 & 56 & 48 \\
Filter Media 1 & $269^{*}$ & 59 & 50 & 49 & 49 & 54 & 51 & 56 & 58 \\
Filter Media 2 & $271^{*}$ & 58 & 49 & 50 & 47 & 53 & 49 & 58 & 49 \\
\hline
\end{tabular}

*Data-point excluded from analysis 


\section{Appendix B: Example of Normalization Calculation}

Data was normalized to the turbidity level after each dose of sunscreen. Table 7-30, below, shows raw and normalized turbidity readings through the duration of Experiment I-3.

US FOG began with $48 \mathrm{NTU}$ at $\mathrm{T}=0$ Days and dropped to $7 \mathrm{NTU}$ at $\mathrm{T}=1$ Days. To normalize the data, the readings from $\mathrm{T}=0$ Days to $\mathrm{T}=3$ Days were each divided by 48 NTU. The Turbidity after the re-dose of sunscreen at $\mathrm{T}=3.01$ Days was 41 . Data were normalized from $\mathrm{T}=3.01$ Days to $\mathrm{T}=7$ Days by dividing each value by 41 . This method was repeated for each treatment at each re-dose.

Table 7-30: Experiment I-3 Raw and Normalized Turbidity Data

\begin{tabular}{lcccc|cccc}
\hline & \multicolumn{4}{c}{ Raw Data [NTU] } & \multicolumn{3}{c}{ Normalized Data [NTU/NTU0] } \\
\cline { 2 - 8 } Day & US & Thai & Rice & & US & Thai & Rice & \\
\hline 0 & 48 & 55 & 66 & 47 & 1.00 & 1.00 & 1.00 & 1.00 \\
1 & 7 & 2 & 30 & 9 & 0.15 & 0.04 & 0.45 & 0.19 \\
2 & 2 & 3 & 20 & 4 & 0.04 & 0.05 & 0.30 & 0.09 \\
3 & 1 & 6 & 15 & 1 & 0.02 & 0.11 & 0.23 & 0.02 \\
3.01 & 41 & 63 & 69 & 50 & 1.00 & 1.00 & 1.00 & 1.00 \\
4 & 9 & 33 & 34 & 16 & 0.22 & 0.52 & 0.49 & 0.32 \\
5 & 3 & 16 & 22 & 3 & 0.07 & 0.25 & 0.32 & 0.06 \\
6 & 0 & 14 & 19 & 8 & 0.00 & 0.22 & 0.28 & 0.16 \\
7 & 2 & 13 & 22 & 2 & 0.05 & 0.21 & 0.32 & 0.04 \\
7.01 & 48 & 55 & 73 & 37 & 1.00 & 1.00 & 1.00 & 1.00 \\
8 & 6 & 22 & 48 & 11 & 0.13 & 0.40 & 0.66 & 0.30 \\
9 & 3 & 16 & 44 & 5 & 0.06 & 0.29 & 0.60 & 0.14 \\
10 & 3 & 13 & 43 & 5 & 0.06 & 0.24 & 0.59 & 0.14 \\
10.01 & 53 & 65 & 93 & 58 & 1.00 & 1.00 & 1.00 & 1.00 \\
12 & 7 & 28 & 51 & 9 & 0.13 & 0.43 & 0.55 & 0.16 \\
\hline 13 & 5 & 45 & 42 & 6 & 0.09 & 0.69 & 0.45 & 0.10 \\
14 & 5 & 55 & 48 & 5 & 0.09 & 0.85 & 0.52 & 0.09 \\
\hline
\end{tabular}




\begin{tabular}{lcccc|cccc}
\hline & \multicolumn{4}{c}{ Raw Data [NTU] } & \multicolumn{4}{c}{ Normalized Data [NTU/NTU $]$} \\
\cline { 2 - 8 } Day & US & Thai & Rice & & US & Thai & Rice & \\
\hline 15 & 5 & 59 & 46 & 6 & 0.09 & 0.91 & 0.49 & 0.10 \\
16 & 5 & 62 & 49 & 4 & 0.09 & 0.95 & 0.53 & 0.07 \\
16.01 & 50 & 105 & 91 & 35 & 1.00 & 1.00 & 1.00 & 1.00 \\
17 & 8 & 62 & 75 & 10 & 0.16 & 0.59 & 0.82 & 0.29 \\
18 & 8 & 75 & 62 & 8 & 0.16 & 0.71 & 0.68 & 0.23 \\
\hline
\end{tabular}




\section{Appendix C: Example of HPLC Calibration and Conversion of Peak Area to CYA Concentration from Experiment IV-20}

Calibration was carried out for experiments IV-17 through IV-20 with increasing complexity, to provide accurate conversion of peak area to concentration of CYA. A fourpoint calibration was run for Experiment IV-20 using CYA standards of 63, 85, and 105 $\mathrm{mg} / \mathrm{L}$, followed by a DI water blank. Calibration and conversion of peak areas to concentration for Day 13 of Experiment IV-20 is shown, below. All peak shapes are representative of duplicate treatments.

Figure 7-1 shows the chromatogram and integration for the $63 \mathrm{mg} / \mathrm{L}$ CYA Standard.

Figure 7-2 shows the chromatogram and integration for the "Control 1" treatment.

Figure 7-3 shows the chromatogram and integration for the "Thai FOG 1" treatment.

Figure 7-4 shows the chromatogram and integration for the "Filter Media 2" treatment. 


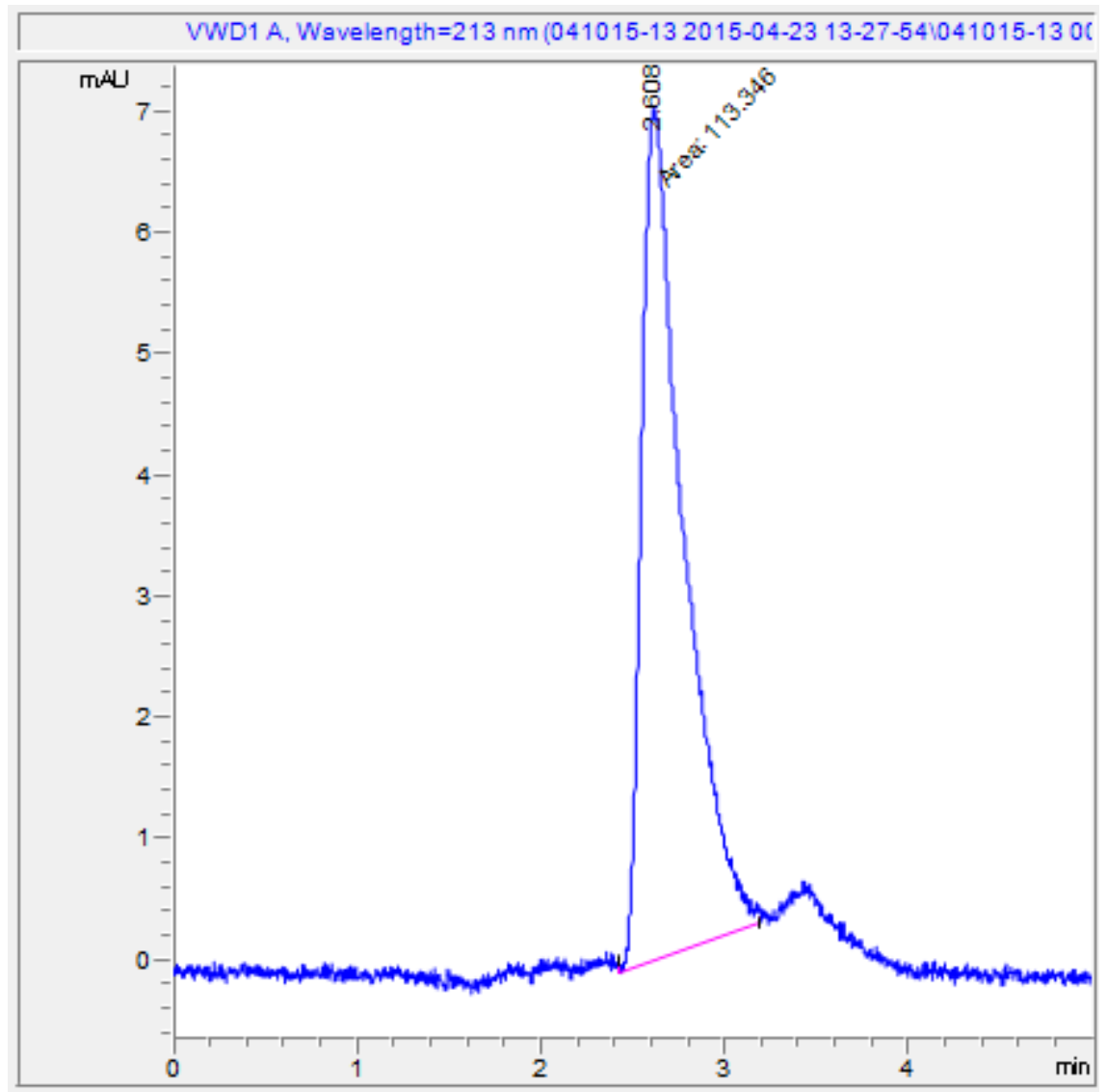

Figure 7-1: Chromatogram for Experiment IV-20, Day 13, 63 mg/L CYA Standard 




Figure 7-2: Chromatogram for Experiment IV-20, Day 13, “Control 1” Treatment 


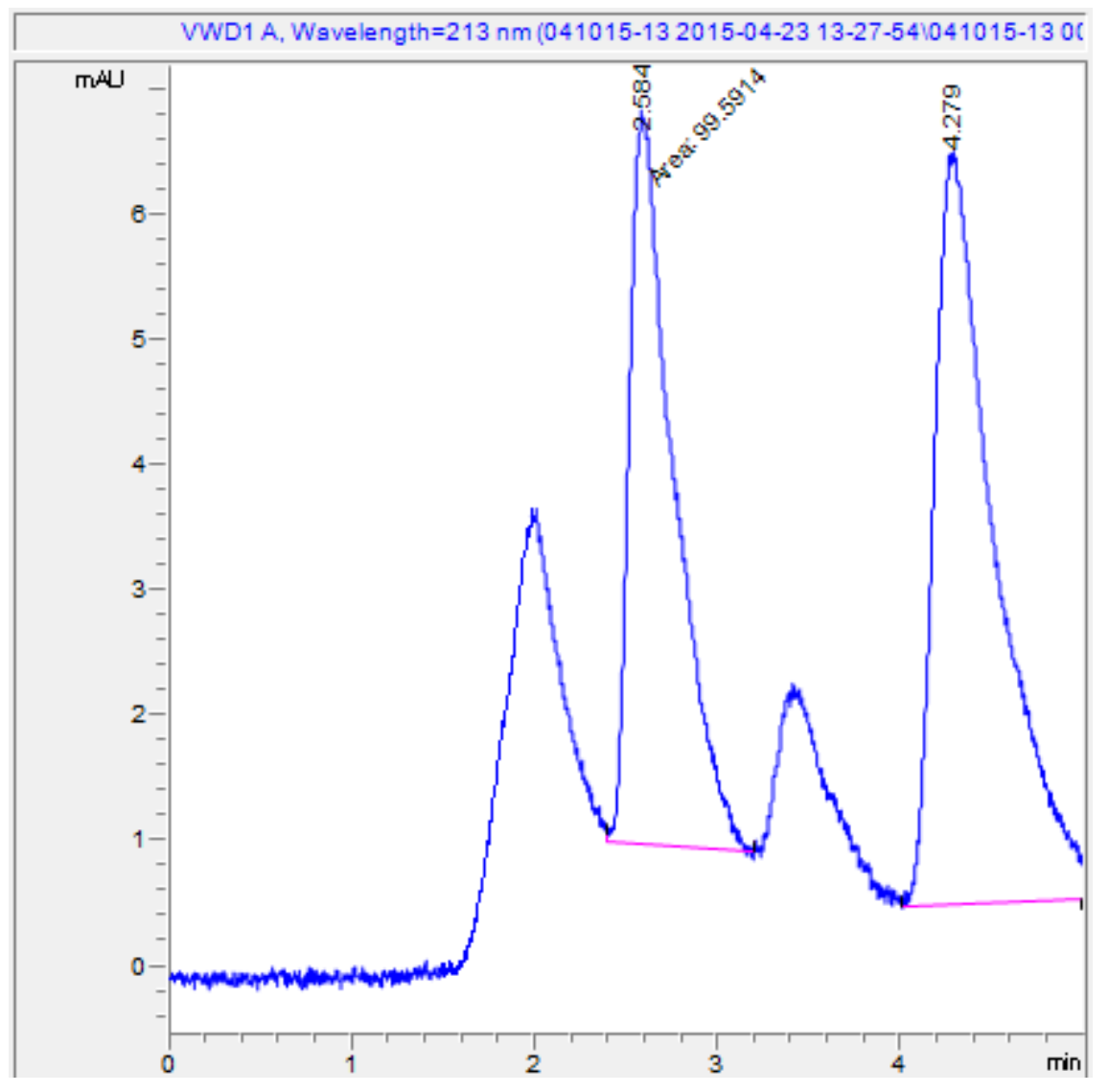

Figure 7-3: Chromatogram for Experiment IV-20, Day 13, “Thai FOG 1" Treatment 


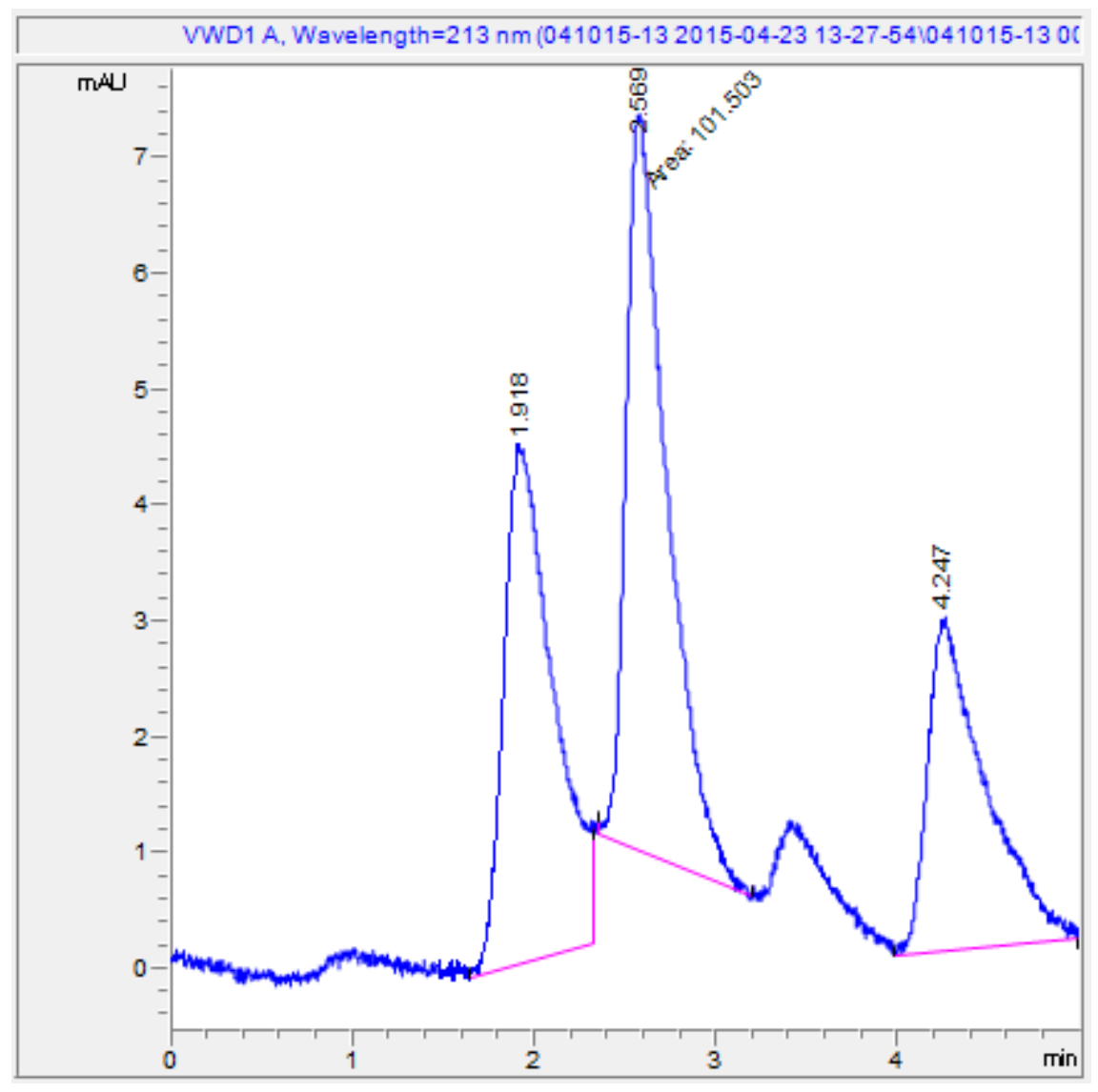

Figure 7-4: Chromatogram for Experiment IV-20, Day 13, "Filter Media 2" Treatment

Peak areas of the standards and blank measured as follows in Table 7-31, below.

Table 7-31: Experiment IV-20, Day 13, CYA Standard Curve Peak Areas

\begin{tabular}{ll}
\hline CYA & \\
Standard & Peak \\
mg/L & Area \\
\hline 63 & 113.3 \\
85 & 149.5 \\
105 & 176.6 \\
0 & 4.4 \\
\hline
\end{tabular}

The resulting peak areas were graphed and fitted with a linear regression model in Figure 7-5, below. 


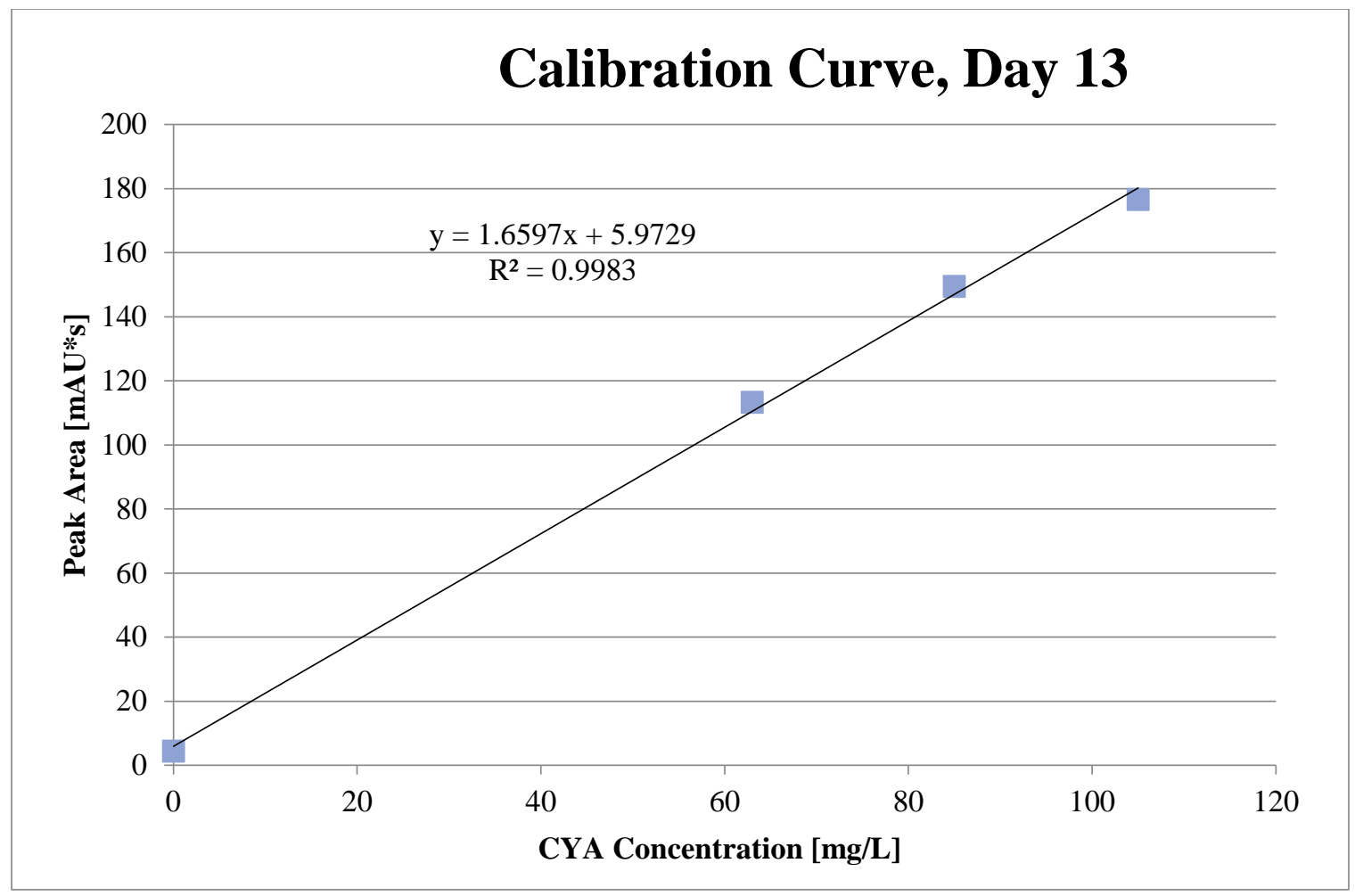

Figure 7-5: Experiment IV-20, Day 13, CYA Calibration Curve

The linear regression returned the equation $y=1.6597 x+5.9729$, where " $y$ " represents Peak Area, and " $\mathrm{x}$ " represents mg/L CYA. This equation was used to convert peak areas from each chromatogram to $\mathrm{mg} / \mathrm{L}$ CYA, in Table 7-32, below. Concentrations were rounded to the nearest whole number, to match the precision of prepared standards.

Table 7-32: Experiment IV-20, Day 13, Peak Area and CYA Concentration

\begin{tabular}{lll}
\hline Treatment & Peak Area [mAU*s] & CYA Concentration [mg/L] \\
\hline Control 1 & 91.4 & 51 \\
Control 2 & 90.3 & 48 \\
Thai FOG 1 & 99.6 & 52 \\
Thai FOG 2 & 99.5 & 51 \\
Filter Media 1 & 99.2 & 51 \\
Filter Media 2 & 101.5 & 49 \\
\hline
\end{tabular}


Appendix D: SEM Images from Experiment I-8



Figure 7-6: Premix New 400x (Left), Premix New 1600x (Right)
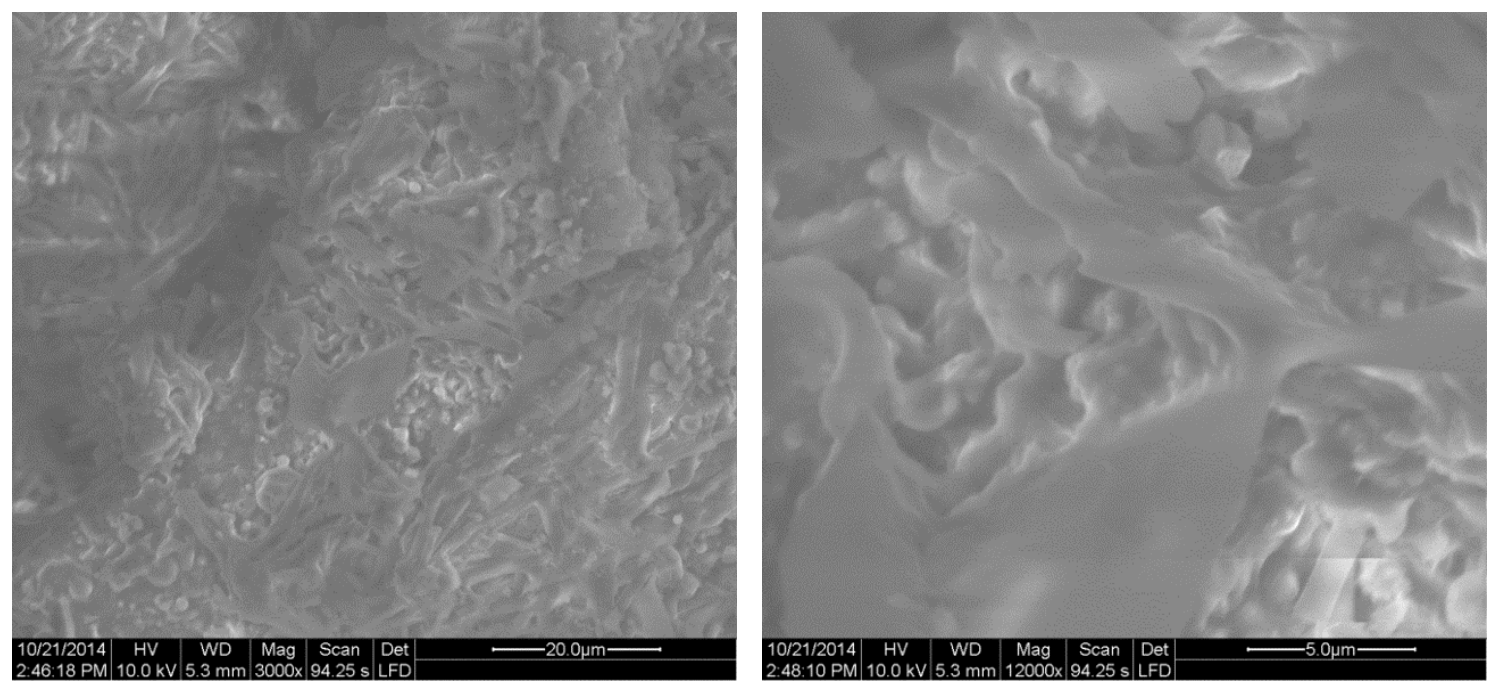

Figure 7-7: Premix New 3000x (Left), Premix New 12000x (Right) 


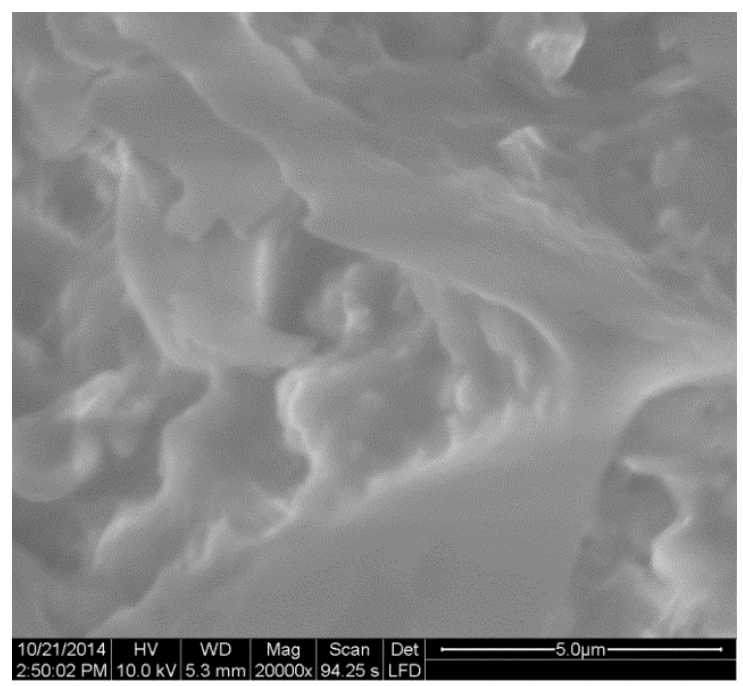

Figure 7-8: Premix New 20000x
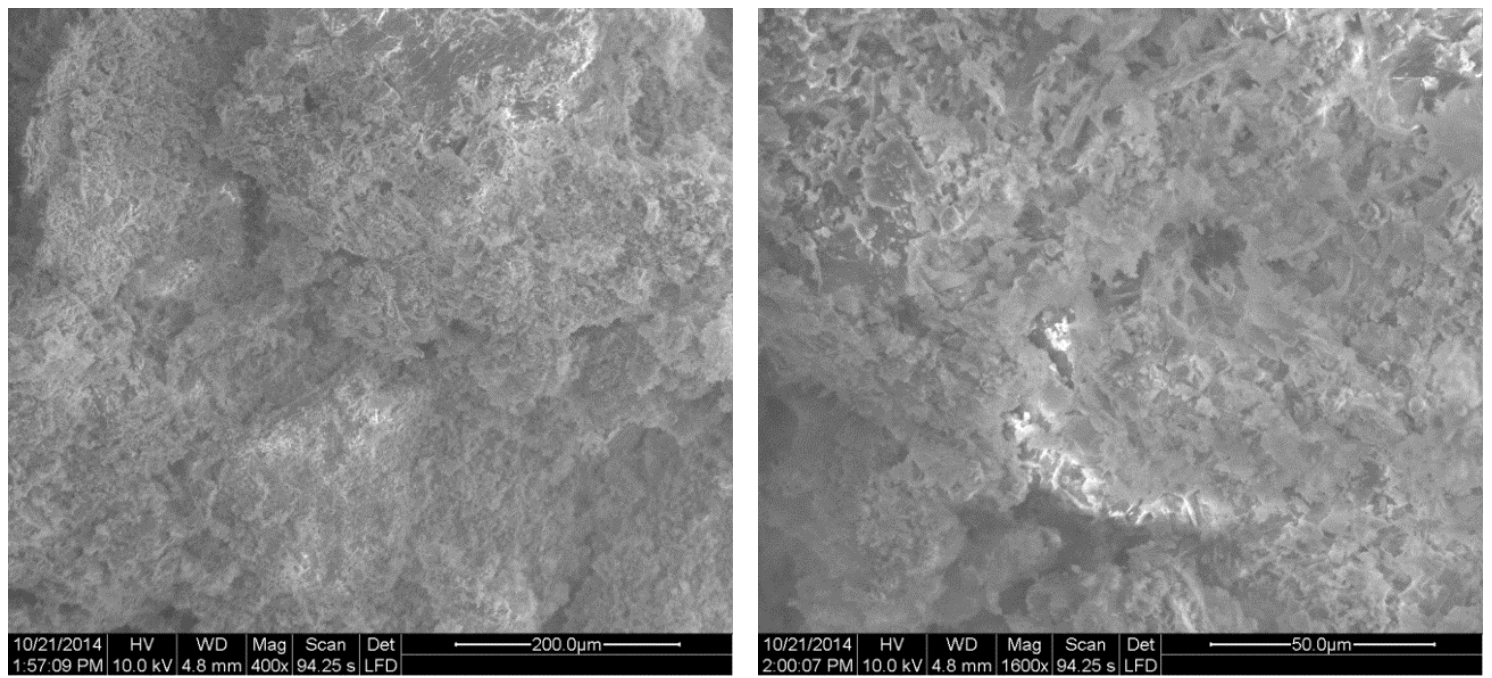

Figure 7-9: Premix Used 400x (Left), Premix Used 1600x (Right) 

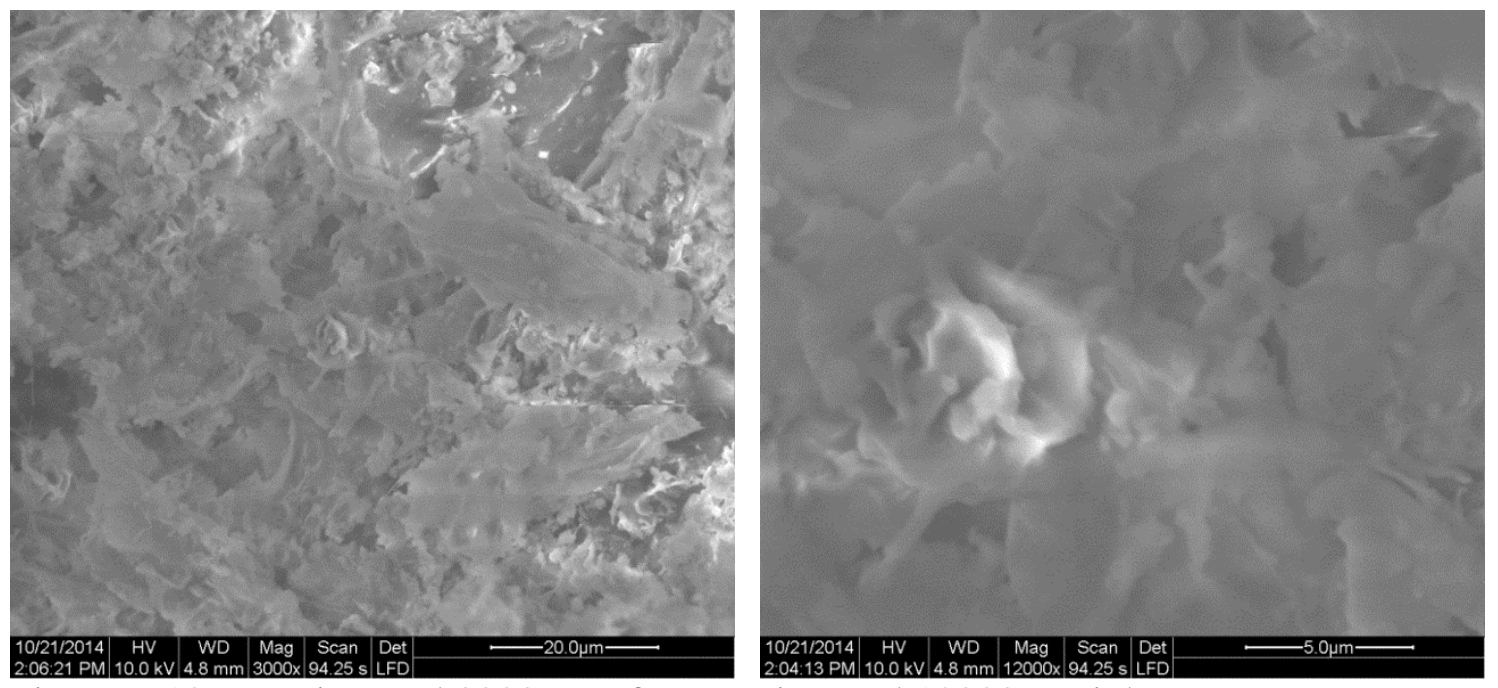

Figure 7-10: Premix Used 3000x (Left), Premix Used 12000x (Right)

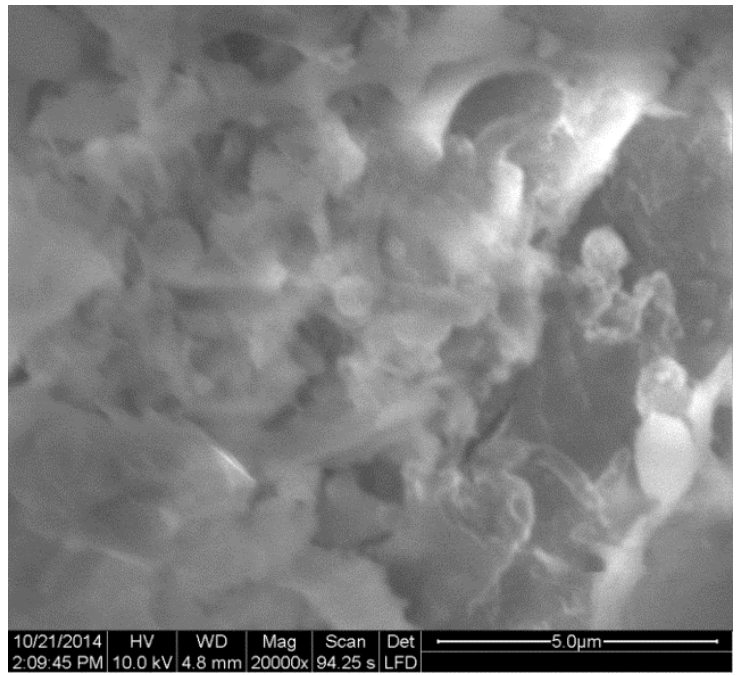

Figure 7-11: Premix Used 20000x 

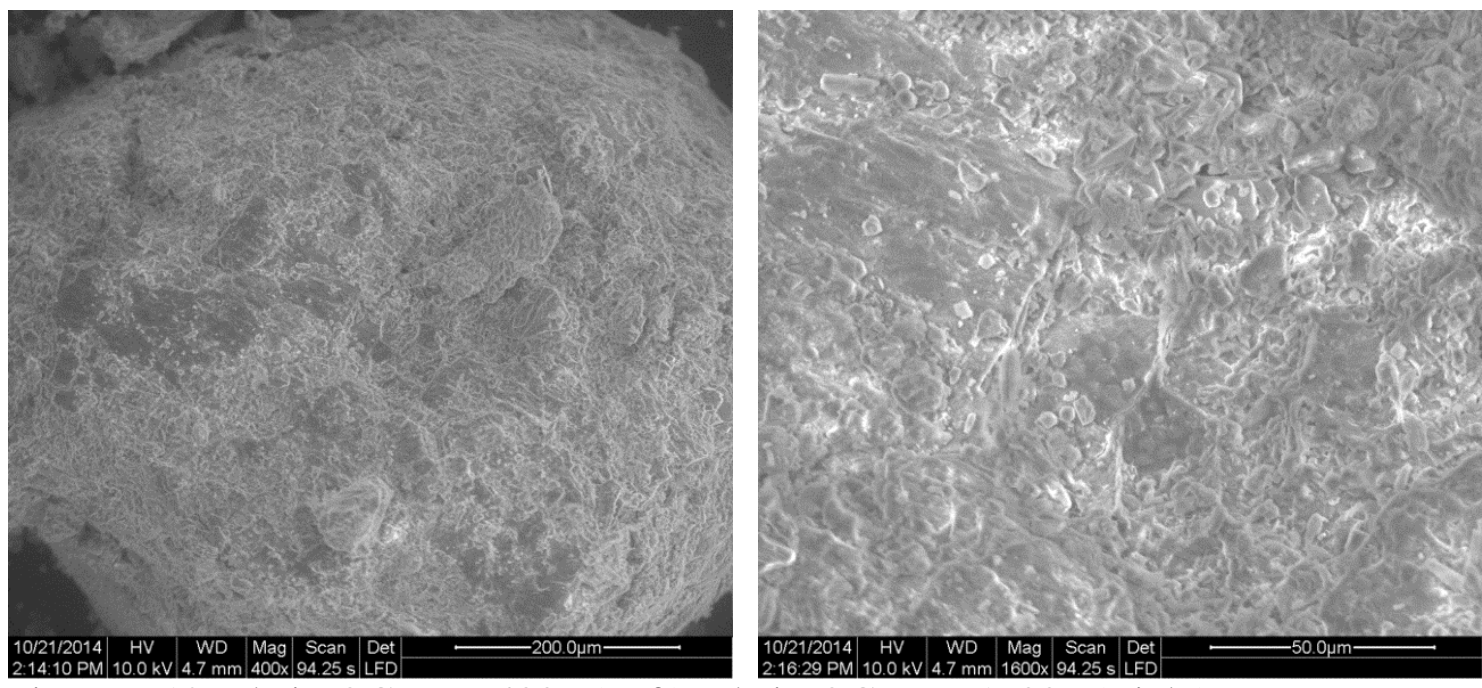

Figure 7-12: Thai FOG New 400x (Left), Thai FOG New 1600x (Right)
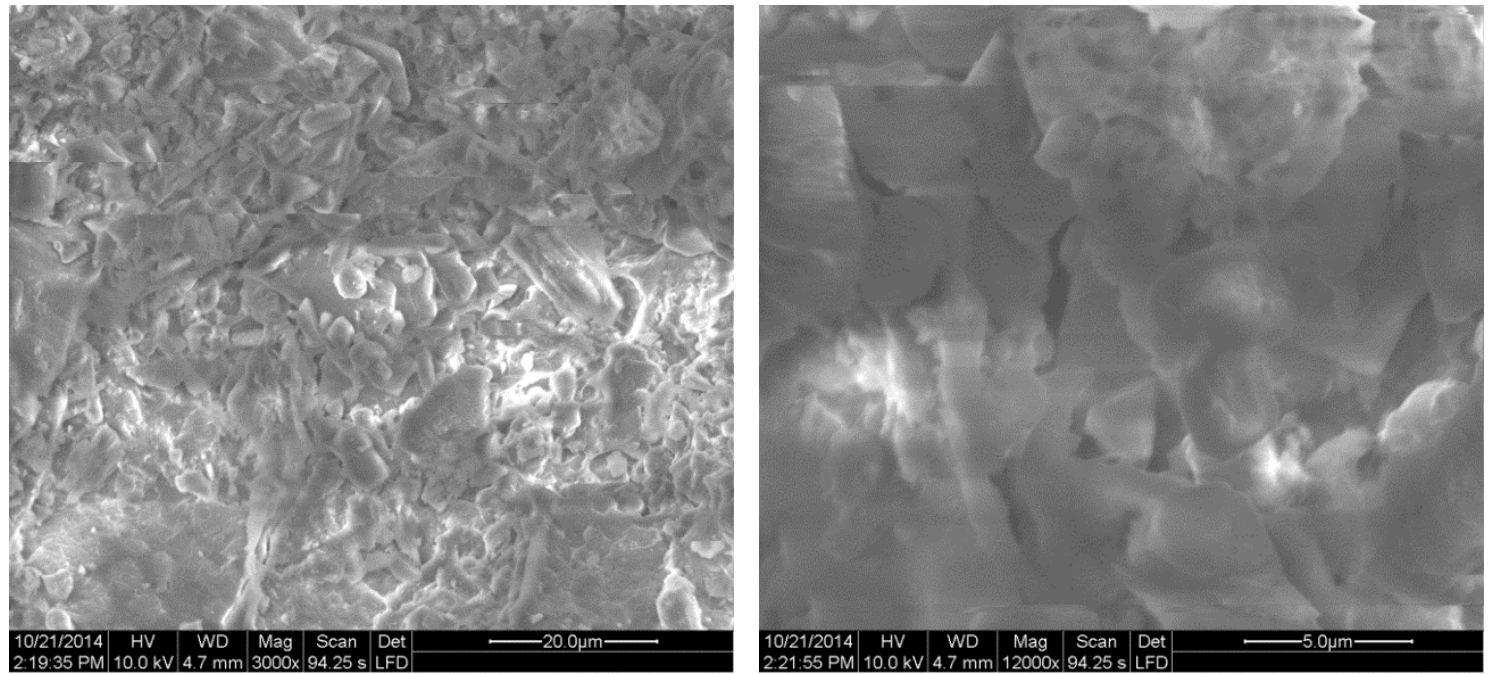

Figure 7-13: Thai FOG New 3000x (Left), Thai FOG New 12000x (Right) 


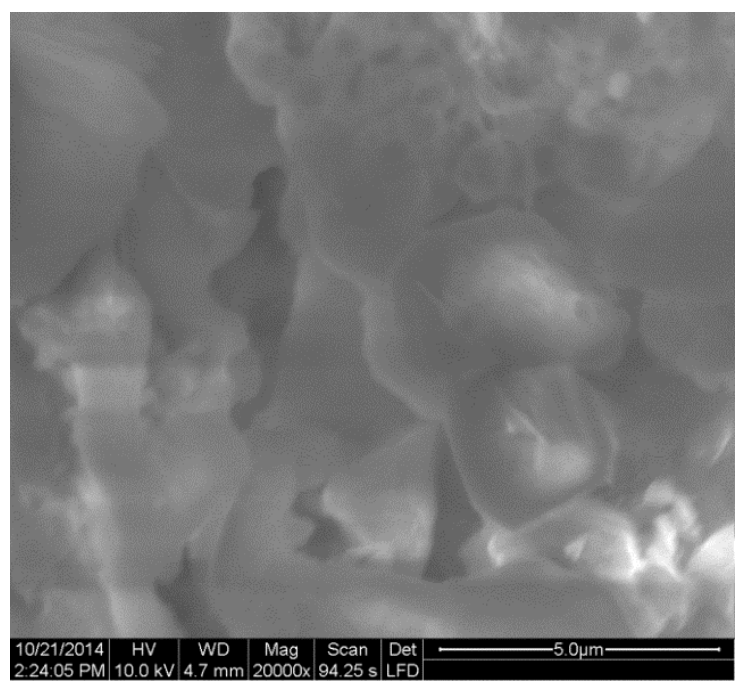

Figure 7-14: Thai FOG New 20000x



Figure 7-15: Thai FOG Used 400x (Left), Thai FOG Used 1600x (Right) 

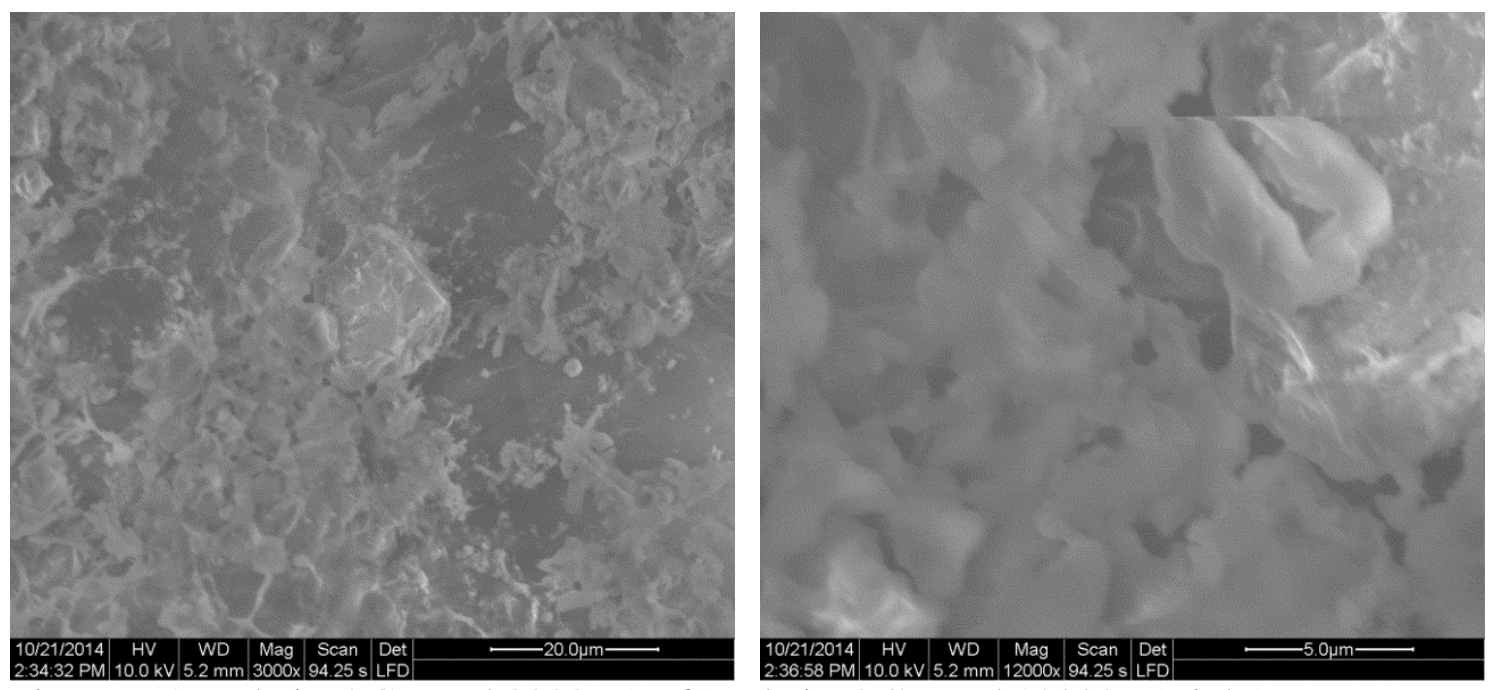

Figure 7-16: Thai FOG Used 3000x (Left), Thai FOG Used 12000x (Right)

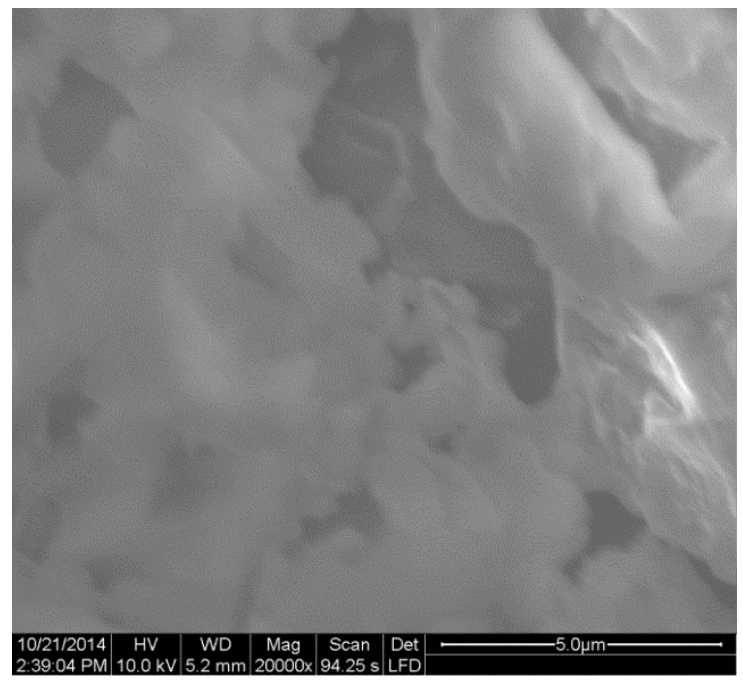

Figure 7-17: Thai FOG Used 20000x 


\section{Appendix E: Example HPLC Chromatograms from Experiment IV-20}

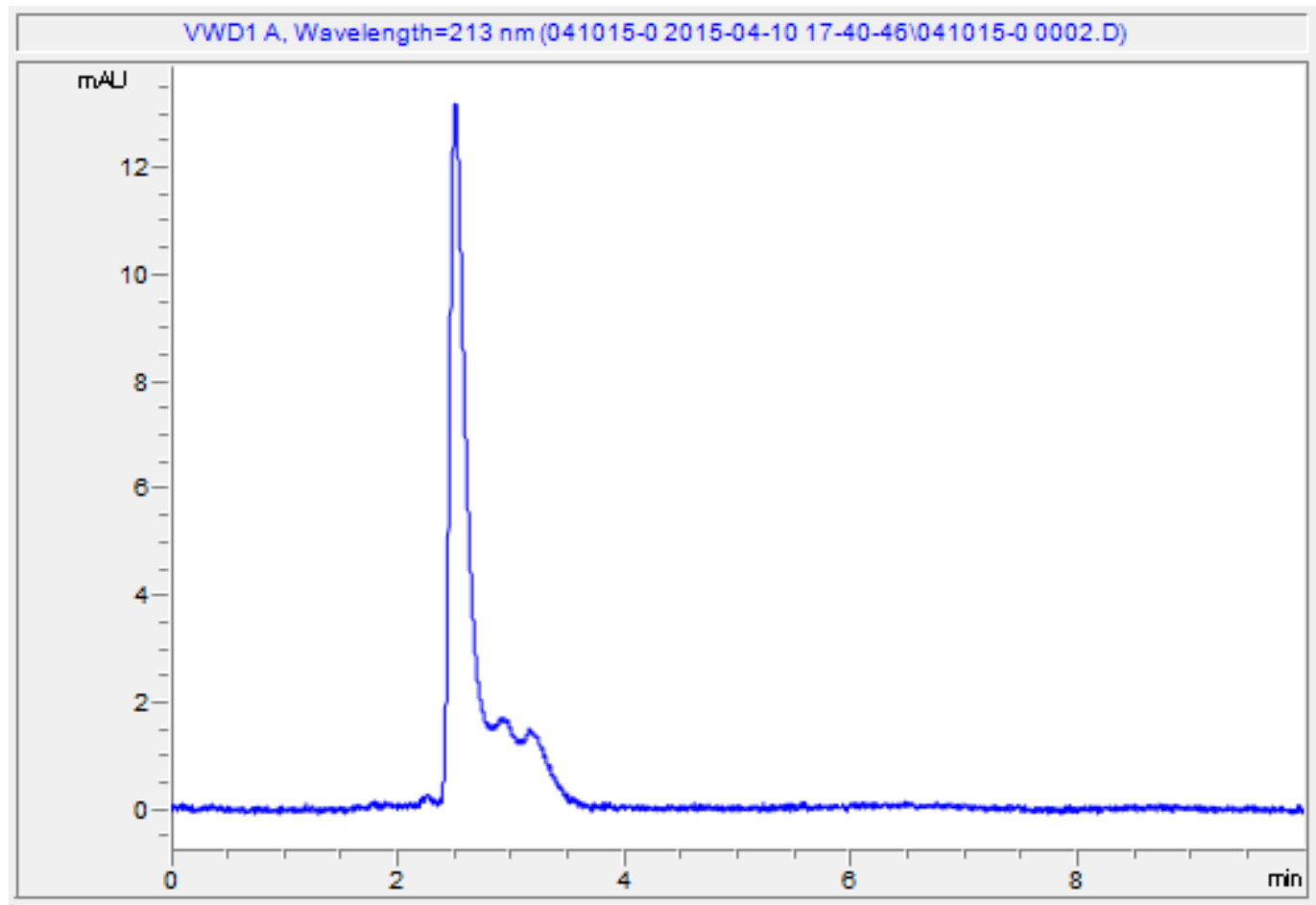

Figure 7-18: Experiment IV-20, 85 mg/L CYA Standard, Day 0

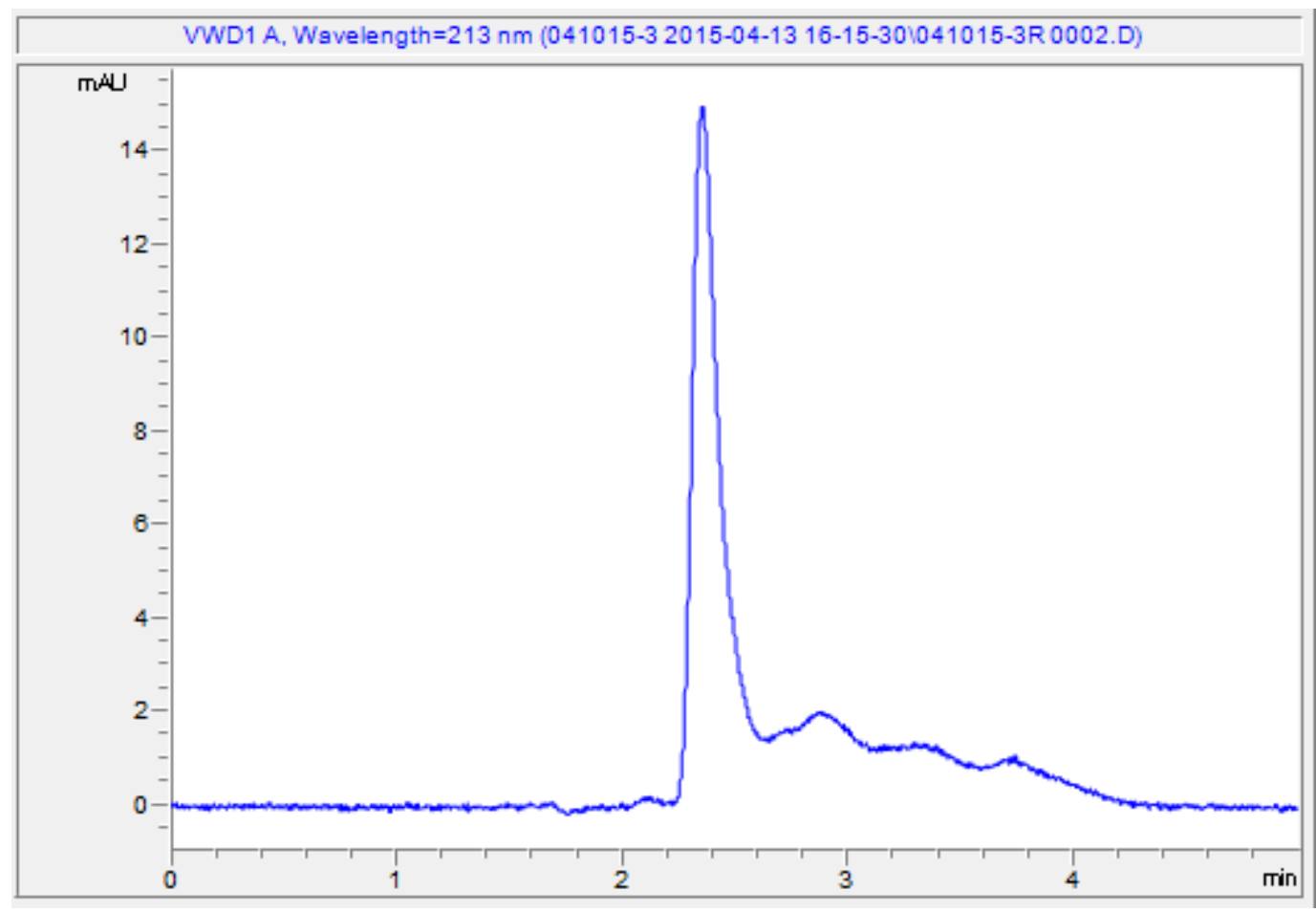

Figure 7-19: Experiment IV-20, 85 mg/L CYA Standard, Day 3 




Figure 7-20: Experiment IV-20, 85 mg/L CYA Standard, Day 10

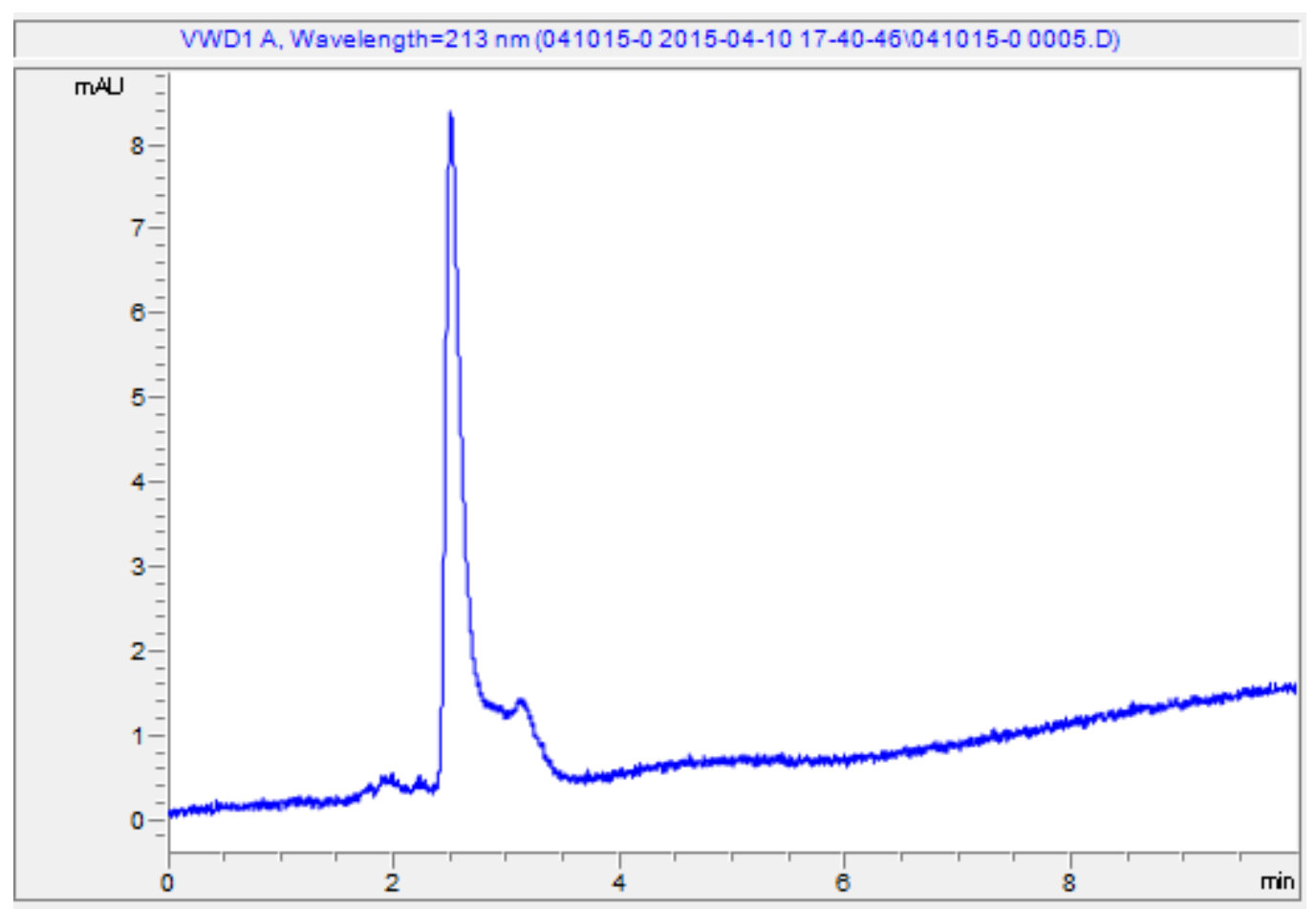

Figure 7-21: Experiment IV-20, 50 mg/L CYA Control, Day 0 


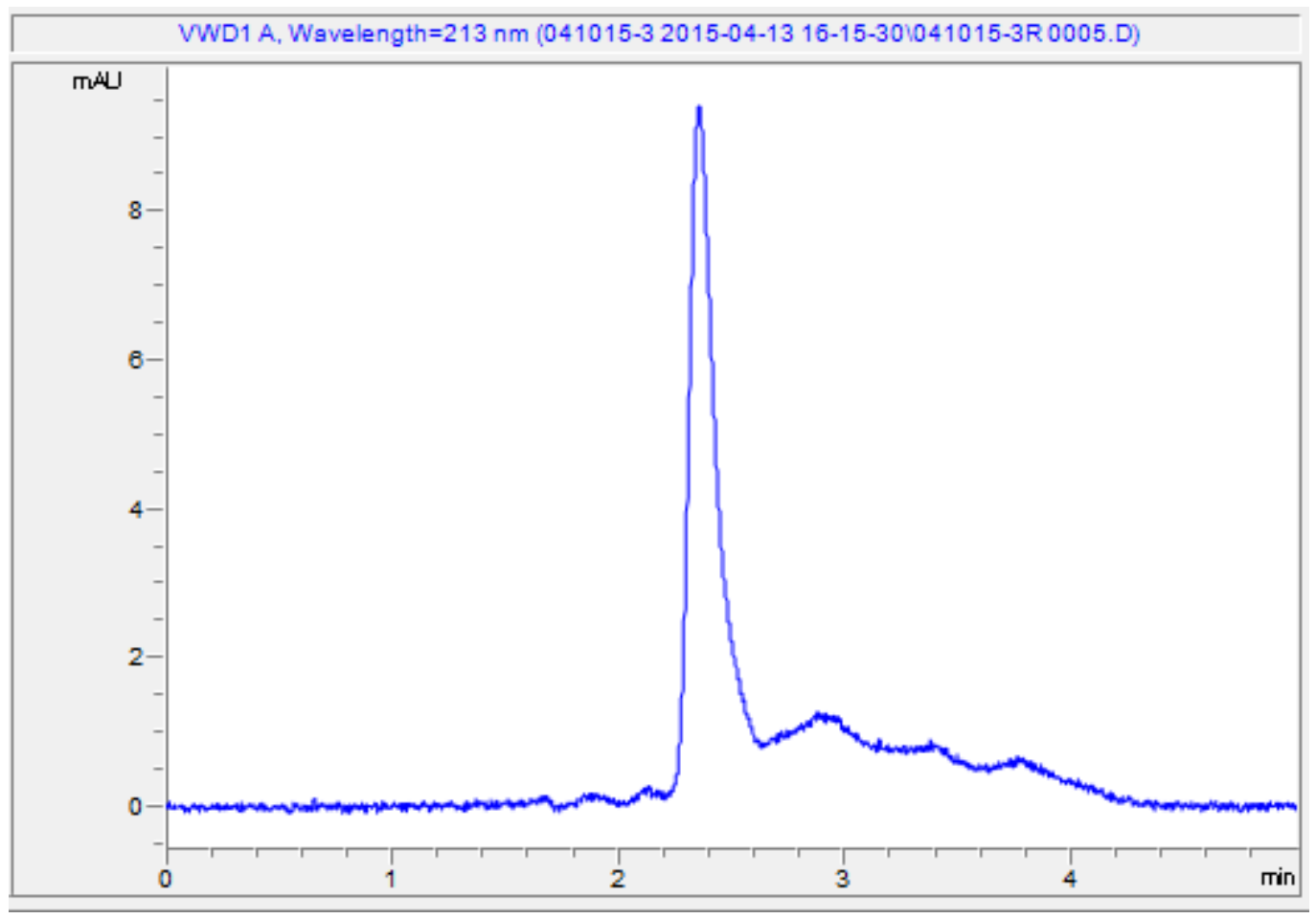

Figure 7-22: Experiment IV-20, 50 mg/L CYA Control, Day 3

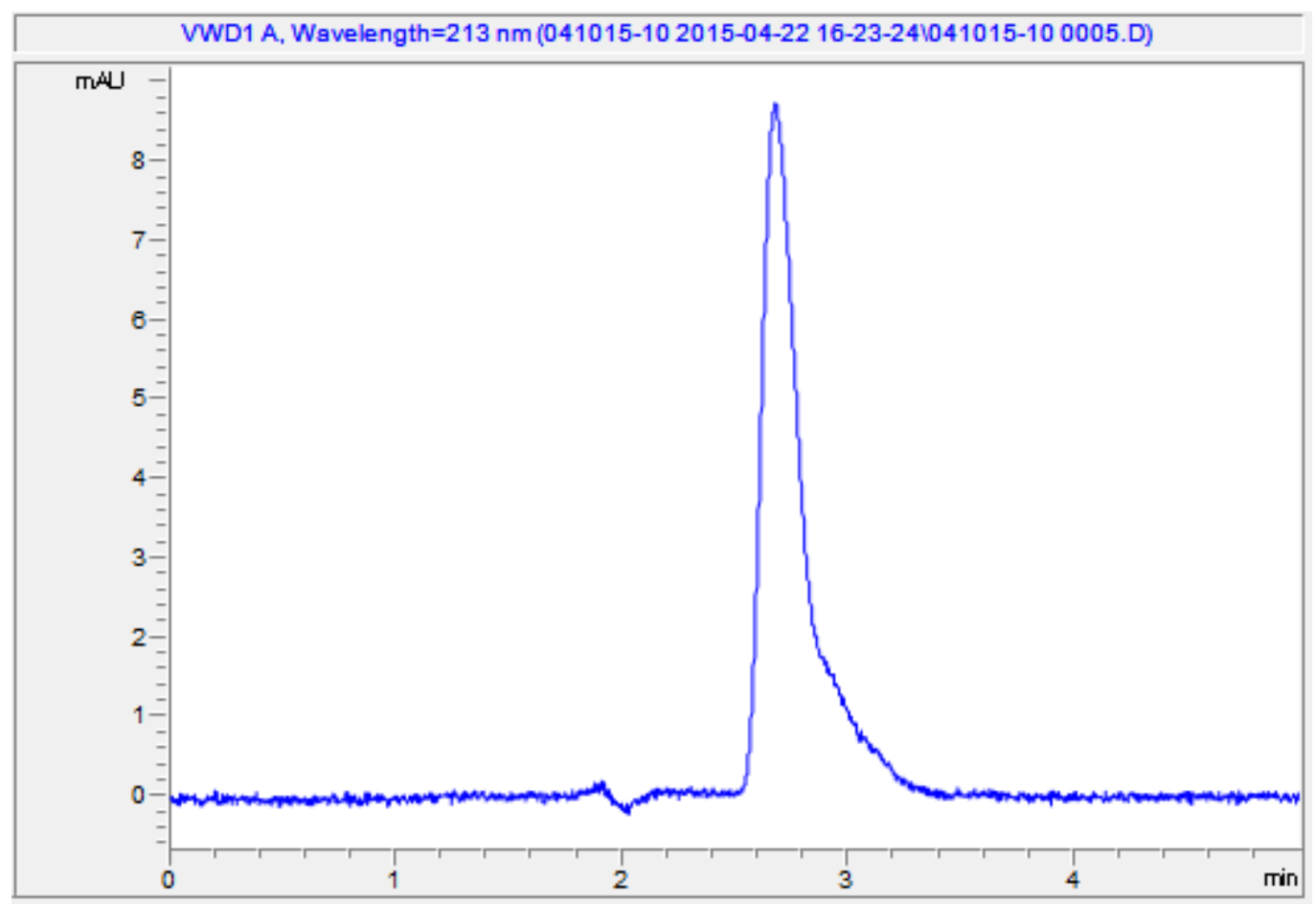

Figure 7-23: Experiment IV-20, 50 mg/L CYA Control, Day 10 


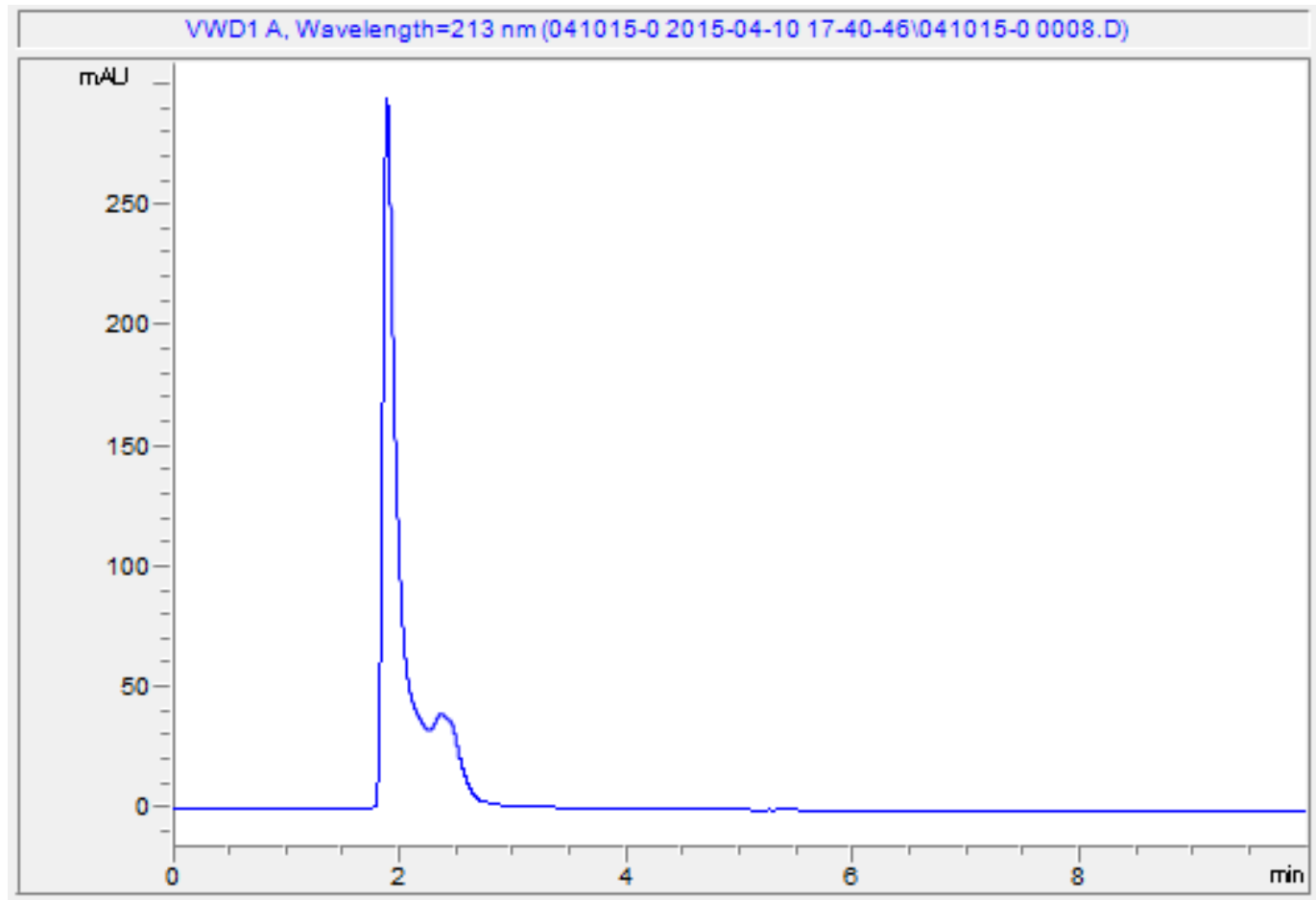

Figure 7-24: Experiment IV-20, Growth Media, Thai FOG with CYA, Day 0

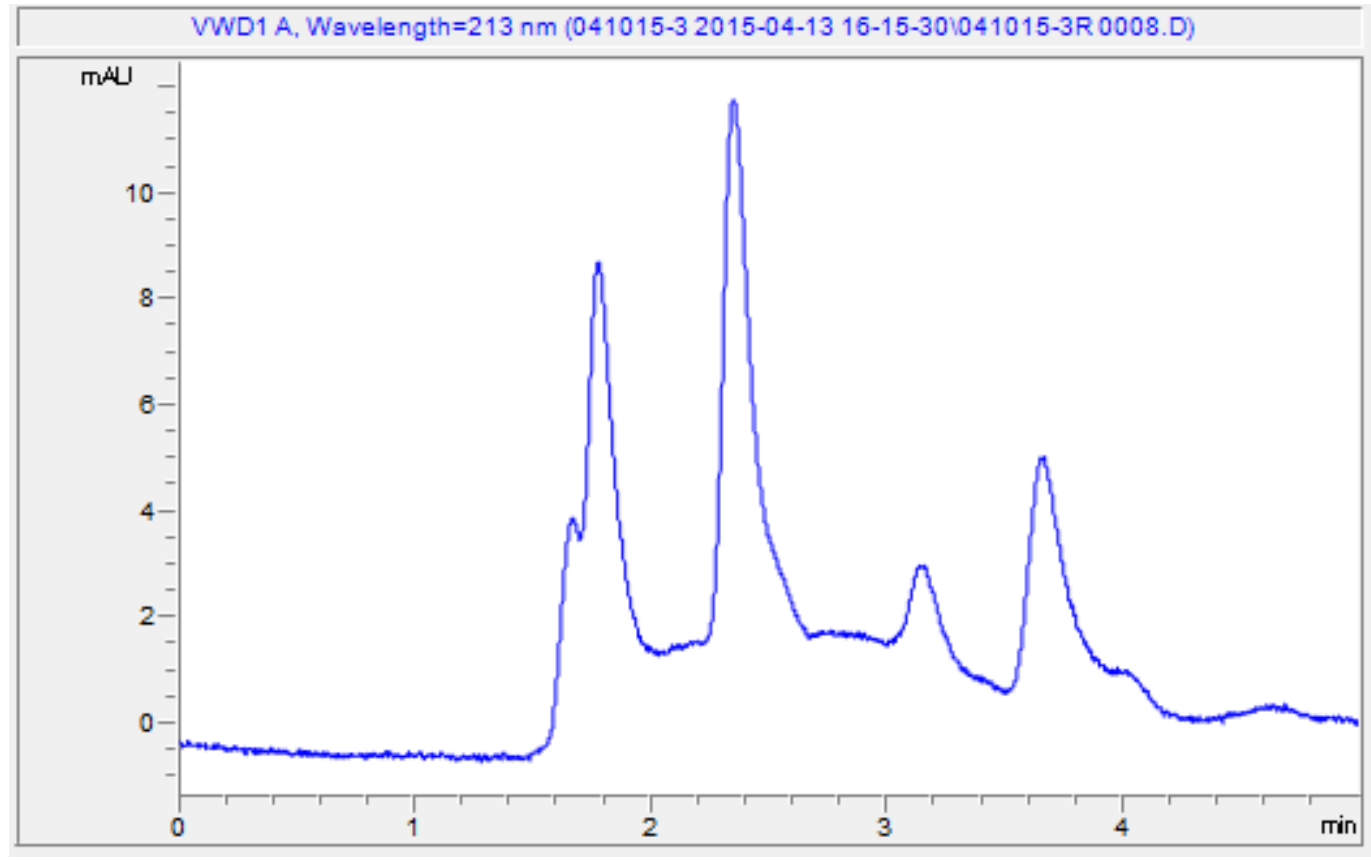

Figure 7-25: Experiment IV-20, Growth Media, Thai FOG with CYA, Day 3 


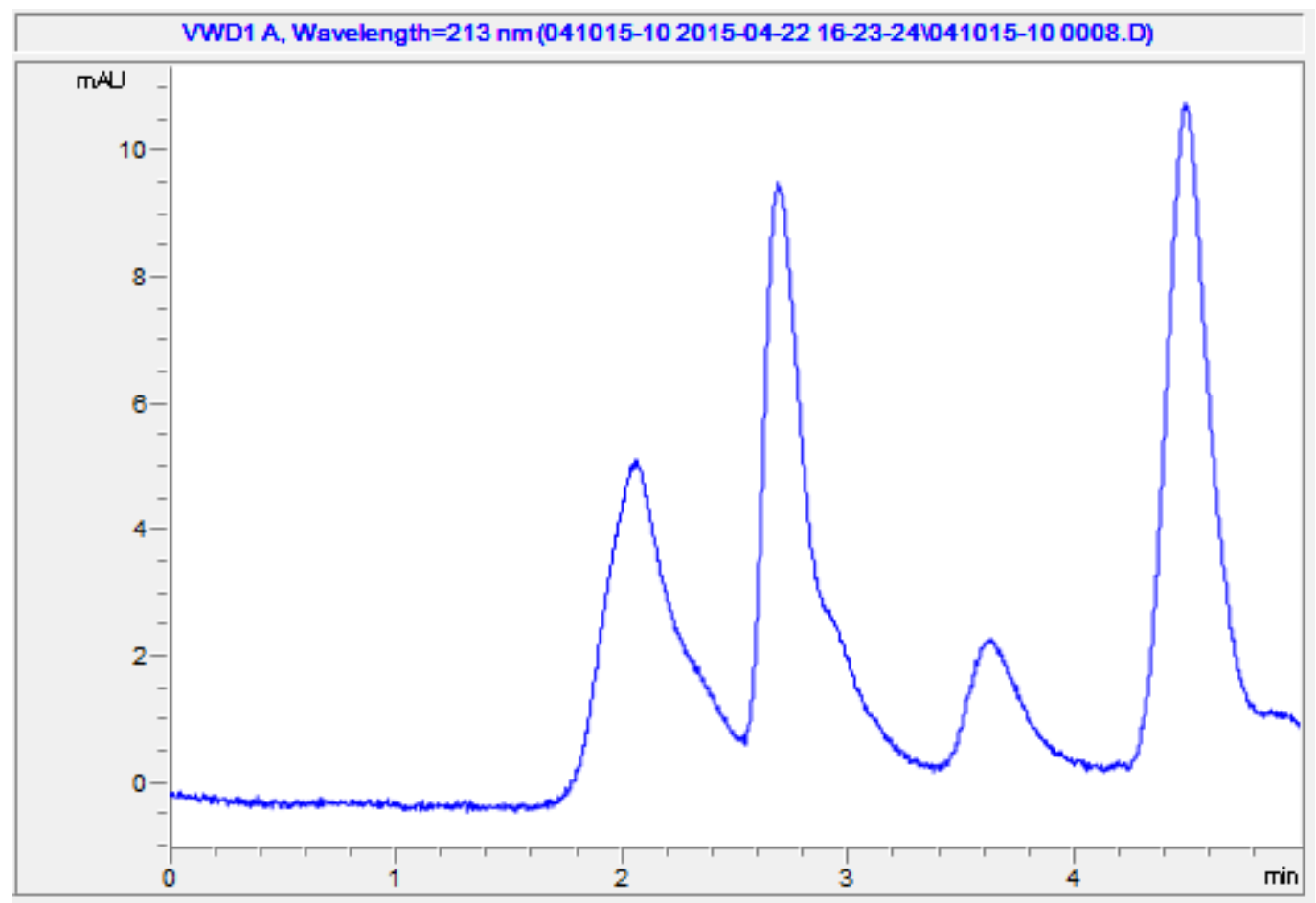

Figure 7-26: Experiment IV-20, Growth Media, Thai FOG with CYA, Day 10

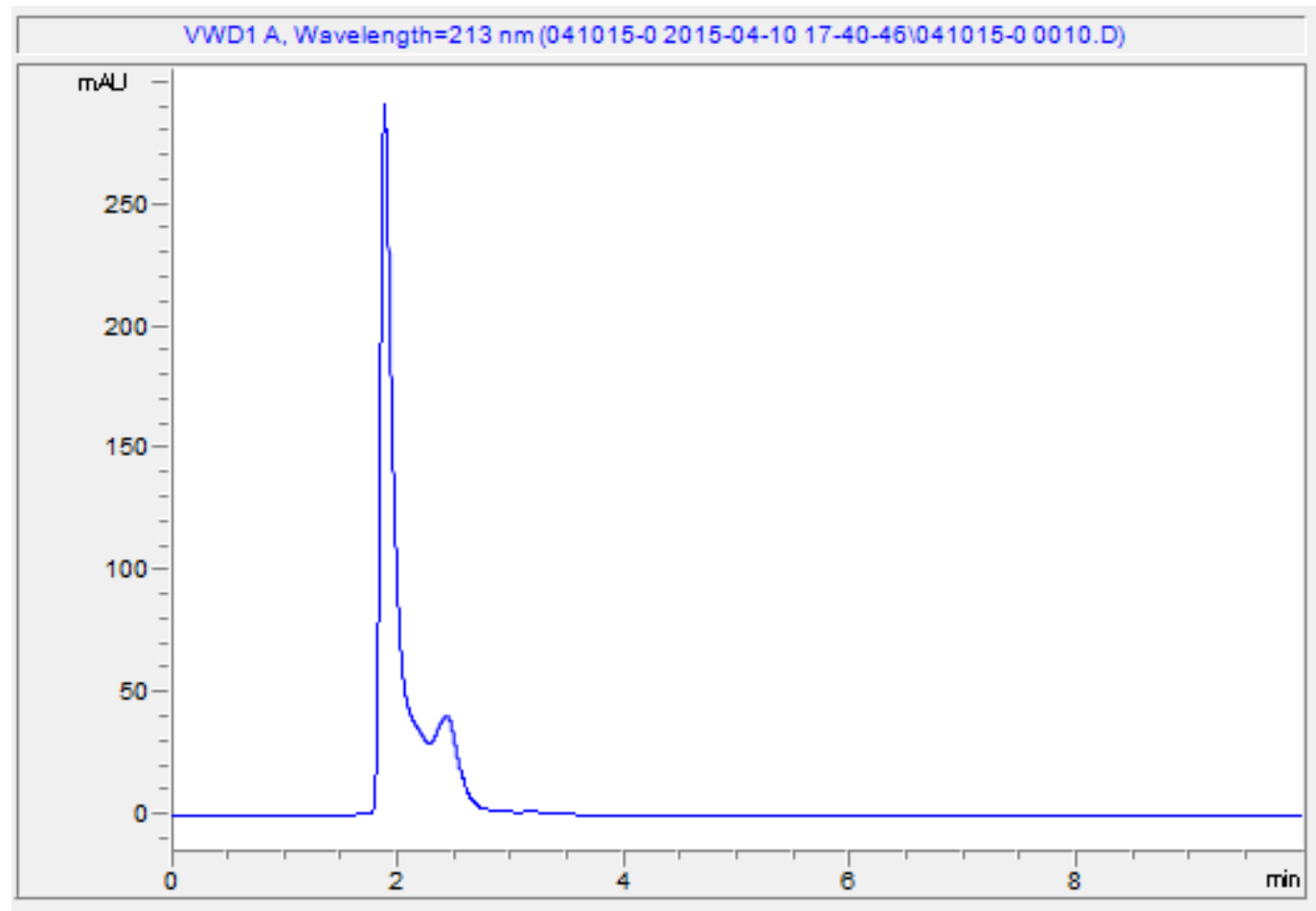

Figure 7-27: Experiment IV-20, Growth Media, Filter Media with CYA, Day 0 


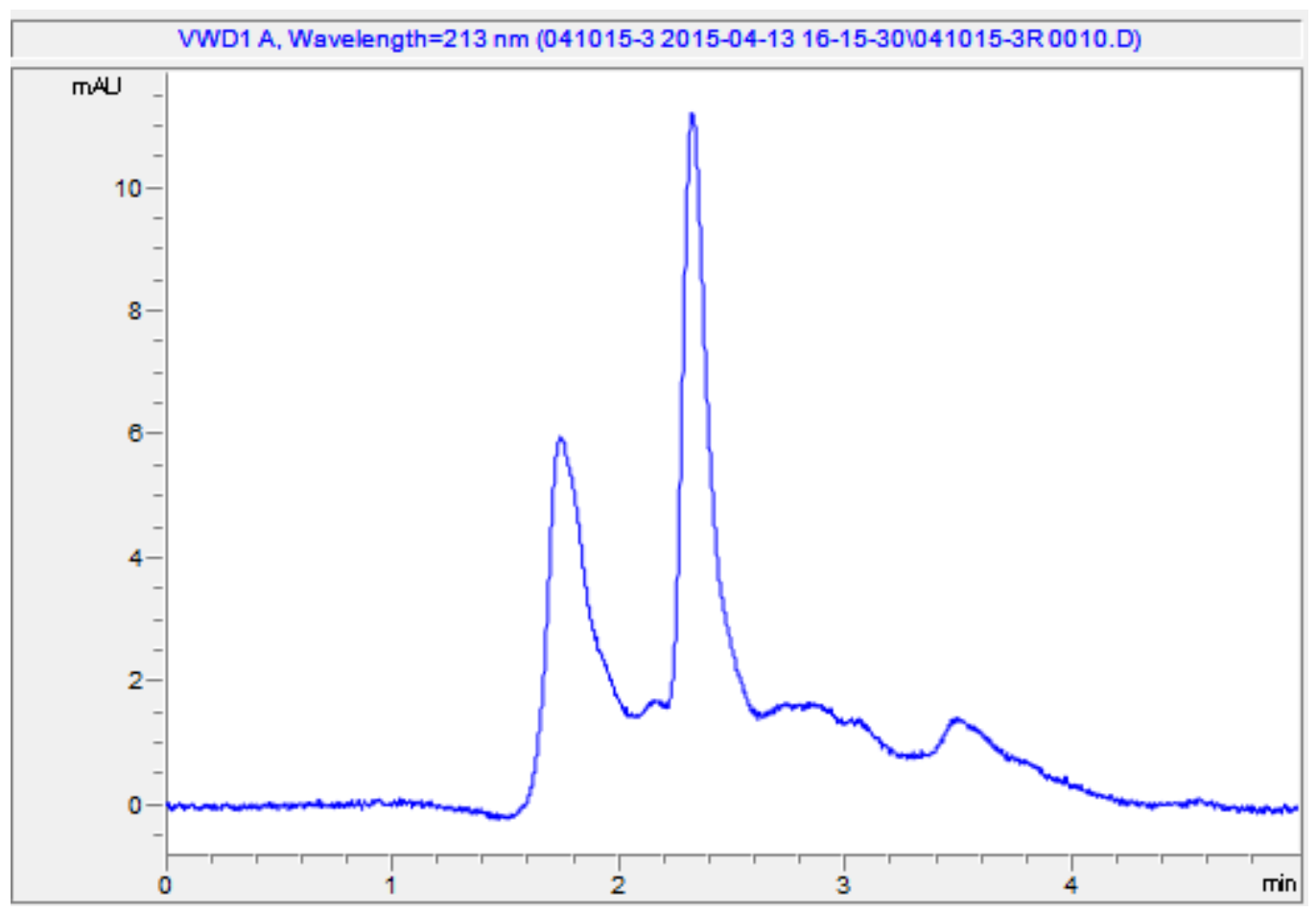

Figure 7-28: Experiment IV-20, Growth Media, Filter Media with CYA, Day 3



Figure 7-29: Experiment IV-20, Growth Media, Filter Media with CYA, Day 10 